\title{
Investigations into the origins of polyatomic ions in inductively coupled plasma-mass spectrometry
}

\author{
by
}

\author{
Sally M. McIntyre \\ A dissertation submitted to the graduate faculty \\ in partial fulfillment of the requirements for the degree of \\ DOCTOR OF PHILOSOPHY
}

\author{
Major: Analytical Chemistry \\ Program of Study Committee: \\ R.S. Houk, Major Professor \\ Joseph Burnett \\ Mark Gordon \\ Klaus Schmidt-Rohr \\ Emily Smith
}

Iowa State University

Ames, Iowa

2010 


\section{TABLE OF CONTENTS}

$\begin{array}{lr}\text { CHAPTER 1. INTRODUCTION } & \mathbf{1} \\ \text { ICP-MS } & 1 \\ \text { Extraction Process in ICP-MS } & 2 \\ \text { Polyatomic Ions } & 4 \\ \text { Thermodynamic Equilibrium and Temperatures } & 6 \\ \text { Dissertation Organization } & 7 \\ \text { References } & 8\end{array}$

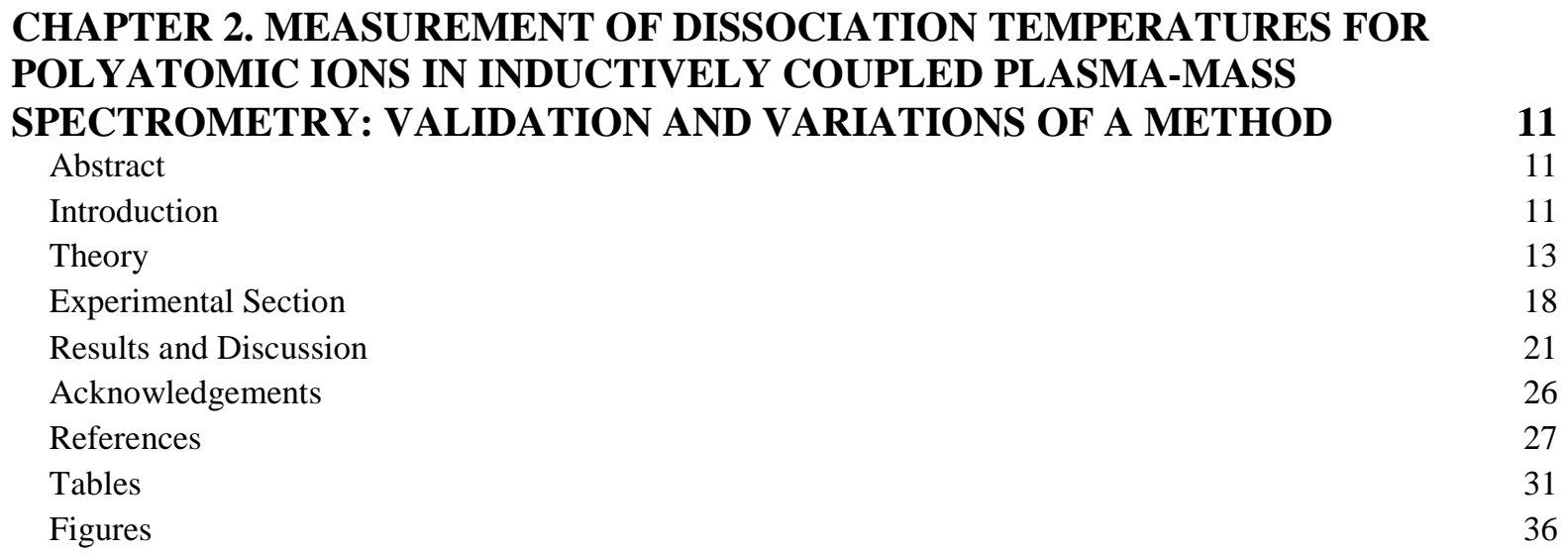

CHAPTER 3. GAS KINETIC TEMPERATURES OF POLYATOMIC IONS IN INDUCTIVELY COUPLED PLASMA-MASS SPECTROMETRY: EFFECTS OF CONE MATERIAL, SKIMMER CONE GEOMETRY AND COOL PLASMA CONDITIONS ON CALCULATED VERSUS MEASURED ION RATIOS 38 Abstract $\quad 38$ Introduction $\quad 39$

Experimental Section $\quad 41$

$\begin{array}{ll}\text { Results and Discussion } & 43\end{array}$

$\begin{array}{ll}\text { Acknowledgements } & 48\end{array}$

$\begin{array}{ll}\text { References } & 48\end{array}$

Tables $\quad 51$

$\begin{array}{ll}\text { Figures } & 55\end{array}$

CHAPTER 4. DETERMINATION OF DISSOCIATION TEMPERATURE FOR ArO ${ }^{+}$IN INDUCTIVELY COUPLED PLASMA-MASS SPECTROMETRY $\mathbf{5 8}$ Abstract $\quad 58$ $\begin{array}{ll}\text { Introduction } & 58\end{array}$

$\begin{array}{ll}\text { Experimental Section } & 61\end{array}$

$\begin{array}{ll}\text { Results and Discussion } & 62\end{array}$

$\begin{array}{ll}\text { Acknowledgements } & 68\end{array}$

$\begin{array}{lr}\text { References } & 68\end{array}$

\begin{tabular}{ll} 
Tables & 72 \\
\hline
\end{tabular}

$\begin{array}{ll}\text { Figures } & 75\end{array}$ 


\section{CHAPTER 5. METAL OXIDE MEMORY EFFECTS}

IN INDUCTIVELY COUPLED PLASMA-MASS SPECTROMETRY

Abstract

Introduction

Experimental Section

Results and Discussion

Acknowledgements

References

Tables

Figures

CHAPTER 6. GENERAL CONCLUSIONS

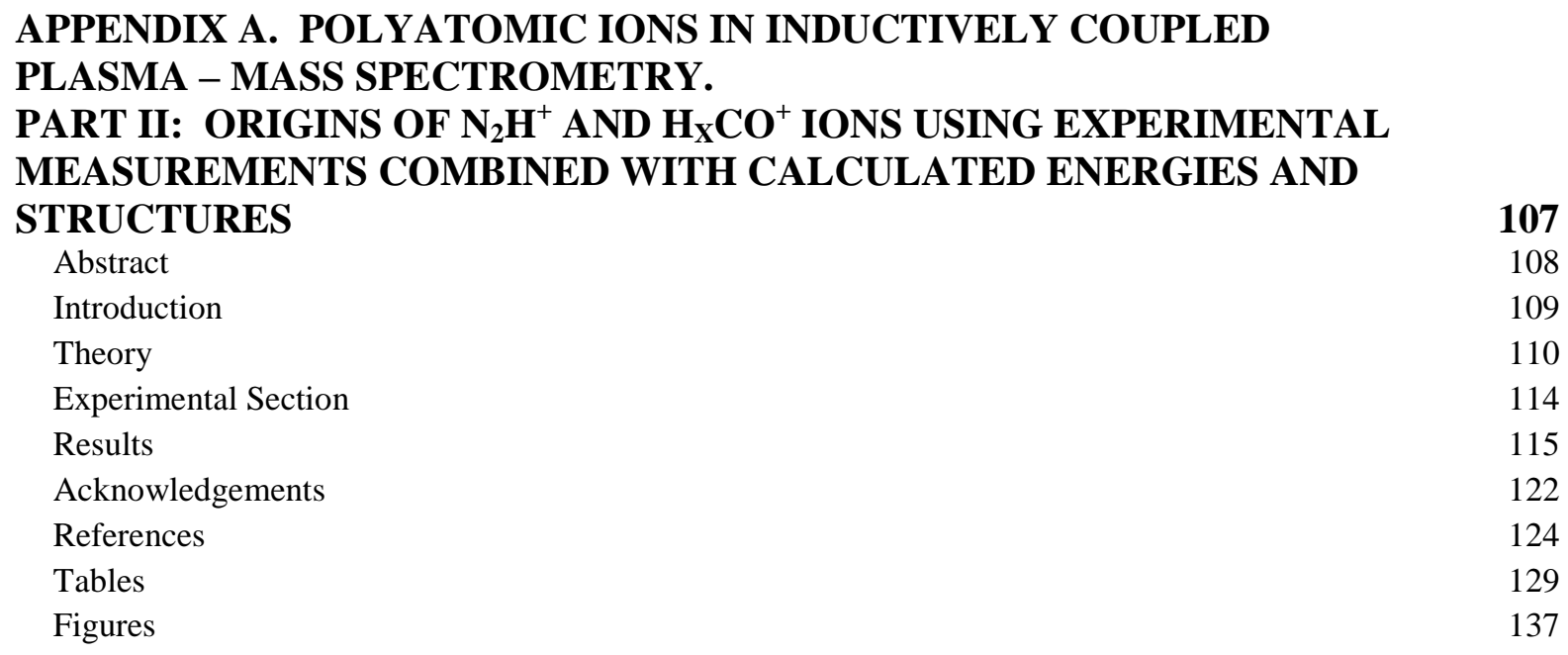

APPENDIX B. REDUCTION OF MATRIX EFFECTS

IN INDUCTIVELY COUPLED PLASMA MASS SPECTROMETRY BY FLOW INJECTION WITH AN UNSHIELDED TORCH

Abstract

Introduction

Experimental Section

140

Conclusion

142

Acknowledgements

150

References

152

Tables

152

Figures

156

160 


\section{CHAPTER 1. INTRODUCTION}

\section{ICP-MS}

An inductively coupled plasma-mass spectrometer (ICP-MS) is an elemental analytical instrument capable of determining nearly all elements in the periodic table at limits of detection in the parts per quadrillion and with a linear analytical range over 8-10 orders of magnitude [1-2]. Three concentric quartz tubes make up the plasma torch. Argon gas is spiraled through the outer tube and generates the plasma powered by a looped load coil operating at 27.1 or $40.6 \mathrm{MHz}$. The argon flow of the middle channel is used to keep the plasma above the innermost tube through which solid or aqueous sample is carried in a third argon stream. A sample is progressively desolvated, atomized and ionized.

The torch is operated at atmospheric pressure. To reach the reduced pressures of mass spectrometers, ions are extracted through a series of two, approximately one millimeter wide, circular apertures set in water cooled metal cones. The space between the cones is evacuated to approximately one torr. The space behind the second cone is pumped down to, or near to, the pressure needed for the mass spectrometer (MS). The first cone, called the sampler, is placed directly in the plasma plume and its position is adjusted to the point where atomic ions are most abundant. The hot plasma gas expands through the sampler orifice and in this expansion is placed the second cone, called the skimmer. After the skimmer traditional MS designs are employed, i.e. quadrupoles, magnetic sectors, time-of-flight. 


\section{Extraction Process in ICP-MS}

ICP-MS is the coupling of two devices with opposite requirements. A hot collision rich environment is needed in the plasma for atomization and ionization. A mass spectrometer needs a cooler environment with long path lengths so collisions do not deflect and remove ions trajectories. These two diametrically opposite zones are bridged with the interface region. Plasma is pulled from the ICP via a vacuum. The space behind a circular aperture is pumped down to $\sim 1$ torr or 0.1 mbar. As the plasma species enter the aperture they retain their temperature and collisional behavior, but as they expand into the low pressure interface region they speed up until they surpass the local speed of sound. This occurs at a distance from the sampler tip of about half the sampler diameter. If the diameter of the sampler is 1 $\mathrm{mm}$, the gas velocity hits Mach one at approximately $0.5 \mathrm{~mm}$ [3]. After this point the gas expands quickly and the mean free path increases. Velocity is gained at the expense of temperature, or gas kinetic energy. Thus, this region appears dark in photographs and is called the zone of silence [4]. The zone is shaped like an elliptical paraboloid with bright sides and end cap due to the cool slow background gas of the interface finally colliding with the hot plasma gas to convert enough speed back into temperature and consequent collisions transfer energy and produce emission. But now the collisions are undesirable because they can be an area for ion-electron recombinations, formation reactions and general scatter and loss of analyte ions [5]. New polyatomic ions are avoided as much as possible by placing the second cone inside the zone of silence, away from and before these shock zones. Sharp fine tips are used in skimmers to minimize their disturbance to the expanding gas but evidence still suggests some shock waves develop around and even in front of the skimmer tip [6]. This means collisional frequency would assume a bimodal distribution along the centerline of the 
cones; first, the zone at the sampler tip where the plasma first enters the interface, then the zone of silence where collisions drop and finally an upsurge as atoms expand through shock waves at the skimmer tip into the second and higher vacuum stage.

The particles during the journey above appear to be in electrical 'quasineutrality', meaning roughly equal amounts of electrons and ions [5]. This is thanks to a small Debye length in the plasma $\left(\sim 10^{-3} \mathrm{~mm}\right)[5]$. The Debye length is the distance in which ions in a plasma will be influenced by electric fields. The sampler aperture is orders of magnitude larger $(\sim 1 \mathrm{~mm})$ and therefore the charged particles in the ICP can pass through uninhibitated by the conductive metal. The Debye length grows to $\sim 10^{-2} \mathrm{~mm}$ by the skimmer [5], but this is still small enough to allow the electrons and ions to pass undisturbed into second vacuum stage. After the skimmer tip is another story.

The pressure behind the skimmer is sufficiently low that enough electrons have enough mobility to leave the ion beam emerging from the skimmer significantly positive [5]. The cations repel each other and the ion beam defocuses. Lightweight species are repelled farthest and fastest and so heavier masses are transmitted preferentially. Most, if not all, ICP-MS instruments have some degree of a mass bias. The entire distance from sampler to skimmer is traveled in $\sim 3 \mu \mathrm{s}$.

The need to extract positive ions and repel negative ones requires putting a voltage difference between the cones and ion optics. This is not so much a problem however as a voltage difference between the cones and the plasma. In the early days of ICP-MS the RF powered load coil was connected to the power source at one end and grounded at the other. The resulting potential gradient would capacitively couple with the plasma. If the plasma gained too much potential an electrical discharge would occur between the plasma and the 
sampler cone. This discharge would widen the kinetic energy spread of the ions degrading resolutions. Methods to reduce the plasma potential were quickly developed. The method used in this dissertation is a guard or shield electrode. A grounded sheath of Pt is wrapped around the torch so that it is positioned between the load coil and the plasma. ICP's with this type of shield electrode are referred to as shielded.

\section{Polyatomic Ions}

\section{General Problem}

Although the high temperature of the ICP ( $5500 \mathrm{~K})$ gives extensive atomization, large concentrations of $\mathrm{Ar}, \mathrm{O}, \mathrm{H}$ and $\mathrm{N}$ move dissociation reactions back toward polyatomic ions. This rather annoying fact has been a constant since the ICP-MS was developed in the 1980's [7]. The most common polyatomic ions involve atoms from the plasma, the solvent, and entrained air. Diatomics dominate $\left(\mathrm{Ar}_{2}{ }^{+}, \mathrm{ArH}^{+}, \mathrm{ArO}^{+}, \mathrm{MO}^{+}, \mathrm{NO}^{+}, \mathrm{OH}^{+}, \mathrm{O}_{2}{ }^{+}\right)$although $\mathrm{H}_{2} \mathrm{O}^{+}$and $\mathrm{H}_{3} \mathrm{O}^{+}$are abundant as well.

Though mostly low in mass, these diatomic ions interfere with certain important isotopes. For example, ${ }^{40} \mathrm{Ar}^{1} \mathrm{H}^{+}$and ${ }^{38} \mathrm{Ar}^{1} \mathrm{H}^{+}$overlap with ${ }^{39} \mathrm{~K}^{+}$and ${ }^{41} \mathrm{~K}^{+}(93.3 \%$ and $6.7 \%$ abundance), ${ }^{15} \mathrm{~N}^{16} \mathrm{O}^{+}$and ${ }^{14} \mathrm{~N}^{17} \mathrm{O}^{+}$with the monoisotopic ${ }^{31} \mathrm{P}^{+},{ }^{16} \mathrm{O}^{16} \mathrm{O}^{+}$with the major isotope of ${ }^{32} \mathrm{~S}^{+}$(95\% abundance), ${ }^{40} \mathrm{Ar}^{16} \mathrm{O}^{+}$with ${ }^{56} \mathrm{Fe}^{+}$and ${ }^{40} \mathrm{Ar}^{40} \mathrm{Ar}^{+}$and ${ }^{36} \mathrm{Ar}^{40} \mathrm{Ar}^{+}$with ${ }^{80} \mathrm{Se}^{+}$and ${ }^{78} \mathrm{Se}^{+}$. These examples can be separated with a sector-field instrument but not with the more prevalent quadrupoles. Also, metal oxides $\left(\mathrm{MO}^{+}\right)$and metal hydrides $\left(\mathrm{MH}^{+}\right)$ starting near mass-to-charge 90 require resolutions exceeding that of the current magnetic sector instruments [2]. 


\section{Behavior of Polyatomic Ions}

At first it was thought that polyatomics might serve as internal standards during analyses [8]. Unfortunately it became apparent that polyatomics behaved differently than analyte ions and sometimes differently than other polyatomics. For instance, while analyte ions give a Gaussian signal profile across the ICP, $\mathrm{Ar}^{+}$and argon containing polyatomics have a bimodal profile with a minimum where analyte ions are maximized [9]. Along the length of the ICP, analyte and polyatomic ions tend to peak at different points [9].

\section{Dealing with Polyatomic Ions in ICP-MS}

Several successful techniques have been developed to ameliorate polyatomic ions. Cool plasma refers to operating the ICP at lower powers (600-800 W) and higher argon gas flow rates. This reduces the ionizing energy of the plasma dramatically reducing the presence of high ionization energy species such as $\mathrm{Ar}^{+}$, and $\mathrm{O}^{+}$and their compounds like $\mathrm{ArX}^{+}$and $\mathrm{CO}^{+}$. Unfortunately, analyte ions with high ionization energies are also greatly reduced. Still this is a common technique for measuring $\mathrm{Ca}^{+}, \mathrm{K}^{+}$and $\mathrm{Fe}^{+}$.

Collision cells have become nearly ubiquitous for newer quadrupole instruments. In collision cells another gas is added to a multipole through which the ion beam passes. For example, $\mathrm{NH}_{3}$ gas added to a collision cell will react with $\mathrm{ArO}^{+}$to produce $\mathrm{Ar}, \mathrm{O}$ and $\mathrm{NH}_{3}{ }^{+}$. The charged ammonia molecules can then be removed to prevent further, unwanted, reactions [10-11]. Alternatively, the gas can be added to the ion beam at the cone tips through special cones with hollow sides, with similar results [12].

Solvent removal can reduce polyatomic ions with solvent constituent atoms while maintaining, or even enhancing, analyte levels [11]. The sample spray from the nebulizer is 
passed through a cooled and/or heated apparatus before reaching the plasma. A heated porous membrane is also used in some configurations to prevent solvent nucleation [13].

Several polyatomic ions can be resolved away from isobaric analyte ions with the use of double focusing mass spectrometers. Paired magnetic and electric sectors give resolutions up to $\sim 10,000$ although at the sacrifice of signal.

Although usually used for isobaric analyte signals, mathematical corrections could be applied to polyatomic ions as well [14]. For instance, the signal at $\mathrm{m} / \mathrm{z} 52\left({ }^{38} \mathrm{Ar}^{14} \mathrm{~N}^{+}\right)$could be used to correct for ${ }^{40} \mathrm{Ar}^{14} \mathrm{~N}^{+}$at $\mathrm{m} / \mathrm{z}$ 54. In another method, ion ratios could be measured in a blank sample so that monitoring the non-interfering ion in the sample would give the interference's levels [14].

\section{Thermodynamic Equilibrium and Temperatures}

Chemists are used to working with systems that can be described with one temperature. However, temperature is a measure of energy and there can be different energies in a system. The ICP is such a system and it cannot be described with one temperature. This goes beyond the obvious temperature gradients that appear as different levels of brightness. If attention is focused on a small area of the plasma and different types of data are collected, the resulting temperatures can span a fair range [15].

Ions are extracted from the ICP at just such an area. Tuning an ICP-MS for maximum signal places the sampler at a certain point. This point will have similar characteristics from day to day, electron number density, optical emission line intensities, and temperature. The temperature values measured, however, vary with the method and species used. 
The energy that exists as kinetic motion can be found in terms of a gas kinetic temperature, $\mathrm{T}_{\text {gas }}$. $\mathrm{T}_{\text {gas }}$ can be measured using ion kinetic energies, Doppler widths of emission lines, Thomson and Rayleigh scattering and gas velocities [15-18]. Similarly, energy available for ionization processes can be found in terms of ionization temperature, $\mathrm{T}_{\text {ion. }} \mathrm{T}_{\text {ion }}$ can be found by optical or mass spectrometric measurements of neutral atoms, single and doubly charged ions finding the temperature in the corresponding Saha equation [5]. These two temperatures describe most of the work in this dissertation, but other temperatures have been measured in the ICP, including rotational temperature, $\mathrm{T}_{\text {rot }}$, from molecular band emissions [15], and excitation temperature $\mathrm{T}_{\mathrm{exc}}$ from optical measurements and Bolzmann plots [19].

At the sampling point, ionization temperatures $(\sim 7000 \mathrm{~K})$ tend to be one to two thousand Kelvin higher than gas kinetic temperatures $(\sim 5500 \mathrm{~K})$ while rotational temperatures measured from $\mathrm{OH}$ lines tend to be substantially lower ( 3500 K) [15]. Excitation temperatures tend be similar to gas kinetic temperatures [20-23]. Some have found a non-Boltzmann distribution of particles among energy states [20,24-25], but later studies saw Boltzmann distributions and their conditions are closer to those studied in this dissertation[21-23,26-27].

\section{Dissertation Organization}

This dissertation is organized into five chapters and two appendices. The first chapter is a general introduction to ICP-MS and polyatomic ion interferences. Chapters 2, 3, 4 and 5 are manuscripts of papers to be submitted to Spectrochimica Acta Part B. Chapter 2 describes the mathematical method used throughout the chapters and in Appendix A, 
evaluating the effect of certain modifications and additions. Chapter 3 applies the mathematical method to a set of experimental data, using the results to draw conclusions on the behavior of specific polyatomic ions. Chapter 4 examines variations of the mathematical method applied to $\mathrm{ArO}^{+}$, an ion requiring a different approach than the ions in chapter 3 . Chapter 5 reports studies on the memory behavior of certain metal oxides. Appendix A is a paper published in Spectrochimica Acta Part B on which I appear as a secondary author. I contributed data analysis and minor editing assistance. Appendix B is a paper published in Analytical Chemistry on which I also appear as a secondary author. I contributed by replicating several of the experiments; this was necessary because the results were very surprising.

\section{References}

[1] Houk, R.S., ICP-MS Short Course I.

[2] Thermo-Finnegan ELEMENT2 software.

[3] D.J. Douglas, J.B. French, Gas dynamics of the inductively coupled plasma mass spectrometer interface, J. Anal. At. Spectrom. 3(1988) 743-747.

[4] K.E. Jarvis, A.L. Gray, R.S. Houk, Handbook of Inductively Coupled Plasma Mass Spectrometry, Blackie, Glasgow, 1992.

[5] H. Niu, R.S. Houk, Fundamental aspects of ion extraction in inductively coupled plasmamass spectrometry, Spectrochim. Acta Part B 51 (1996) 779-815.

[6] M. Liezers, 1.2 Sampling Interface Design and Function and 1.3 Ion Extraction and Focusing, in ICP Mass Spectrometry Handbook, Ed. S.M. Nelms, Blackwell Publishing, Oxford UK, 2005.

[7] Houk, R.S., Fassel, V.A., Flesch, G.D., Svec, H.J., Gray, A.L., and Taylor, C.E. Inductively coupled argon plasma as an ion source for mass spectrometric determination of trace elements, Anal. Chem., 52 (1980) 2283-2289. 
[8] Chen, X. and R.S. Houk, Polyatomic Ions as Internal Standards for Matrix Corrections in Inductively Coupled Plasma Mass Spectrometry, J. Anal. At. Spect., 10 (1995) 837-841.

[9] Holliday, A.E., and D. Beauchemin, Review: Spatial profiling of analyte signal intensities in inductively coupled plasma mass spectrometry, Spectrochim. Acta B 59 (2004) 291-311. [10] S.D. Tanner, V.I. Baranov, D.R. Bandura, Review: Reaction cells and collision cells for ICP-MS: a tutorial review, Spectrochim. Acta B 57 (2002) 1361-1452.

[11] R. Thomas, Practical Guide to ICP-MS, Marcel Dekker, Inc., New York, 2004 [12] Varian, Inc., Palo Alto, CA, USA

[13] J.L. Todoli, F. Vanhaecke, Liquid Sample Introduction and Electrothermal Vaporisation for ICP-MS: Fundamentals and Applications, in ICP Mass Spectrometry Handbook, Ed. S.M. Nelms, Blakwell Publishing, Oxford, UK, 2005.

[14] J.W. Ferguson, Chapter 1. Introduction, Ph.D. Dissertation, Iowa State University, 2006. [15] R.S. Houk, N. Praphairaksit, Dissociation of polyatomic ions in inductively coupled plasma, Spectrochim. Acta B 56 (2001) 1069-1096.

[16] A. Montaser, H. Zhang, Mass spectrometry with mixed-gas and helium ICPs, in Inductively Coupled Plasma Mass Spectrometry ed. A. Montaser, Wiley-VCH, New York, 1998.

[17] D.J. Douglas, S.D. Tanner, Fundamental considerations in ICPMS, in Inductively Coupled Plasma Mass Spectrometry ed. A. Montaser, Wiley-VCH, New York, 1998. [18] J.B. Olsen, J.H. Macedone, P.B. Farnsworth, Source fas kinetic temperatures in an ICPMS determined by measurements of the gas velocities in the first vacuum stage, J. Anal. At. Spectrom. 21 (2006) 856-860.

[19] E.L. Bydder, G.P. Miller, A relaxation method for determining state of equilibrium and temperature ratio $\mathrm{T}_{\mathrm{e}} / \mathrm{T}_{\mathrm{g}}$ in an argon ICPT, Spectrochim. Acta B 43 (1988) 819-829.

[20] G. Kruening, F.J.M.J. Maessen, Effects of the solvent plasma load of various solvents on the excitation conditions in medium power inductively coupled plasma, Spectrochim. Acta B 44 (1989) 367-384.

[21 K. Wagatsuma, Y. Danzaki, T. Nakahara, Comparative Study on the Excitation Mechanism of Chromium Emission Lines in the Argon Radio-Frequency Inductively- 
Coupled Plasma, Nitrogen Microwave Induced Plasma, and Argon or Nitrogen Glow Discharge Plasmas, Spectr. Letters 36 (2003) 99-115.

[22] S. Sengoku, K. Wagatsuma, Comparative Studies of Spectrochemical Characteristics between Axial and Radial Observations in Inductively Coupled Plasma Optical Emission Spectrometry, Anal. Sciences 22 (2006) 245-248.

[23] Z. Cui, K. Kodama, H. Oyama, K. Kitagawa, Two-dimensional observation of excited atoms and ions and excitation temperature in inductively coupled plasma using newly developed four channel spectrovideo camera, J. Vis. 13 (2010) 89-96.

[24] P.B. Farnsworth, The Inductively Coupled Plasma as a Source for the Measurement of Fundamental Spectroscopic Constants, Physica Scripta. T47 (1993) 36-41.

[25] M. Grotti, C. Lagomarsino, J.M. Mermet, Effect of operating conditions on excitation temperature and electron number density in axially-viewed ICP-OES with introduction of vapours or aerosols, J. Anal. At. Spectrom. 21 (2006) 963-969.

[26] Y. Danzaki, K. Wagatsuma, Effect of acid concentrations on the excitation temperature for vanadium ionic lines in inductively coupled plasma-optical emission spectrometry, Analytica Chimica Acta 447 (2001) 171-177.

[27] P. Andre, J. Ondet, R. Pellet, A. Lefort, The calculation of monatomic spectral lines' intensities and composition in plasma out of thermal equilibrium; evaluation of thermal disequilibrium in ICP torches, J. Phys. D: Appl. Phys. 30 (1997) 2043-2055. 


\title{
CHAPTER 2. MEASUREMENT OF DISSOCIATION TEMPERATURES FOR POLYATOMIC IONS IN INDUCTIVELY COUPLED PLASMA-MASS SPECTROMETRY: VALIDATION AND VARIATIONS OF A METHOD
}

\author{
A paper to be submitted to Spectrochimica Acta Part B \\ Sally M. McIntyre, Jill Wisnewski Ferguson, R.S. Houk
}

\begin{abstract}
The general method of comparing measured ion ratios to calculated ion ratios to determine a gas kinetic temperature, $\mathrm{T}_{\text {gas }}$, is reviewed. Various mathematical refinements to the calculated partition functions are examined for their effect on the determined $\mathrm{T}_{\text {gas. }}$ It is found that, (a) excited electronic states should be included for $\mathrm{ArO}^{+}$, and neutral $\mathrm{NO}$, and $\mathrm{O}_{2}$; (b) a $10 \%$ error in solvent load, sample gas flow rate, vibrational constant, rotational constant or measured ion ratio produces only a $1-3 \%$ error in $\mathrm{T}_{\text {gas }}$; (c) a $10 \%$ error in dissociation energy creates nearly a $10 \%$ error in $\mathrm{T}_{\text {gas }}$; (d) high temperature corrections to the partition functions produce minimal change and can generally be neglected; (e) sufficient collisions occur in the supersonic expansion to account for additional polyatomic ions created after the plasma.
\end{abstract}

\section{Introduction}

Inductively coupled plasma-mass spectrometry (ICP-MS) is one of the major elemental analysis techniques used today. An ICP-MS instrument works by atomizing and ionizing a liquid or gas sample. Unfortunately, even at 5000 to $6000 \mathrm{~K}$, not all of the sample is con- 
verted to single atoms [1-2]. Statistical thermodynamics shows that a small fraction of polyatomic ions will survive the plasma, even those with very weak bonds like $\mathrm{ArO}^{+}$and $\mathrm{Ar}_{2}^{+}(0.312$ and $1.2 \mathrm{eV})[3-4]$

Polyatomic ions that interfere with elemental signals at the same nominal mass-tocharge $(\mathrm{m} / \mathrm{z})$ values lead to incorrect analyses and poorer limits of detection. Particular problems arise from polyatomic ions containing $\mathrm{Ar}, \mathrm{O}, \mathrm{H}$ and $\mathrm{N}$ due to the great abundance of those elements in the plasma, sample and/or solvent. Many studies have investigated the effect of various plasma and instrument conditions on polyatomic signals [5]. Methods such as collision cells [6-7], high resolution instruments [8], cool plasmas [9-10], and solvent removal [11-12], have been developed to attenuate their effects. While these techniques have been largely successful, a better fundamental understanding of the origin and behavior of polyatomic ions could lead to the construction of instruments that intrinsically minimize the formation of these interferences. Existing techniques would be even more effective resulting in lower limits of detection, higher throughput and lower costs.

In 1988 Douglas and French applied a hemispherical sink model to the flow of plasma particles through the sampler cone of an ICP-MS. They calculated that an analyte atom would collide with argon atoms at most 250 times during the flow from Mach 0.7 (0.1 mm downstream from the sampler tip) to the skimmer tip [13]. Collisions between analyte atoms and atoms of oxygen and hydrogen from the sample solvent would be two to three orders of magnitude less frequent. They concluded that the production of metal oxide ions $\left(\mathrm{MO}^{+}\right)$after the Mach 0.7 position would be essentially nonexistent.

In 1994, Nonose et al. compared measured polyatomic ion signals to theoretical number densities calculated from spectroscopic data [4]. This allowed them to divide the polya- 
tomics studied into two groups. $\mathrm{ArX}^{+}$species appeared to reach dissociation equilibrium in the interface. $\mathrm{NO}^{+}, \mathrm{O}_{2}{ }^{+}$and $\mathrm{MO}^{+}$species were observed at levels characteristic of the plasma.

In 1996 Cleland and Meeks used a similar technique to determine the most probably formation mechanism of $\mathrm{Ar}_{2}{ }^{+}$. They found a $\mathrm{T}_{\text {gas }}$ at which experimental ion ratios equaled calculated ion ratios. Of the mechanisms investigated, they found the collision of neutral and charged argon atoms to give the argon dimer to have the most realistic $\mathrm{T}_{\text {gas }}$ of $2400 \mathrm{~K}$ [14].

In 2001, Houk and Praphairaskit used this same idea and reported the $\mathrm{T}_{\text {gas }}$ at which experimental ion ratios equaled ion ratios calculated at various $\mathrm{T}_{\text {gas }}$ values [3]. They postulated that the $T_{\text {gas }}$ value measured in this way would be indicative of the area of the instrument where final dissociation equilibrium was established. They argued that, at the very least, comparison between polyatomic ions would be instructive. In 2006 Ferguson et al. expanded this work to investigate the effect of operating conditions on $\mathrm{T}_{\mathrm{gas}}$, and to apply the method to some additional polyatomic ions not considered previously, e.g. $\mathrm{C}_{\mathrm{x}} \mathrm{H}_{\mathrm{y}} \mathrm{O}^{+}$[15-17].

In 2002, Evans, et al. used this same technique along with two variations of Boltzmann plots [18]. Although the Evans' group used only a few of the polyatomics listed in Nonose et al., and Houk and Praphairaksit, similar results were found for the ions that did overlap.

\section{Theory[3,19-22]}

\subsection{Origin of Polyatomic Ion from $T_{\text {gas }}$}

The method used in Nonose et al., Houk and Praphairaskit, Evans et al. and Ferguson et al. postulates a dissociation reaction for the polyatomic ion. Assume a generic polyatomic 
ion, $\mathrm{AB}^{+}$, with a dissociation energy, $\mathrm{D}_{\mathrm{o}}$, and where $\mathrm{A}$ may be one or more atoms and $\mathrm{B}$ is either $\mathrm{Ar}, \mathrm{O}$ or $\mathrm{H}$,

$$
\mathrm{AB}^{+} \rightleftharpoons \mathrm{A}^{+}+\mathrm{B}, \Delta \mathrm{E}=\mathrm{D}_{\mathrm{o}}
$$

The equilibrium constant, $\mathrm{K}_{\mathrm{d}}$, for this reaction can be found in two ways, by measuring equilibrium number densities, $n$, concentrations and by calculation with partition functions, $\mathrm{Z}$, at a given temperature.

$$
\frac{n_{A^{+}} n_{B}}{n_{A B^{+}}}=\mathrm{K}_{\mathrm{d}}=\frac{Z_{A^{+}} Z_{B}}{Z_{A B^{+}}} e^{-D_{o} / k T}
$$

The $T_{\text {gas }}$ that gives best agreement between the two sides is considered to be indicative of the region where the polyatomic ion is made. The sampling point of the plasma, the position that gives highest atomic ion signal, is consistently at a gas kinetic temperature of 5000 to 6000 $\mathrm{K}$. If the measured $\mathrm{T}_{\text {gas }}$ values fall within that range, $\mathrm{AB}^{+}$is made in the plasma and neither created nor destroyed in the interface. If $\mathrm{T}_{\text {gas }}<5000 \mathrm{~K}$ there is an excess of $\mathrm{AB}^{+}$; if $\mathrm{T}_{\text {gas }}>$ $6000 \mathrm{~K}$, less $\mathrm{AB}^{+}$is being measured compared to that expected from the plasma. To avoid misnaming and confusion $\mathrm{K}_{\mathrm{d}}$ is called the dissociation constant.

\subsection{Mass Bias Corrections and Number Densities of Neutral Species}

When using the measured ion ratio a correction should be done to account for mass bias in the instrument. We use an instrument response curve based on Ingle et al. [23,15]. To calculate neutral B number density entrained air is neglected leaving the major constituents of the plasma as argon, oxygen and hydrogen from the plasma and aqueous sample solution. These three elements have low ionization efficiencies in the plasma, $0.04 \%, 0.1 \%$ and 
$0.1 \%$ respectively, so they are present almost totally as neutrals [1]. The total number density in the plasma is calculated from the Ideal Gas Law.

$$
n_{t o t}=n_{A r}+n_{O}+n_{H}=\frac{P}{R T_{g a s}}
$$

Neutral oxygen and hydrogen atoms are assumed to come from the nearly complete dissociation of water. If the amount of water loaded into the ICP torch per unit time is measured and the sample carrier gas flow rate is known, $n_{\mathrm{o}}$ can be calculated by the following,

$$
n_{O}=\frac{\mathrm{N}_{\mathrm{A}} \mathrm{LT}_{\text {room }}}{\mathrm{FM}_{\mathrm{H}_{2} \mathrm{O}} \mathrm{T}_{\mathrm{gas}} 1000}
$$

Where $\mathrm{N}_{\mathrm{A}}$ is Avogadro's number, $\mathrm{L}$ is the measured solvent load $\left(\mathrm{g} \mathrm{min}^{-1}\right), \mathrm{T}_{\text {room }}$ is the room temperature $(298 \mathrm{~K}), \mathrm{F}$ is the sample gas flow rate $\left(1 \mathrm{~min}^{-1}\right)$ and $\mathrm{M}$ is the molar mass of water $\left(\mathrm{g} \mathrm{mol}^{-1}\right)$.

Once the number density of oxygen is known the density of the other neutrals can be found,

$$
\begin{gathered}
n_{H}=2 n_{O} \\
n_{A r}=\frac{P}{R T_{g a s}}-3 n_{O}
\end{gathered}
$$

\subsection{High Temperature Corrections to the Partition Functions}

Partition functions come from the denominator of the Boltzmann equation,

$$
\mathrm{Z}=\sum_{i=0}^{\infty} g_{i} e^{-\epsilon_{i} / k_{B} T}
$$

where $\epsilon_{i}$ is the energy of the ith level, $g_{i}$ is the degeneracy of ith level and $k_{B}$ is the Boltzmann constant. Energy level equations are derived using the time-independent Schroedinger 
equation and simple models. For a molecule, the energy levels are treated as the sum of the electronic, translational, vibrational and rotational energies. The total partition function then becomes a product.

$$
Z=z_{\text {elec }} z_{\text {trans }} z_{\text {vib }} z_{\text {rot }}
$$

Translational energy levels are addressed simply and accurately with the particle-in-a-box model and the resulting partition function works for both atoms and molecules.

Electronic partition functions for atoms and atomic ions have been conveniently computed in the form of polynomials for temperatures ranging from $1500 \mathrm{~K}$ to $\sim 12,000 \mathrm{~K}$ [24-26]. For molecules the first excited electronic state is usually high enough in energy that it makes an insignificant contribution to the electronic partition function. Statistical thermodynamics texts recommend addition of electronic levels other than ground state only if highly accurate calculations are being done, there is an unusually low-lying excited state, or high temperatures are being used $[19,22]$. Because $\epsilon_{0}$ can be set to zero, the molecular electronic partition function simplifies to the degeneracy of the ground state which is approximated by the multiplicity for sigma terms and two times the multiplicity for all other terms $[19,22]$.

Vibrational and rotational energy levels come from the harmonic oscillator and rigid rotor models. More accurate models would be the Morse oscillator and the vibrating rotor, but agreement between the first and second models is good for all but the most precise calculations, as long as the majority of molecules remain in low vibrational levels. As temperature increases and higher levels are populated the two sets of models will gradually diverge leading to larger errors in the overall partition function. Since the ICP is at high temperatures, such corrections should be investigated. 
At high temperatures three corrections can be applied to the energy levels of the harmonic oscillator and rigid rotor [19,27].

1. Addition of centrifugal stretching constants $\left(D_{e}, \ldots\right)$ to account for the increased rotational energy increasing the centrifugal force and stretching the internuclear bond.

$$
E_{r o t}=\operatorname{Bh} c J(J+1)-\mathrm{D}_{\mathrm{e}} h c J^{2}(J+1)^{2}+\ldots
$$

$E_{\text {rot }}$ is rotational energy, B is the rotational constant, $h$ is Planck's constant, $c$ is the speed of light and $J$ is the rotational quantum number.

2. Addition of anharmonicity constants $\left(x_{e}, y_{e}, \ldots\right)$ to help correct deviation from Morse oscillator behavior:

$$
E_{v i b}=h c \omega\left(v+\frac{1}{2}\right)-x_{e} h c \omega\left(v+\frac{1}{2}\right)^{2}+y_{e} h c \omega\left(v+\frac{1}{2}\right)^{3}+\ldots
$$

where $v$ is the vibrational quantum number and $\omega$ is the vibrational constant.

3. Addition of coupling constants $(\alpha, \beta, \ldots)$ because rotation and vibration are not truly independent. In the Morse oscillator changing vibrational levels changes the mean internuclear distance, changing the moment of inertia and thus the rotational constant. B and $D_{e}$ from equation 9 then become $B_{v}$ and $D_{v}$ where,

$$
\begin{aligned}
& \mathrm{B}_{\mathrm{v}}=\mathrm{B}-\alpha\left(v+\frac{1}{2}\right)+\ldots \\
& \mathrm{D}_{\mathrm{v}}=\mathrm{D}_{\mathrm{e}}+\beta\left(v+\frac{1}{2}\right)+\ldots
\end{aligned}
$$

Unless very precise calculations are needed, the expansions are truncated after the first correction terms, $\mathrm{D}_{\mathrm{e}}, x_{\mathrm{e}}$ and $\alpha$. 


\subsection{Correction for Ionization Reactions}

The previous work approached the polyatomic ion dissociation reaction as isolated from any additional equilibria considerations. In particular, the extent of ionization for neutral polyatomic and atomic ions was not incorporated because overall number densities are much larger than losses to ionization, formation and dissociation reactions. One way to test any impact of considering multiple reactions is to expand reaction 1 into three reactions using a thermodynamic cycle.

$$
\begin{array}{cc}
\mathrm{AB} \rightleftharpoons \mathrm{A}+\mathrm{B} & \mathrm{K}_{\mathrm{d}}(\mathrm{AB})=f\left(\mathrm{~T}_{\text {gas }}\right) \\
\mathrm{A} \rightleftharpoons \mathrm{A}^{+}+\mathrm{e}^{-} & \mathrm{K}_{\text {ion }}(\mathrm{A})=f\left(\mathrm{~T}_{\text {ion }}\right) \\
\mathrm{AB}^{+}+\mathrm{e}^{-} \rightleftharpoons \mathrm{AB} & 1 / \mathrm{K}_{\text {ion }}(\mathrm{AB})=f\left(\mathrm{~T}_{\text {ion }}\right)
\end{array}
$$

where $\mathrm{T}_{\mathrm{ion}}=$ ionization temperature. The dissociation constant for reaction 1 can then be calculated by multiplying the constants of reactions $13-15$. Note that 14 and 15 use ionization constants which are functions of $\mathrm{T}_{\text {ion }}$ which does not equal $\mathrm{T}_{\text {gas }}$ in the ICP [28]. Otherwise $\mathrm{K}_{\text {ion }}$ can be calculated in the same manner as $K_{d}$ (equation 2) where neutral B is just replaced with an electron.

\section{Experimental Section}

Adjustments were done to the original calculations from 24 experimental runs outlined in another paper [29]. These trials spanned different cone materials (Ni, Pt, $\mathrm{Al}$ and mixes), plasma conditions (hot vs. cold) and X vs H skimmer cone geometries. All data analysis and calculations were done in Microsoft Excel 2003 or 2007.

All partition functions, neutral B number densities, and dissociation constants were calculated iteratively in $10 \mathrm{~K}$ increments. Ionization constants were calculated using the Saha 
equation [1] and a $\mathrm{T}_{\mathrm{ion}}$ of $7000 \mathrm{~K}$ for hot plasma conditions. This value is a compromise between older values of $7500 \mathrm{~K}$ [1] and $6529 \mathrm{~K}$ from a newer study by Bayon et al. [28]. For cold plasma conditions $\mathrm{T}_{\text {ion }}=4750 \mathrm{~K}$ was used [30]. For the ionization efficiencies shown in Table $3, \mathrm{n}_{\mathrm{e}}=1 \times 10^{15} \mathrm{~cm}^{-3}[1]$ was used.

Instrument response curves for hot plasma conditions take blank subtracted intensities divided by isotope abundance, ionization efficiency in the plasma [1], and concentration in solution and plot the response versus $\mathrm{m} / \mathrm{z}$. Under cold plasma conditions ionization efficiencies were recalculated but resulting response curves made no sense and a polynomial line could only be fit to an $\mathrm{R}^{2}$ of 0.2748 . When ionization efficiency was ignored or hot plasma efficiencies were used a polynomial could be fit to the result with an $\mathrm{R}^{2}=0.9671$. Therefore, instrument response curves for cold plasma runs were calculated in the same manner as for hot plasma runs.

High temperature corrections for diatomic molecules were done by using the following equation [19] for the rotational and vibrational partition functions. Pitzer's appendix was also useful in understanding this derivation [27].

$$
z_{r v}^{\prime}=\frac{1}{\sigma y}\left(\frac{1}{1-e^{-t}}\right)\left(1+\frac{y}{3}+\frac{2 \gamma}{y}+\frac{\delta}{e^{t}-1}+\frac{2 x_{e} t}{\left(e^{t}-1\right)^{2}\left(1-2 x_{e}\right)}\right)
$$

where $\sigma$ is the symmetry number of the diatomic molecule. Heteronuclear diatomic ions

have $\sigma=1$ and homonuclear diatomic ions have $\sigma=2$. Symbols $y, t, \gamma$ and $\delta$ are substitution constants as follows,

$$
y=\frac{h c}{k T}\left(\mathrm{~B}-\frac{1}{2} \alpha\right)
$$




$$
\begin{gathered}
t=\frac{h c}{k T}\left(\omega-2 \omega x_{e}\right) \\
\gamma=\frac{\mathrm{D}_{\mathrm{e}}}{\left(\mathrm{B}-\frac{1}{2} \alpha\right)} \\
\delta=\frac{\alpha}{\left(\mathrm{B}-\frac{1}{2} \alpha\right)}
\end{gathered}
$$

As can be seen, only the first order corrections for centripedal stretching, $\mathrm{D}_{\mathrm{e}}$, anharmonicity, $x_{e}$, and vibrational stretching, $\alpha$, are used. These constants are often reported with basic spectroscopic data [31] but can also be calculated as was done in this work.

$$
\begin{gathered}
x_{e}=\frac{h c \omega}{4 D} \\
\mathrm{D}_{\mathrm{e}}=\frac{4 \mathrm{~B}^{3}}{\omega^{2}} \\
\alpha=\frac{6 \mathrm{~B}^{2}}{\omega}\left[\left(\frac{x_{e} \omega}{\mathrm{B}}\right)^{1 / 2}-1\right]
\end{gathered}
$$

$D$ is well depth or the dissociation energy plus the zero point energy.

Equation 16 is the result of truncating after the first or second terms of the EulerMaclaurin expansions of the energy level summations. Preliminary work with MATLAB (MathWorks, Natick, Massachusetts) showed no effect when additional terms were added. 


\section{Results and Discussion}

\subsection{Electronic Partition Functions of Diatomic Molecules}

Table 1 lists ground and excited electronic states for each of the diatomic ions studied in this paper (excluding $\mathrm{CeO}^{+}$and $\mathrm{ScO}^{+}$), the energy difference between the ground and first excited electronic levels and any error in the electronic partition function that comes from not adding the first excited electronic state. The ground electronic state assumption at $5000 \mathrm{~K}$ gives a less than $5 \%$ difference for every diatomic ion except $\mathrm{ArO}^{+} . \mathrm{ArO}^{+}$proved to be surprisingly difficult to evaluate for gas kinetic temperatures. Work with this polyatomic ion is discussed in another paper [36].

In equations 13 and 15 the partition function for the neutral diatomic molecule needs to be calculated. Table 2 lists the first two electronic states of some neutral diatomic molecules and their contributions to the electronic partition function. Two species have an important low lying electronic level, $\mathrm{O}_{2}$ and NO. In fact, these two molecules are often given as cases when excited electronic states need to be included, even at room temperature [19,21]. Therefore calculations with these two neutral diatomics always included the first excited electronic states.

\subsection{Effect of High Temperature Rotational-Vibrational Corrections to Partition Functions}

The high temperatures of 5000 to $6000 \mathrm{~K}$ at the sampling point in the ICP are well above the warning line of 3000 to $4000 \mathrm{~K}$ given in some statistical thermodynamics texts [19]. Yet when equation 16 was used there were only minimal changes in $\mathrm{T}_{\text {gas }}$ compared to simpler calculation models [3]. Across the 23 trials $\mathrm{T}_{\text {gas }}$ measured from $\mathrm{Ar}_{2}{ }^{+}, \mathrm{ArH}^{+}, \mathrm{O}_{2}{ }^{+}$,

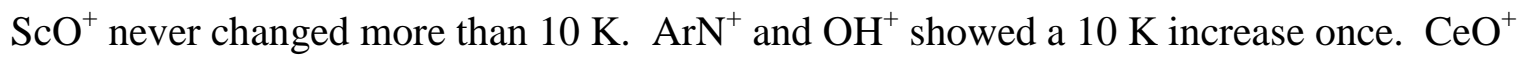


and $\mathrm{NO}^{+}$gave the largest $\mathrm{T}_{\text {gas }}$ values in this work and therefore would be expected to need the temperature correction most. The largest changes in $\mathrm{T}_{\text {gas }}$ were seen in these two with increases by up to $40 \mathrm{~K}$, although this would still not change the diagnoses of the origins of these ions [29].

Because the main goal of this work is to estimate ion origin and such minor changes in $\mathrm{T}_{\text {gas }}$ do not affect these diagnoses, high temperature corrections were therefore not used further in this work.

\subsection{Addition of Ionization Energy for Neutral Diatomic Molecules}

$\mathrm{O}_{2}^{+}, \mathrm{NO}^{+}, \mathrm{OH}^{+}, \mathrm{CeO}^{+}$and $\mathrm{ScO}^{+}$were examined for the effect of including ionization equilibria. Table 3 lists the ionization energies and calculates the percent ionization of each species at $\mathrm{T}_{\mathrm{ion}}=7000 \mathrm{~K}$ and an electron density of $1 \times 10^{15} \mathrm{~cm}^{-3}[40-41]$. The results are given in Figures 1 and 2. Note that $n_{e}$ was only used to calculate the values in Table 3. In equations 14 and 15 the electron number densities cancel.

In the hot plasma trials no species changed its essential behavior. $\mathrm{CeO}^{+}$and $\mathrm{O}_{2}{ }^{+}$still gave characteristic plasma temperatures at the sampling point. $\mathrm{NO}^{+}$still gave a high temperature indicating less $\mathrm{NO}^{+}$than expected. $\mathrm{OH}^{+}$still gave a low temperature indicating more $\mathrm{OH}^{+}$than expected given plasma conditions alone.

For cool plasma conditions $\mathrm{ScO}^{+}$was used to give the estimated temperature range for the plasma at the sampling point because $\mathrm{Ce}^{+}$signal was insufficient. Inclusion of ionization energies led to similar changes as described above as shown in Figure 2. Average $\mathrm{T}_{\text {gas }}$ values changed slightly but overall diagnoses did not. The two possible exceptions are $\mathrm{NO}^{+}$ and $\mathrm{O}_{2}{ }^{+}$. The average $\mathrm{T}_{\text {gas }}$ for $\mathrm{NO}^{+}$dropped by $240 \mathrm{~K}$. The black box in Figure 2 shows an 
approximate $1000 \mathrm{~K}$ difference with the center on the $\mathrm{T}_{\text {gas }}$ of $\mathrm{ScO}^{+} . \mathrm{NO}^{+}$goes from just above this box to just below the top line of this box. This could move $\mathrm{NO}^{+}$from loss of polyatomic ion after extraction to levels expected in the plasma. However, it seems more likely that the possible temperature spread for the plasma would be smaller under cold conditions shrinking the box and keeping $\mathrm{NO}^{+}$at a diagnosis of loss-in-the-interface.

By the same consideration $\mathrm{O}_{2}^{+}$could change its diagnosis from plasma levels to excess polyatomic ion. However, the argument from $\mathrm{NO}^{+}$applied here would leave $\mathrm{O}_{2}{ }^{+}$firmly in the later category for both calculation methods.

To summarize, inclusion of ionization reactions in the calculated $\mathrm{K}_{\mathrm{d}}$ does change the $\mathrm{T}_{\text {gas }}$ but not to a degree outside the day to day variations and not to a point of changing the diagnosis of the probable origin of the ions.

\subsection{Error Analysis}

Error analysis in these calculations is not a matter of simple error propagation. Iteration is used precisely because there is no straightforward equation to find $\mathrm{T}_{\text {gas }}$ from the measured signal ratio and $\mathrm{K}_{\mathrm{d}}$. Therefore, to test the effect of change in one variable, value $+10 \%$ was entered into the spreadsheet and the new $\mathrm{T}_{\text {gas }}$ evaluated. In this way the effect of $10 \%$ errors in solvent load, sample gas flow rate, vibrational constant, rotational constant, dissociation energy and the ion ratio were investigated for one day's data. Results from this error analysis are presented in Table 4. The day under consideration used nickel cones, an Hgeometry skimmer, and 'hot' plasma conditions.

As expected, the dissociation energy had the largest impact. A $10 \%$ change in $\mathrm{D}_{\mathrm{o}}$ led to about $10 \%$ changes in temperature. Thus, reasonably accurate values for this quantity are 
a priority. Changing solvent load, sample gas flow rate, vibrational constants, rotational constants and even ion ratios by $10 \%$ usually produced errors in the $\mathrm{T}_{\text {gas }}$ only about a tenth of that (-140 to $40 \mathrm{~K}$ change, $0.7-3.1 \%$ of $\left.\mathrm{T}_{\text {gas }}\right)$. In general, such errors will not affect the diagnosis of ion origin.

\subsection{Number of Collisions}

It is a valid question to ask whether these observed variations to the equilibrium ion ratios are even possible from a kinetics perspective. For example, excess polyatomic ions can only be made if the constituents first collide. Douglas and French believed that there were insufficient collisions to create many polyatomic ions after the sampler cone [13]. They calculated that in the nozzle of the sampler cone analyte ions collide 120 times with argon atoms before the Mach 1 position ( $\sim .5 \mathrm{~mm}$ downstream of the sampler tip). Use of number densities to scale down gives approximately 10 collisions with $\mathrm{O}$ atoms and 20 collisions with $\mathrm{H}$ atoms.

New work has been done using experimental data and more complex modeling to show that the plasma cools more extensively than Douglas and French calculated [42], mainly due to thermal contact of the plasma with the cooled metal sampler cone. This would increase the number of collisions. Nevertheless, French and Douglas can be treated as a conservative estimate and their model will be taken as the basis for the following discussion.

First the number of two body collisions was calculated.

$$
\mathrm{A}^{+}+\mathrm{B} \rightarrow \mathrm{AB}^{+}
$$

Number densities for neutral $\mathrm{Ar}, \mathrm{O}$ and $\mathrm{H}$ were calculated based on solvent load and the $\mathrm{T}_{\text {gas }}$ measured from the $\mathrm{CeO}^{+} / \mathrm{Ce}^{+}$ratio on the same day. $\mathrm{O}^{+}$and $\mathrm{Ar}^{+}$number densities were 
found by assuming 0.1 and $0.04 \%$ ionization of the $\mathrm{O}$ and $\mathrm{Ar}[1]$. All other atomic and polyatomic ion number densities were found using mass bias adjusted ratios.

The number density of $\mathrm{A}^{+}$was then multiplied by 120,10 or 20 depending on the identity of the neutral B species. This was the number of two-body collisions.

Using the calculated dissociation constant and the neutral B number density, the predicted number density of $\mathrm{AB}^{+}$at the $\mathrm{CeO}^{+} \mathrm{T}_{\text {gas }}$ was calculated. This predicted number density was subtracted from the number density of $\mathrm{AB}^{+}$calculated from the spectral signal. This difference is the amount of $\mathrm{AB}^{+}$that would need to be made after the plasma and was divided by the number of two-body collisions and multiplied by 100 to find the percentage of the $\mathrm{A}^{+}$ and $\mathrm{B}$ collisions that would need to result in the creation of an $\mathrm{AB}^{+}$molecule. Those results are presented in Table 5.

The fraction of the collisions needed depends on the reaction under consideration. For example, $\mathrm{Ar}^{+}$and $\mathrm{Ar}$ collisions only needed to make $\mathrm{Ar}_{2}{ }^{+} 0.0002 \%$ of the time to account for the measured $\mathrm{T}_{\text {gas }}$ for $\mathrm{Ar}_{2}{ }^{+}$while $\sim 14 \%$ of the $\mathrm{OH}^{+}$and $\mathrm{H}$ collisions would need to make $\mathrm{H}_{2} \mathrm{O}^{+}$to produce the temperatures measured.

Of course, the production of polyatomic ions is unlikely by two-body collisions. A three-body collision is most likely needed with the third species carrying off excess kinetic energy and allowing the other two species to bond. The rate of three-body collisions is $10^{-2}-$ $10^{-3}$ times that of two-body collisions [43]. However, collisions with Ar are six times more likely than with $\mathrm{H}$ and 12 times more likely than with $\mathrm{O}$. So, for polyatomic ions where the dissociation product is neutral $\mathrm{O}$, the percentage of successful two-body collisions should be divided by $0.12-0.012$. When neutral $\mathrm{H}$ is considered, the percentage should be divided by 0.06-0.006 and when neutral Ar is the dissociation product the percentage should be divided 
by $0.01-0.001$ to get the percentage of the three-body collisions needed to form the excess polyatomic ions seen.

Now the creation of excess polyatomic ions through collisions in the interface looks less realistic. However, the number of collisions was calculated for only the first $0.5 \mathrm{~mm}$ of the expansion. French and Douglas predicted an analyte species would collide with Ar another 120 times in the zone of silence of the supersonic expansion [13]. Also other reaction paths than the one used here are possible. In the case of $\mathrm{H}_{2} \mathrm{O}^{+}$for instance, neutral $\mathrm{OH}$ and $\mathrm{H}$ may collide to make $\mathrm{H}_{2} \mathrm{O}$ and then be ionized to $\mathrm{H}_{2} \mathrm{O}^{+}$or $\mathrm{H}_{3} \mathrm{O}^{+}$may collide with another species and disassociate into $\mathrm{H}_{2} \mathrm{O}^{+}$and $\mathrm{H}$. In short, production of excess polyatomic ions in the interface to the levels seen in the mass spectrum is not outside the realm of possibility.

On certain days, $\mathrm{Ar}_{2}{ }^{+}, \mathrm{ArN}^{+}, \mathrm{O}_{2}{ }^{+}$and $\mathrm{NO}^{+}$gave gas kinetic temperatures higher than that for $\mathrm{CeO}^{+}$indicating less polyatomic ion than expected from the plasma. If it assumed that all of the loss is through collision induced dissociations and that the two-body collisions are between the polyatomic ions and argon, only $1 \%$ of the collisions or less would be needed to explain the loss seen.

\section{Acknowledgements}

This research was supported by the National Science Foundation through the Institute for Physical Research and Technology at ISU. The ICP-MS instrument was obtained with funds provided by the U. S. Department of Energy, Office of Nuclear Nonproliferation (NA22) and the Office of Basic Energy Sciences. 


\section{References}

[1] H. Niu, R.S. Houk, Fundamental aspects of ion extraction in inductively coupled plasmamass spectrometry, Spectrochim. Acta Part B 51 (1996) 779-815.

[2] D.J. Douglas, J.B. French, An improved interface for inductively coupled plasma mass spectrometry, Spectrochim. Acta B 41 (1986) 197-204.

[3] R.S. Houk, N. Praphairaksit, Dissociation of polyatomic ions in inductively coupled plasma, Spectrochim. Acta B 56 (2001) 1069-1096.

[4] N.S. Nonose, N. Matsuda, N. Fudagawa, M. Kubota, Some characteristics of polyatomic ion spectra in inductively coupled plasma-mass spectrometry, Spectrochim. Acta Part B 49 (1994) 955-974.

[5] A.E. Holliday, D. Beauchemin, Review: Spatial profiling of analyte signal intensities in inductively coupled plasma mass spectrometry, Spectrochim. Acta B 59 (2004) 291-311. And references therein.

[6] J.T. Rowan, R.S. Houk, Attenuation of polyatomic ion interferences in inductively coupled plasma mass spectrometry by gas-phase collisions, Appl. Spectrosc. 43 (1989) 976980.

[7] S.D. Tanner, V.I. Baranov, D.R. Bandura, Reaction cells and collision cells for ICPMS:a tutorial review, Spectrochim. Acta B 57 (2002) 1361-1452.

[8] N. Bradshaw, E.F.H. Hall, N.E. Sanderson, Inductively coupled plasma as an ion source for high-resolution mass spectrometry, J. Anal. At. Spectrom. 8 (1989) 801-803. [9] S.J. Jiang, R.S. Houk, M.A. Stevens, Alleviation of overlap interferences for determination of potassium isotope ratios by inductively coupled plasma mass spectrometry, Anal. Chem. 60 (1988) 1217-1221.

[10] S.D. Tanner, Characterization of ionization and matrix suppression in inductively coupled 'cold' plasma mass spectrometry, J. Anal. At. Spectrom. 10 (1995) 905-921. [11] L.C. Alves, D.R. Wiederin, R.S. Houk, Reduction of polyatomic ion interferences in inductively coupled plasma mass spectrometry by cryogenic desolvation, Anal. Chem. 64 (1992) 1164-1169. 
[12] M.G. Minnich, R.S. Houk, Comparison of cryogenic and membrane desolvation for attenuation of oxide, hydride and hydroxide ions and ions containing chlorine in inductively coupled plasma mass spectrometry, J. Anal. At. Spectrom. 13 (1998) 167-174.

[13] D.J. Douglas, J.B. French, Gas dynamics of the inductively coupled plasma mass spectrometer interface, J. Anal. At. Spectrom. 3 (1988) 743-747.

[14] T.J. Cleland, F.R. Meeks, Statistical mechanics of $\mathrm{Ar}_{2}{ }^{+}$in an inductively coupled plasma, Spectrochim. Acta B 51 (1996) 1487-1490.

[15] J.W. Ferguson, R.S. Houk, High resolution studies of the origins of polyatomic ions in inductively coupled plasma-mass spectrometry, Part 1. Identification methods and effects of neutral gas density assumptions, extraction voltage, and cone material, Spectrochim. Acta Part B 61 (2006) 905-915.

[16] J.W. Ferguson, T.J. Dudley, K.C. Sears, S.M. McIntyre, M.S. Gordon, R.S. Houk, Polyatomic ions in inductively coupled plasma-mass spectrometry Part II: Origins of $\mathrm{N}_{2} \mathrm{H}^{+}$ and $\mathrm{H}_{\mathrm{x}} \mathrm{CO}^{+}$ions using experimental measurements combined with calculated energies and structures, Spectrochim. Acta B 64 (2009) 690-696.

[17] J.W. Ferguson, T.J. Dudley, M.S. Gordon, R.S. Houk, High resolution studies of the origins of polyatomic ions in ICP-MS Part III: $\mathrm{CrO}_{\mathrm{x}} \mathrm{H}_{\mathrm{y}}{ }^{+}$ions, Manuscript (2006).

[18] E.H. Evans, L. Ebon, L. Rowley, Comparative study of the determination of equilibrium dissociation temperature in inductively coupled plasma-mass spectrometry, Spectrochim. Acta Part B 57 (2002) 741-754.

[19] R.E. Sonntag and G.J. Van Wylen, Fundamentals of Statistical Thermodynamics, John Wiley and Sons, Inc., New York, 1966.

[20] J.H. Knox, Molecular Thermodynamics: An Introduction to Statistical Mechanics for Chemists, Chapter 6, Rev. Ed. John Wiley and Sons, Chichester, 1978.

[21] K.J. Laidler, J.H. Meiser, Physical Chemistry, Chapter 15, Houghton Mifflin Co., Boston, 1999.

[22] N.M. Laurendeau, Statistical Thermodynamics: Fundamentals and Applications, Chapter 9, Cambridge University Press, Cambridge, 2005.

[23] C.P. Ingle, B.L. Sharp, M.S.A. Horstwood, R.R. Parrish, D.J. Lewis, Instrument response functions, mass bias and matrix effects in isotope ratio measurements and semi- 
quantitative analysis by single and multi-collector ICP-MS, J. Anal. At. Spect. 18 (2003) 219-229.

[24] L. De Galan, R. Smith, J.D. Winefordner, The electronic partition function of atoms and ions between $1500^{\circ} \mathrm{K}$ and $7000^{\circ} \mathrm{K}$, Spectrochim. Acta B 23 (1968) 521-525.

[25] S. Tamaki, T. Kuroda, The electronic partition functions of atoms and ions between 7000 and 12000 K, Spectrochim. Acta B 42 (1987) 1105-1111.

[26] B. Faggetter, G. Heisz, M.W. Blades, Research Note: The electronic partition functions of lanthanide atoms and ions between 1500 and 8000 K, Spectrochim. Acta B 42 (1987) 1235-1236.

[27] K.S. Pitzer, Quantum Chemistry. Prentice-Hall, Inc. New York, 1953.

[28] M.M. Bayón, J.I.G. Alonso, A.S. Medel, Enhanced semiquantitative multi-analysis of trace elements in environmental samples using inductively coupled plasma mass spectrometry, J. Anal. At. Spect., 13 (1998) 277-282.

[29] S. M. McIntyre, J.W. Ferguson, R.S. Houk, Polyatomic ions in inductively coupled plasma-mass spectrometry: Effects of cone material, skimmer cone geometry and cold plasma conditions on calculated versus measured ion ratios, manuscript (2010).

[30] D.M. McClenathan, W.C. Wetzel, S.E. Lorge, G.M. Hieftje, Effect of the plasma operating frequency on the figures of merit of an inductively coupled plasma time-of-flight mass spectrometer, J.Anal. At. Spectrom., 21 (2006) 160-167.

[31] K.P. Huber, G. Herzberg, Molecular Spectra and Molecular Structure IV. Constants of Diatomic Molecules, Van Nostrand Reinhold, New York, 1979.

[32] W.R. Wadt, The electronic states of $\mathrm{Ar}^{+}{ }_{2}, \mathrm{Kr}^{+}{ }_{2}, \mathrm{Xe}_{2}^{+}$. I. Potential curves with and without spin-orbit coupling, J. Chem. Phys., 68 (1978) 402-414.

[33] L. Broström, M. Larsson, S. Mannervik, D. Donnek, The visible photoabsorption spectrum and potential curves of $\mathrm{ArN}^{+}$, J. Chem. Phys., 94 (1991) 2734-2740.

[34] A.V. Stolyarov, M.S. Child, Phys. Chem. Chem. Phys., 7 (2005) 2259-2265.

[35] H.Frenking, W. Koch, D. Cremer, J. Gauss, J.F.Liebman, Neon and Argon Bonding in First-Row Cations $\mathrm{NeX}^{+}$and $\mathrm{ArX}^{+}$(X = Li-Ne), J. Phys. Chem., 93, (1989) 3410-3418.

[36] S. M. McIntyre, J.W. Ferguson, R.S. Houk, Determination of dissociation temperature for $\mathrm{ArO}^{+}$in inductively coupled plasma-mass spectrometry, manuscript (2010). 
[37] Periodic Table of the Elements, VWR Scientific Products Sargent Welch (1996) Buffalo Grove, IL.

[38] R.J. Ackermann, E.G. Rauh, R.J. Thorn, The thermodynamics of ionization of gaseous oxides; the first ionization potentials of the lanthanide metals and monoxides, J. Chem. Phys., 65 (1976) 1027-1031.

[39] D.E. Clemmer, J.L. Elkind, N. Aristov, P.B. Armentrout, Reaction of $\mathrm{Sc}^{+}, \mathrm{Ti}^{+}$, and $\mathrm{V}^{+}$ with CO. $\mathrm{MC}^{+}$and $\mathrm{MO}^{+}$bond energies, J. Chem. Phys. 95 (1991) 3387-3393.

[40] R.S. Houk, Y. Zhai, Comparison of mass spectrometric and optical measurements of temperature and electron density in the inductively coupled mass spectrometric sampling, Spectrochim. Acta B 56 (2001) 1055-1067.

[41] D.J. Douglas, S.D. Tanner, Chapter 8 "Fundamental considerations in ICPMS", in Inductively Coupled Plasma Mass Spectrometry, Ed. A. Montaser, Wiley-VCH, New York, 1998.

[42] R.L Spencer, N. Taylor, P.B. Farnsworth, Comparison of calculated and experimental flow velocities upstream from the sampling cone of an inductively coupled plasma mass spectrometer, Spectrochim. Acta B 64 (2009) 921-924.

[43] H. Pauly, Atom, Molecule, and Cluster Beams: Basic theory, production, and detection of thermal energy beams, Springer, 2000. 


\section{Tables}

Table 1. Effect of including first excited state on the electronic partition function of certain charged diatomic molecules.

\begin{tabular}{|c|c|c|c|c|c|c|c|c|c|}
\hline Ion & $\begin{array}{l}\text { Groun } \\
\text { Term } \\
\text { Symbol }\end{array}$ & $\begin{array}{l}\text { State } \\
\mathrm{g}_{0}\left(\mathrm{z}_{\text {elec }}\right)\end{array}$ & $\begin{array}{r}\text { Fi } \\
\text { Term } \\
\text { Symbol }\end{array}$ & $\mathbf{g}_{1}$ & $\begin{array}{l}\text { Eneited Electroni } \\
\text { Energy }\left(\mathrm{cm}^{-1}\right)\end{array}$ & $\begin{array}{l}\text { State } \\
\mathrm{g}_{1} \mathrm{e}^{(-\mathrm{E} 1 / \mathrm{kT})}\end{array}$ & $\mathbf{z}_{\text {elec }}$ & $\%$ Difference in $\mathrm{z}_{\text {elec }}$ & Source \\
\hline 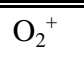 & $\overline{2} \Pi$ & 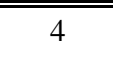 & $\overline{4} \Pi$ & 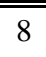 & 32,964 & 0.00060723 & 4.00060723 & 0.0152 & 31 \\
\hline $\mathrm{NO}^{+}$ & ${ }^{1} \Sigma$ & 1 & ${ }^{3} \Sigma$ & 3 & 52,190 & 0.00000090 & 1.00000090 & 0.00009 & 31 \\
\hline $\mathrm{OH}^{+}$ & ${ }^{3} \Sigma$ & 3 & ${ }^{1} \Delta$ & 2 & 17,660 & 0.01241478 & 3.01241478 & 0.4 & 31 \\
\hline $\mathrm{Ar}_{2}^{+}$ & ${ }^{2} \Sigma$ & 2 & ${ }^{2} \Pi$ & 4 & 12,986 & 0.09531766 & 2.09531766 & 4.8 & 32 \\
\hline $\mathrm{ArN}^{+}$ & ${ }^{3} \Sigma$ & 3 & ${ }^{3} \Pi$ & 6 & 14,047 & 0.10534204 & 3.10534204 & 3.5 & 33 \\
\hline $\mathrm{ArH}^{+}$ & ${ }^{1} \Sigma$ & 1 & ${ }^{3} \Pi$ & 6 & 49,163 & 0.00000430 & 1.00000430 & 0.0004 & 34 \\
\hline $\mathrm{ArO}^{+}$ & ${ }^{4} \Sigma$ & 4 & ${ }^{2} \Pi$ & 4 & 3,490 & 1.46515850 & 5.46515850 & 36.6 & 35 \\
\hline
\end{tabular}


Table 2. Effect of including first excited state on the electronic partition function of certain neutral species.

\begin{tabular}{|c|c|c|c|c|c|c|c|c|c|}
\hline Ion & \begin{tabular}{|c|} 
Ground \\
Term \\
Symbol
\end{tabular} & $\begin{array}{l}\text { State } \\
\mathbf{g}_{0}\left(\mathbf{z}_{\text {elec }}\right)\end{array}$ & $\begin{array}{c}\text { First Ex } \\
\text { Term } \\
\text { Symbol }\end{array}$ & ited & $\begin{array}{l}\text { Electronic State } \\
\text { Energy }\left(\mathrm{cm}^{-1}\right)\end{array}$ & $\mathbf{g}_{1} \mathbf{e}^{(-\mathrm{E} 1 / \mathrm{kT})}$ & $\mathbf{z}_{\text {elec }}$ & \%error & Source \\
\hline$\overline{\mathrm{O} \mathrm{O}_{2}}$ & $\overline{{ }^{3} \Sigma}$ & 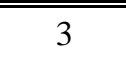 & $\overline{{ }^{1} \Delta}$ & 2 & 7,918 & 0.20485707 & 3.20485707 & 6.8 & 31 \\
\hline NO & ${ }^{2} \Pi$ & 4 & ${ }^{2} \Pi$ & 4 & 120 & 3.86442842 & 7.86442842 & 96.6 & 31 \\
\hline $\mathrm{OH}$ & ${ }^{2} \Pi$ & 4 & ${ }^{2} \Sigma$ & 2 & 32,684 & 0.00016454 & 4.00016454 & 0.0 & 31 \\
\hline $\mathrm{ScO}$ & ${ }^{2} \Sigma$ & 2 & ${ }^{2} \Delta$ & 4 & 15,030 & 0.05292773 & 2.05292773 & 2.6 & 31 \\
\hline
\end{tabular}


Table 3. Ionization energies and ionization efficiencies for atoms and neutral polyatomic ions under hot plasma conditions. $\%=\frac{n_{A^{+}}}{n_{A}+n_{A^{+}}} \times 100$

\begin{tabular}{|c|c|c|c|}
\hline Species & Ionization Energy (eV) & $\begin{array}{c}\left(\text { at } T_{\text {ion }}=7000 \mathrm{~K}, \mathrm{~T}_{\mathrm{gas}}=5000 \mathrm{~K}\right. \\
\left.\text { and } \mathbf{n}_{\mathrm{e}}=1 \times 10^{15} \mathrm{~cm}^{-3}\right) \\
\% \text { ionization }\end{array}$ & Reference \\
\hline $\mathrm{O}_{2}$ & 12.071 & 0.5 & 31 \\
\hline $\mathrm{O}$ & 13.618 & 0.02 & 37 \\
\hline $\mathrm{OH}$ & 12.9 & 0.1 & 31 \\
\hline $\mathrm{NO}$ & 9.26436 & 5 & 31 \\
\hline $\mathrm{N}$ & 14.534 & 0.02 & 37 \\
\hline $\mathrm{CeO}$ & 4.9 & 100 & 38 \\
\hline $\mathrm{Ce}$ & 5.47 & 100 & 37 \\
\hline $\mathrm{ScO}$ & 6.6 & 100 & 39 \\
\hline Sc & 6.54 & 100 & 37 \\
\hline
\end{tabular}


Table 4. Error analysis of one run. Hot plasma mode, Ni cones, H-skimmer geometry.

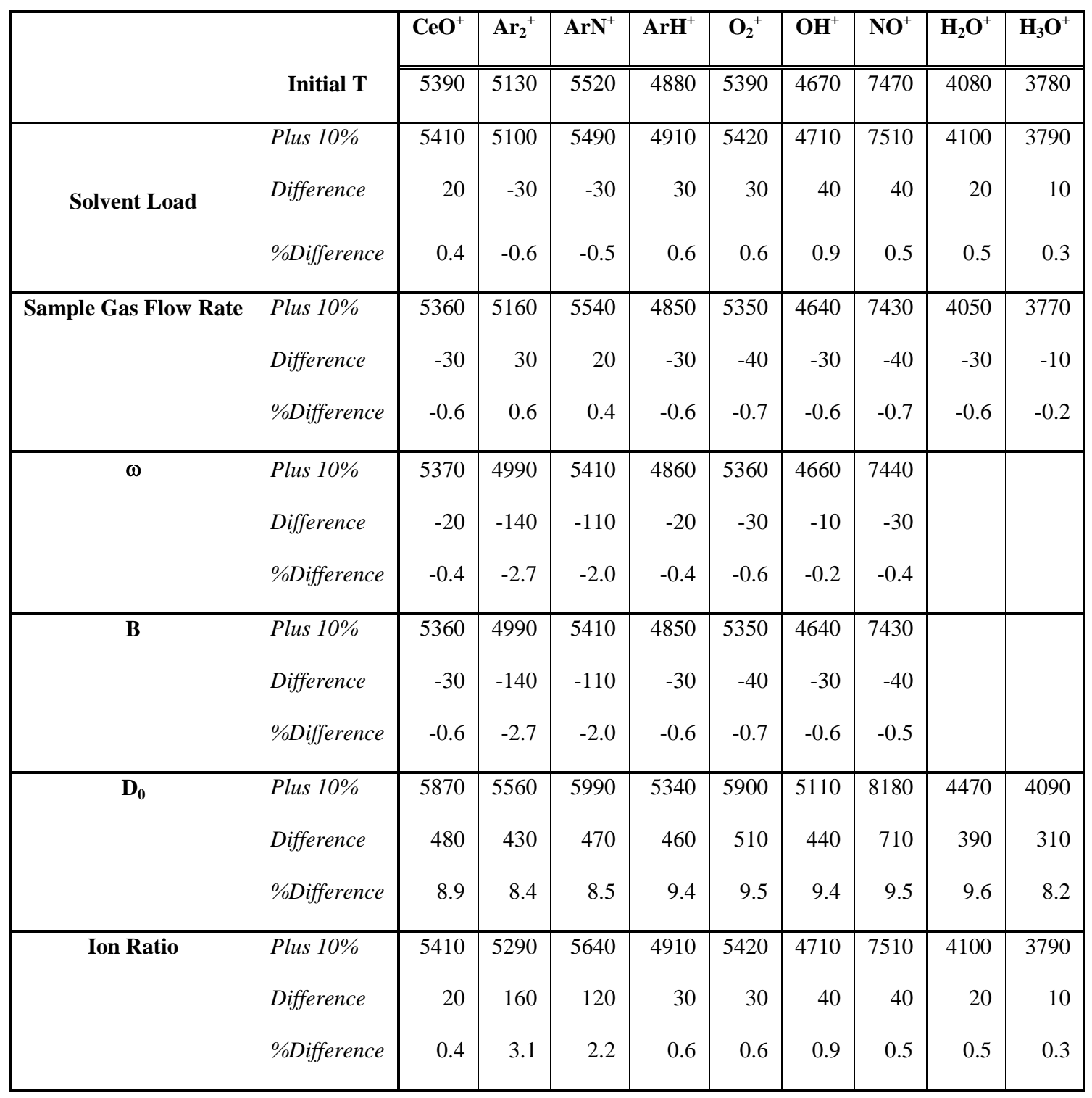


Table 5. Summary of percent of 2 and 3-body collisions needed to make additional polyatomic as indicated by measured $\mathrm{T}_{\text {gas }}$.

\begin{tabular}{|c|c|c|c|c|}
\hline $\begin{array}{c}\text { Collision } \\
\text { Species }\end{array}$ & $\begin{array}{c}\text { Polyatomic } \\
\text { Ion }\end{array}$ & $\begin{array}{l}\text { Average \% of 2-body colli- } \\
\text { sions needed to make polya- } \\
\text { tomic. }\end{array}$ & $\begin{array}{l}\text { Average \% of 3-body colli- } \\
\text { sions needed to make Polya- } \\
\text { tomic }\end{array}$ & $\begin{array}{l}\text { Number } \\
\text { of trials }\end{array}$ \\
\hline $\mathrm{Ar}^{+}+\mathrm{Ar}$ & $\overline{\mathrm{Ar}_{2}}{ }^{+}$ & 0.00024 & $0.024-0.24$ & $\overline{7} 7$ \\
\hline $\mathrm{H}^{+}+\mathrm{Ar}$ & $\overline{\mathrm{ArH}^{+}}$ & 0.57 & $57-570$ & 20 \\
\hline $\mathrm{N}^{+}+\mathrm{Ar}$ & $\overline{\mathrm{ArN}^{+}}$ & 0.00034 & $0.034-0.34$ & 12 \\
\hline $\mathrm{O}^{+}+\mathrm{O}$ & $\mathrm{O}_{2}^{+}$ & 0.40 & $3.3-33$ & 13 \\
\hline $\mathrm{O}^{+}+\mathrm{H}$ & $\mathrm{OH}^{+}$ & 0.58 & $9.7-97$ & 20 \\
\hline $\mathrm{OH}^{+}+\mathrm{H}$ & $\overline{\mathrm{H}_{2} \mathrm{O}^{+}}$ & 13.7 & $230-2,300$ & 20 \\
\hline $\mathrm{H}_{2} \mathrm{O}^{+}+\mathrm{H}$ & $\mathrm{H}_{3} \mathrm{O}^{+}$ & 0.80 & $13-130$ & 19 \\
\hline
\end{tabular}




\section{Figures}

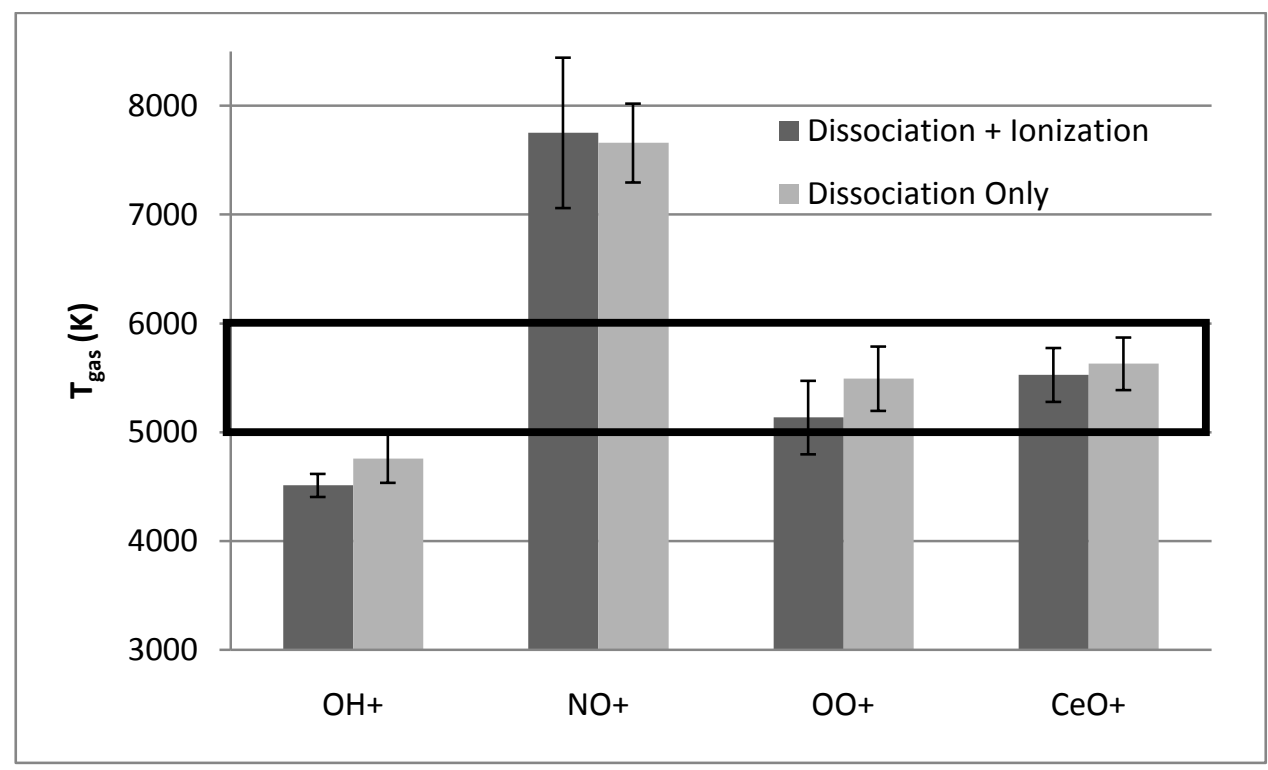

Figure 1. Gas kinetic temperature calculated setting Equations 2 and 3 equal to each other

(Original) and calculated including ionization energy of the polyatomic molecule and charged dissociation product (Equations 8-10) (New) in a hot plasma. Box represents the typical range of plasma temperatures at the sampling point $(5000-6000 \mathrm{~K}) . \mathrm{n}=20$ and error bars correspond to standard deviation. 


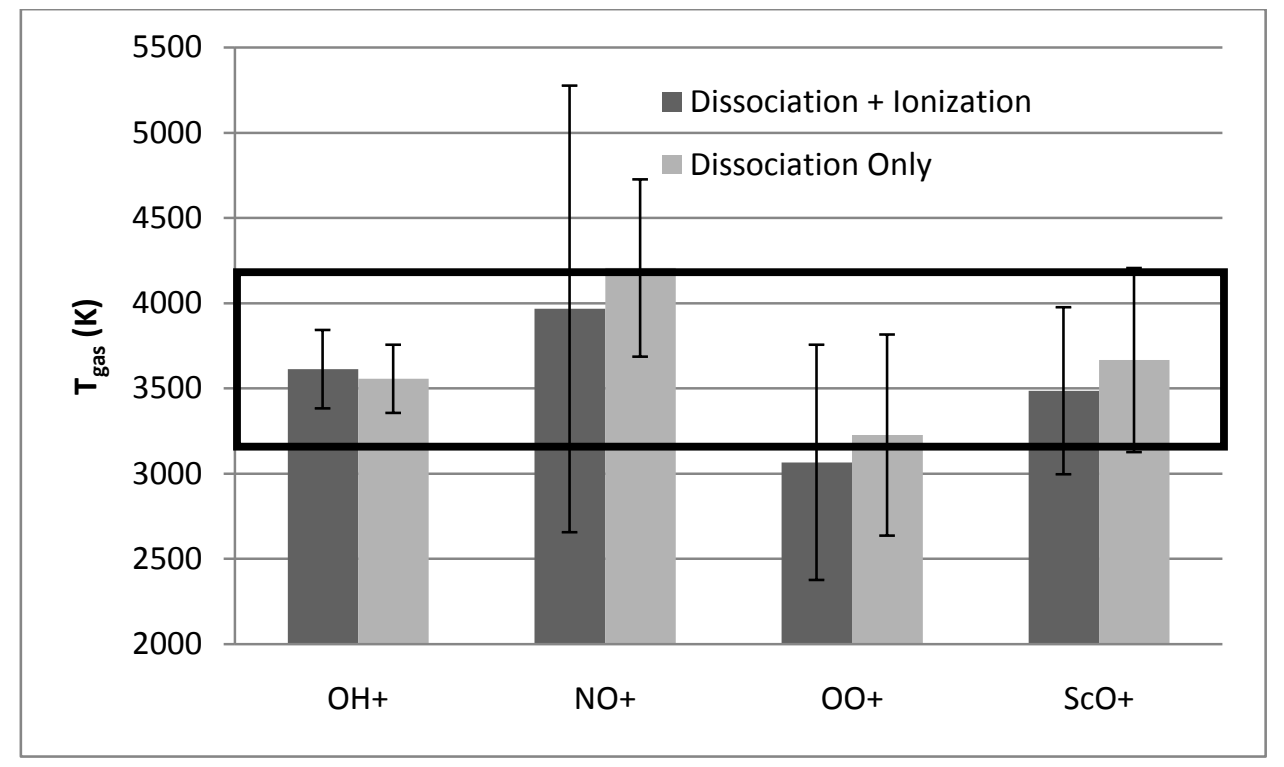

Figure 2. Gas kinetic temperature calculated setting Equations 2 and 3 equal to each other (Dissociation Only) and calculated including ionization energy of the polyatomic molecule and charged dissociation product (Equations 8-10) (Dissociation + Ionization) in a 'cold' plasma. Assuming the metal oxide gives a characteristic temperature of the plasma, the box represents a one thousand Kelvin range for the plasma temperature. Sixteen spectra on each of three days were averaged. Error bars correspond to range over the three days. 


\title{
CHAPTER 3. GAS KINETIC TEMPERATURES OF POLYATOMIC IONS \\ IN INDUCTIVELY COUPLED PLASMA-MASS SPECTROMETRY: EFFECTS OF \\ CONE MATERIAL, SKIMMER CONE GEOMETRY AND COOL PLASMA \\ CONDITIONS ON CALCULATED VERSUS MEASURED ION RATIOS
}

\author{
A paper to be submitted to Spectrochimica Acta Part B \\ Sally M. McIntyre, Jill Wisnewski Ferguson, R.S. Houk
}

\begin{abstract}
Gas kinetic temperatures $\left(\mathrm{T}_{\mathrm{gas}}\right)$ are measured for eight common polyatomic species $\left(\mathrm{NO}^{+}, \mathrm{H}_{2} \mathrm{O}^{+}, \mathrm{H}_{3} \mathrm{O}^{+}, \mathrm{Ar}_{2}{ }^{+}, \mathrm{ArN}^{+}, \mathrm{OH}^{+}, \mathrm{ArH}^{+}, \mathrm{O}_{2}{ }^{+}\right)$as well as $\mathrm{CeO}^{+}$and $\mathrm{ScO}^{+}$by comparing measured ion ratios to ratios calculated with partition functions. Temperatures are reported for nickel, aluminum and platinum-tipped nickel cones and certain mixtures of sampler and skimmer cones. Temperatures are reported for standard H-skimmer geometry versus the newer X-skimmer geometry and for 'hot' and 'cool' plasmas. In general, for hot plasmas $\mathrm{CeO}^{+}, \mathrm{Ar}_{2}{ }^{+}, \mathrm{ArN}^{+}, \mathrm{ArH}^{+}$, and $\mathrm{O}_{2}^{+}$gave temperatures characteristic of the plasma at the point of ion extraction $(5000-6000 \mathrm{~K}), \mathrm{NO}^{+}$gave a temperature above the plasma temperature (> $6000 \mathrm{~K})$ and $\mathrm{H}_{2} \mathrm{O}^{+}, \mathrm{H}_{3} \mathrm{O}^{+}$and $\mathrm{OH}^{+}$gave temperatures below the plasma temperature $(<5000$ K). X-skimmers lowered $\mathrm{T}_{\text {gas }}$ values from $\mathrm{Ar}_{2}{ }^{+}$and $\mathrm{ArH}^{+}$to below the plasma temperature except when the X-skimmer was paired with an aluminum sampler. Cool plasmas gave lower gas kinetic temperatures and less ion-to-ion variations in temperature overall, as ex-
\end{abstract}


pected. In the cool plasma $\mathrm{Ar}_{2}{ }^{+}$and $\mathrm{ArN}^{+}$were again uniquely affected and gave temperature below that of the plasma.

\section{Introduction}

Polyatomic ions have been observed and investigated since the beginnings of inductively coupled plasma-mass spectrometry (ICP-MS) [1]. Combinations of Ar, O, H, and N are particularly prevalent due to their presence in the plasma and solvents. Polyatomic ions made from these elements overlap with major isotopes of several important elements including iron, calcium, potassium and selenium. Oxides and hydrides formed with analyte and matrix elements interfere with isotopes across the periodic table. Consequently, several methods and instrumentations have been developed to decrease the deleterious effect of polyatomic ions. For example, most commercial quadrupole ICP-MS instruments sold today include collision cells, or other ways to add a collision gas [2], to attenuate polyatomic ions.

Beyond their attenuation and elimination, the nature and origin of polyatomic ions have also been studied. It has been calculated that for the strongly bound metal oxides like $\mathrm{CeO}^{+}(8.81 \mathrm{eV})[3-5]$ the metal oxide to metal $\left(\mathrm{MO}^{+} / \mathrm{M}^{+}\right)$signal ratios should be $1-2 \%$ given the plasma temperature [6-7]. It has also been shown that dissociation and ionization reactions occur in the interface as well [8-9] offering another possible pathway for polyatomic ion generation or loss. The behavior of various polyatomics with plasma operating conditions has been a common subject [10].

In terms of determining generation or depletion behavior of polyatomic ions, this paper follows the method outlined in Nonose et al., Cleland and Meeks, Evans et al. and Houk 
and Praphairaksit [11-16]. For polyatomic ions containing Ar, O or H, a dissociation reaction is proposed such that polyatomic ion $\mathrm{AB}^{+}$dissociates into $\mathrm{A}^{+}$and $\mathrm{B}$ where $\mathrm{B}$ is $\mathrm{Ar}, \mathrm{O}$ or $\mathrm{H}$ and $\mathrm{A}^{+}$may be one or more atoms.

$$
A B^{+} \rightleftharpoons A^{+}+B, \Delta \mathrm{E}=\mathrm{D}_{\mathrm{o}}\left(\mathrm{A}^{+}-\mathrm{B}\right)
$$

A dissociation constant, $\mathrm{K}_{\mathrm{d}}$, is found from experimental data (number densities, $n$ ) and calculated partition functions $(\mathrm{Z})$,

$$
\frac{n_{A^{+}} n_{B}}{n_{A B^{+}}}=\mathrm{K}_{\mathrm{d}}=\frac{Z_{A^{+}} Z_{B}}{Z_{A B^{+}}} e^{-\mathrm{D}_{\mathrm{o}} / k_{B} T_{\text {gas }}}
$$

where $\mathrm{D}_{\mathrm{o}}$ is the bond dissociation energy of $\mathrm{AB}^{+}$and $k_{B}$ is the Boltzmann constant in the units of $\mathrm{D}_{\mathrm{o}}$. The $\mathrm{T}_{\text {gas }}$ that gives the best agreement between the two sides of equation 2 is considered to be indicative of the origin of the polyatomic ion. If $\mathrm{T}_{\text {gas }}$ is between 5000 and $6000 \mathrm{~K}$ the polyatomic ion is considered to come only from the plasma as this is the general temperature range of the part of the plasma that is extracted into the mass spectrometer [13]. If the $\mathrm{T}_{\text {gas }}$ is below $5000 \mathrm{~K}$ then it is considered that additional polyatomic ion is being made after the plasma, during the extraction through the interface where temperature falls as the expansion cools. If the $\mathrm{T}_{\text {gas }}$ is above $6000 \mathrm{~K}$ then it is considered that some of the polyatomic ion is removed during the extraction through the interface.

This paper compares $\mathrm{T}_{\text {gas }}$ values measured with different cone metals, $\mathrm{X}$-geometry skimmer cones and cool plasma conditions. Cone material and structure have been shown to affect $\mathrm{MO}^{+} / \mathrm{M}^{+}$ratios [17-19]. Skimmer cone geometry and cool plasma conditions can dramatically alter $\mathrm{ArX}^{+}$signal intensities [19-20]. 


\section{Experimental Section}

The instrument and basic experiment have been described elsewhere [14]. Basic operating conditions are reiterated in Table 1. For each daily run gas flows and ion optical voltages (occasionally torch position but not every run) were tuned to maximize ${ }^{7} \mathrm{Li}^{+},{ }^{115} \mathrm{In}^{+}$and ${ }^{238} \mathrm{U}^{+}$signal. For this reason gas flows varied from day to day. A mass bias response curve $[14,21]$ was measured using a 50 or 10 ppb solutions of $\mathrm{Li}, \mathrm{B}, \mathrm{Na}, \mathrm{Si}, \mathrm{Sc}, \mathrm{Fe}, \mathrm{Co}, \mathrm{Ga}, \mathrm{Y}, \mathrm{Rh}$, In, $\mathrm{Lu}, \mathrm{Tl}, \mathrm{U}$ in $1 \%$ nitric acid. Unfortunately, there was no way to test whether an atomic ion response curve is valid for polyatomic ions because at this time there is no known way of introducing standard amounts of polyatomic molecules into the ICP. This would be expescially problematic for additional polyatomic ions made in the interface if significant mass bias occurred there because the new polyatomic ions would not be exposed to the biasing effects for as long as the atomic ions. There is some evidence of mass bias occuring as far upstream as the plasma [22].

In hot plasma mode $\mathrm{Ce}^{+}, \mathrm{CeO}^{+}, \mathrm{N}^{+} \mathrm{ArN}^{+}, \mathrm{NO}^{+}$and the elements in the response curve were measured in counting mode. The other species were measured in analog mode. All ratios were calculated using species measured in the same detection mode, i.e., $\mathrm{CeO}^{+}$and $\mathrm{Ce}^{+}$ were both measured in counting mode to determine the ratio $\mathrm{CeO}^{+} / \mathrm{Ce}^{+}, \mathrm{Ar}_{2}{ }^{+}$and $\mathrm{Ar}^{+}$in ana$\log$ mode to determine the ratio $\mathrm{Ar}_{2}{ }^{+} / \mathrm{Ar}^{+}$. All ions were measured at least 16 times for each run.

All solutions were made with deionized water (MilliporeQ, 18M $\Omega$ ), and Ultrapure sub-boiled distilled nitric acid (J.T. Baker). Solvent load was found to be $0.04438 \mathrm{~g} \mathrm{~min}^{-1}$ (+/- 13.9\% standard deviation). As reported in McIntyre et al. [15] a 10\% difference in sol- 
vent load yields less than a $1 \%$ change in $\mathrm{T}_{\text {gas }}$ so the standard deviation on the solvent load was not a concern.

The calculated dissociation constant equations are described elsewhere [13-15]. Statistical comparisons were done using a t-test at the 95\% confidence interval [23].

Two skimmer geometries were used in these experiments: the standard, or older, Hskimmer and the newer X-skimmer. Both types were purchased from dealers and were specific to this commerical instrument. Magnified pictures of both types were taken in a LSX500 (Cetac Technologies, Omaha, NE, USA) laser ablation cell of both an H and X geometry skimmer. A drawing detailing the observed differences is given in Figure 1. The outside of the cones are identical; the wall near the tip is narrower and the inner tip widens at a sharper angle in the $\mathrm{X}$ geometry.

Cool plasma mode was used on three days. To attain a cool plasma, ${ }^{36} \mathrm{Ar}^{16} \mathrm{O}^{+},{ }^{115} \mathrm{In}^{+}$ and ${ }^{238} \mathrm{U}^{16} \mathrm{O}^{+}$were monitored as the power was slowly reduced to $700 \mathrm{~W}$ and the sample gas flow rate was increased. The cool plasma mass bias response curves used some combination of ions from a $50 \mathrm{ppb}$ solution of $\mathrm{Li}, \mathrm{Na}, \mathrm{Mg}, \mathrm{Fe}, \mathrm{Co}, \mathrm{Cu}, \mathrm{Ga}$, and $\mathrm{Rh}$ in $1 \% \mathrm{HNO}_{3}$. In cold plasma mode there is little $\mathrm{Ce}^{+}$signal, so $\mathrm{Sc}^{+}$and $\mathrm{ScO}^{+}$was measured with a 50 ppb solution of $\mathrm{Sc}$ in $1 \% \mathrm{HNO}_{3}$. Isotopes were chosen so that all ions could be measured in counting mode. 


\section{Results and Discussion}

\subsection{Cone Material}

Aluminum, nickel and platinum-tipped-nickel cones were investigated (Table 2).

The results of the statistical comparison are given in Table 3. One data point for $\mathrm{ArN}^{+}$in the aluminum cone sets could be rejected by the $\mathrm{t}_{\mathrm{n}}$ test at the $95 \%$ confidence interval.

This study found few significant changes based on cone material. $\mathrm{O}_{2}{ }^{+}$and $\mathrm{OH}^{+}$gave very consistent temperatures. In two comparisons where there was a statistical difference, there was still no change in the origin diagnosis for $\mathrm{O}_{2}{ }^{+}$and $\mathrm{OH}^{+}(\mathrm{NCD}$ in Table 3). Interestingly, both comparisons involved a Ni vs a Pt skimmer. However, a Pt skimmer was only used two times, once with a Pt sampler and once with a Ni sampler. Further trials may show this to only be a coincidence, a suggestion supported by the fact that while both polyatomic ions yielded a higher temperature when moving from $\mathrm{Ni}$ sets to a $\mathrm{Pt}$ set, the $\mathrm{T}_{\text {gas }}$ of $\mathrm{OH}^{+}$was lower for a Pt skimmer/Ni sampler than for Ni skimmer/Ni sampler average.

Any other possible changes in origin diagnosis based on observed average gas $T_{\text {gas }}$ values between different metal cones of the same geometry were not statistically different (NSD in Table 3) at the 95\% confidence interval of a t-test. Interestingly, $\mathrm{Ar}_{2}{ }^{+}$tends to return a higher $\mathrm{T}_{\text {gas }}$ when an aluminum sampler is used. The skimmer material does not affect this trend. This is also seen for $\mathrm{ArN}^{+}$but only when the skimmer is nickel and the difference in $\mathrm{T}_{\mathrm{gas}}$ is also smaller.

Ferguson and Houk also found few diagnosis changes for these common polyatomic ions between nickel and aluminum cones [14]. If diagnosis changes are drawn sharply at 5000 and $6000 \mathrm{~K}$ then their results showed two possibilities, $\mathrm{ArH}^{+}$and $\mathrm{O}_{2}{ }^{+}$shifting from 5050 to $4880 \mathrm{~K}$ and 5070 to $4590 \mathrm{~K}$ using $\mathrm{Ni}$ or $\mathrm{Al}$ cones respectively. The shift in the $\mathrm{T}_{\text {gas }}$ 
for $\mathrm{ArH}^{+}$of $170 \mathrm{~K}$ is essentially within the standard deviation seen in this paper and less than the $250 \mathrm{~K}$ shift in $\mathrm{T}_{\text {gas }}$ for $\mathrm{CeO}^{+}$. The $480 \mathrm{~K}$ shift for $\mathrm{O}_{2}{ }^{+}$is more surprising given the low variation in $\mathrm{T}_{\text {gas }}$ for this polyatomic ion. Still, a range of $700 \mathrm{~K}$ was observed in three trials of $\mathrm{Al}$ cones for $\mathrm{O}_{2}{ }^{+}$although in the twenty trials of this study it gave only one temperature below $5000 \mathrm{~K}$ and should probably be classified as coming from the plasma primarily.

Ferguson and Houk also saw a difference in the $\mathrm{NO}^{+} / \mathrm{N}^{+}$ratio between $\mathrm{Ni}$ and $\mathrm{Al}$ cones and speculated that a smaller ratio for $\mathrm{Ni}$ cones was the result of $\mathrm{NO}^{+}$reacting with the hot Ni surface. This study on the other hand found essentially no difference between the two types of cones. In fact the highest gas kinetic temperature found for $\mathrm{NO}^{+}$was from an aluminum set.

\subsection{Skimmer Cone Geometry}

Distinct, statistically significant, origin diagnoses were observed for $\mathrm{Ar}_{2}{ }^{+}$and $\mathrm{ArN}^{+}$ between $\mathrm{H}$ and $\mathrm{X}$ skimmers. With the more blunt-tipped H-skimmer the ratio of these polyatomic ions to their atomic ion dissociation product was at levels expected from the plasma. With the thinner-tipped X-skimmer the gas kinetic temperatures indicated more polyatomic ion than expected from the plasma alone. An aluminum sampler mitigates the decrease in $\mathrm{T}_{\text {gas }}$ nearly offsetting any change due to the X-skimmer. This agrees with their behavior in the previous section where $\mathrm{Al}$ sampler cones gave higher temperatures than $\mathrm{Ni}$ or $\mathrm{Pt}$ samplers. $\mathrm{ArH}^{+}$also gives a lower $\mathrm{T}_{\text {gas }}$ when a nickel sampler and $\mathrm{X}$-skimmer are used, but a similar $\mathrm{T}_{\text {gas }}$ to a standard $\mathrm{Ni}$ set when the sampler is aluminum. This is further evidence for the consistent behavior of $\mathrm{ArX}^{+}$species seen by Nonose et al. [11]. While the skimmer clearly plays a role in $\mathrm{ArX}^{+}$behavior, the sampler seems to play a larger one. 
The other polyatomic ions remain unaffected by the new skimmer geometry. $\mathrm{NO}^{+}$ and $\mathrm{H}_{2} \mathrm{O}^{+}$are statistically different, but only one measurement was done for the $\mathrm{Al}$ sampler/Ni X-skimmer combination.

\subsection{Cool Plasma}

$\mathrm{ScO}^{+} / \mathrm{Sc}^{+}$replaced $\mathrm{CeO}^{+} / \mathrm{Ce}^{+}$when cool plasma conditions were used because sufficient $\mathrm{Ce}^{+}$could not be seen in the cool plasma spectrum. As expected, lower temperatures were seen for all polyatomics (Table 4). Cool plasma conditions are used to decrease the presence of Ar polyatomic ions and atomic $\mathrm{Ar}^{+}$itself so that isobaric analyte elements can be measured with lower resolution instruments. Given this it was expected that $\mathrm{ArX}^{+}$gas kinetic temperatures might rise above the metal oxide temperature to indicate the decreased presence of the diatomic ion. In fact, the opposite occurred, $\mathrm{Ar}_{2}{ }^{+}$and $\mathrm{ArN}^{+}$move from averages representative of the plasma temperature to averages below the temperature from $\mathrm{ScO}^{+}$. It would appear that while absolute $\mathrm{ArX}^{+}$signals decreased, $\mathrm{Ar}^{+}$and $\mathrm{N}^{+}$signals decreased by a larger factor yielding ratios weighted toward the polyatomic ions. In terms of equilibrium this makes sense. The lower temperature of the plasma shifts the dissociation reaction toward the left although why this should occur to a larger extent in $\mathrm{Ar}_{2}{ }^{+}, \mathrm{ArN}^{+}, \mathrm{O}_{2}{ }^{+}$and $\mathrm{OH}^{+}$ than $\mathrm{ArH}^{+}$is unclear.

The large decrease in $\mathrm{NO}^{+}$temperature is consisent with the observations of others that $\mathrm{NO}^{+}$signal increased with cool operating conditions $[20,24] . \mathrm{H}_{2} \mathrm{O}^{+}$changed origin diagnoses by moving from a temperature indicative of additional formation in the interface in hot plasmas to a temperature $140 \mathrm{~K}$ below the $\mathrm{ScO}^{+}$temperature in cool plasmas. Under hot plasma conditions $\mathrm{H}_{3} \mathrm{O}^{+}$would be scraping the bottom of the assumed $500 \mathrm{~K}$ range around 
the $\mathrm{CeO}^{+}$temperature used as the dividing lines for diagnoses. Because the total range of temperatures found in the cool plasma is narrower, the plasma temperature range would logically be narrower as well. An argument could be made for placing $\mathrm{H}_{3} \mathrm{O}^{+}$in one of two origin regions.

Houk and Praphairaksit also compared plasmas with a home-made quadrupole instrument. Their second set of operating conditions produced a plasma described as 'warm' and power was lowered from 1.25 to $0.8 \mathrm{~kW}$. This study lowered power to $0.7 \mathrm{~kW}$ and this is reflected in the lower temperatures seen. Gas kinetic temperatures for $\mathrm{ArN}^{+}, \mathrm{O}_{2}^{+}, \mathrm{NO}^{+}$and $\mathrm{ScO}^{+}$were $\sim 1000$ to $2000 \mathrm{~K}$ lower than seen in Houk and Praphairaksit. $\mathrm{Ar}_{2}^{+}, \mathrm{OH}^{+}, \mathrm{H}_{2} \mathrm{O}^{+}$, and $\mathrm{H}_{3} \mathrm{O}^{+}$gave temperatures 203 to $767 \mathrm{~K}$ lower than Houk and Praphairaksit. Only one polyatomic ion, $\mathrm{ArH}^{+}$gave a temperature higher than the previous paper. The range in temperature differences are probably an artefact of the different partition functions' responses to changes in ratios and flow rates. The $\mathrm{ArH}^{+}$behavior is more puzzling and is part of the larger question of why the $\mathrm{ArX}^{+}$behaved differently between the two studies. Houk and Praphairaksit saw temperatures of $4050 \mathrm{~K}, 4220 \mathrm{~K}$ and $4190 \mathrm{~K}$ for $\mathrm{Ar}_{2}^{+}, \mathrm{ArN}^{+}$and $\mathrm{ArH}^{+}$in a hot plasma (generation of more polyatomic ion after extraction) while this study found an averge of $5890 \mathrm{~K}, 5810 \mathrm{~K}$ and $4960 \mathrm{~K}$ (expected plasma levels) across all twenty trials. The difference may lay in the fact Houk and Praphairaksit used a nickel sampler but a stainless steel skimmer or in the fact that these cones had larger orifices than the Element1 $(1.4 \mathrm{~mm}$ vs. $\sim 1 \mathrm{~mm})$. As noted in the previous sections, if cone geometry and material affect any polyatomic ions it would be these three.

Among the various polyatomic ions studied the temperature spread was $2690 \mathrm{~K}$ in cold plasma mode as compared to $4700 \mathrm{~K}$ in hot plasma. This may be significant or merely a 
result of the lower overall temperature of the cool plasma. Note that the range is $\sim 77 \%$ of the plasma temperature in the cool conditions and $\sim 85 \%$ in the hot.

\subsection{Response Curves}

Ferguson and Houk found that the instrument had a greater mass bias when aluminum cones were used instead of nickel ones [14]. Ferguson and Houk attributed the behavior of aluminum to its larger thermal conductivity. These experiments found the same behavior for $\mathrm{Al}$ and Ni. Cones with a Ni base and a Pt tip were also used and the one set studied was found to give a response curve slightly shallower than the Ni average (Figure 2). Again, pure platinum has a thermal conductivity slightly lower than that of $\mathrm{Ni}$ at room temperature. Of course, the cones will be much warmer than room temperature when the plasma is running and thermal conductivities are a function of temperature. Ni, Pt and most Ni and Pt alloys have thermal conductivities within $\sim 15 \mathrm{~W} \mathrm{~m}^{-1} \mathrm{~K}^{-1}$ of each other in the temperature range of $273 \mathrm{~K}$ to $973 \mathrm{~K}[25]$.

One X-skimmer gave a steeper response curve than the traditional H-skimmer while another X-skimmer's response curve was more shallow (Figure 3). It would be logical to assume the thinner tip of the X-skimmer should conduct heat to the lower body of the skimmer slower than the thicker H-skimmer tip. This decreased thermal conductivity should correspond to a sharper response curve as seen with aluminum cones and the second $\mathrm{X}$ -

skimmer. Perhaps response curves are more variable than metal thermal conductivities alone can explain. The vastly different response curves do not translate into greatly different gas kinetic temperatures. The three $\mathrm{X}$-skimmer/Ni sampler trials had some of the lowest standard deviations. 


\section{Acknowledgements}

This research was supported by the National Science Foundation through the Institute for Physical Research and Technology at ISU. The Element1 ICP-MS was obtained with

funds provided by the U. S. Department of Energy, Office of Nuclear Nonproliferation (NA22) and the Office of Basic Energy Sciences.

The authors would also like to thank D.C. Perdian for making the CAD drawings of the skimmer tips.

\section{References}

[1] R.S. Houk, V.A. Fassel, G.D. Flesch, H.J. Svec, A.L. Gray, C.E. Taylor, Inductively coupled argon plasma as an ion source for mass spectrometric determination of trace elements, Anal. Chem. 52 (1980) 2283-2289.

[2] Y. Abdelnour, J. Murphy, The analysis of whole blood samples by Collision Reaction Interface Inductively Coupled Plasma Mass Spectrometry: Varian 820-MS, Varian ICP-MS Application Note Number 28. Accessed through www.varianinc.com on 05/24/10.

[3] IE Ce (5.47) + $\mathrm{D}_{\mathrm{o}} \mathrm{CeO}(8.18 \mathrm{eV})-\mathrm{IE} \mathrm{CeO}$ (4.9). IE Ce from reference 4, IE CeO and $\mathrm{D}_{\mathrm{o}}$ from reference 5 .

[4] Periodic Table of the Elements, VWR Scientific Products Sargent Welch (1996) Buffalo Grove, IL.

[5] R.J. Ackermann, E.G. Rauh, R.J. Thorn, The thermodynamics of ionization of gaseous oxides; the first ionization potentials of the lanthanide metals and monoxides, J. Chem. Phys., 65 (1976) 1027-1031.

[6] D.J. Douglas, J.B. French, An improved interface for inductively coupled plasma mass spectrometry, Spectrochim. Acta B 41 (1986) 197-204. 
[7] H. Niu, R.S. Houk, Fundamental aspects of ion extraction in inductively coupled plasmamass spectrometry, Spectrochim. Acta Part B 51 (1996) 779-815.

[8] H. Togashi, A. Hashizume, Y. Niwa, Molecular ionization in the interface of an inductively coupled plasma mass spectrometer, Spectrochim. Acta B 47 (1992) 561-568.

[9] J.H. Macedone, P.B. Farnsworth, Changes in plasma composition during the expansion into the first vacuum stage of an inductively coupled plasma mass spectrometer, Spectrochim. Acta B 61 (2006) 1030-1038.

[10] A.E. Holliday, D. Beauchemin, Spatial profiling of analyte signal intensities in inductively coupled plasma mass spectrometry, Spectromchim. Acta Part B 59 (2004) 291311. And references therein.

[11] N.S. Nonose, N. Matsuda, N. Fudagawa, M. Kubota, Some characteristics of polyatomic ion spectra in inductively coupled plasma-mass spectrometry, Spectrochim. Acta Part B 49 (1994) 955-974.

[12] T.J. Cleland, F.R. Meeks, Statistical mechanics of $\mathrm{Ar}_{2}{ }^{+}$in an inductively coupled plasma, Spectrochim. Acta B 51 (1996) 1487-1490.

[13] R.S. Houk, N. Praphairaksit, Dissociation of polyatomic ions in inductively coupled plasma, Spectrochim. Acta Part B 56 (2001) 1069-1096.

[14] J.W. Ferguson, R.S. Houk, High resolution studies of the origins of polyatomic ions in inductively coupled plasma-mass spectrometry, Part 1. Identification methods and effects of neutral gas density assumptions, extraction voltage, and cone material, Spectrochim. Acta Part B 61 (2006) 905-915.

[15] S. M. McIntyre, J.W. Ferguson, R.S. Houk, Measurement of dissociation temperatures for polyatomic ions in ICP-MS: Validation and variations of a method, Manuscript (2010). [16] E.H. Evans, L. Ebon, L. Rowley, Comparative study of the determination of equilibrium dissociation temperature in inductively coupled plasma-mass spectrometry, Spectrochim. Acta Part B 57 (2002) 741-754.

[17] C. Latkoczy, D. Guenther, Enhanced sensitivity in inductively coupled plasma sector field mass spectrometry for direct solid analysis using laser ablation (LA-ICP-SFMS), J. Anal. At. Spectrom. 17 (2002) 1264-1270. 
[18] K. Newman, P.A. Freedman, J. Williams, N.S. Belshaw, A.N. Halliday, High sensitivity skimmers and non-linear mass dependent fractionatio in ICP-MS, J. Anal. At. Spetrom. 24 (2009) 742-751.

[19] K.E. Jarvis, P. Mason, T. Platzner, J.G. Williams, Critical assessment of the effects of skimmer cone geometry on spectroscopic and non-spectroscopic interference in inductively coupled plasma mass spectrometry, J. Anal. At. Spectrom. 13 (1998) 689-696.

[20] S.J. Jiang, R.S. Houk, M.A. Stevens, Alleviation of overlap interferences for determination of potassium isotope ratios by inductively coupled plasma mass spectrometry, Anal. Chem. 60 (1988) 1217-1221.

[21] C.P. Ingle, B.L. Sharp, M.S.A. Horstwood, R.R. Parrish, D.J. Lewis, Instrument response functions, mass bias and matrix effects in isotope ratio measurements and semiquantitative analysis by single and multi-collector ICP-MS, J. Anal. At. Spectrom. 18 (2003) 219-229.

[22] H. Andren, I. Rodushkin, A. Stenber, D. Malinovsky, D.C. Baxter, Sources of mass bias and isotope ratio variation in multi-collector ICP-MS: optimization of instrumental parameters based on experimental observations, J. Anal. At. Spectrom. 19 (2004) 1217-1224. [23] D.C. Harris, Quantitative Chemical Analysis, $5^{\text {th }}$ Ed. W.H. Freeman and Company, New York, 1999.

[24] S.D. Tanner, Characterization of Ionization and Matrix Suppression in Inductively Coupled 'Cold' Plasma Mass Spectrometry, J. Anal. At. Spectrom. 10 (1995) 905-921. [25] CRC Handbook of Chemistry and Physics, $90^{\text {th }}$ Ed. 2009-2010, accessed online at http://www.hbcpnetbase.com/ in May 2010. 


\section{Tables}

Table 1. Instrument conditions for 'hot' and 'cool' plasmas.

\begin{tabular}{|r|c|c|}
\hline & Hot & Cool \\
\hline Power & $1200 \mathrm{~W}$ & $700 \mathrm{~W}$ \\
\hline Cool Gas & $13-16.081 \mathrm{~min}^{-1}$ & $16.08-16.181 \mathrm{~min}^{-1}$ \\
\hline Auxiliary Gas & $0.7-0.81 \mathrm{~min}^{-1}$ & $0.8-0.951 \mathrm{~min}^{-1}$ \\
\hline Sample Gas & $0.994-1.147 \mathrm{~min}^{-1}$ & $0.991-1.201 \mathrm{~min}^{-1}$ \\
\hline Tuning & maximize $\mathrm{Li}^{+}, \mathrm{Co}^{+}, \mathrm{In}^{+}$ & minimize $\mathrm{ArO}^{+}$ \\
& & maximize $\mathrm{Li}^{+}, \mathrm{In}^{+}, \mathrm{U}^{+}$ \\
\hline
\end{tabular}


Table 2. Summary of measured $\mathrm{T}_{\text {gas }}$ results for various cone materials and geometries. $\mathrm{n}$ is the number of days.

\begin{tabular}{|c|c|c|c|c|c|c|c|}
\hline & & & & & & Ni Sampler & \\
\hline & Ni Sets & $n=4$ & Al Sets & $n=3$ & Pt Set ${ }^{a}$ & Ni X-skimmer & $n=3$ \\
\hline $\begin{array}{c}\text { Polyatomic lon } \\
\text { ratio }\end{array}$ & $\begin{array}{c}\text { Average } T_{\text {gas }} \\
\text { (K) }\end{array}$ & $\begin{array}{c}\text { Standard } \\
\text { deviation }\end{array}$ & $\begin{array}{c}\text { Average } T_{\text {gas }} \\
\text { (K) }\end{array}$ & $\begin{array}{l}\text { Standard } \\
\text { deviation }\end{array}$ & $\mathrm{T}_{\text {gas }}(\mathrm{K})$ & $\begin{array}{c}\text { Average } \mathrm{T}_{\text {gas }} \\
\text { (K) }\end{array}$ & $\begin{array}{c}\text { Standard } \\
\text { deviation }\end{array}$ \\
\hline $\mathrm{CeO}^{+} / \mathrm{Ce}^{+}$ & 5680 & 267 & 5363 & 206 & 5660 & 5590 & 193 \\
\hline $\mathrm{Ar}_{2}^{+} / \mathrm{Ar}^{+}$ & 5825 & 1040 & 6987 & 1174 & 5800 & 3580 & 200 \\
\hline $\mathrm{ArN}^{+} / \mathrm{N}^{+}$ & 5453 & 613 & $5910^{b}$ & 552 & 5230 & 4453 & 159 \\
\hline $\mathrm{ArH}^{+} / \mathrm{Ar}^{+}$ & 4968 & 162 & 4967 & 101 & 5060 & 4743 & 51 \\
\hline $\mathrm{O}_{2}^{+} / \mathrm{O}^{+}$ & 5485 & 67 & 5500 & 354 & 5670 & 5417 & 81 \\
\hline $\mathrm{OH}^{+} / \mathrm{O}^{+}$ & 4715 & 39 & 4953 & 569 & 4860 & 4690 & 56 \\
\hline $\mathrm{NO}^{+} / \mathrm{N}^{+}$ & 7695 & 288 & 7847 & 792 & 7490 & 7253 & 117 \\
\hline $\mathrm{H}_{2} \mathrm{O}^{+} / \mathrm{OH}^{+}$ & 4228 & 517 & 3550 & 201 & 3860 & 4260 & 10 \\
\hline $\mathrm{H}_{3} \mathrm{O}^{+} / \mathrm{H}_{2} \mathrm{O}^{+}$ & 3718 & 210 & 3780 & 113 & 3870 & 3820 & 17 \\
\hline
\end{tabular}

\begin{tabular}{|c|c|c|c|c|c|c|}
\hline & Ni Sampler & & Ni Sampler & Al Sampler & & Al Sampler \\
\hline & Al skimmer & $n=3$ & Pt Skimmer ${ }^{a}$ & Ni Skimmer ${ }^{a}$ & $n=3$ & Ni X-Skimmer ${ }^{\mathrm{a}}$ \\
\hline $\begin{array}{c}\text { Polyatomic lon } \\
\text { ratio }\end{array}$ & $\begin{array}{c}\text { Average } T_{\text {gas }} \\
(\mathrm{K})\end{array}$ & $\begin{array}{c}\text { Standard } \\
\text { deviation }\end{array}$ & $\mathrm{T}_{\text {gas }}(\mathrm{K})$ & $\begin{array}{c}\text { Average } T_{\text {gas }} \\
(\mathrm{K})\end{array}$ & $\begin{array}{c}\text { Standard } \\
\text { deviation }\end{array}$ & $\mathrm{T}_{\text {gas }}(\mathrm{K})$ \\
\hline $\mathrm{CeO}^{+} / \mathrm{Ce}^{+}$ & 5690 & 195 & 5960 & 5477 & 119 & 6010 \\
\hline $\mathrm{Ar}_{2}^{+} / \mathrm{Ar}^{+}$ & 5787 & 1289 & 6030 & 7237 & 1106 & 5170 \\
\hline $\operatorname{ArN}^{+} / \mathrm{N}^{+}$ & 5410 & 373 & 5650 & 6430 & 313 & 4870 \\
\hline $\mathrm{ArH}^{+} / \mathrm{Ar}^{+}$ & 5103 & 98 & 4970 & 4890 & 62 & 4910 \\
\hline $\mathrm{O}_{2}^{+} / \mathrm{O}^{+}$ & 5087 & 481 & 5760 & 5680 & 142 & 5550 \\
\hline $\mathrm{OH}^{+} / \mathrm{O}^{+}$ & 4727 & 146 & 4630 & 4733 & 115 & 4610 \\
\hline $\mathrm{NO}^{+} / \mathrm{N}^{+}$ & 7783 & 189 & 7900 & 7603 & 212 & 7640 \\
\hline $\mathrm{H}_{2} \mathrm{O}^{+} / \mathrm{OH}^{+}$ & 3613 & 259 & 3900 & 3713 & 168 & 3950 \\
\hline $\mathrm{H}_{3} \mathrm{O}^{+} / \mathrm{H}_{2} \mathrm{O}^{+}$ & 3863 & 38 & 3860 & 3763 & 49 & 3790 \\
\hline
\end{tabular}

${ }^{a} \mathrm{n}=1$

${ }^{b} n=2$ 
Table 3. Summary of statistical comparisons. NSD: No Statistical Difference but average $\mathrm{T}_{\text {gas }}$ changes origin. NCD: statistically different but No Change in Diagnosis. Blank: $\mathrm{T}_{\text {gas }}$ between the two sets considered are not statically different and show no change in diagnosis.

\begin{tabular}{|c|c|c|c|c|c|c|c|c|c|}
\hline Polyatomic lon & Sets & & & & Ni Sampler & & Al Sampler & & \\
\hline Ratio & Nivs Al & Ni vs Pt & Al vs Pt & $\mathrm{Ni} \mathrm{H}$ vs X Sk & $\mathrm{Ni}$ vs Al sk & Ni vs Pt sk & Al vs Ni sk & Al vs Xsk & $\mathrm{Al} / \mathrm{Ni}$ vs Xsk \\
\hline $\mathrm{CeO}^{+} / \mathrm{Ce}^{+}$ & & & & & & & & $5360-6010$ & $5480-6010$ \\
\hline $\mathrm{Ar}_{2}^{+} / \mathrm{Ar}^{+}$ & NSD5830-6990 & & NSD6990-5800 & $5830-3580$ & & & & & \\
\hline $\mathrm{ArN}^{+} / \mathrm{N}^{+}$ & & & & $5450-4450$ & & & NSD5910-6430 & & $6430-4870$ \\
\hline $\mathrm{ArH}^{+} / \mathrm{Ar}^{+}$ & & & & & NSD4970-5100 & & & & \\
\hline $\mathrm{O}_{2}^{+} / \mathrm{O}^{+}$ & & $N C D$ & & & & NCD & & & \\
\hline $\mathrm{OH}^{+} / \mathrm{O}^{+}$ & & $N C D$ & & & & NCD & & & \\
\hline \multicolumn{10}{|l|}{$\mathrm{NO}^{+} / \mathrm{N}^{+}$} \\
\hline \multicolumn{10}{|l|}{$\mathrm{H}_{2} \mathrm{O}^{+} / \mathrm{OH}^{+}$} \\
\hline \multicolumn{10}{|l|}{$\mathrm{H}_{3} \mathrm{O}^{+} / \mathrm{H}_{2} \mathrm{O}^{+}$} \\
\hline & Ni Skimmer & Al skimmer & Ni X-Skimmer & & & & & & \\
\hline Sampler change & Nivs Al & Al vs $\mathrm{Ni}$ & Nivs Al & & & & & & \\
\hline \multicolumn{10}{|l|}{$\mathrm{CeO}^{+} / \mathrm{Ce}^{+}$} \\
\hline $\mathrm{Ar}_{2}^{+} / \mathrm{Ar}^{+}$ & NSD5830-7240 & NSD6990-5790 & $3580-5170$ & & & & & & \\
\hline $\mathrm{ArN}^{+} / \mathrm{N}^{+}$ & NSD5450-6430 & & $N C D$ & & & & & & \\
\hline $\mathrm{ArH}^{+} / \mathrm{Ar}^{+}$ & & NSD4970-5100 & NCD & & & & & & \\
\hline \multicolumn{10}{|l|}{$\mathrm{O}_{2}^{+} / \mathrm{O}^{+}$} \\
\hline \multicolumn{10}{|l|}{$\mathrm{OH}^{+} / \mathrm{O}^{+}$} \\
\hline $\mathrm{NO}^{+} / \mathrm{N}^{+}$ & & & NCD & & & & & & \\
\hline $\mathrm{H}_{2} \mathrm{O}^{+} / \mathrm{OH}^{+}$ & & & NCD & & & & & & \\
\hline $\mathrm{H}_{3} \mathrm{O}^{+} / \mathrm{H}_{2} \mathrm{O}^{+}$ & & & & & & & & & \\
\hline
\end{tabular}


Table 4. Cold plasma results. Average $\mathrm{T}_{\text {gas }}$ taken from three days. Each day measured one $\mathrm{T}_{\text {gas }}$ by averaging 16 spectra.

\begin{tabular}{|c|c|c|}
\hline \multicolumn{2}{|c|}{ Cold Plasma Conditions } \\
\hline & \multicolumn{2}{|c|}{ Ni sets } \\
\hline ratio & $T_{\text {gas }}$ (K) & deviation \\
\hline $\mathrm{Ar}_{2}{ }^{+} / \mathrm{Ar}^{+}$ & 2240 & 412 \\
\hline $\mathrm{ArN}^{+} / \mathrm{N}^{+}$ & 2300 & 157 \\
\hline $\mathrm{ArH}^{+} / \mathrm{Ar}^{+}$ & 4227 & 379 \\
\hline $\mathrm{O}_{2}{ }^{+} / \mathrm{O}^{+}$ & 3227 & 295 \\
\hline $\mathrm{OH}^{+} / \mathrm{O}^{+}$ & 3557 & 104 \\
\hline $\mathrm{NO}^{+} / \mathrm{N}^{+}$ & 4207 & 261 \\
\hline $\mathrm{H}_{2} \mathrm{O}^{+} / \mathrm{OH}^{+}$ & 3527 & 91 \\
\hline $\mathrm{H}_{3} \mathrm{O}^{+} / \mathrm{H}_{2} \mathrm{O}^{+}$ & 3163 & 178 \\
\hline $\mathrm{ScO}^{+} / \mathrm{Sc}^{+}$ & 3667 & 280 \\
\hline
\end{tabular}




\section{Figures}
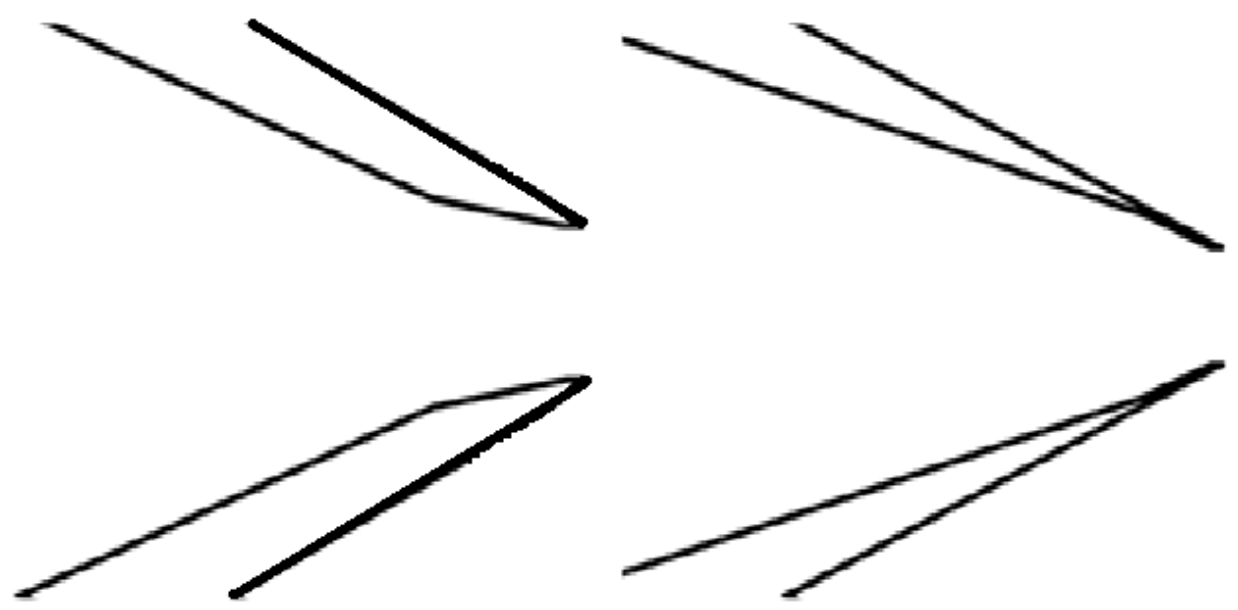

Figure 1. Drawing of observed differences between H-skimmer (left) and X-skimmer (right). Please note that the outside of the skimmers look identical. 


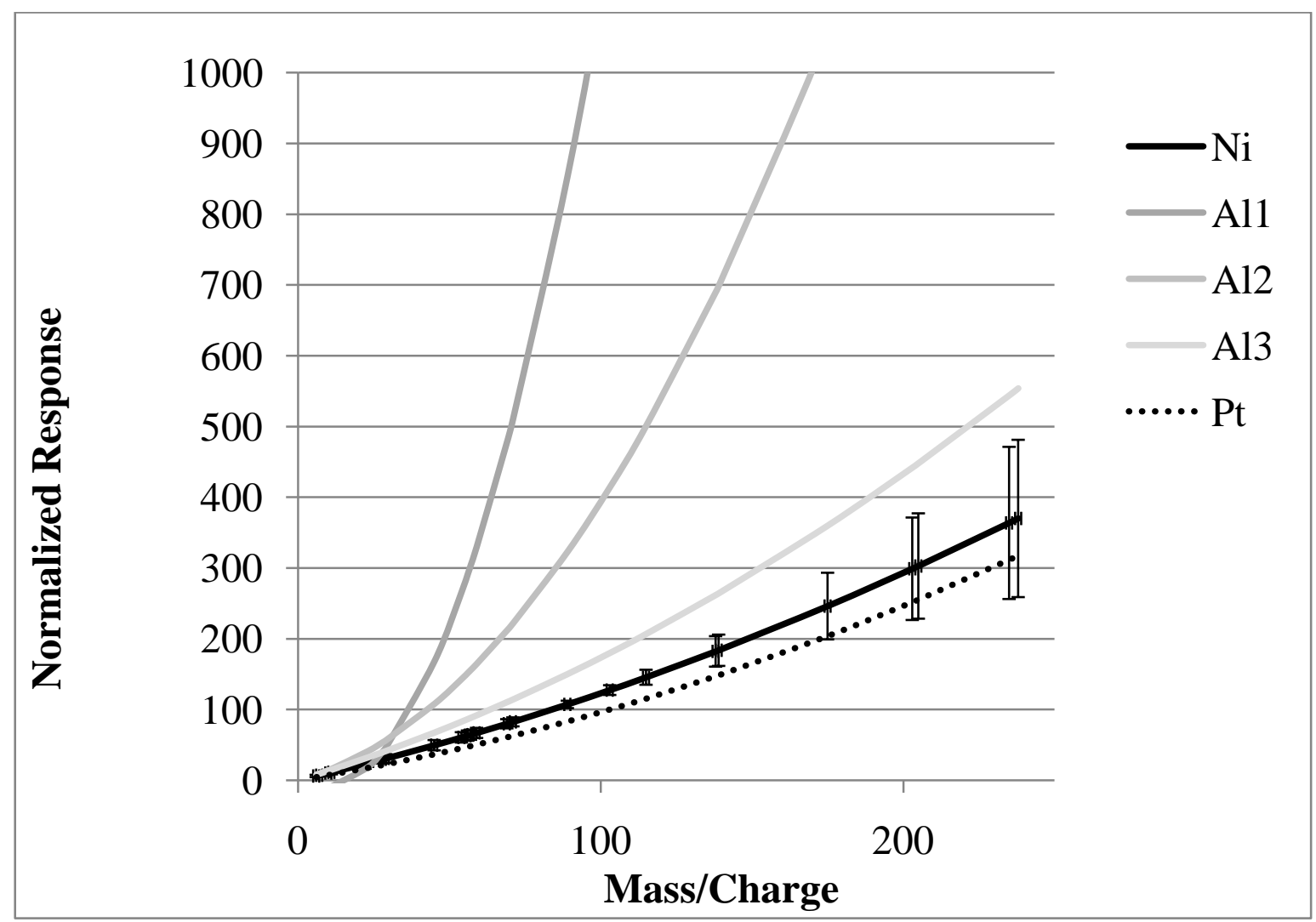

Figure 2. Instrument response curves. Ni line is average of 4 days with error bars corresponding to standard deviation. Only one Pt set was run so no error bars are given. For Al sets the individual runs were plotted instead of the average. 


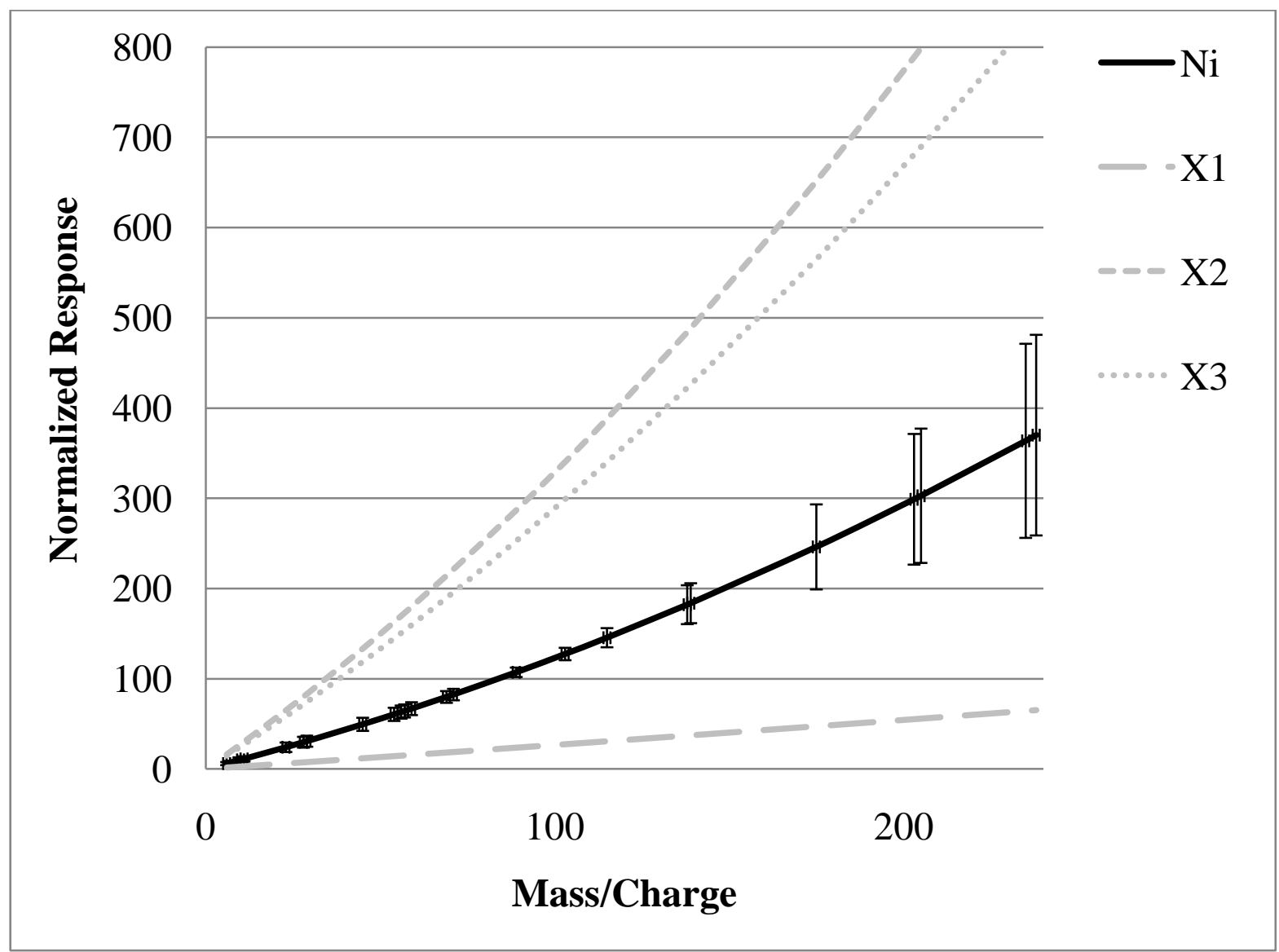

Figure 3. Normalized instrument response curves comparing $\mathrm{H}$ and $\mathrm{X}$ nickel skimmers. Ni line is average of 4 days with error bars corresponding to standard deviation. $\mathrm{X} 1, \mathrm{X} 2$ and $\mathrm{X} 3$ are individual runs. $\mathrm{X} 2$ and $\mathrm{X} 3$ are the same skimmer and different from $\mathrm{X} 1$. 


\title{
CHAPTER 4. DETERMINATION OF DISSOCIATION TEMPERATURE FOR ArO+ IN INDUCTIVELY COUPLED PLASMA-MASS SPECTROMETRY
}

A paper to be submitted to Spectrochimica Acta Part B

Sally M. McIntyre, Jill Wisnewski Ferguson, R.S. Houk

\begin{abstract}
The method of comparing experimental and calculated ion ratios to determine a gas kinetic temperature $\left(\mathrm{T}_{\mathrm{gas}}\right)$ characteristic of the origin of a polyatomic ion in inductively coupled plasma-mass spectrometry (ICP-MS) was applied to $\mathrm{ArO}^{+}$. Complications arise from the predicted presence of a low-lying excited ${ }^{2} \Pi$ electronic state $\left(\sim 2000-4000 \mathrm{~cm}^{-1}\right)$. Omission of this excited state yields unreasonably high temperatures in excess of 10,000 K for nine out of nineteen trials. Inclusion of the excited electronic state in the partition function of $\mathrm{ArO}^{+}$causes temperatures to increase futher. The problem appears to be related to the prediction that $\mathrm{ArO}^{+}$in the ${ }^{2} \Pi$ excited state dissociates into $\mathrm{Ar}^{+}$and $\mathrm{O}$, different products than the ${ }^{4} \Sigma$ ground state which dissociates into $\mathrm{Ar}$ and $\mathrm{O}^{+}$. Adjustments to the calculations to account for these different products yield reasonable temperatures $(<10,000 \mathrm{~K})$ that are similar to those seen for other polyatomic ion interferences.
\end{abstract}

\section{Introduction}

Polyatomic ion interferences are a major concern in ICP-MS. Previous studies have examined formation and dissociation reactions by calculating dissociation equilibrium con- 
stants $\left(\mathrm{K}_{\mathrm{d}}\right)$ using statistical thermodynamics and comparing them to the experimental data [19]. One theory holds that the gas kinetic temperature, $\mathrm{T}_{\mathrm{gas}}$, at which the two methods agree is indicative of the region in which polyatomic ions reach their final concentrations [3]. At the very least, similar temperatures can indicate groups of polyatomic ions that have similar behavior in ICP-MS. The diatomic ion $\mathrm{ArO}^{+}$is very common in the argon plasmas of ICP-MS [10] and was studied in three laboratories using the above method [1,3-9].

$\mathrm{ArO}^{+}$is of interest in other fields and spectroscopic constants for $\mathrm{ArO}^{+}$have been found from experimental data [11-12] and theoretical calculations [1,13-15]. In 1977 Ding et al. used elastic ion scattering to find the potential curve of ground state $\operatorname{ArO}^{+}\left({ }^{4} \Sigma\right)$ so that it might be used as a reference [11]. In 1989 Frenking et al. calculated spectroscopic constants for ground and excited states of $\mathrm{ArO}^{+}$as part of a study of first row cations of neon and argon and with the purpose of understanding trends in noble gas chemistry [13]. In 1990 Flesch et al. found a dissociation energy for the ground state $\mathrm{ArO}^{+}$as part of their paper studying the cross-sections of reactions between $\operatorname{Ar}^{+}\left({ }^{2} \mathrm{P}_{3 / 2,1 / 2}\right)+\mathrm{O}_{2}$ [12]. In 2003 Ascenzi et al. focused on cross sections for reactions between $\mathrm{Ar}^{2+}$ and $\mathrm{O}_{2}$ [16]. From their computed heats of formation (at $0 \mathrm{~K}$ ) a difference in energy between $\operatorname{ArO}^{+}\left({ }^{4} \Sigma\right)$ and $\mathrm{ArO}^{+}\left({ }^{2} \Pi\right)$ can be found. In 2008 Danailov et al. calculated ab initio potential energy curves for $\mathrm{ArO}^{+}\left({ }^{4} \Sigma\right)$ and $\mathrm{ArO}^{+}\left({ }^{2} \Pi\right)$ so that calculated transport properties of $\mathrm{O}^{+}$in Ar could be compared to experiment [14]. Also in 2008 Arnold et al. conducted theoretical studies of $\mathrm{ArO}^{+}$and $\mathrm{ArOH}^{+}$in order to better understand their experimental reactions with $\mathrm{H}_{2}$ with the ultimate goal of improving the use of hydrogen gas to remove these two argon polyatomic ions from the ICP-MS [15]. The results pertinent to this work are summarized in Table 1. 
Nonose et al. did their own ab initio calculations for $\mathrm{ArO}^{+}, \mathrm{ArH}^{+}, \mathrm{ArN}^{+}$, and $\mathrm{ArC}^{+}$in 1994 so that they could compare calculated dissociation equilibria between the four ions [1]. In a quadrupole mass spectrometer with a shielded load coil they determined that extra $\mathrm{ArO}^{+}$ was being formed in the interface. In 2001, Nonose and Kubota returned to $\mathrm{ArO}^{+}$, this time with a shielded high resolution mass spectrometer, and found a range of temperatures (4800 to $6741 \mathrm{~K}$ ) that depended on the acceleration voltage [17]. Houk and Praphairaksit used Nonose et al.'s 1994 values and determined $\mathrm{ArO}^{+}$was formed after the plasma $(1810 \mathrm{~K})$, but only when a shielded torch was used [3]. On a different instrument but also with a shielded torch, Ferguson and Houk found gas kinetic temperatures of 2930, 2880 and $1410 \mathrm{~K}$ [5]. Houk and Praphairaksit did an experiment on an unshielded torch and found a very different $\mathrm{T}_{\text {gas }}$ of $6350 \mathrm{~K}$ indicating plasma levels of $\mathrm{ArO}^{+}$only and perhaps even some loss [3]. In contradiction, Evans et al. found temperatures lower than $2800 \mathrm{~K}$ with their unshielded torch [4]. The Houk and Praphairaksit unshielded temperture of $6350 \mathrm{~K}$ would seem to be an outlier but it shall be seen this not uncommon given the method used.

However, none of these papers have included the fact that computational methods have revealed a low-lying excited electronic state $\left({ }^{2} \Pi\right)$ only $\sim 4000 \mathrm{~cm}^{-1}$ above the ground state [13,15-16]. At plasma temperatures larger than $5000 \mathrm{~K}$ this excited state changes the electronic partition function of $\mathrm{ArO}^{+}$by over $30 \%$. Its existence must be accounted for in some way. This study is an attempt to find the best manner in which to do so. 


\section{Experimental Section}

All data were collected on a magnetic sector ICP-MS (Element1, ThermoFinnigan, now Thermo Electron Corporation) as described elsewhere [5,9]. Various polyatomic ions were measured in medium resolution $(\mathrm{m} / \Delta \mathrm{m} \approx 4000)$ over two years. On each day the forward power was $1200 \mathrm{~W}$, the cool gas flow rate was usually around $161 \mathrm{~min}^{-1}$, the auxilary gas flow rate around $0.81 \mathrm{~min}^{-1}$ and the sample gas flow rate between 0.994 and $1.147 \mathrm{~min}^{-}$

1. On each day the sample gas flow rate and ion lens voltages were tuned for maximum signal of ${ }^{7} \mathrm{Li}^{+},{ }^{115} \mathrm{In}^{+}$and ${ }^{238} \mathrm{U}^{+}$. A 10 or $50 \mathrm{ppb}$ solution of Li, B, Na, Sc, Fe, Co, Ga, Y, Rh, Lu, Tl, and $\mathrm{U}$ in $1 \% \mathrm{HNO}_{3}$ (diluted from sub-boiled Ultrapure concentrated J.T. Baker acid using $18 \mathrm{M} \Omega$ Millipore deionized water) was used to construct a mass response curve $[5,8,18]$. A $50 \mathrm{ppb}$ solution of $\mathrm{Ce}$ in $1 \% \mathrm{HNO}_{3}$ was then analyzed to measure ${ }^{140} \mathrm{Ce}^{+},{ }^{142} \mathrm{Ce}^{+},{ }^{140} \mathrm{Ce}^{16} \mathrm{O}^{+}$ and ${ }^{142} \mathrm{Ce}^{16} \mathrm{O}^{+}$. While the blank $1 \% \mathrm{HNO}_{3}$ was aspirated, ions at $\mathrm{m} / \mathrm{z} 15,17,18,19,20,21$, $30,31,36,37,38,39,54,56,78$, and 80 were measured 16 times. Signals for $\mathrm{Ar}^{+}, \mathrm{O}^{+}$, and $\mathrm{ArO}^{+}$were measured in analog mode.

Using Microsoft Excel 2003 or 2007, peaks were integrated from baseline to baseline and the average found. Signals for the mass response curve elements were blank subtracted; in general these blank corrections were small. Ion ratios were adjusted for mass bias using the second order polynomial of best fit for the mass response points normalized to the lowest data point.

Neutral atom number densities and dissociation constants were calculated iteratively at $10 \mathrm{~K}$ temperature intervals. The temperature which gave the minimum difference between the calculated dissociation constant and the experimental ratio multiplied by neutral atom density was reported as $\mathrm{T}_{\text {gas }}$. Atomic electronic partition function equations were taken from 
De Galan et al. [19], except when the indicated $\mathrm{T}_{\text {gas }}$ was above $7000 \mathrm{~K}\left(8750 \mathrm{~K}_{\text {for }} \mathrm{O}^{+}\right)$then the equations from Tamaki and Kuroda were used [20].

Thirteen different mathematical methods for the calculated dissociation constant are reported here. Each method is labeled with a Greek letter. The results and methods used are summarized in Tables 2 and 3 and Figure 1. Each method is described in more detail with their Results. When chemical reactions are discussed, the associated dissociation constants $\left(K_{d}\right)$ and bond energies $\left(D_{o}\right)$ are labeled with a subscripted number equal to the identifying number for the chemical reaction as listed in the text.

\section{Results and Discussion}

Mass bias corrected signal ratios are listed in Table 3. Note that the $\mathrm{ArO}^{+} / \mathrm{O}^{+}$and $\mathrm{ArO}^{+} / \mathrm{Ar}^{+}$ratios vary substantially from day to day. Methods Alpha and Beta assume only the ground ${ }^{4} \Sigma$ electronic state of $\mathrm{ArO}^{+}$is populated but use different dissociation energies.

Methods Gamma and Delta include the ${ }^{2} \Pi$ state in the electronic partition function of $\mathrm{ArO}^{+}$ but use different energy differences, $\Delta \epsilon$, between the two levels.

$$
z_{\text {elec }}^{\text {ArO+ }}=\mathrm{g}_{0}+\mathrm{g}_{1} * e^{-\Delta \epsilon / k_{B} T}
$$

Statistical weights $\left(\mathrm{g}_{\mathrm{i}}\right)$ are found from the term symbols using the rules in Sonntag and Van Wylen and Laurendeau [21-22], i.e. $\mathrm{g}=$ multiplicity when the term symbol is a sigma and $\mathrm{g}=$ $2 *$ multiplicity when the term symbol is anything else. Boltzmann's constant, $k_{B}$, is in the same units as the energy difference.

Method Epsilon includes the electronic, vibrational and rotation partition functions of the ${ }^{2} \Pi$ level: 


$$
Z_{A r O^{+}}=z_{\text {trans }}\left[z_{v i b, 0} z_{\text {rot }, 0} g_{0} e^{-\epsilon_{0} / k_{B} T}+z_{v i b, 1} z_{\text {rot }, 1} g_{1} e^{-\epsilon_{1} / k_{B} T}\right]
$$

where $z_{v i b, i}$ is the vibrational partition function, $z_{\text {rot, } i}$ is the rotational paritition function, $g_{i}$ is the electronic degeneracy and $\epsilon_{\mathrm{i}}$ is the energy for the ith electronic level. The energy of the ground electronic state is placed at zero.

Method Zeta uses only the ground electronic state but includes high temperature corrections to the internal partition function using equations found in Sonntag and Van Wylen [21].

All the methods described so far assume the only products are $\mathrm{Ar}$ and $\mathrm{O}^{+}$. The experimental temperatures are in excess of $20,000 \mathrm{~K}$ are seen for some trials. Such temperatures are unrealistically high for the ICP. Furthermore, the polynomials used for atomic partition functions are only valid up to $\sim 12,000 \mathrm{~K}$ for Ar and $\sim 19,000 \mathrm{~K}$ for $\mathrm{O}^{+}$[20].

It is possible that these high temperatures indicate extensive removal of $\mathrm{ArO}^{+}$molecules between the plasma and mass spectrometer due to the low binding energy of the ground state. However, this seems unlikely considering the large $\mathrm{ArO}^{+}$signal. $\mathrm{ArO}^{+}$signals were usually on the order of $\mathrm{Ar}_{2}{ }^{+}$and $\mathrm{Ar}_{2}{ }^{+}$would be expected to be more prevalent due to its higher bond energy (1.2 eV) [23]. For these reasons further improvements were desired and methods Alpha-Zeta were dismissed as inaccurate.

In the above methods $\mathrm{ArO}^{+}$dissociates to $\mathrm{Ar}$ and $\mathrm{O}^{+}$so the signal ratio $\mathrm{ArO}^{+} / \mathrm{O}^{+}$is measured. Frenking et al. found that $\operatorname{ArO}^{+}\left({ }^{2} \Pi\right)$ preferentially dissociates to $\mathrm{Ar}^{+}$and $\mathrm{O}$ [13] . Methods Eta, Theta and Iota attempt to include this detail by having all $\mathrm{ArO}^{+}$dissociate to $\mathrm{Ar}^{+}$and $\mathrm{O}$. The dissociation energy for the ground state to these products was found using a thermodynamic cycle.

$$
\mathrm{ArO}^{+} \rightleftharpoons \mathrm{Ar}+\mathrm{O}^{+}, \mathrm{D}_{\mathrm{o}, 3}=0.312 \mathrm{eV}
$$




$$
\begin{gathered}
\mathrm{Ar} \rightleftharpoons \mathrm{Ar}^{+}+\mathrm{e}^{-}, \quad \mathrm{IE}_{4}=15.76 \mathrm{eV} \\
\underline{\mathrm{O}^{+}+\mathrm{e}^{-} \rightleftharpoons 0, \quad-\mathrm{IE}_{5}=-13.61 \mathrm{eV}} \\
\mathrm{ArO}^{+} \rightleftharpoons \mathrm{Ar}^{+}+0, \quad \mathrm{D}_{0,6}=2.46 \mathrm{eV}
\end{gathered}
$$

IE is ionization energy.

Method Eta considers only the ground electronic state. Theta includes the electronic, vibrational and rotational partition functions of $\mathrm{ArO}^{+}\left({ }^{2} \Pi\right)$. Iota includes high temperature corrections for $\mathrm{ArO}^{+}\left({ }^{4} \Sigma\right)$ and $\mathrm{ArO}^{+}\left({ }^{2} \Pi\right)$.

Temperatures using methods Eta, Theta and Iota are far more reasonable although they still span the three diagnostic regions for origin determination. Various techniques have measured the gas kinetic temperature at the usual sampling of the ICP to be around 5000 to $6000 \mathrm{~K}$ [24-25]. Therefore if $5000 \mathrm{~K} \lesssim \mathrm{T}_{\text {gas }} \lesssim 6000 \mathrm{~K}, \mathrm{ArO}^{+}$is assumed to be at levels consistent with plasma conditions and that these levels remain unchanged until the detector. If, however, $\mathrm{T}_{\text {gas }} \lesssim 5000 \mathrm{~K}$ then more $\mathrm{ArO}^{+}$may be created during the extraction process. Although French and Douglas calculated this to be a well-behaved supersonic expansion, optical and Langmuir probe studies have indicated the possibility of turbulent shock waves, particularly at or near the skimmer tip [26-28]. These shock waves are cooler, smaller plasmas where collisions could create more polyatomic ions. On the other hand, collision induced dissociation could also occur to preferentially remove $\mathrm{ArO}^{+}$and generate a $\mathrm{T}_{\text {gas }} \gtrsim 6000 \mathrm{~K}$. High gas kinetic temperatures might also simply mean equilibrium is not fully established.

None of the methods so far discussed have allowed for the fact that the two electronic levels have different dissociation energies and different products. Method Kappa attempts to incorporate this fact as follows, 


$$
\begin{gathered}
\mathrm{ArO}^{+}\left({ }^{4} \Sigma\right) \rightleftharpoons \mathrm{Ar}+\mathrm{O}^{+}, \quad \mathrm{K}_{\mathrm{d}, 7} \\
\mathrm{ArO}^{+}\left({ }^{2} \Pi\right) \rightleftharpoons \mathrm{Ar}^{+}+\mathrm{O}, \quad \mathrm{K}_{\mathrm{d}, 8} \\
\mathrm{ArO}^{+}\left({ }^{4} \Sigma\right) \rightleftharpoons \mathrm{ArO}^{+}\left({ }^{2} \Pi\right), \quad \mathrm{K}_{\mathrm{exc}, 9}
\end{gathered}
$$

If these three reactions are added together,

$$
2 \mathrm{ArO}^{+}\left({ }^{4} \Sigma\right) \rightleftharpoons \mathrm{Ar}+\mathrm{O}^{+}+\mathrm{Ar}^{+}+\mathrm{O}, \quad \mathrm{K}_{\mathrm{d}, 10}=\mathrm{K}_{\mathrm{d}, 7} \mathrm{~K}_{\mathrm{d}, 8} \mathrm{~K}_{\mathrm{exc}, 9}
$$

The experimental side would be

$$
\mathrm{K}_{\mathrm{d}, 11}=n_{A r} n_{O}\left(\frac{n_{O^{+}}}{n_{A r O^{+}\left({ }^{4} \Sigma\right)}}\right)\left(\frac{n_{A r^{+}}}{n_{A r O^{+}\left({ }^{4} \Sigma\right)}}\right)
$$

Note however, that $n_{\mathrm{ArO}^{+}}$is only for ions in the ground state ${ }^{4} \Sigma$.

$$
\begin{gathered}
n_{A r O^{+}, \text {tot. }}=n_{A r O^{+}\left({ }^{4} \Sigma\right)}+n_{A r O^{+}\left({ }^{2} \Pi\right)} \\
\mathrm{K}_{\mathrm{exc}, 9}=\frac{n_{A r O^{+}\left({ }^{2} \Pi\right)}}{n_{A r O^{+}\left({ }^{4} \Sigma\right)}} \\
n_{\operatorname{ArO}^{+}\left({ }^{4} \Sigma\right)}=\frac{n_{A r O^{+}, \text {tot. }}}{\left(1+\mathrm{K}_{\mathrm{exc}, 9}\right)}
\end{gathered}
$$

Use of method Kappa yields reasonable temperatures but they still span a large range that covers all three origin regions. Five trials give temperatures lower than $5000 \mathrm{~K}$, five trials give temperatures between $5000 \mathrm{~K}$ and $6000 \mathrm{~K}$ and the rest are above $6000 \mathrm{~K}$.

The concern with method Kappa is that the two electronic states of $\mathrm{ArO}^{+}$have very different bond lengths. Figure 2 is plotted using the Morse oscillator equation and the constants in Frenking et al $[13,21]$. All methods so far have assumed a Boltzmann distribution of $\mathrm{ArO}^{+}$between the two electronic levels. This would mean more molecules in the ground ${ }^{4} \Sigma$ state than the in the excited ${ }^{2} \Pi$ state even though the ground state is less stable. Method 
Lambda attempts to avoid this assumption by finding the relative distribution between the two levels in another way.

From Frenking et al. three dissociation reactions can be written.

$$
\begin{aligned}
& \operatorname{ArO}^{+}\left({ }^{2} \Pi\right) \rightleftharpoons \operatorname{Ar}\left({ }^{1} \mathrm{~S}\right)+\mathrm{O}^{+}\left({ }^{2} \mathrm{D}\right), \frac{{ }_{A r\left({ }^{1} S\right)^{n} O^{+}\left({ }^{2} D\right)}}{{ }_{A r O^{+}}\left({ }^{2} \Pi\right)}=K_{d, 15}=\frac{Z_{A r\left({ }^{1} S\right)^{Z} O^{+}\left({ }^{2} D\right)}}{{ }_{A r O^{+}}\left({ }^{2} \Pi\right)} e^{-\mathrm{D}_{0,15} / k_{B} T} \\
& \mathrm{ArO}^{+}\left({ }^{2} \Pi\right) \rightleftharpoons \operatorname{Ar}^{+}\left({ }^{2} \mathrm{P}\right)+\mathrm{O}\left({ }^{3} \mathrm{P}\right), \frac{{ }_{A r^{+}\left({ }^{2} P\right)}{ }^{n} o\left({ }^{3} P\right)}{n_{A r O^{+}}\left({ }^{2} \Pi\right)}=K_{d, 16}=\frac{\left.{ }_{A r^{+}\left({ }^{2} P\right)} Z_{o(}{ }^{3} P\right)}{Z_{A r O^{+}\left({ }^{2} \Pi\right)}} e^{-\mathrm{D}_{0,16} / k_{B} T} \\
& \operatorname{ArO}^{+}\left({ }^{4} \Sigma\right) \rightleftharpoons \operatorname{Ar}\left({ }^{1} \mathrm{~S}\right)+\mathrm{O}^{+}\left({ }^{4} \mathrm{~S}\right), \frac{{ }_{A r}\left({ }^{1} S\right)^{n O^{+}\left({ }^{4} S\right)}}{n_{A r O^{+}}\left({ }^{4} \Sigma\right)}=K_{d, 17}=\frac{{ }_{A r}\left({ }^{1} S\right)^{Z} O^{+}\left({ }^{4} S\right)}{Z_{A r O^{+}}\left({ }^{4} \Sigma\right)} e^{-\mathrm{D}_{0,17} / k_{B} T}
\end{aligned}
$$

The ratio of $\mathrm{ArO}^{+}$in the excited electronic state over the ground electronic state can be found by using reactions 15 and 17 .

$$
\frac{n_{{A r O^{+}}\left({ }^{2} \Pi\right)}}{n_{A r O^{+}\left({ }^{4} \Sigma\right)}}=\frac{K_{d, 17}}{K_{d, 15}} \frac{n_{O^{+}\left({ }^{2} D\right)}}{n_{O^{+}\left({ }^{4} S\right)}}
$$

Since the ratio of $\mathrm{O}^{+}$partition functions and the ratio of $\mathrm{O}^{+}$number densities are equal equation 18 simplifies to,

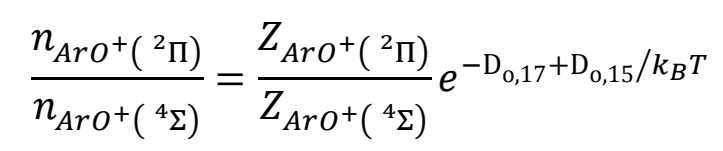

To find the number density for atoms in specific levels the electronic partition function for the level was divided by the total atomic electronic partition function and multiplied by the ion signal or calculated neutral number density. Unfortuanely, it must still be assumed that $\mathrm{ArO}^{+}$is all in the ground state and the first calculated excited state. Then reaction 16 can be used to find $\mathrm{T}_{\mathrm{gas}}$. 
Method Lambda indicates that most $\mathrm{ArO}^{+}$is in the ${ }^{2} \Pi$ state relative to ${ }^{4} \Sigma$ and that the ratio of ${ }^{2} \Pi$ to ${ }^{4} \Sigma$ decreases as temperature increases. This seems counterintuitive but may make sense from an equilibrium perspective. Even at the low temperature of $2000 \mathrm{~K}$, very little ground state $\mathrm{ArO}^{+}$will exist simply because equilibrium lies far to the right because of the low dissociation energy. Excited $\mathrm{O}^{+}$atoms that collide with neutral argon see a much deeper energy well. As temperature increases $\mathrm{K}_{\mathrm{d}, 15}$ increases more than $\mathrm{K}_{\mathrm{d}, 17}$.

Method Mu uses the same calculations as Lambda but substitutes ground state values from Danailov et al. [14]. Both Mu and Lambda give consistent temperatures in the range 2000 to $4000 \mathrm{~K}$ indicating creation of additional $\mathrm{ArO}^{+}$after extraction from the plasma. These temperatures agree with the previous work [1,3-5]. It should be noted that the other argon containing polyatomic ion ratios, $\mathrm{ArN}^{+} / \mathrm{N}^{+}, \mathrm{ArH}^{+} / \mathrm{Ar}^{+}, \mathrm{Ar}_{2}^{+} / \mathrm{Ar}^{+}$, give average gas kinetic temperatures in the high 4000's to low 6000's, more consistent with the results of methods Eta through Iota. In addition, the small ranges in $\mathrm{T}_{\mathrm{gas}}$ from methods Lambda and $\mathrm{Mu}$ may not seem reasonable given the large range in measured $\mathrm{ArO}^{+} / \mathrm{O}^{+}$signal ratios (three orders of magnitude) but similar large ratio range/small temperature ranges are seen in other polyatomics [9]. For example $\mathrm{O}_{2}{ }^{+} / \mathrm{O}^{+}$can vary over three orders of magnitude for a temperature that differs by only $1270 \mathrm{~K}$.

Method $\mathrm{Nu}$ addresses the fact that Arnold et al. calculated the dissociation of $\mathrm{ArO}^{+}\left({ }^{2} \Pi\right)$ to the same products as $\mathrm{ArO}^{+}\left({ }^{4} \Sigma\right)$, therefore finding a smaller dissociation energy for the excited state [Arnold].

$$
\operatorname{ArO}^{+}\left({ }^{4} \Sigma\right) \rightleftharpoons \operatorname{Ar}\left({ }^{1} \mathrm{~S}\right)+\mathrm{O}^{+}\left({ }^{4} \mathrm{~S}\right), \frac{{ }_{A r}\left({ }^{1} S\right)^{n O^{+}\left({ }^{4} S\right)}}{{ }_{A r O^{+}}\left({ }^{4} \Sigma\right)}=K_{d, 20}=\frac{{ }_{A r\left({ }^{1} S\right)^{Z} O^{+}\left({ }^{4} S\right)}}{Z_{A r O^{+}}\left({ }^{4} \Sigma\right)} e^{-\mathrm{D}_{0,20} / k_{B} T}
$$


$\operatorname{ArO}^{+}\left({ }^{2} \Pi\right) \rightleftharpoons \operatorname{Ar}\left({ }^{1} \mathrm{~S}\right)+\mathrm{O}^{+}\left({ }^{4} \mathrm{~S}\right), \frac{{ }^{n_{A r}+\left({ }^{2} P\right)}{ }^{n O^{+}\left({ }^{4} S\right)}}{{ }_{A r O^{+}}\left({ }^{2} \Pi\right)}=K_{21}=\frac{\left.{ }_{A r}{ }_{A r}{ }^{1} S\right)^{Z} O^{+}\left({ }^{4} S\right)}{Z_{A r O^{+}}\left({ }^{2} \Pi\right)} e^{-D_{0,21} / k_{B} T}$

The total $\mathrm{ArO}^{+}$signal was again assumed to be the sum of $\operatorname{ArO}^{+}\left({ }^{4} \Sigma\right)$ and $\operatorname{ArO}^{+}\left({ }^{2} \Pi\right)$. A third reaction is needed so the excitation of $\mathrm{ArO}^{+}$from the ground state to the excited state was used (Equation 9). All the same objections to this reaction apply; unsurprisingly, similar $\mathrm{T}_{\text {gas }}$ values to methods Gamma through Zeta result.

Method $\mathrm{Nu}$ is considered inferior to methods Kappa, Lambda and Mu because Arnold et al. appeared to be more concerned with the ground state and implied that $\operatorname{ArO}^{+}\left({ }^{2} \Pi\right)$ was simply $0.293 \mathrm{eV}$ lower in energy than the ground state products, not that $\mathrm{ArO}^{+}\left({ }^{2} \Pi\right)$ necessarily dissociated to these same products. Frenking et al. and Danilov et al. agreed that the excited state is more stable than the ground state.

\section{Acknowledgements}

This research was supported by the National Science Foundation through the Institute for Physical Research and Technology at ISU. The ICP-MS instrument was obtained with funds provided by the U. S. Department of Energy, Office of Nuclear Nonproliferation (NA22) and the Office of Basic Energy Sciences.

\section{References}

[1] N.S. Nonose, N. Matsuda, N. Fudagawa, M. Kubota, Some characteristics of polyatomic ion spectra in inductively coupled plasma-mass spectrometry, Spectrochim. Acta Part B 49 (1994) 955-974. 
[2] T.J. Clelend, F.R. Meeks, Statistical mechanics of $\mathrm{Ar}_{2}{ }^{+}$in an inductively coupled plasma, Spectrochim. Acta B 51 (1996) 1487-1490.

[3] R.S. Houk, N. Praphairaksit, Dissociation of polyatomic ions in inductively coupled plasma, Spectrochim. Acta B 56 (2001) 1069-1096.

[4] E.H. Evans, L. Ebon, L. Rowley, Comparative study of the determination of equilibrium dissociation temperature in inductively coupled plasma-mass spectrometry, Spectrochim. Acta Part B 57 (2002) 741-754.

[5] J.W. Ferguson, R.S. Houk, High resolution studies of the origins of polyatomic ions in inductively coupled plasma-mass spectrometry, Part 1. Identification methods and effects of neutral gas density assumptions, extraction voltage, and cone material, Spectrochim. Acta Part B 61 (2006) 905-915.

[6] J.W. Ferguson, T.J. Dudley, K.C. Sears, S.M. McIntyre, M.S. Gordon, R.S. Houk, Polyatomic ions in inductively coupled plasma-mass spectrometry Part II: Origins of $\mathrm{N}_{2} \mathrm{H}^{+}$ and $\mathrm{H}_{\mathrm{x}} \mathrm{CO}^{+}$ions using experimental measurements combined with calculated energies and structures, Spectrochim. Acta B 64 (2009) 690-696.

[7] J.W. Ferguson, T.J. Dudley, M.S. Gordon, R.S. Houk, High resolution studies of the origins of polyatomic ions in ICP-MS Part III: $\mathrm{CrO}_{\mathrm{x}} \mathrm{H}_{\mathrm{y}}{ }^{+}$ions, manuscript (2006).

[8] S. M. McIntyre, J.W. Ferguson, R.S. Houk, Measurement of dissociation temperatures for polyatomic ions in ICP-MS: Validation and variations of a method, manuscript (2010). [9] S. M. McIntyre, J.W. Ferguson, R.S. Houk, Polyatomic ions in inductively coupled plasma-mass spectrometry: Effects of cone material, skimmer cone geometry and cold plasma conditions on calculated versus measured ion ratios, manuscript (2010).

[10] R.S. Houk, V.A. Fassel, G.D. Flesch, H.J. Svec, A.L. Gray, C.E. Taylor, Inductively coupled argon plasma as an ion source for mass spectrometric determination of trace elements, Anal. Chem. 52 (1980) 2283-2289.

[11] A. Ding, J. Karlau, J. Weise, The potential of Ar-- $\mathrm{O}^{+}\left({ }^{4} \Sigma^{-}\right)$, Chem. Phys. Letters 45 (1977) 92-95.

[12] G.D. Flesch, S. Nourbakhsh, C.Y. Ng, Absolute state-selected and staate-to-state total cross sections for the reaction $\mathrm{Ar}^{+}\left({ }^{2} \mathrm{P}_{3 / 2,1 / 2}\right)+\mathrm{O}_{2}$, J. Chem. Phys. 92 (1990) 3590-3604. 
[13] H.Frenking, W. Koch, D. Cremer, J. Gauss, J.F.Liebman, Neon and Argon Bonding in First-Row Cations $\mathrm{NeX}^{+}$and $\mathrm{ArX}^{+}(\mathrm{X}=\mathrm{Li}-\mathrm{Ne})$, J. Phys. Chem., 93, (1989) 3410-3418. [14] D.M. Danailov, L.A. Viehland, R. Johnsen, T.G. Wright, A.S. Dickinson, Transport of $\mathrm{O}^{+}$through argon gas, J. Chem. Phys. 128 (2008) 134302.

[15] T. Arnold, J.N. Harvey, D.J. Weiss, An experimental and theoretical investigation into the use of $\mathrm{H}_{2}$ for the simultaneous removal of $\mathrm{ArO}^{+}$and $\mathrm{ArOH}^{+}$isobaric interferences during Fe isotope ratio analysis with collision cell based Multi-collector Inductively Coupled Plasma Mass Spectrometry, Spectrochim. Acta B 63 (2008) 666-672.

[16] D. Ascenzi, P. Franceschi, P. Tosi, D. Bassi, M. Kaczorowska, J.N. Harvey, Bondforming reactions of dications: Production of $\mathrm{ArO}^{+}$and $\mathrm{ArO}^{2+}$ in the reaction of $\mathrm{Ar}^{2+}$ with $\mathrm{O}_{2}$, J. Chem. Phys., 118 (2003) 2159-2163.

[17] N. Nonose, M. Kubota, Non-spectral and spectral interferences in inductively coupled plasma high-resolution mass spectrometry Part I. Optical characteristics of micro-plasmas observed just behind the sampler and the skimmer in inductively coupled plasma high resolution mass spectrometry, J. Anal. At. Spectrom. 16 (2001) 551-559.

[18] C.P. Ingle, B.L. Sharp, M.S.A. Horstwood, R.R. Parrish, D.J. Lewis, Instrument response functions, mass bias and matrix effects in isotope ratio measurements and semiquantitative analysis by single and multi-collector ICP-MS, J. Anal. At. Spect. 18 (2003) 219-229.

[19] L. De Gelan, R. Smith, J.D. Winefordner, The electronic partition function of atoms and ions between $1500^{\circ} \mathrm{K}$ and $7000^{\circ} \mathrm{K}$, Spectrochim. Acta B 23 (1968) 521-525.

[20] S. Tamaki, T. Kuroda, The electronic partition functions of atoms and ions between 7000 and 12000 K, Spectrochim. Acta B 42 (1987) 1105-1111.

[21] R.E. Sonntag and G.J. Van Wylen, Fundamentals of Statistical Thermodynamics, John Wiley and Sons, Inc., New York, 1966.

[22] N.M. Laurendeau, Statistical Thermodynamics: Fundamentals and Applications, Chapter 9, Cambridge University Press, Cambridge, 2005.

[23] W.R. Wadt, The electronic states of $\mathrm{Ar}^{+}{ }_{2}, \mathrm{Kr}^{+}{ }_{2}, \mathrm{Xe}^{+}$. I. Potential curves with and without spin-orbit coupling, J. Chem. Phys., 68 (1978) 402-414. 
[24] J.B. Olsen, J.H. Macedone, P.B. Farnsworth, Source gas kinetic temperatures in an ICPMS determined by measurements of the gas velocities in the first vacuum stage, J. Anal. At. Spectrom. 21 (2006) 856-860.

[25] R.L Spencer, N. Taylor, P.B. Farnsworth, Comparison of calculated and experimental flow velocities upstream from the sampling cone of an inductively coupled plasma mass spectrometer, Spectrochim. Acta B 64 (2009) 921-924.

[26] K.E. Jarvis, A.L. Gray, R.S. Houk, Handbook of Inductively Coupled Plasma Mass Spectrometry, Blackie, Glasgow, 1992.

[27] H. Niu, R.S. Houk, Fundamental aspects of ion extraction in inductively coupled plasma-mass spectrometry, Spectrochim. Acta Part B 51 (1996) 779-815.

[28] B.S. Duersch, P.B. Farnsworth, Characterization of the ion beam inside the skimmer cone of an inductively coupled plasma mass spectrometer by laser excited atomic and ionic fluorescence, Spectrochim. Acta B 54 (1999) 545-555. 


\section{Tables}

Table 1. Summary of spectroscopic constants for $\mathrm{ArO}^{+}$found in the literature.

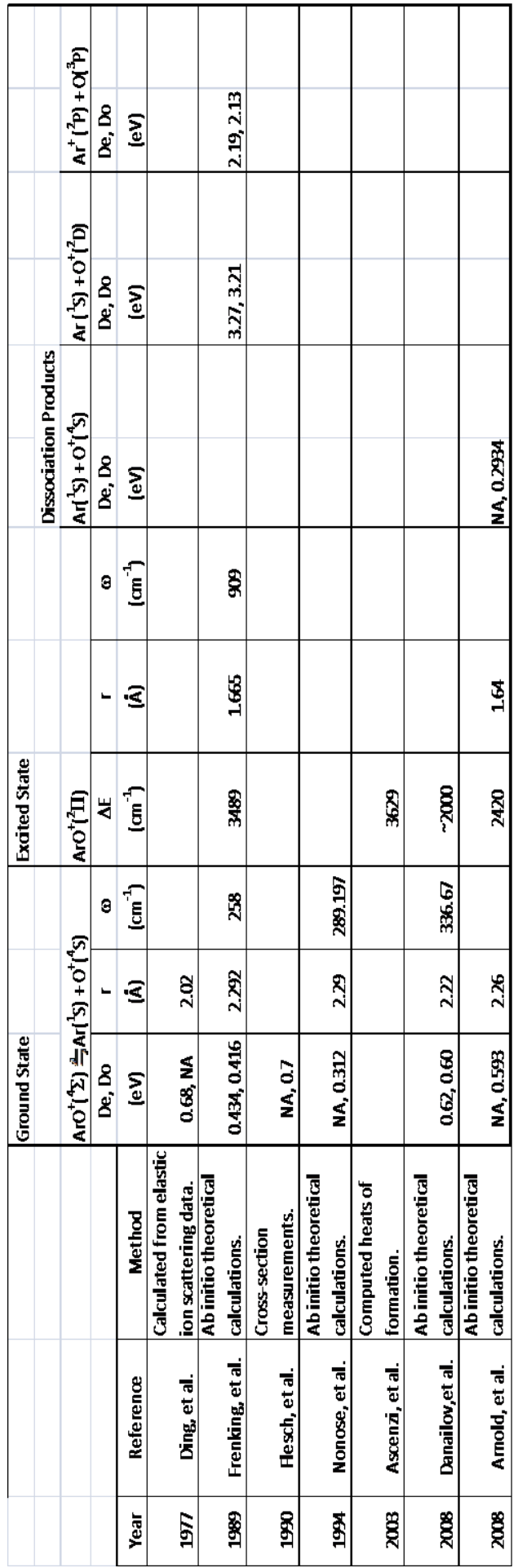


Table 2. Summary of numbers used in each mathematical method.

\begin{tabular}{|c|c|c|c|c|c|c|c|c|c|c|c|}
\hline $\begin{array}{c}\text { Mathematical } \\
\text { Method }\end{array}$ & $\begin{array}{c}\text { Dissociation } \\
\text { Products } \\
\end{array}$ & $\begin{array}{l}\text { Ground } \\
\text { Do }(\mathrm{eV})\end{array}$ & $\omega_{0}$ & $\mathbf{B}_{0}$ & $z_{\text {elec1 }} ?$ & $\Delta \mathrm{E}\left(\mathrm{cm}^{-1}\right)$ & $\mathrm{z}_{\mathrm{v} 1}, \mathrm{z}_{\mathrm{r} 1}$ ? & $\omega_{1}$ & $\mathbf{B}_{1}$ & \begin{tabular}{|c|}
$\begin{array}{c}\text { Excited Do } \\
(\mathrm{eV})\end{array}$ \\
\end{tabular} & $\begin{array}{c}\text { High } \\
\text { Temperature } \\
\text { Corrections? }\end{array}$ \\
\hline A & $\mathrm{Ar}+\mathrm{O}^{+}$ & 0.312 & 289.197 & 0.2804 & $\mathrm{~N}$ & & & & & & $\mathrm{~N}$ \\
\hline B & $\mathrm{Ar}+\mathrm{O}^{+}$ & 0.416 & \begin{tabular}{|l|}
289.197 \\
\end{tabular} & 0.2804 & $\mathrm{~N}$ & & & & & & $\mathrm{~N}$ \\
\hline$\Gamma$ & $\mathrm{Ar}+\mathrm{O}^{+}$ & 0.312 & \begin{tabular}{|l|}
289.197 \\
\end{tabular} & 0.2804 & $Y$ & 3489 & $\mathrm{~N}$ & & & & $\mathrm{~N}$ \\
\hline$\Delta$ & $\mathrm{Ar}+\mathrm{O}^{+}$ & 0.312 & \begin{tabular}{|l|}
289.197 \\
\end{tabular} & 0.2804 & $\mathrm{Y}$ & 3629 & $\mathrm{~N}$ & & & & $\mathrm{~N}$ \\
\hline $\mathrm{E}$ & $\mathrm{Ar}+\mathrm{O}^{+}$ & 0.312 & 289.197 & 0.2804 & $\mathrm{Y}$ & 3489 & $\mathrm{Y}$ & 909 & 0.532 & & $\mathrm{~N}$ \\
\hline $\mathrm{Z}$ & $\mathrm{Ar}+\mathrm{O}^{+}$ & 0.312 & \begin{tabular}{|l|}
289.197 \\
\end{tabular} & 0.2804 & $\mathrm{~N}$ & & & & & & $Y$ \\
\hline $\mathrm{H}$ & $\mathrm{Ar}^{+}+\mathrm{O}$ & 2.453 & \begin{tabular}{|l|}
289.197 \\
\end{tabular} & 0.2804 & $\mathrm{~N}$ & & & & & & $\mathrm{~N}$ \\
\hline$\Theta$ & $\mathrm{Ar}^{+}+\mathrm{O}$ & 2.453 & 289.197 & 0.2804 & $Y$ & 3489 & $Y$ & 909 & 0.532 & & $\mathrm{~N}$ \\
\hline $\mathrm{I}$ & $\mathrm{Ar}^{+}+\mathrm{O}$ & 2.453 & 289.197 & 0.2804 & $\mathrm{Y}$ & 3490 & $Y$ & 909 & 0.532 & & $Y$ \\
\hline $\mathrm{K}$ & See Text & 0.312 & 289.197 & 0.2804 & $\mathrm{Y}$ & 3489 & $\mathrm{Y}$ & 909 & 0.532 & 2.13 & $\mathrm{~N}$ \\
\hline$\Lambda$ & See Text & 0.416 & 258 & 0.2807 & $\mathrm{Y}$ & 3489 & $\mathrm{Y}$ & 909 & 0.532 & 2.13 and 3.21 & $\mathrm{~N}$ \\
\hline $\mathbf{M}$ & See Text & 0.6008 & 336.67 & 0.2996 & $\mathrm{Y}$ & 3489 & & 909 & 0.532 & 2.13 and 3.21 & $\mathrm{~N}$ \\
\hline $\mathbf{N}$ & See Text & 0.593 & \begin{tabular}{|l|}
289.197 \\
\end{tabular} & 0.2804 & $\mathrm{Y}$ & 2420 & $\mathrm{Y}$ & 909 & 0.532 & 0.2934 & $\mathrm{~N}$ \\
\hline
\end{tabular}


Table 3. Summary of experiments run and the resulting $\mathrm{T}_{\mathrm{gas}}$ results for each mathematical method.

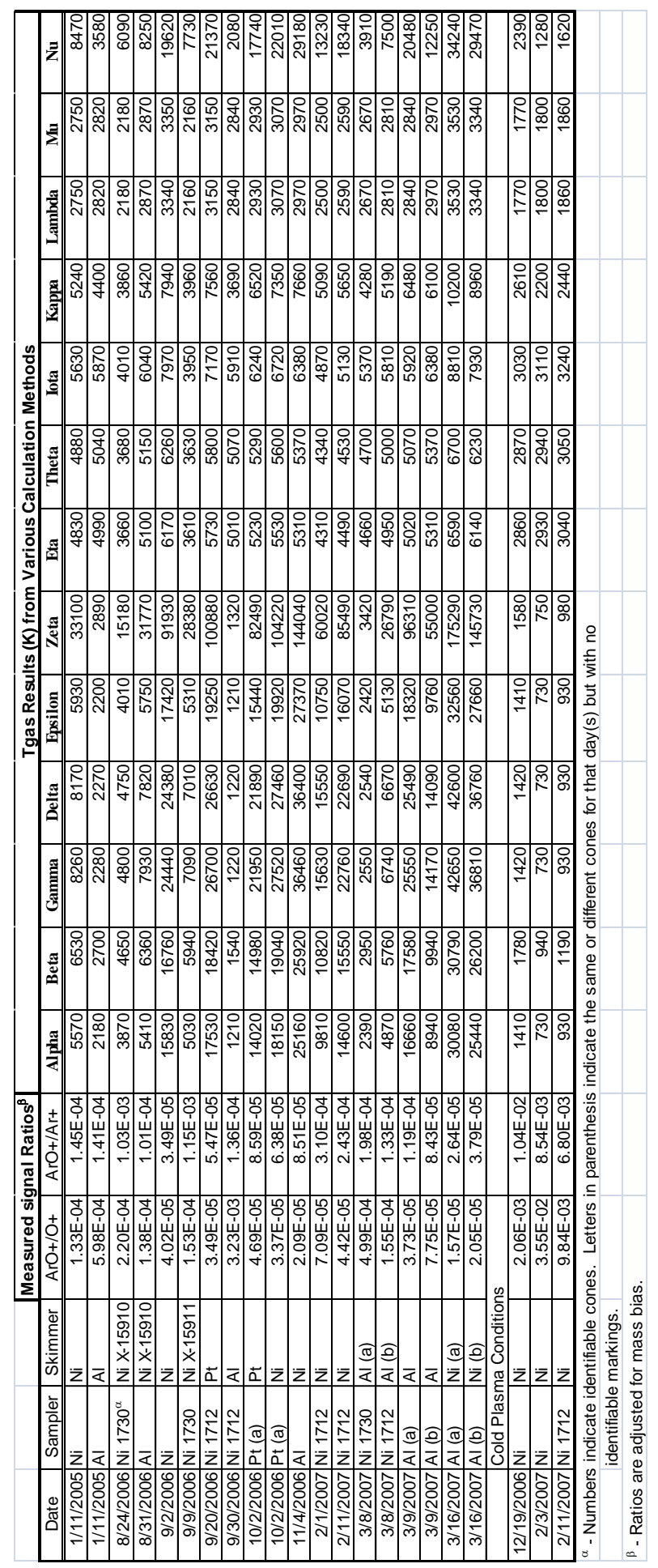




\section{Figures}

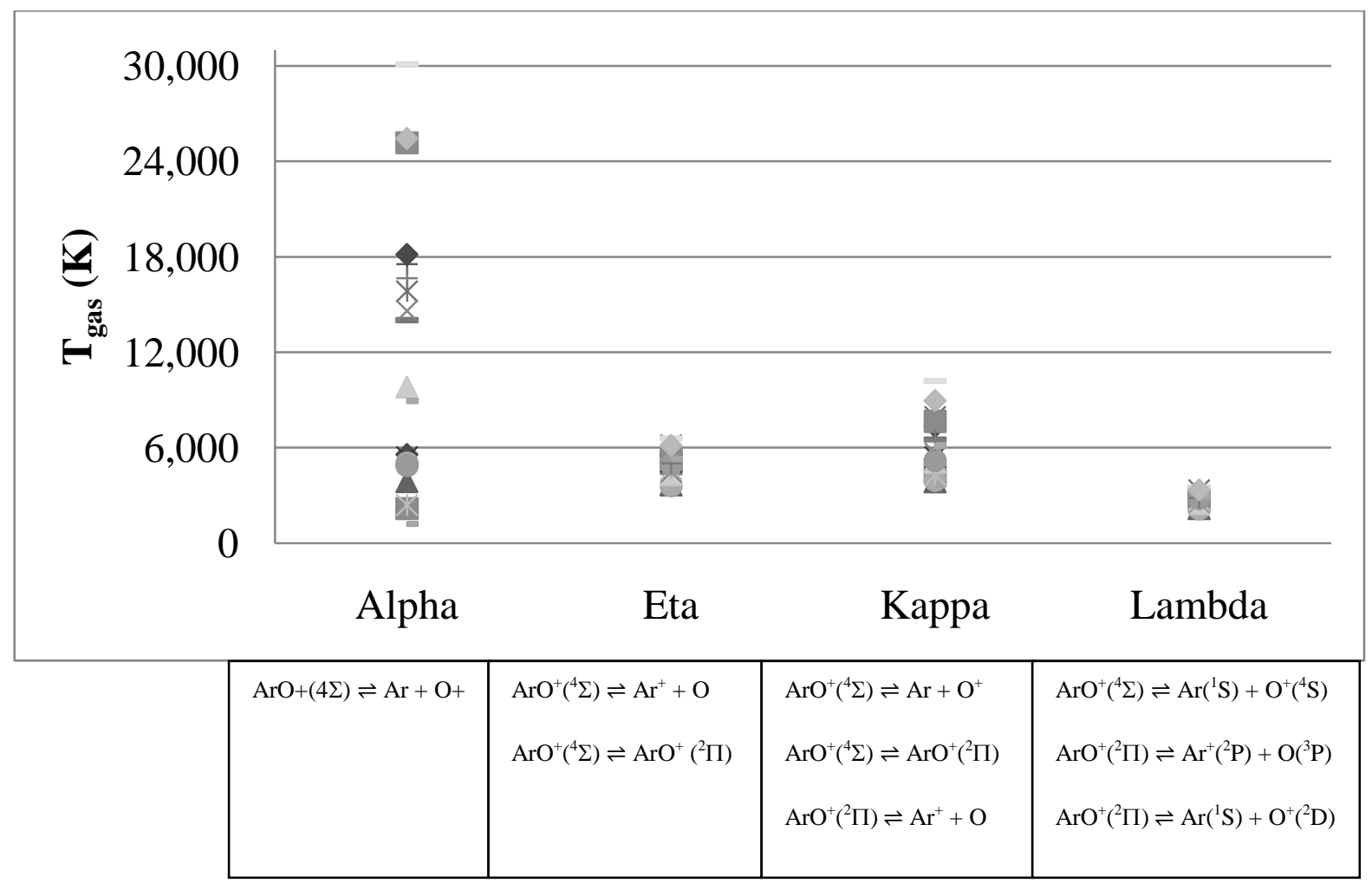

Figure 1. Graphical representation of $\mathrm{T}_{\text {gas }}$ values from the major methods of Table 3. 


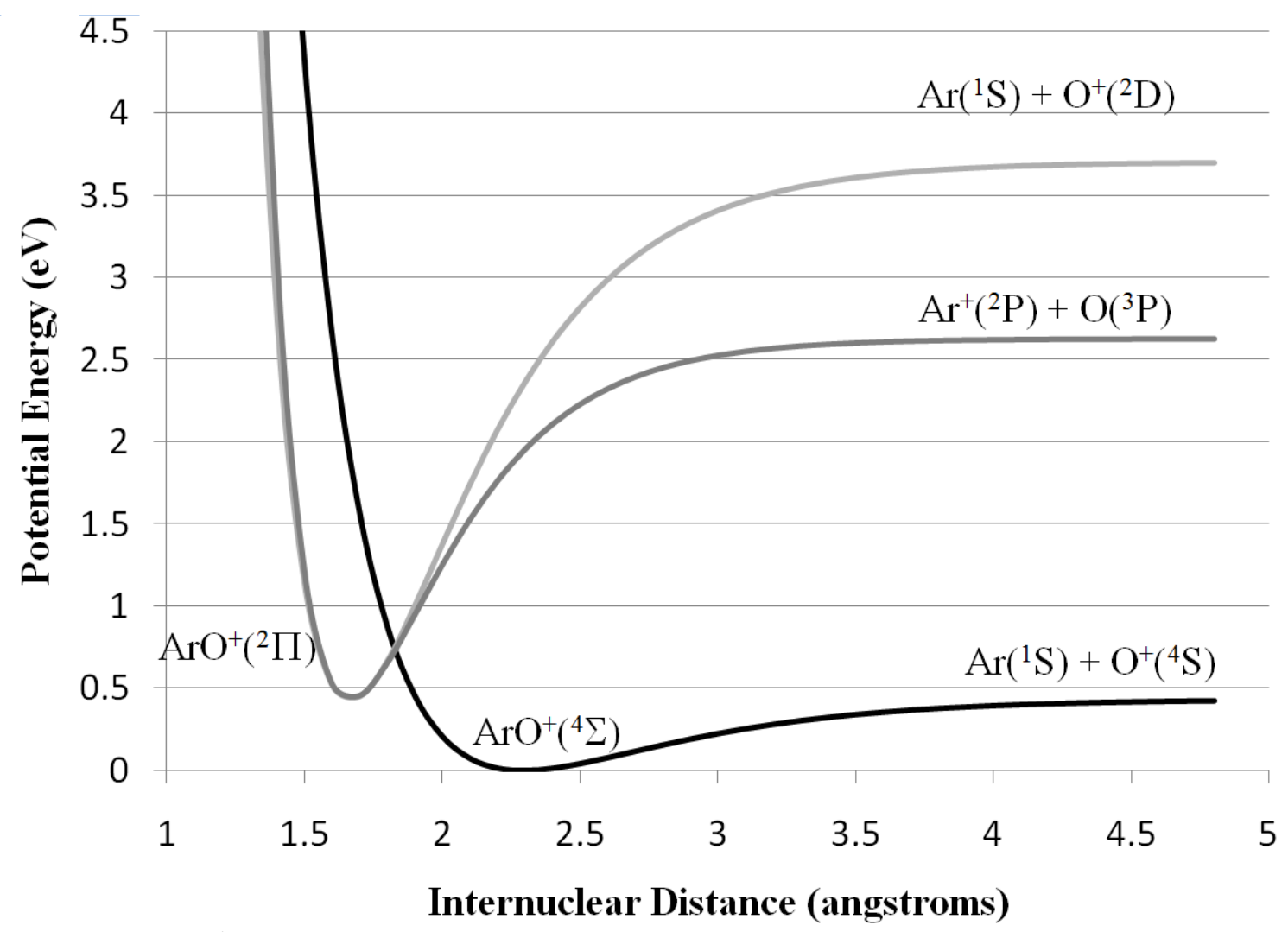

Figure 2. $\mathrm{ArO}^{+}$potential energies graphed using Morse oscillator equation [21]. Well depths, bond lengths and vibrational frequencies taken from Frenking et al. [13]. 


\title{
CHAPTER 5. METAL OXIDE MEMORY EFFECTS
}

\section{IN INDUCTIVELY COUPLED PLASMA-MASS SPECTROMETRY}

\author{
A paper to be submitted to Spectrochimica Acta Part B
}

Sally M. McIntyre and R.S. Houk

\begin{abstract}
$\mathrm{Ce}^{+}$and $\mathrm{CeO}^{+}$signals were monitored during the $1 \%$ nitric acid rinse-out of a $\sim 3$ ppm solution of cerium on a ThermoFinnigan Element1. While both signals faded, $\mathrm{CeO}^{+}$memory unexpectedly leveled out at a greater level than $\mathrm{Ce}^{+}$memory. This oxide memory grew more prominent as higher concentrations and longer aspirating times were used. $\mathrm{Sr}, \mathrm{Ba}, \mathrm{Y}, \mathrm{Zr}, \mathrm{Ga}$, and Ti showed large oxide memories as well, although none were as striking as cerium. Coating and cleaning experiments showed that the metal oxide memory was localized on the skimmer. The effect was not seen on a HP4500 quadrupole ICP-MS.
\end{abstract}

\section{Introduction}

While generally considered a good thing in daily life, long-term memory is very much unwanted in analytical instruments. Long rinse-out times degrade limits of detection. Time required to clean the instrument decreases throughput and costs companies and research groups manpower and money. Elements like B, $\mathrm{Hg}, \mathrm{I}$, and $\mathrm{Br}$ are infamous in ICP-MS for lingering in tubing and spray chambers and forming gaseous compounds that diffuse into the plasma slowly over time [1]. However, nearly any element can cause memory effects in 
ICP-MS if the concentration is high enough. Chemicals lingering in the introduction system are not the only source either, memory has been seen coming from the cones and extraction lens [2-3]. The last requires breaking vacuum on the mass spectrometer to fully clean.

Memory effects are not restricted to isobaric elements. Memory from $\mathrm{B}$ and $\mathrm{Hg}$ comes in the form of hydrides and certain amounts of $\mathrm{MO}^{+}, \mathrm{MH}^{+}$, and $\mathrm{MAr}^{+}$will form in the plasma and interface $[1,4]$. These polyatomic ions tend to stay at a small fraction of the $\mathrm{M}^{+}$ memory [3]. This paper reports a $\mathrm{MO}^{+}$memory higher in intensity than the corresponding $\mathrm{M}^{+}$signal. Though a $\mathrm{MO}^{+} / \mathrm{M}^{+}$ratio greater than one was seen only with $\mathrm{Ce}$, other elements gave a memory $\mathrm{MO}^{+} / \mathrm{M}^{+}$ratio larger than their $\mathrm{MO}^{+} / \mathrm{M}^{+}$ratio when the element comes from nebulized solutions.

\section{Experimental Section}

Most experiments were done on a Thermo-Finnigan Element1 double focusing ICP-MS. A Hewlett-Packard 4500 quadrupole ICP-MS was used for comparison purposes. All nitric acid $\left(\mathrm{HNO}_{3}\right)$ solutions were diluted from Ultrapure J.T. Baker concentrated acid using deionized water (18 M $\Omega$ MilliporeQ). Sampler and skimmer cones were made from nickel and the Element 1 skimmer was H-geometry unless otherwise stated. Data were analyzed using Microsoft Excel 2003 and 2007.

The Element1 was tuned to maximize ${ }^{7} \mathrm{Li}^{+},{ }^{115} \mathrm{In}^{+}$and ${ }^{238} \mathrm{U}^{+}$signals using a 1 or $10 \mathrm{ppb}$ tune solution also containing 1 or 10 ppb B, Na, Si, Sc, Fe, Co, Ga, Y, Rh, Lu, and Tl. Power was left at $1200 \mathrm{~W}$. Coolant and auxiliary gas flows were left mostly alone. Most effort was focused on torch position, sample gas flow and the ion lenses. Autotune was run on the 
Hewlett Packard instrument to maximize ${ }^{7} \mathrm{Li}^{+},{ }^{115} \mathrm{In}^{+}$and ${ }^{238} \mathrm{U}^{+}$signal and minimize $\mathrm{Ce}^{2+} / \mathrm{Ce}^{+}$ and $\mathrm{CeO}^{+} / \mathrm{Ce}^{+}$ratios by adjusting sample gas flow and torch position. Tune parameters were not changed throughout the rest of the experiment.

The basic experiment was as follows. A $\sim 5$ ppm solution of the specific metal was nebulized for five minutes. The sample was then switched to deionized water or $1 \% \mathrm{HNO}_{3}$ in deionized water. As quickly as possible after the switch data collection was started on the instrument.

Cleaning cones was a two step process. In the first step the cones were either sonicated for $\sim 1$ hour in aqueous $1 \% \mathrm{HNO}_{3}$ or soaked $\sim 24$ hours in $0.1 \% \mathrm{HNO}_{3}$. The cones were then rinsed with deionized water. In the second step, the cones were swabbed with deionized water using a cotton applicator. The wet front and back surfaces were polished with 500-grit sandpaper and wiped clean with Kimwipes. Nitrile gloves were used to remove the cones from the acid and hold them during the water rinse off. Sometimes gloves were worn during the polishing step but not when the cones were transferred on and off the instrument. The metals sudied are not usually associated with skin contamination although Ti may come from lotions [5].

Gas kinetic temperatures were calculated using the method outlined in Houk and Praphairaksit [6-7]. The temperatures were calculated in slightly different ways and found to have minimal differences. The temperatures reported here used a thermodynamic cycle employing the dissociation of the neutral oxide, the ionization of the neutral oxide and the ionization of the metal atom [7]. Because the $\mathrm{MO}^{+}$appears to originate at the skimmer, the number density used for neutral oxygen was calculated at the skimmer tip $(9.2 \mathrm{~mm}$ from sampler tip in the Element1) using the equations in Douglas and French [4]. To determine 
$\mathrm{T}_{\text {ion }}$ a $\sim 5$ ppm solution of Ba was nebulized for five minutes. After $\mathrm{Ba}^{2+} / \mathrm{Ba}^{+}$memory was measured, the signal ratio was corrected with the instrument response curve and set equal to the Saha equation [8]. Electron density in the plasma has been measured at $1 \times 10^{15} \mathrm{~cm}^{-3}$. The electron density at the skimmer tip was calculated in the same manner as neutral oxygen density. The result was $\mathrm{T}_{\text {ion }}=5180 \mathrm{~K}$.

Mass bias corrections were done using an instrument response curve generated from a 10 ppb solution of $\mathrm{Li}, \mathrm{B}, \mathrm{Na}, \mathrm{Si}, \mathrm{Sc}, \mathrm{Fe}, \mathrm{Co}, \mathrm{Ga}, \mathrm{Y}, \mathrm{Rh}, \mathrm{In}, \mathrm{Lu}, \mathrm{Tl}, \mathrm{U}$ in $1 \% \mathrm{HNO}_{3}$ [9-10]. With no way to verify and no suitable alternative, it was assumed that the response curve measured in this way would apply to ions made from skimmer deposits.

Laser ablation was done to spatially characterize deposits with a Q-switched quadrupled (266 nm) Nd:YAG laser (LSX 500, CETAC Technologies, Omaha, NE, USA). Each spot was ablated at $100 \%$ power, 20 shots at $10 \mathrm{~Hz}, 9 \mathrm{~mJ}$ energy and $5 \mathrm{~ns}$ pulse width. The skimmer was laid on its side so that the cone slope was flat and perpendicular to the laser axis. Six raster lines of 3-4 spots were done starting at the base of the cone and ending with a single shot at the tip. The laser was refocused between each raster line. For the inside spots the skimmer was rested straight up and down, with the tip pointing to the floor, in the foam ring that was used to package the cone. The laser was refocused for each spot. The first spot inside the cone was mid-way down the slope. Near the tip the cone was set at an angle to reach the very end of the tip. Analysis was done with the same Element1 ICP-MS. The time dependent signal was integrated from baseline to baseline. 


\section{Results and Discussion}

\section{$3.1 \mathrm{Ce}^{+}$and $\mathrm{CeO}^{+}$Memory}

In order to observe the behavior of $\mathrm{M}^{+}$and $\mathrm{MO}^{+}$signals and $\mathrm{MO}^{+} / \mathrm{M}^{+}$signal ratio during the rinse out of a concentrated solution, a $100 \mathrm{ppm}$ Ce solution was aspirated for five minutes. A five minute analog run was started just after the nebulizer was switched to deionized water (Figure 1a). The signals for $\mathrm{Ce}^{+}$and $\mathrm{CeO}^{+}$quickly leveled out, but not at baseline levels and with the $\mathrm{CeO}^{+}$signal well above the $\mathrm{Ce}^{+}$signal. The more extensive memory for $\mathrm{CeO}^{+}$indicates the signal was not from the sample introduction system. The $\mathrm{CeO}^{+} / \mathrm{Ce}^{+}$ratio when the ions come from the ICP is usually 1 to $2 \%$ as the trend indicates at the very beginning of the rinse out. At approxiamately 110, 180 and $280 \mathrm{~s}$ there are spikes in the $\mathrm{Ce}^{+}$and $\mathrm{CeO}^{+}$signals where the $\mathrm{CeO}^{+} / \mathrm{Ce}^{+}$ratio drops 100 fold. We believe these to be extra $\mathrm{Ce}^{+}$and $\mathrm{CeO}^{+}$from residual drops of $\mathrm{Ce}$ solution in the sample introduction system that were carried into the plasma. This is supported by the fact that these spikes disappear when the sample gas is turned to zero and the spray chamber is removed from the back of the torch.

\subsection{Effect of Concentration}

To determine the approximate concentration where this long-lived memory effect develops, clean cones were placed on the instrument and $50 \mathrm{ppb}, 190 \mathrm{ppb}$, and 3 ppm Ce solutions were nebulized for five minutes each with ten minute rinse-outs in between (Figure 1bd). After the $50 \mathrm{ppb}$ solution was run the signal quickly returned to baseline. After the 190 ppb solution was run, the signal quickly drops down to near baseline, however a slight $\mathrm{CeO}^{+}$ signal can still be seen (Figure 1c). After the 3 ppm solution was run the $\mathrm{CeO}^{+}$memory effect 
can be clearly seen. Even with build-up from the previous solutions, the $3 \mathrm{ppm}$ solution did not produce a memory as large as the $100 \mathrm{ppm}$ solution.

Thus we can conclude that a $\mathrm{CeO}^{+}$memory signal effect will appear after at least five minutes of running a $190 \mathrm{ppb}$ solution and the effect will worsen as the concentration of the Ce is increased.

\subsection{Localization of Phenomenon.}

To determine the source of this extra $\mathrm{CeO}^{+}$memory two sets of $\mathrm{Ni}$ cones were cleaned. The 3 ppm Ce solution was then nebulized for five minutes on one set. After a five minute rinse-out the plasma was turned off, the sampler was exchanged for a second, clean one and the plasma was reignited. After approxiamately 15 minutes $\mathrm{Ce}^{+}$and $\mathrm{CeO}^{+}$were measured while nebulizing only the blank solution. The process was repeated again this time with a clean skimmer and the original 'dirty' sampler. In the third repeat both cones were replaced with the second, clean, set. The results are shown in Figure 2. The instrument was tuned only once, before the cones were coated. The same operating conditions were used in all four measurements.

$\mathrm{CeO}^{+}$memory signal dropped somewhat when only the sampler was replaced (Figure 2b) but dropped to the clean set's baseline when only the skimmer was replaced (Figure 2c). Therefore, we conclude that the memory originates mainly from the skimmer cone. The loss in signal when the sampler is replaced may simply be the consequence of turning the instrument off and on, and not retuning or waiting as long for the instrument to stabilize before taking data runs. 
The sharp spikes in $\mathrm{Ce}^{+}$signal during rinse out disappear when the sample gas is turned off (Figure 3), which we take as additional evidence that they are caused by residual aerosol droplets containing Ce leaving the spray chamber and being atomized and ionized in the plasma as usual. If the spikes come from droplets of Ce finally leaving the spray chamber, the droplets cannot reach the plasma if the sample gas is turned off. On the other hand, the peaks decrease in frequency as time goes on and the runs without sample gas were done after five minute runs with sample gas. The runs without sample gas may simply sample a period where peaks would not appear anyway.

Localization of the source of this memory to the skimmer cone is in agreement with Zahran et al. who also ran a blank aqueous $1 \% \mathrm{HNO}_{3}$ solution while monitoring $\mathrm{M}^{+}$and $\mathrm{MO}^{+}$ [3]. However, they examined metals coming from the cones themselves either because the metal made up the composition of the cone or the metal was deposited on the cones via chemical means in solution. In addition, Zahren et al. used an unshielded torch with high positive voltage placed on the cones, both of which probably contributed to a 'pinch', or secondary discharge, from the plasma to the cones. Nonetheless, they found sampler material did not affect ion signals in the mass spectra to anywhere near the extent skimmer material did.

\subsection{Length of Run}

In the interests of learning how long a 3 ppm solution of Ce would need to be run through the instrument to see the memory effect, one, two, three and four minute runs were done in succession with 5-10 minutes of rinse-out in between (Figure 4). Between the two and three minute runs another one minute run was performed to investigate build-up effect. 
$\mathrm{CeO}^{+}$memory first becomes clearly visible after the two minute run (Figure $4 \mathrm{~b}$ ) and becomes more prominent with the three and four minute runs. The one minute run after the two minute run (Figure 4c) shows behavior closer to the two minute run (Figure 4b) rather than the one minute run (Figure 4a) implying the effect is at least somewhat cumulative.

\subsection{Other Elements}

Similar effects could be seen for the elements $\mathrm{Sr}, \mathrm{Ru}, \mathrm{Eu}, \mathrm{Lu}, \mathrm{Zr}, \mathrm{Ti}, \mathrm{Ge}, \mathrm{Ba}$, and Y although the $\mathrm{MO}^{+} / \mathrm{M}^{+}$ratio never exceeded unity except for $\mathrm{Y}\left(\mathrm{YO}^{+} / \mathrm{Y}^{+}=1.09\right)$. For each element a clean skimmer reduced memory to baseline levels while a clean sampler decreased memory slightly, but did not eliminate it. $\mathrm{MO}^{+}$signal did increase in the rinse out plots over baseline levels and in all cases, except ruthenium, the oxide to metal ratio increased. While most elements do not display such dramatic results as $\mathrm{CeO}^{+}$, the memory effect of a concentrated solution of these elements cannot be corrected for mathematically with a solution based ratio.

\subsection{Composition of Cones}

To determine if cone material might have any effect, two aluminum sets were compared to two nickel sets. Cerium and strontium was measured on both types of cones and behavior was found to be identical. Cone material seems to have little effect on this phenomenon. 


\subsection{Geometry of Skimmer Cone}

The above studies were done with H-geometry skimmers as these are the most commonly used ones in our lab. To determine if skimmer geometry had an effect, two nickel Xskimmers were tested. The first X-skimmer had been used several times before with 10-50 ppb solutions of various metals in $1 \%$ nitric acid and had been soaked in $0.1 \%$ nitric acid overnight but not polished. The second X-skimmer was new and had never been used before. Behavior was identical to that seen on the older $\mathrm{H}$ geometry skimmers. Skimmer geometry and the method of cleaning the cones does not appear to affect memory behavior either.

\subsection{Calculation of Temperatures}

Gas kinetic temperatures for certain metal oxide to metal ion ratios were calculated using the Houk/Praphairaksit method [6-7,10]. The number density of oxygen was reduced to the level expected at the skimmer tip by using the equations found in Douglas and French $[4]$,

$$
n_{\mathrm{O}, \text { skimmer }}=0.161 \mathrm{D}^{2}{ }_{\text {sampler }} / \mathrm{x}^{2}{ }_{\text {skimmer }}=0.00161 n_{\mathrm{O}, \text { plasma }}
$$

where $\mathrm{D}$ is diameter and $\mathrm{x}$ is the distance from the sampler. Results are shown in Table 2.

At first temperatures were found for $\mathrm{Ce}$ and Sr during the Ni vs. Al cone test. There was a nearly $1000 \mathrm{~K}$ difference in the calculated temperatures and this suggested that perhaps the $\mathrm{CeO}^{+}$and $\mathrm{SrO}^{+}$memory signals were coming from different spatial regions, or perhaps as a result of mass bias. Tests with $\mathrm{Y}$ and $\mathrm{Ba}$ dispelled this hypothesis. Then it was thought perhaps the order of coating had an effect as both $\mathrm{Y}$ and Ce had been coated before Ba and Sr. But when Ba was applied first its temperature did not change. This seems to leave some 
sort of chemical property as the determinant of temperature region. Table 2 lists the calculated temperatures and various physical properties for $\mathrm{Ce}, \mathrm{Sr}, \mathrm{Ba}, \mathrm{Y}, \mathrm{Zr}, \mathrm{Ge}, \mathrm{Ti}, \mathrm{Lu}, \mathrm{Eu}$ and $\mathrm{Ru}$. The best correlation (excluding $\mathrm{Ru}$ ) was found to be between the $\mathrm{T}_{\mathrm{gas}}$ and elemental boiling point (Figure 5). This is a completely empirical correlation. No causation is implied. The exclusion of Ru is not completely arbitrary. Early work had Ge as an outlier as well but it was found that $\mathrm{GeO}^{+}$has a low lying excited electronic level [18]. Including this excited electronic level yielded the present results. We believe a similar case may be true for $\mathrm{RuO}^{+}$ but we have not found literature concerning excited electronic levels of $\mathrm{RuO}^{+}$as of yet.

\subsection{Other Instruments}

The experiment was repeated on a Hewlett-Packard 4500 quadrupole ICP-MS. Even though the experiment was repeated with longer nebulization times and more concentrated solutions, a cerium oxide memory greater than the cerium memory was never seen (Figure 6). Unfortunately, there are many differences between the two instruments. Though difficult to measure, the HP4500 appears to have a larger cone separation and it definitely has a smaller skimmer orifice diameter $(\sim 0.4 \mathrm{~mm}$ on the HP4500 vs. $\sim 0.8 \mathrm{~mm}$ on the Element $)$. Quadrupoles have much lower extraction voltages than sector instruments like the Element1 and the HP was run with an unshielded torch while the load coil of the Element1 was shielded.

\subsection{Laser Ablation Studies of Skimmer Cone}

An expendable set of aluminum cones ( $\mathrm{H}$ geometry skimmer) was placed on the Element1. Ce and Ba solutions were nebulized for five minutes separately with at least a five 
minute rinse with $1 \% \mathrm{HNO}_{3}$ in between and after the $\mathrm{Ba}$. The instrument was shut off and the cones switched to a Ni set so the instrument could be used for laser ablation ICP-MS. The Al skimmer was ablated in 21 spots on the outside slope (Figure 7a) and in 10 spots on the inside (Figure 7b). Before the $\mathrm{Al}$ cones were exposed to the $\mathrm{Ce}$ and $\mathrm{Ba}$, a blank ablation was taken on the outside base of the cone half-way between the edge and the start of the cone slope. Results are shown in Figure 7. To a rough approximation it appears that Ce is concentrated slightly farther from the tip than is $\mathrm{Ba}$.

The use of points on the outside of the skimmer is not to suggest material is boiling off and somehow making its way into the ion beam. Instead the correlation between deposition inside and outside of the cone was investigated to see if the outside could be sampled alone in the future because of the greater ease of access. The outside points could also be investigated for correlation with shock regions seen in photographic studies [1] and/or the ring patterns often seen on dirty skimmers.

\section{Acknowledgements}

This research was supported by the National Science Foundation through the Institute for Physical Research and Technology at ISU. The magnetic sector ICP-MS was obtained with funds provided by the U. S. Department of Energy, Office of Nuclear Nonproliferation (NA-22) and the Office of Basic Energy Sciences. The quadrupole ICP-MS was donated to Iowa State University by Agilent. 


\section{References}

[1] K.E. Jarvis, A.L. Gray, R.S. Houk, Handbook of Inductively Coupled Plasma Mass Spectrometry, Blackie, Glasgow, 1992.

[2] I. Rodushkin, E. Engstroem, D.C. Baxter, Review: Sources of contamination and remedial strategies in the multi-elemental trace analysis laboratory, Anal. Bioanal. Chem. 396 (2010) 365-377.

[3] N.F. Zahran, A.I. Helal, M.A. Amr, A. Abdel-Hafiez, M.T. Mohsen, Formation of polyatomic ions from the skimmer cone in the inductively coupled plasma mass spectrometry, Int. J. Mass Spectrom. 226 (2003) 271-278.

[4] D.J. Douglas, J.B. French, Gas dynamics of the inductively coupled plasma mass spectrometer interface, J. Anal. At. Spectrom. 3 (1988) 743-747.

[5] R. Richter, Clean Chemistry Techniques for the Modern Laboratory, Milestone Press, Monroe, CT, 2003.

[6] R.S. Houk, N. Praphairaksit, Dissociation of polyatomic ions in inductively coupled plasma, Spectrochim. Acta Part B 56 (2001) 1069-1096.

[7] S. M. McIntyre, J.W. Ferguson, R.S. Houk, Measurement of dissociation temperatures for polyatomic ions in ICP-MS: Validation and variations of a method, Manuscript (2010).

[8] H. Niu, R.S. Houk, Fundamental aspects of ion extraction in inductively coupled plasmamass spectrometry, Spectrochim. Acta Part B 51 (1996) 779-815.

[9] C.P. Ingle, B.L. Sharp, M.S.A. Horstwood, R.R. Parrish, D.J. Lewis, Instrument response functions, mass bias and matrix effects in isotope ratio measurements and semi-quantitative analysis by single and mult-collector ICP-MS, J. Anal. At. Spectrom. 18 (2003) 219-229. [10] J.W. Ferguson, R.S. Houk, High resolution studies of the origins of polyatomic ions in inductively coupled plasma-mass spectrometry, Part 1. Identification methods and effects of neutral gas density assumptions, extraction voltage, and cone material, Spectrochim. Acta Part B 61 (2006) 905-915.

[11] Periodic Table of the Elements, VWR Sargent Welch, Buffalo Grove, IL 1996.

[12] M. Dulick, E. Murad, R.F. Barrow, Thermochemical properties of the rare earth monoxides, J. Chem. Phys. 85 (1986) 385- 390. 
[13] Z.J. Wu, W. Guan, J. Meng, Z.M. Su, Density Functional Studies of Diatomic LaO to LuO, J. Cluster Science 18 (2007) 444-458.

[14] K.P. Huber, G. Herzberg, Molecular Spectra and Molecular Structure IV. Constants of Diatomic Molecules, Van Nostrand Reinhold, New York, 1979.

[15] N.F. Dalleska, P.B. Armentrout, Guided ion beam studies of reactions of alkaline earth ions with $\mathrm{O}_{2}$, Int. J. Mass Spectrom. Ion Processes 134 (1994) 203-212.

[16] P. Song, W. Guan, C. Yao, Z.M. Su, Z.J. Wu, J.D. Feng, L.K. Yan, Electronic structures of $4 \mathrm{~d}$ transition metal monoxides by density functional theory, Theor. Chem. Acc. 117 (2007) 407-415.

[17] E. Murad, D.L. Hildenbrand, Dissociation energies of GdO, HoO, ErO, TmO, and LuO; correlation of results for the lanthanide monoxide series, J. Chem. Phys. 73 (1980) 4005 4011.

[18] C.M.Clouthier, F. Grein, MRCI studies on the electronic spectrum of $\mathrm{GeO}^{+}$, Chem. Phys. 315 (2005) 35-40. 


\section{Tables}

Table 1. Operating Conditions

\section{ThermoFinnigan}

\begin{tabular}{rcc} 
& ELEMENT 1 & Hewlett-Packard 4500 \\
\cline { 2 - 3 } Resolution $(\mathrm{m} / \Delta \mathrm{m})$ & $\sim 300$ & $\sim 300$ \\
Nebulizer & pneumatic type & Babbington type \\
Spray Chamber & Teflon Scott type double pass & Cooled quartz \\
Cones & Nickel, unless otherwise stated & Scott type double pass \\
Power (W) & 1200 & Nickel \\
Gas flow rates & Optimized to produce greatest signal across mass range \\
Torch & Shielded & Unshielded
\end{tabular}


Table 2. Table of calculated temperatures for $\mathrm{MO}^{+} / \mathrm{M}^{+}$alongside certain constants for the metal and metal oxide species. $\mathrm{D}_{\mathrm{o}}$ is dissociation energy, IE is ionization energy, $\Delta \mathrm{H}_{\mathrm{vap}}$ is the enthalpy of vaporization for the atomic metal and B.P. is the boiling point of the atomic metal.

${ }^{\alpha}$ Using $\mathrm{D}_{\mathrm{o}} \mathrm{MO}$ and IE MO, $\mathrm{D}_{\mathrm{o}} \mathrm{MO}^{+}=\mathrm{D}_{\mathrm{o}} \mathrm{MO}-\mathrm{IE} \mathrm{MO}+\mathrm{IE} \mathrm{M}$.

\begin{tabular}{|c|c|c|c|c|c|c|c|}
\hline & $\begin{array}{l}T_{\text {gas }} \\
(\mathrm{K})\end{array}$ & $\begin{array}{c}\mathrm{D}_{\mathrm{o}} \mathrm{MO} \\
(\mathrm{eV})\end{array}$ & $\begin{array}{c}\mathrm{D}_{\mathrm{o}} \mathrm{MO}^{+} \\
(\mathrm{eV})\end{array}$ & IE MO & $\begin{array}{c}\text { IE M } \\
{[11]}\end{array}$ & $\begin{array}{c}\Delta \mathbf{H}_{\mathrm{vap}} \\
{[11]}\end{array}$ & $\begin{array}{l}\text { B.P. } \\
{[11]}\end{array}$ \\
\hline Eu & 2440 & $4.92[12]$ & $4.097^{\alpha}$ & 6.533 [13] & 5.67 & "175.73 & 1800 \\
\hline $\mathrm{Sr}$ & 2560 & $4.88[14]$ & $3.975^{\alpha}$ & 6.6 [15] & 5.695 & 136.9 & 1655 \\
\hline $\mathbf{R u}$ & 2590 & 5.3 [14] & $2.567^{\alpha}$ & $9.00316]$ & 7.37 & 567.77 & 4425 \\
\hline $\mathrm{Ba}$ & 2750 & 5.79 [14] & $4.13^{\alpha}$ & $6.911[14]$ & 5.212 & 140.2 & 2078 \\
\hline ie & 3030 & $6.78[14]$ & $3.579^{\alpha}$ & $11.1[14]$ & 7.899 & 334.3 & 3107 \\
\hline $\mathrm{Lu}$ & 3420 & 6.99 [12] & $5.421^{\alpha}$ & 7.049 [13] & 5.43 & 355 & 3668 \\
\hline Ti & 3450 & $6.87[14]$ & $7.29^{\alpha}$ & 6.4 [14] & 6.82 & 425.2 & 3560 \\
\hline $\mathrm{Ce}$ & 3530 & 8.18 [14] & $8.81[6]$ & $5.2[6,11]$ & 5.47 & 313.8 & 3715 \\
\hline v & 3570 & 7.29 [14] & $7.67^{\alpha}$ & 6.0 [17] & 6.38 & 393.3 & 3611 \\
\hline $\mathrm{Zr}$ & 4040 & 7.85 [14] & $8.95^{\alpha}$ & 6.1 [14] & 6.84 & 590.5 & 4682 \\
\hline
\end{tabular}




\section{Figures}

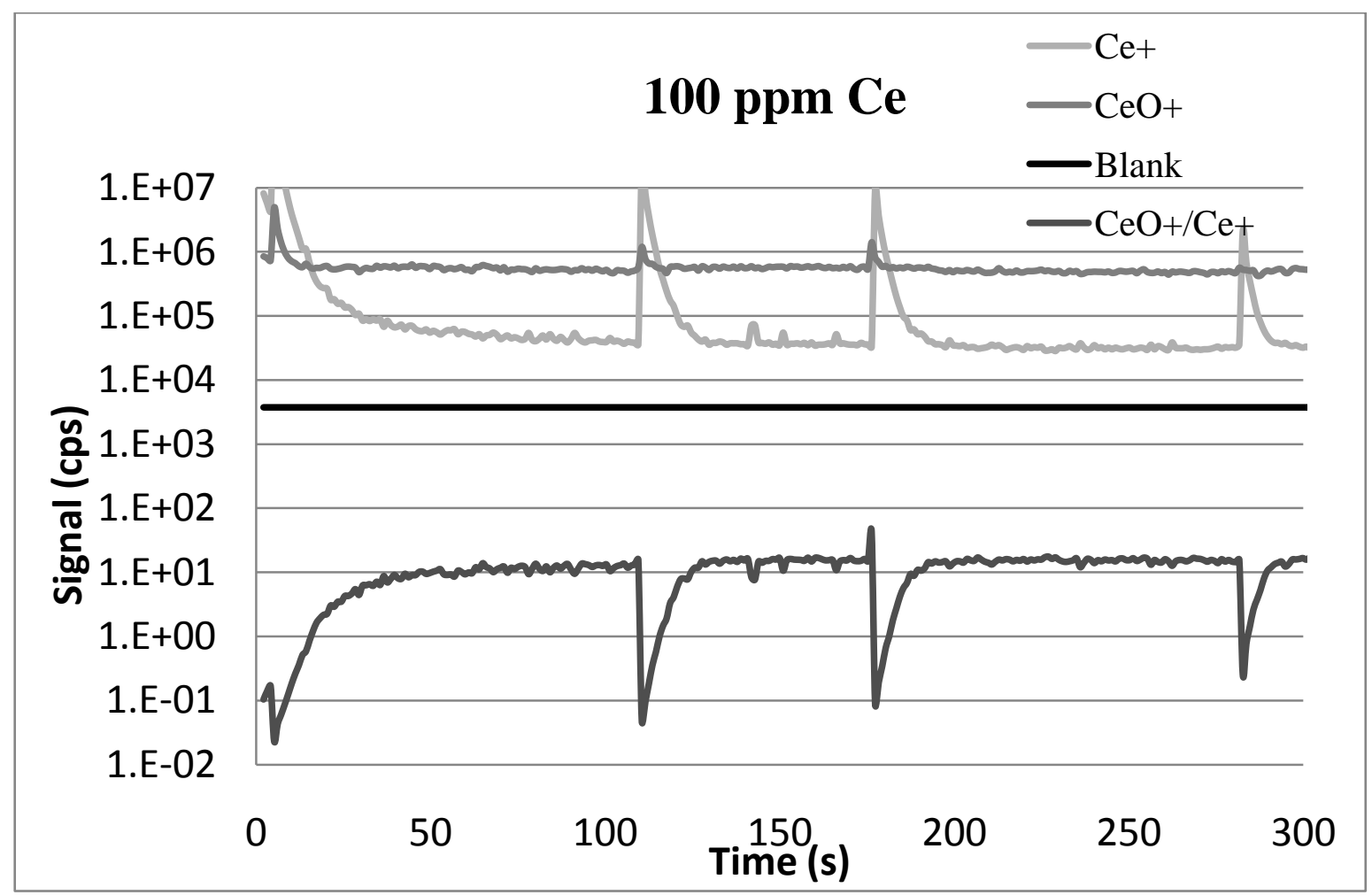

(a)

Figure 1 


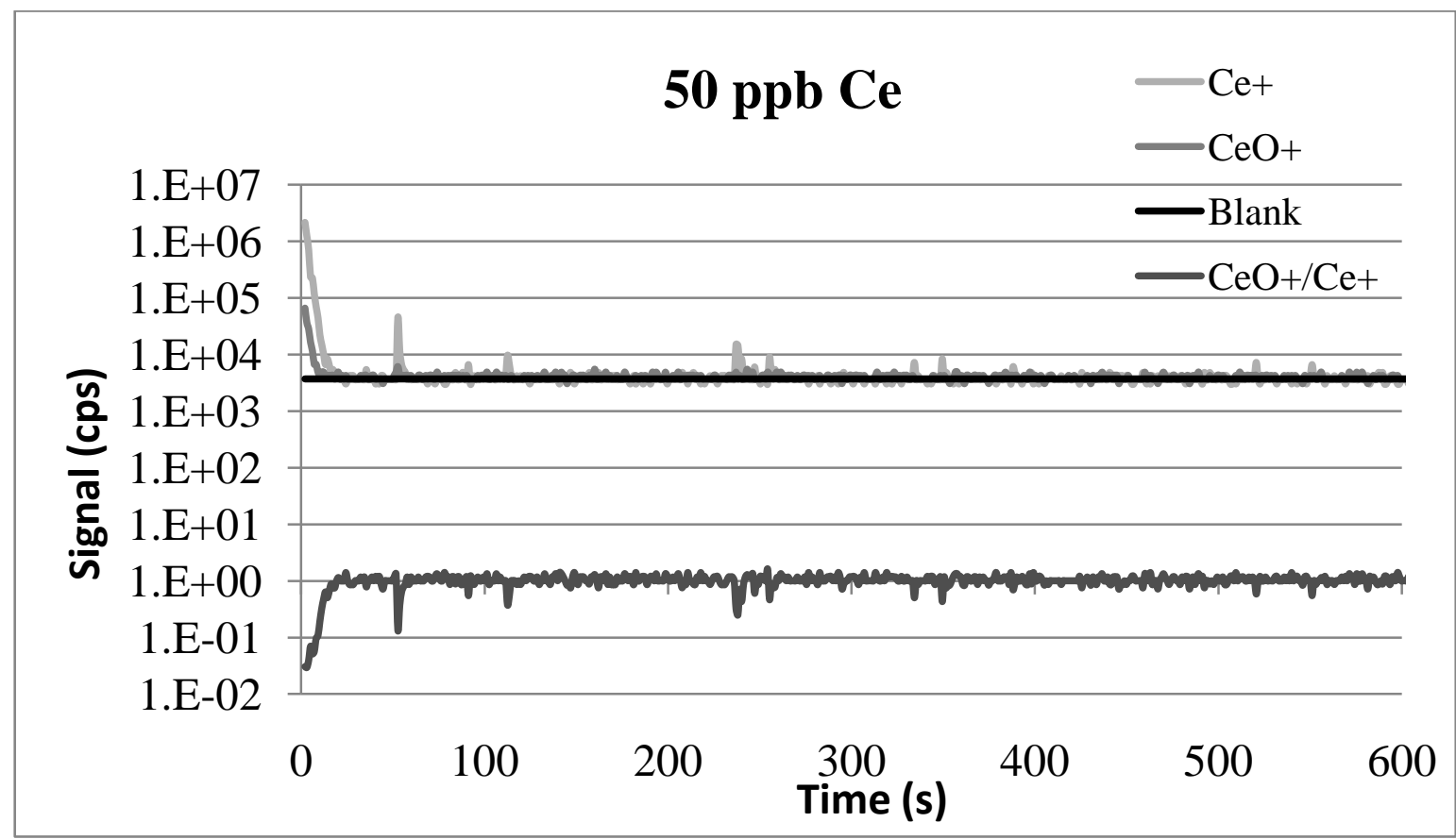

(b)

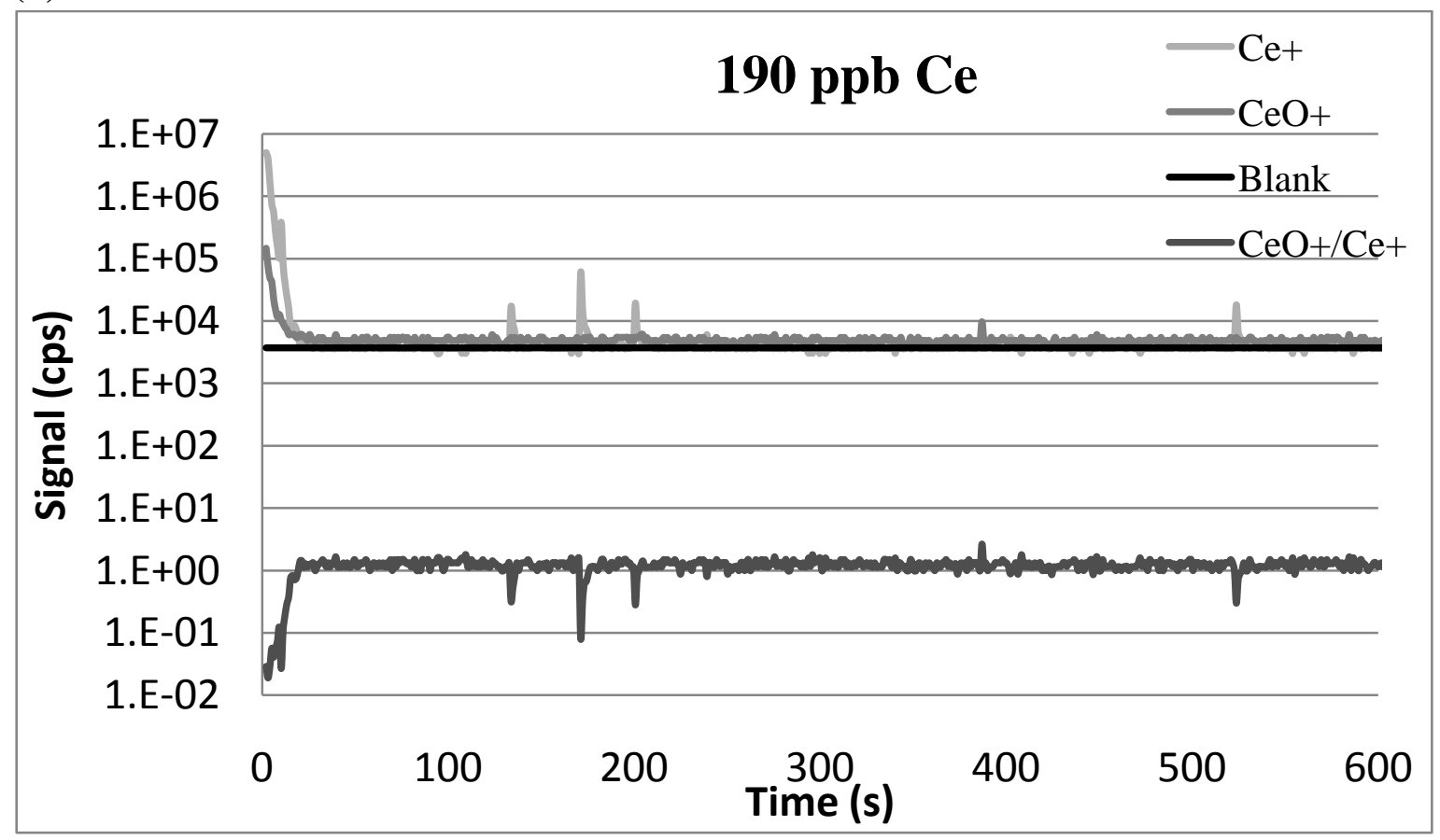

(c)

Figure 1 


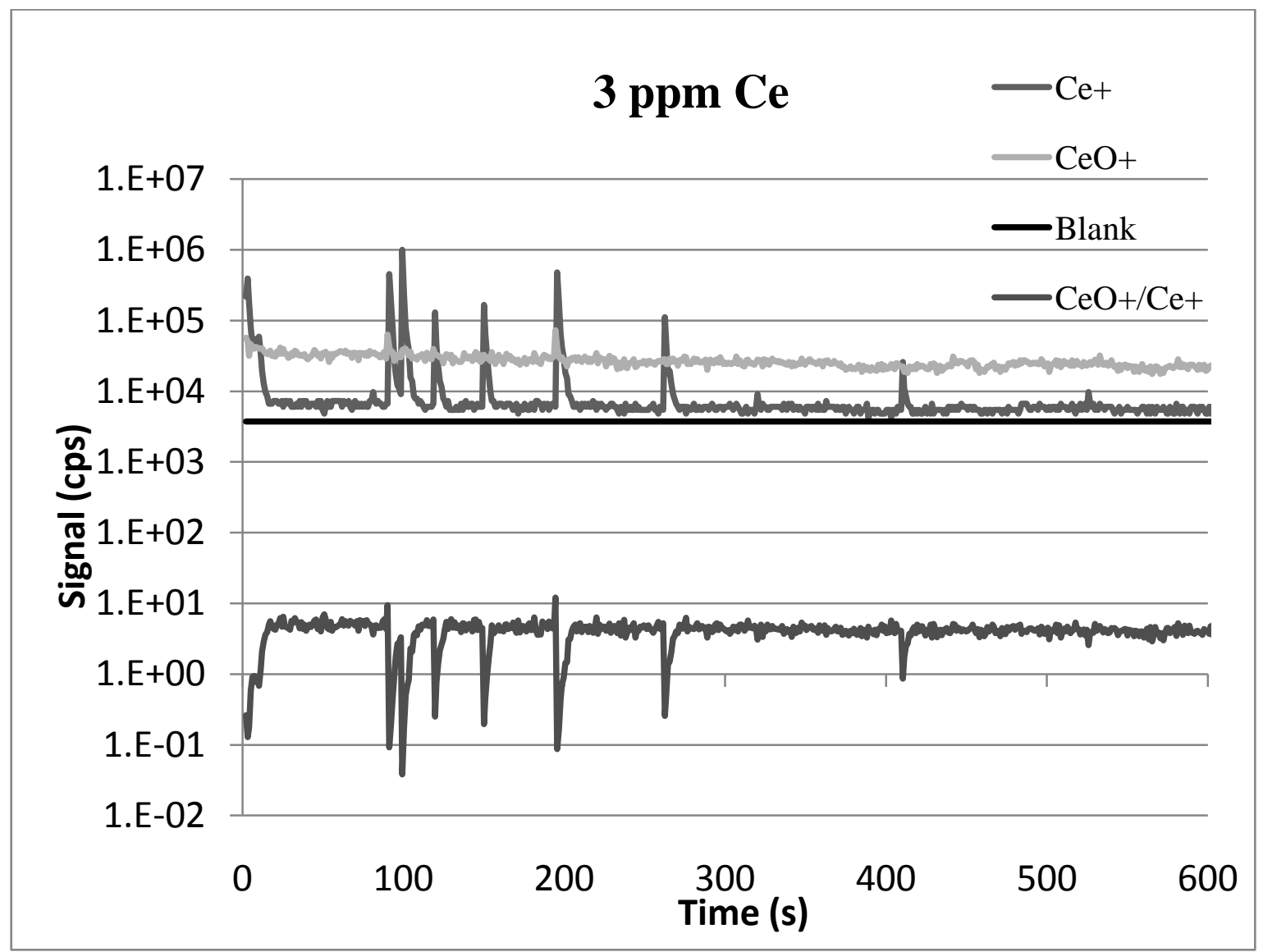

(d)

Figure 1(a-d): Rinse outs from Ce solutions of various concentrations. Notice the slight elevation in $\mathrm{CeO}^{+}$signal in the $185 \mathrm{ppb}$ solution indicating beginnings of $\mathrm{MO}^{+}$memory effect. 


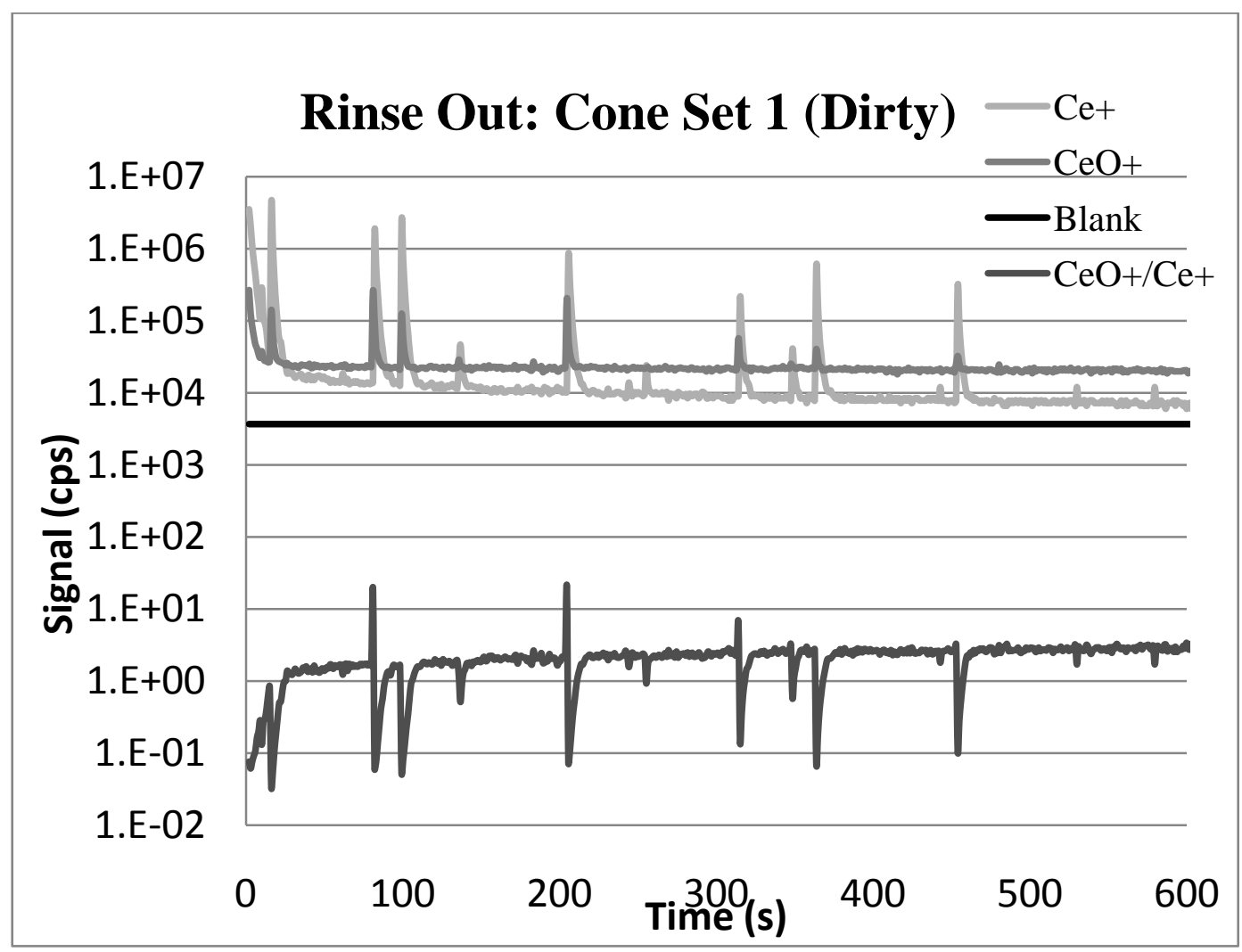

(a)

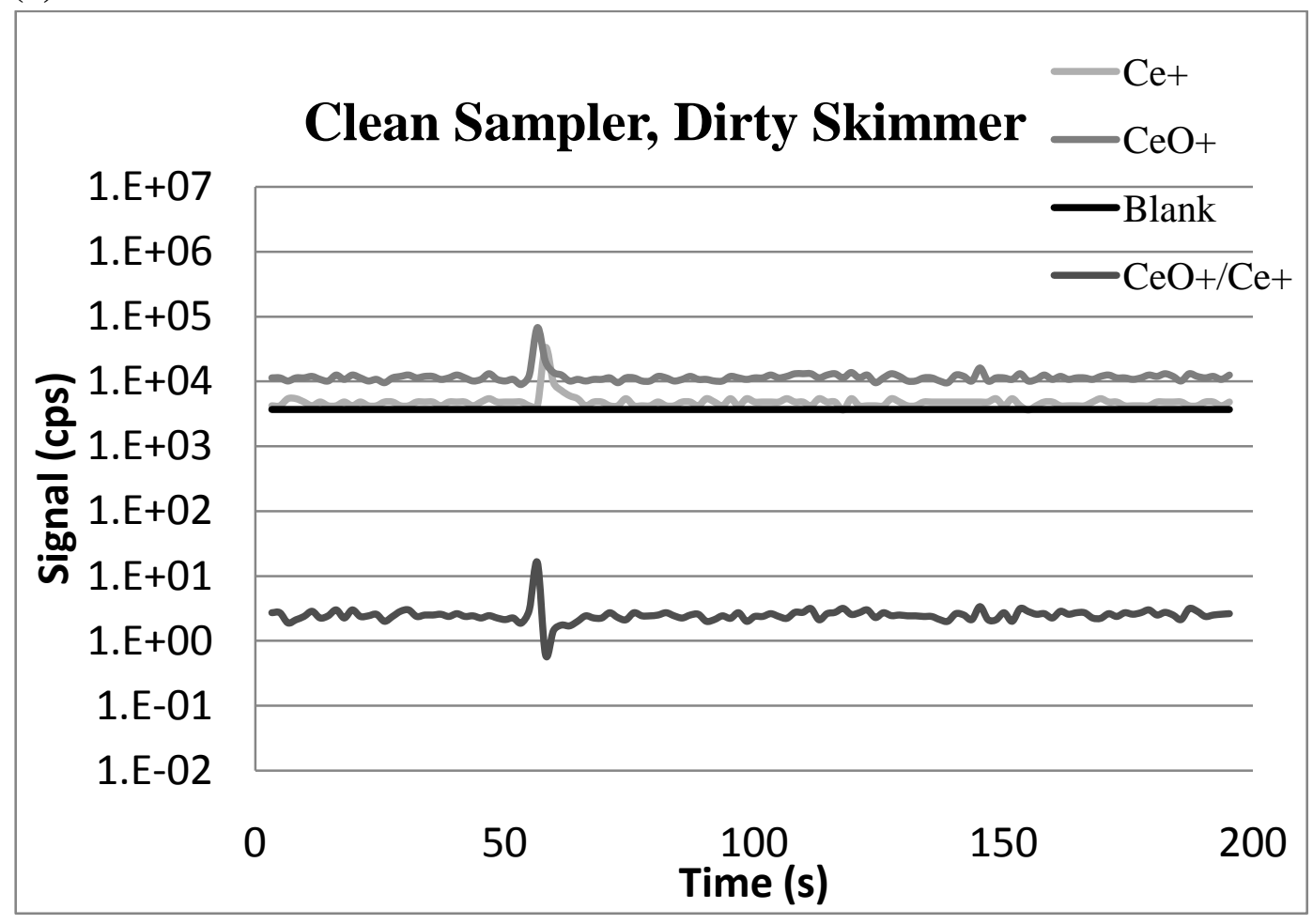

(b)

Figure 2 


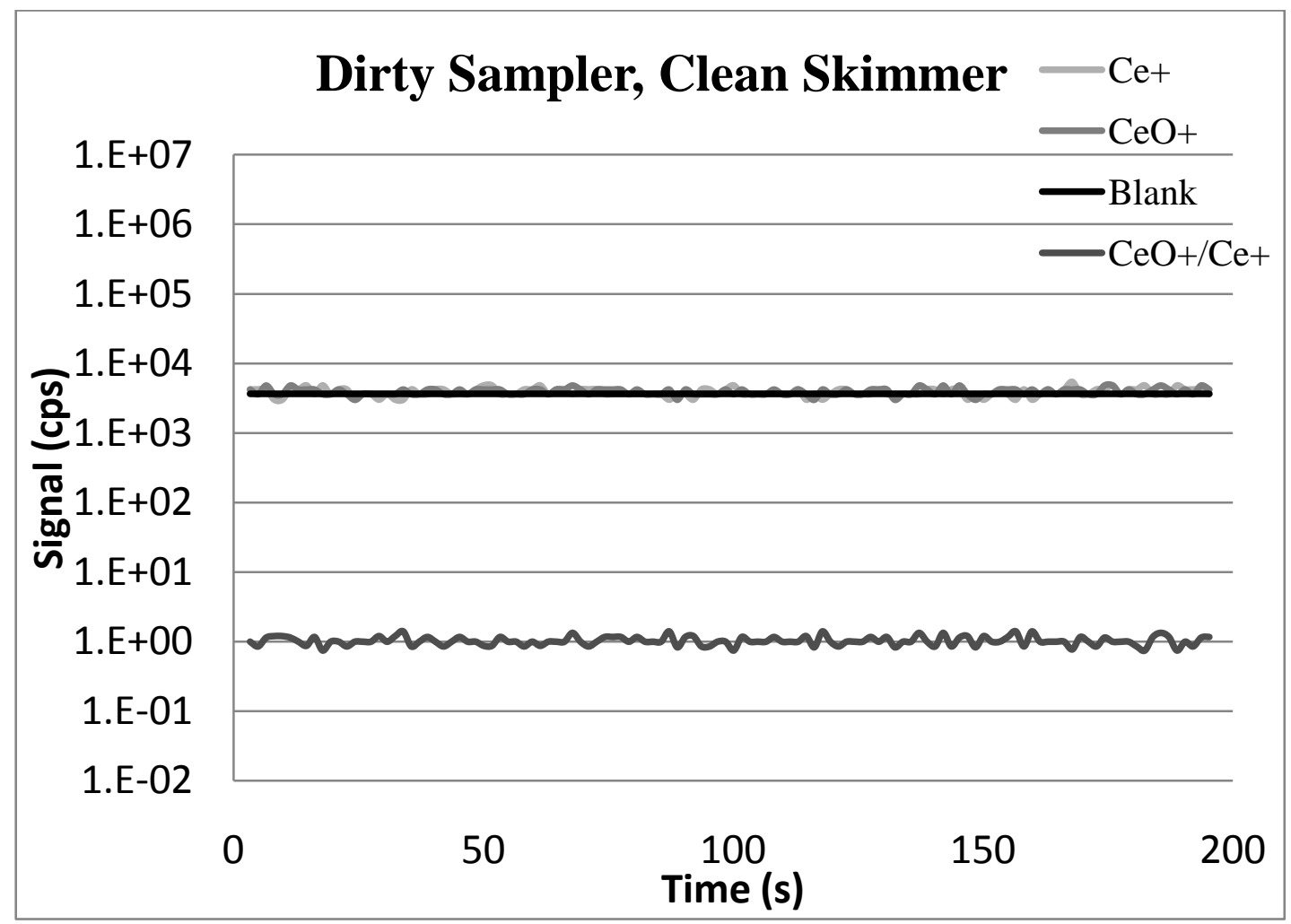

(c)

Figure 2a-c. Experiments to determine source of memory. Skimmer and sampler 1 were on the instrument when a 3ppm Ce solution was aspirated for 5 minutes. Skimmer and sampler 2 were a clean set. 


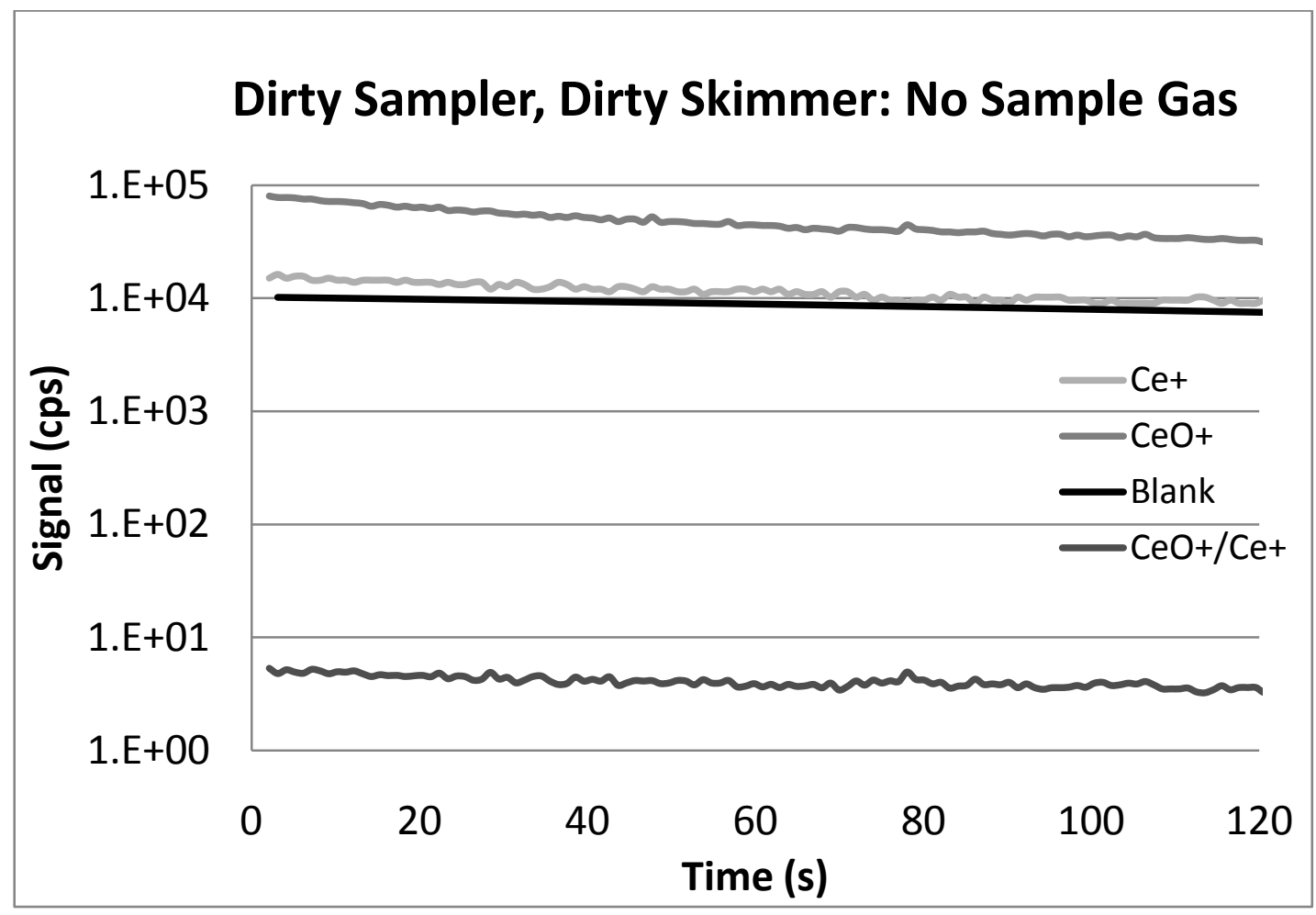

(a)

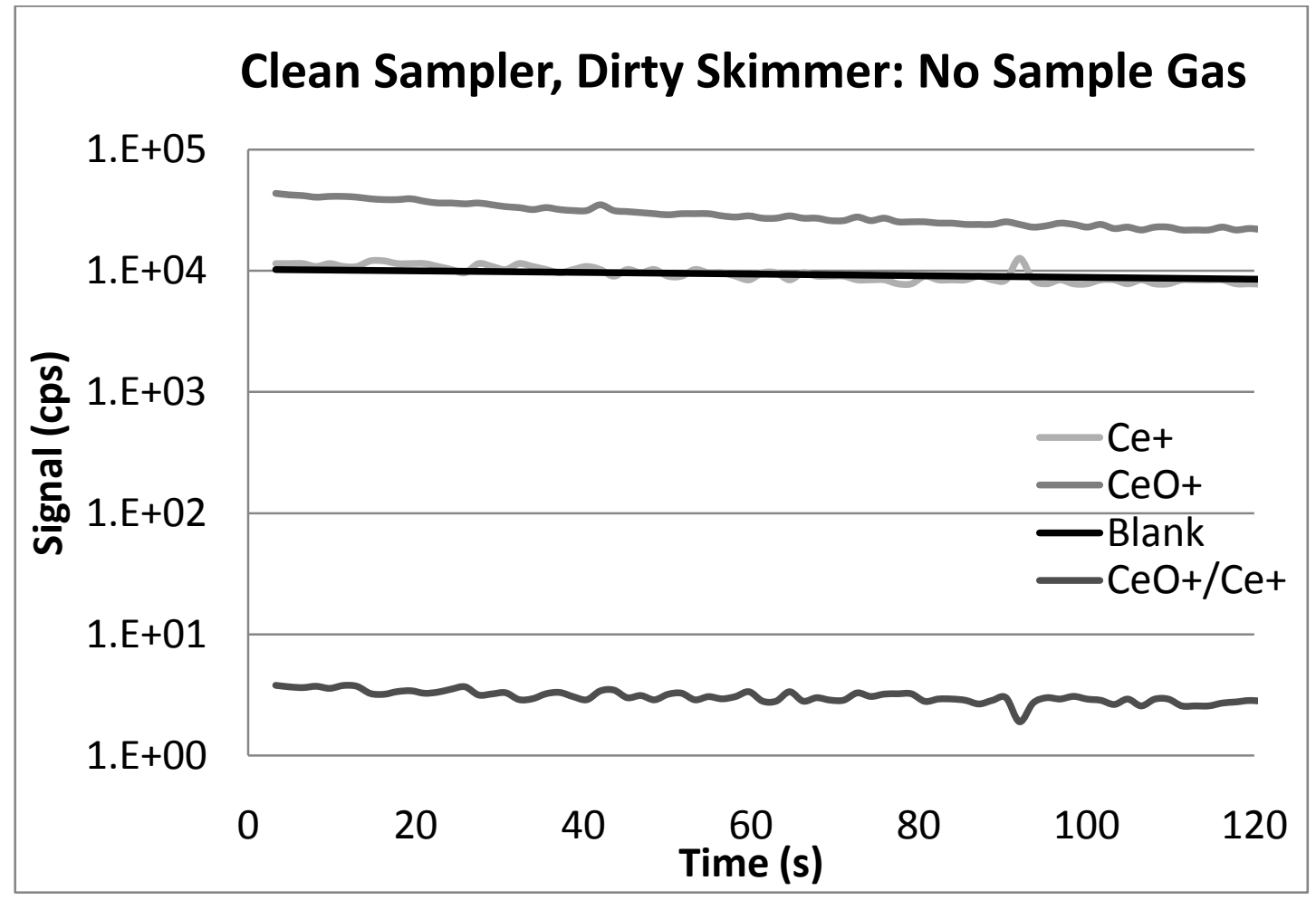

(b)

Figure 3 


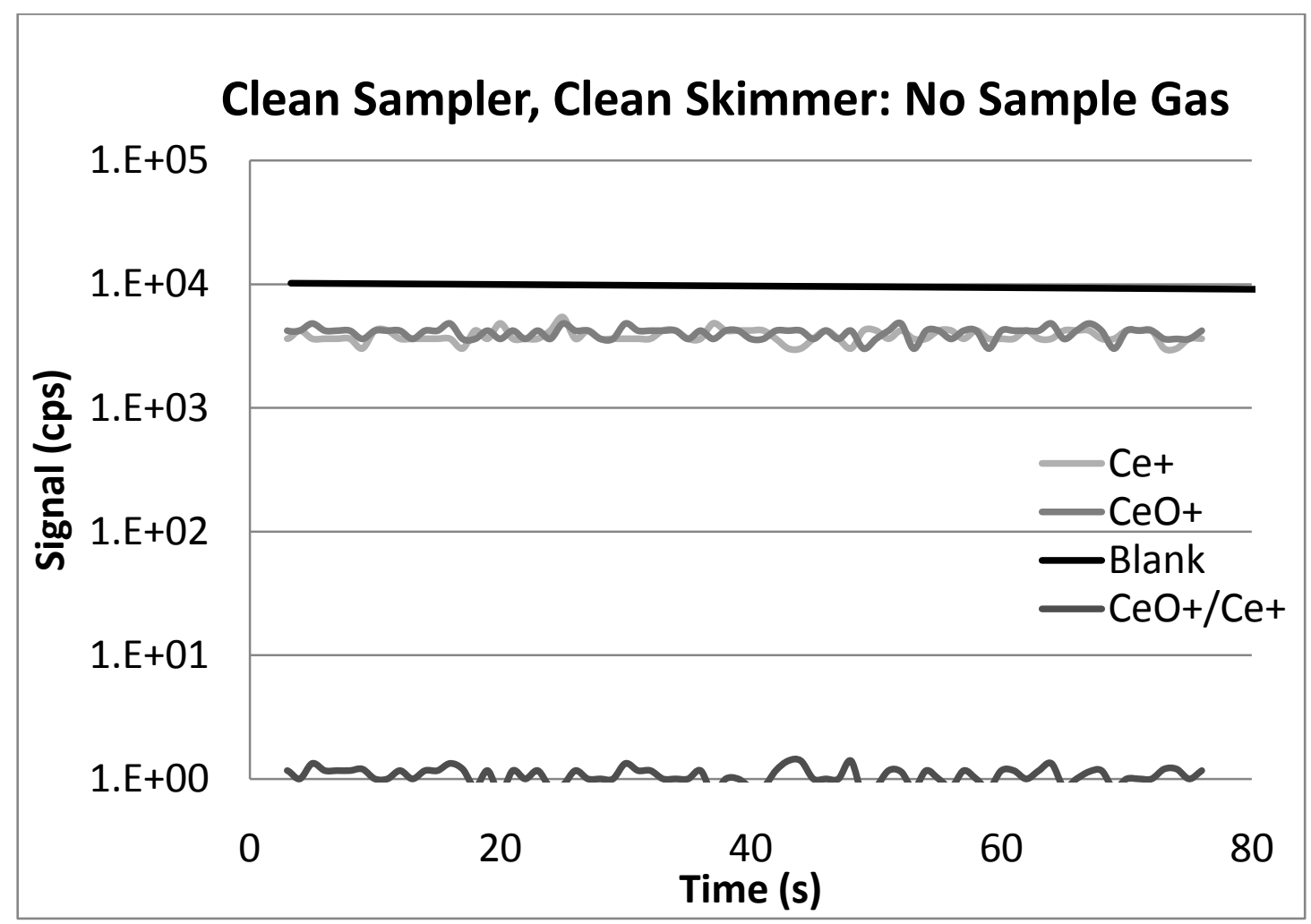

(c)

Figure 3a-c. Same experimental run as in Figure 2. Sampler and skimmer 1 were on the instrument when 3 ppm Ce solution was aspirated for 5 minutes. Sampler and skimmer 2 were a clean set. Sample gas turned to $01 \mathrm{~min}^{-1}$. 


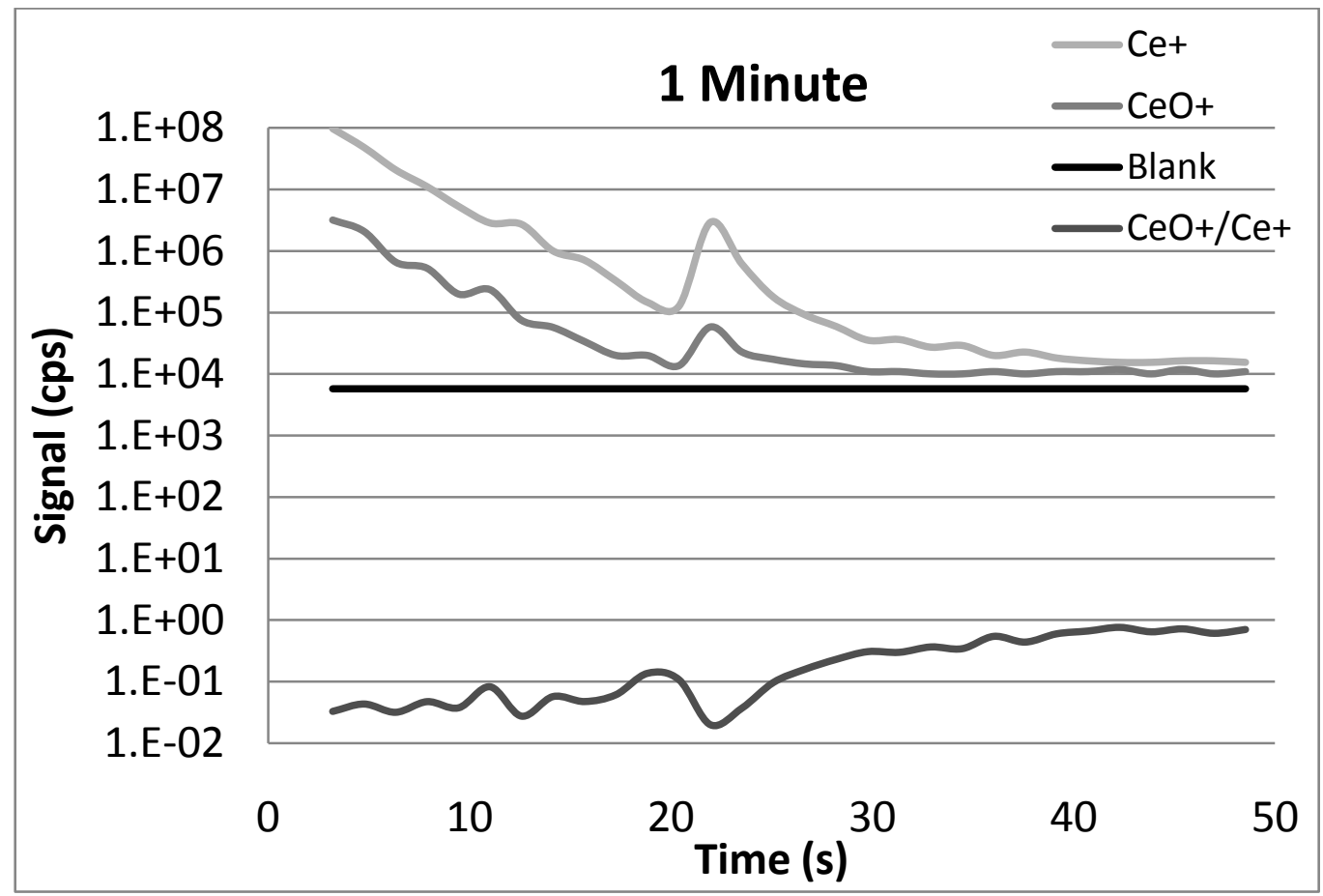

(a)

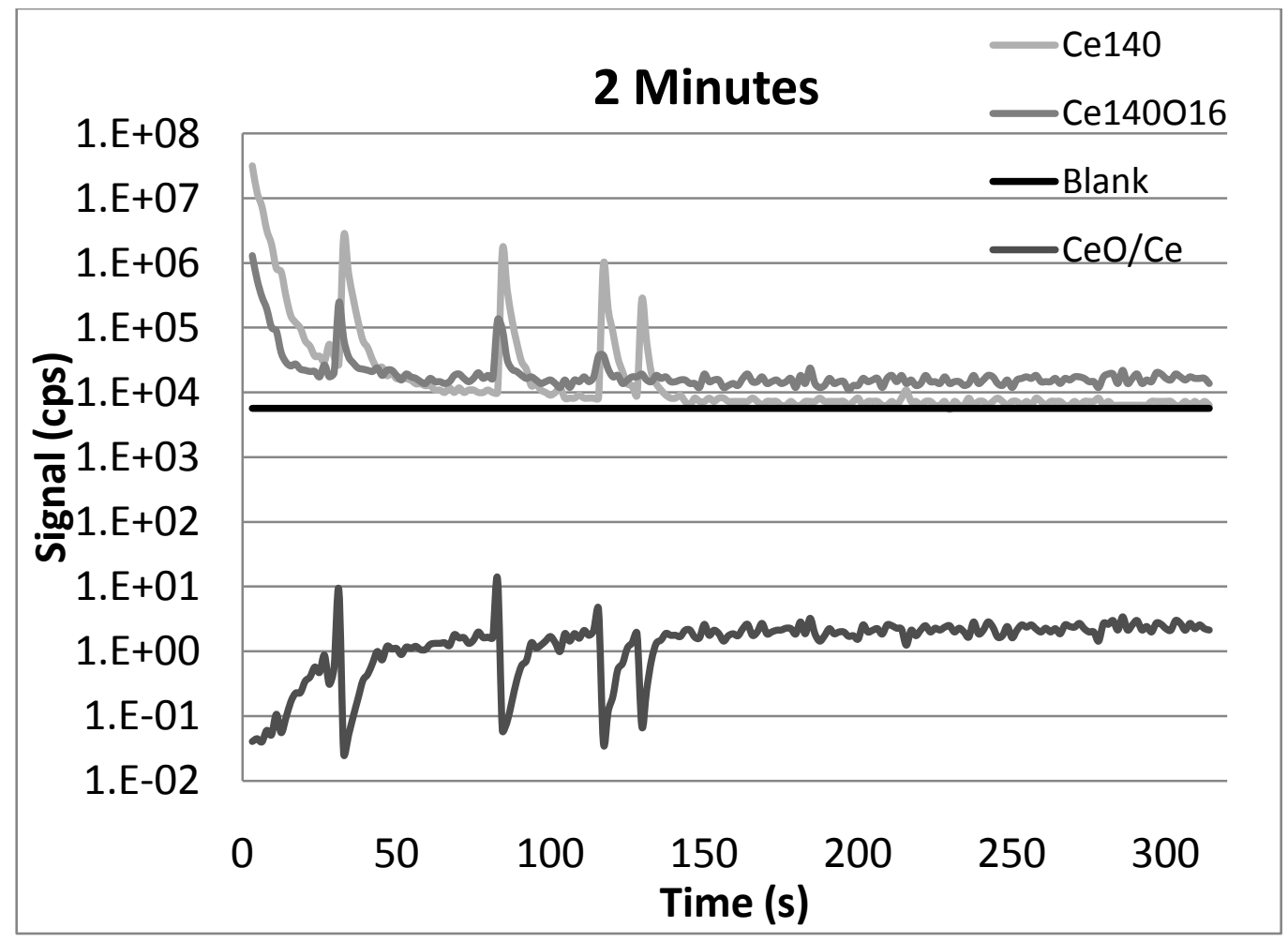

(b)

Figure 4 


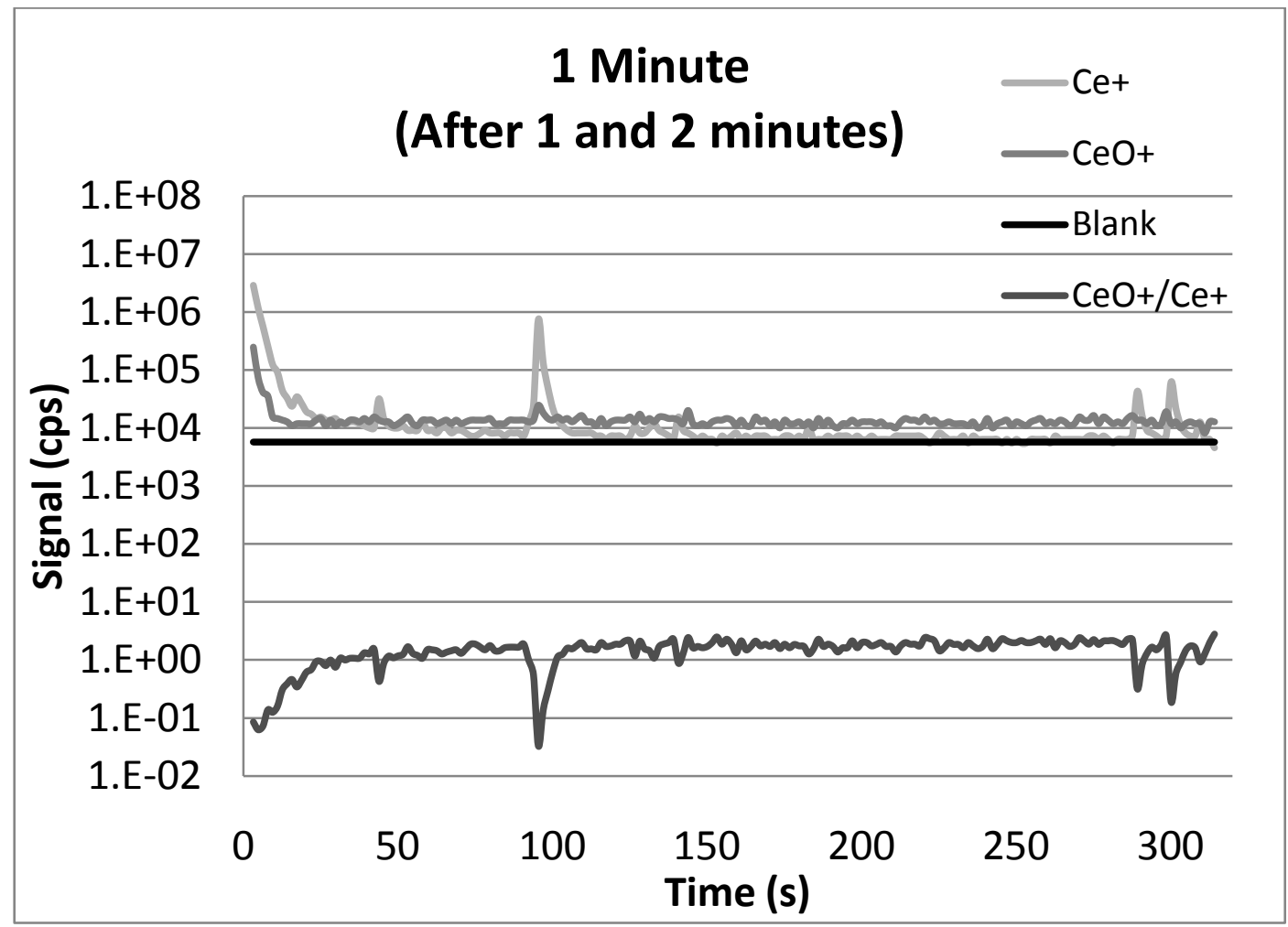

(c)

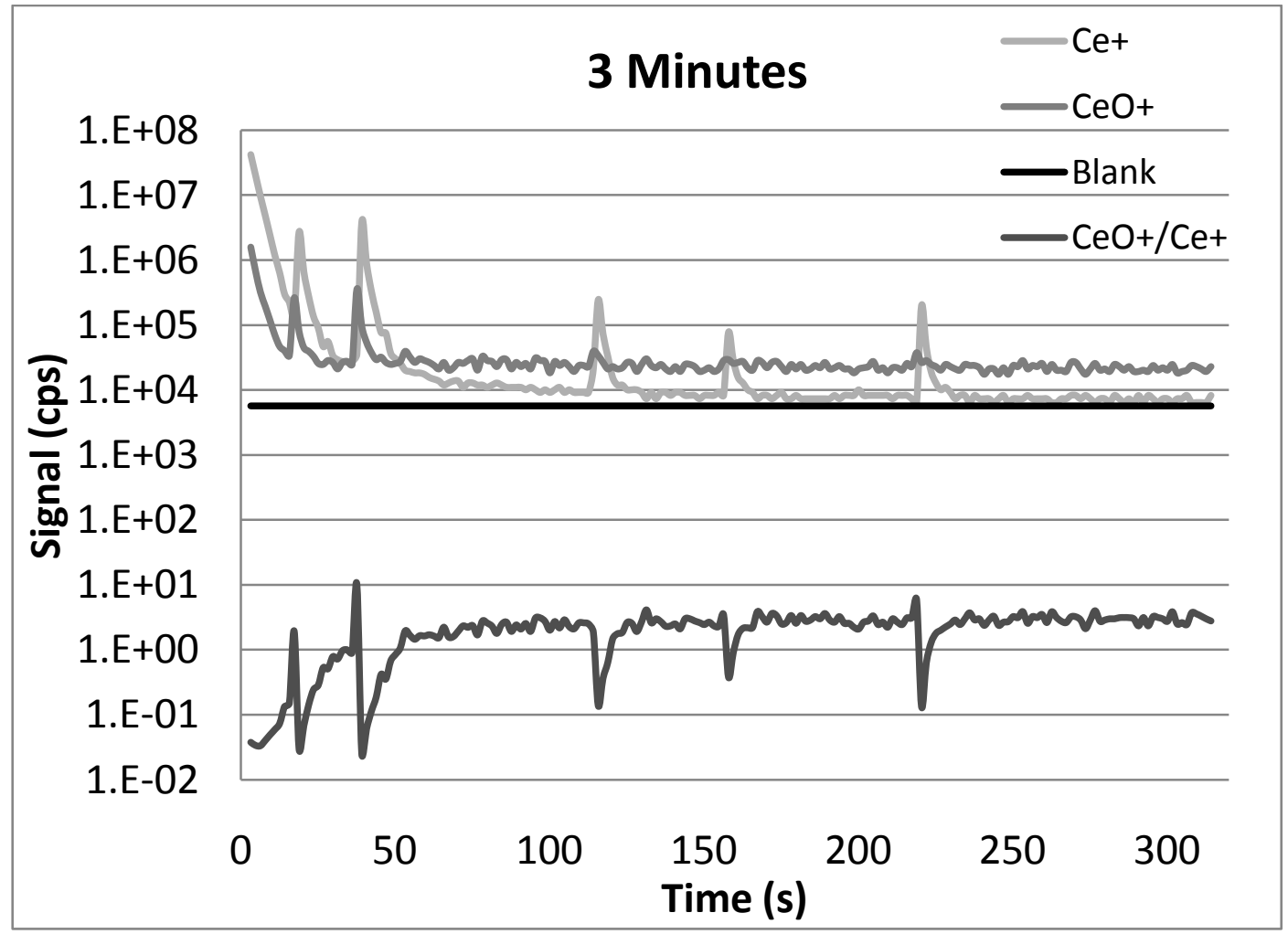

(d)

Figure 4 


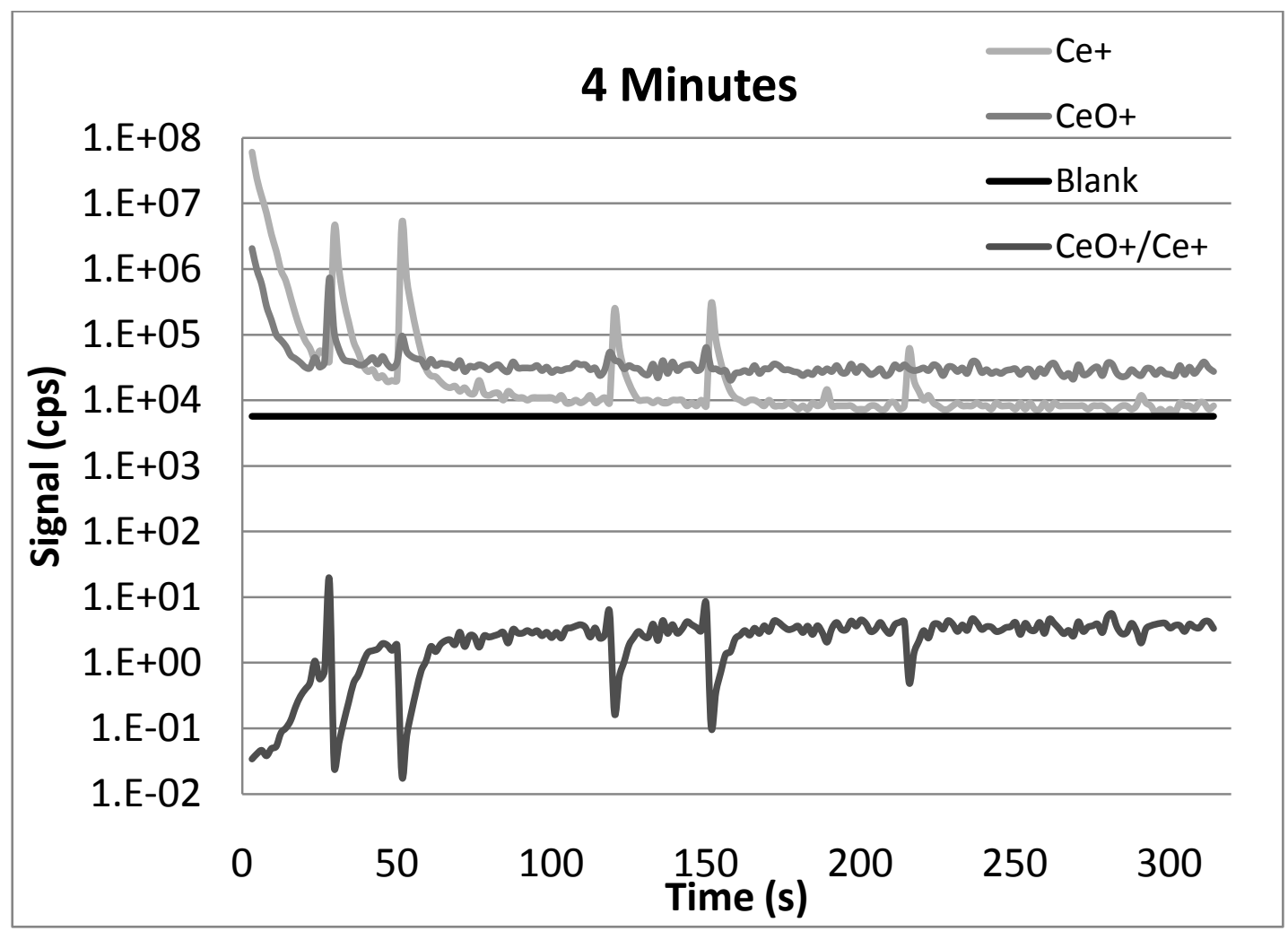

(e)

Figure 4a-e. Rinse-outs from various timed runs of a 3 ppm Ce solution. 


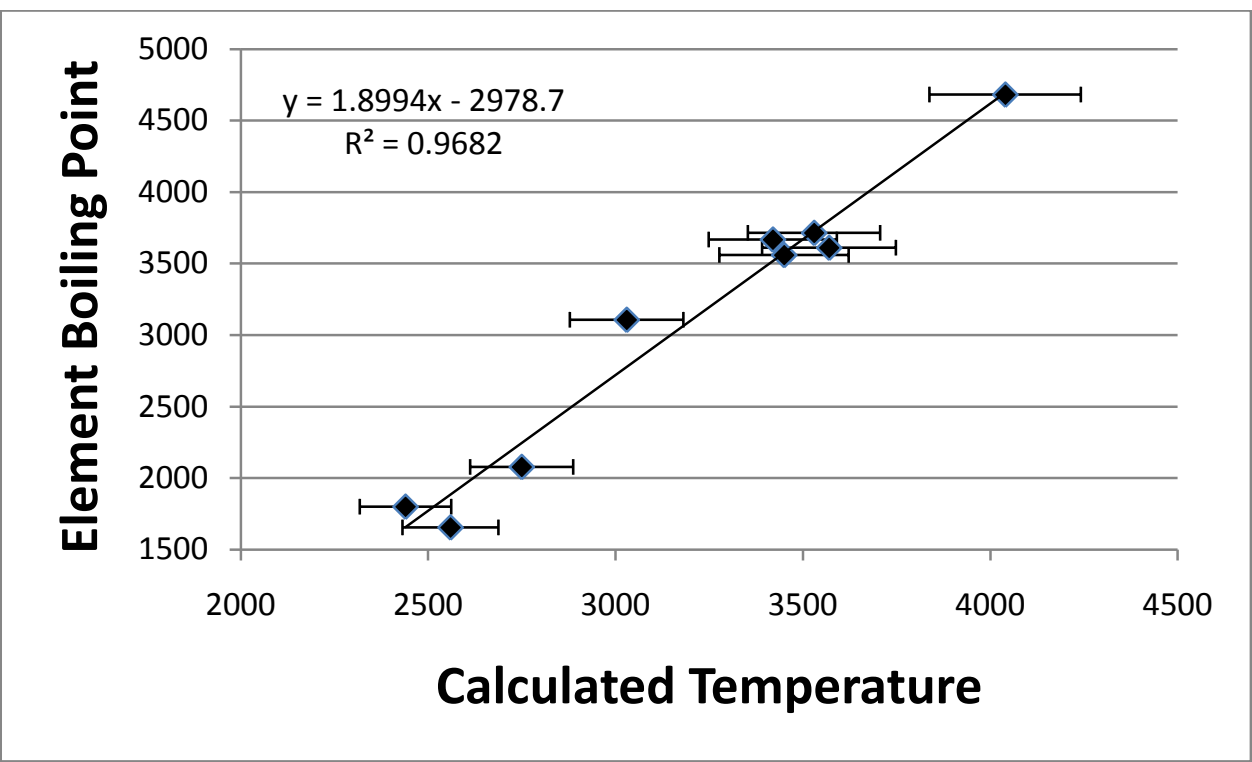

Figure 5. Boiling Point at 1 atm versus calculated temperature of $\mathrm{MO}^{+} / \mathrm{M}^{+}$ratio. Excludes $\mathrm{Ru}$. Error bars correspond to 5\% error in calculated temperature. 


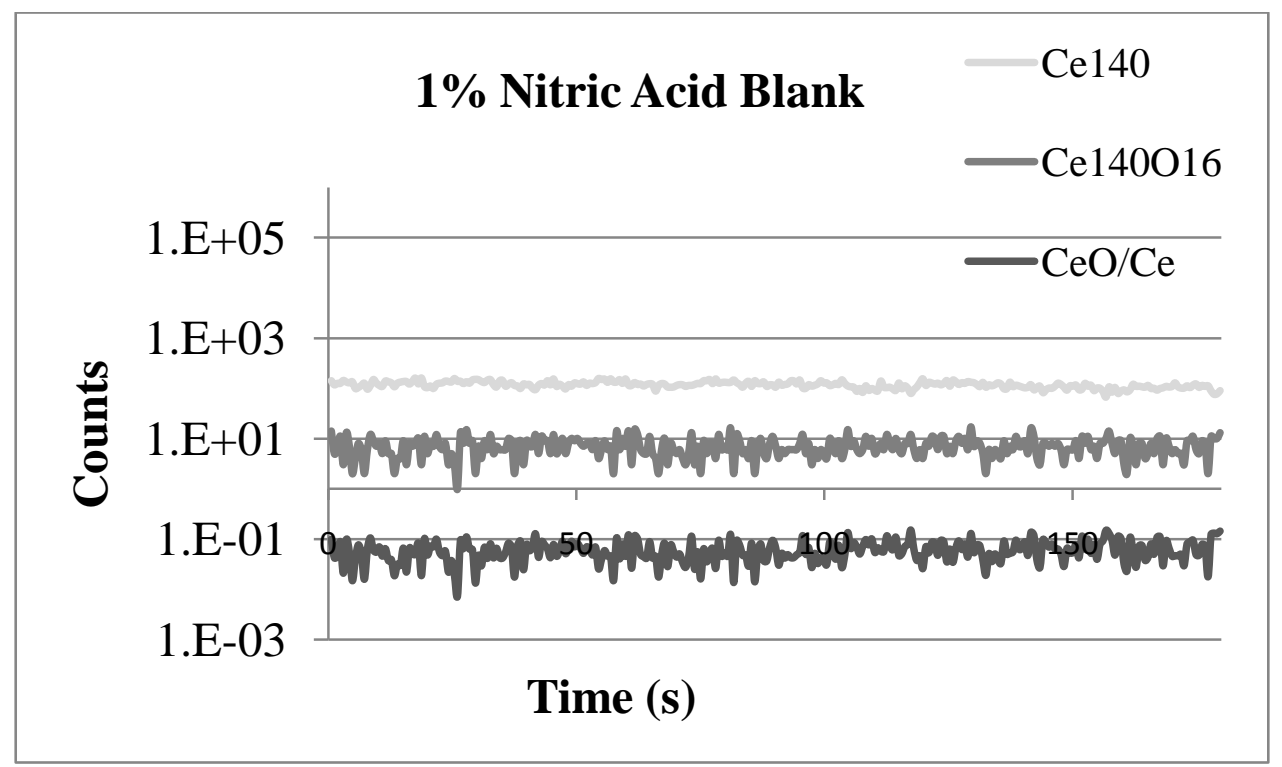

(a)

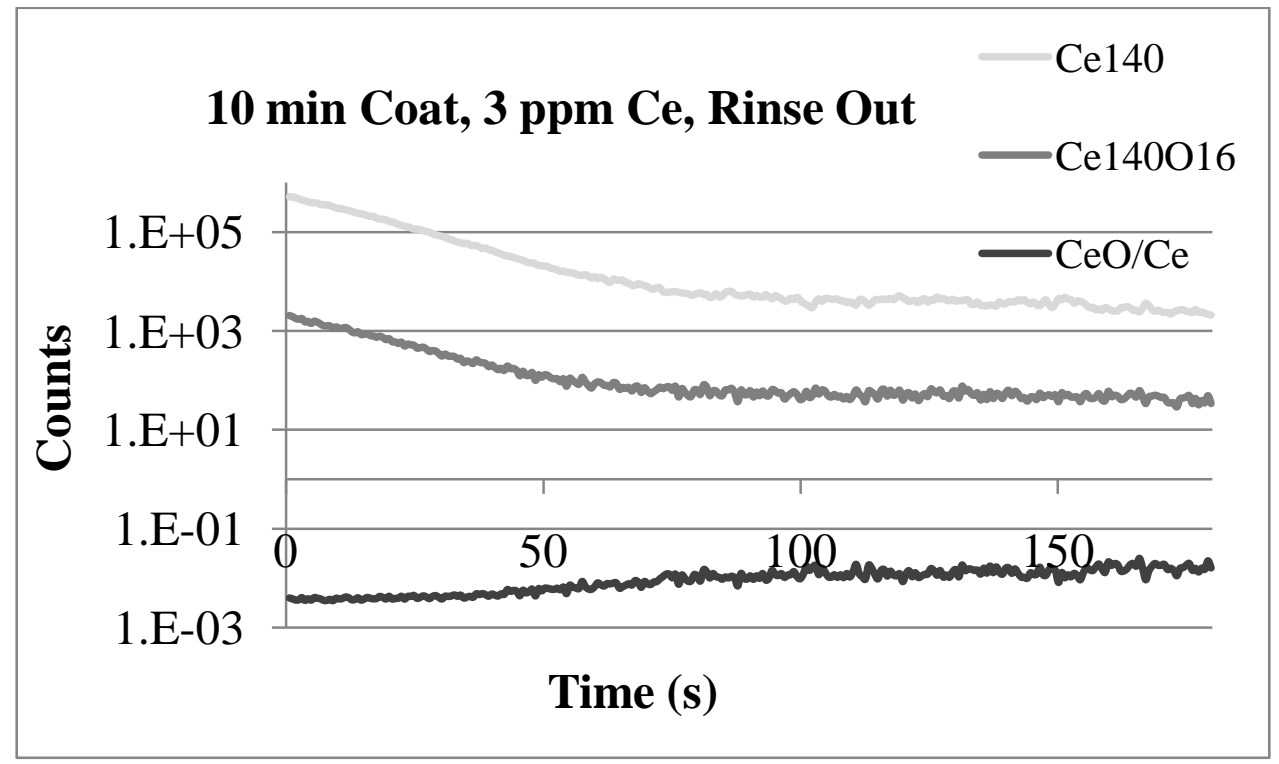

(b)

Figure 6a-b. Run on HP4500 ICP-MS. Note longer run time but lack of memory effect. 

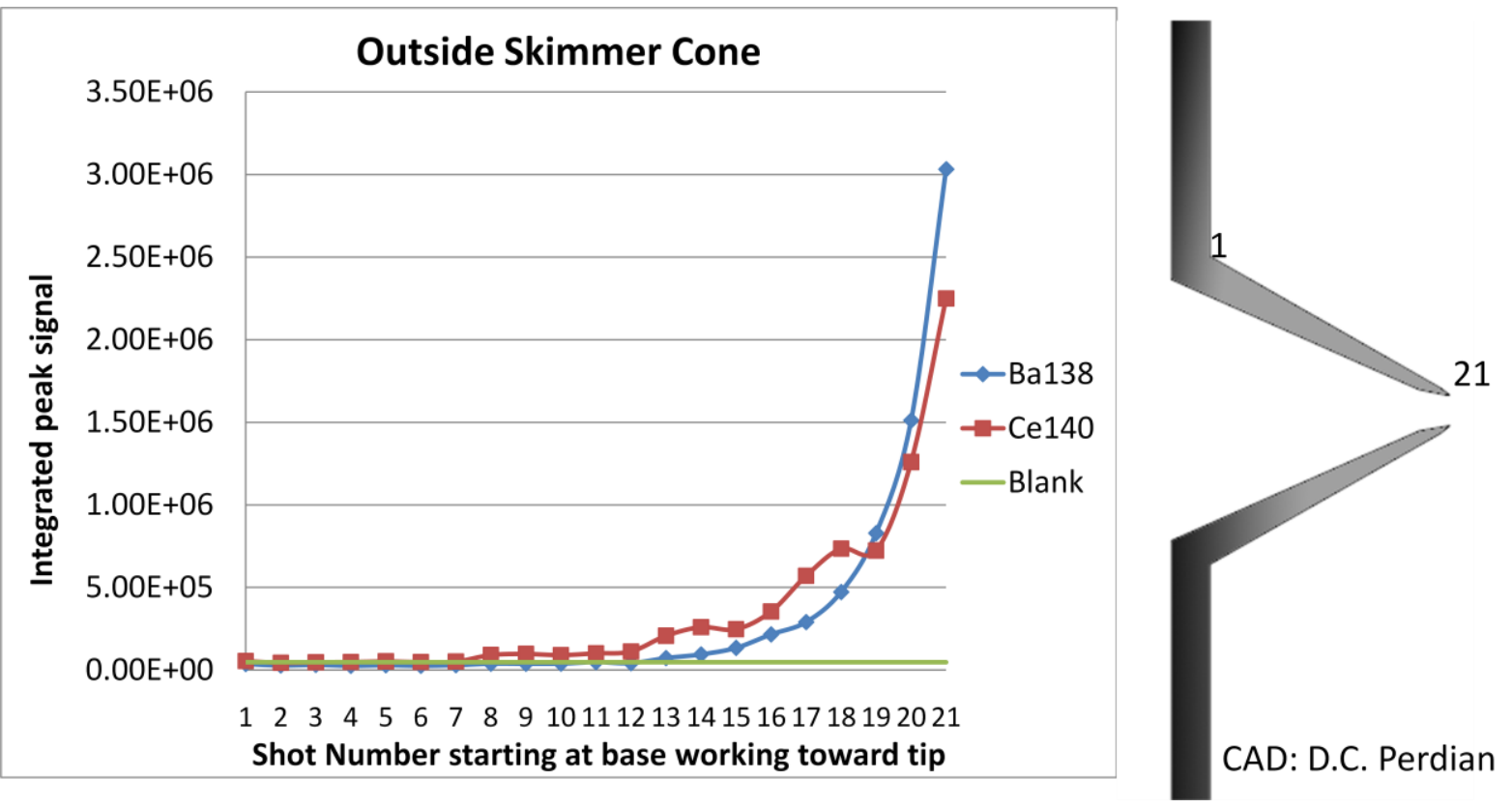

(a)
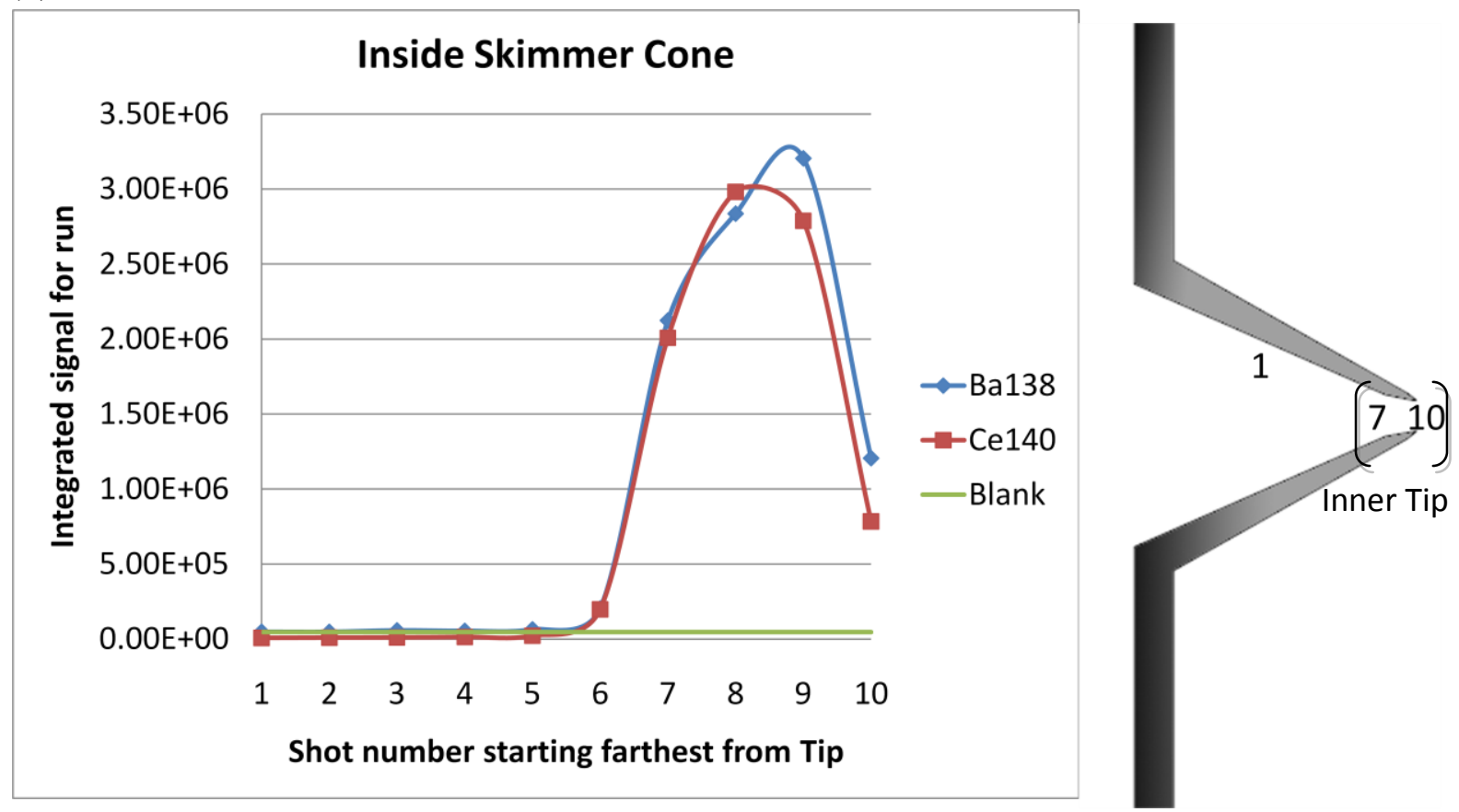

(b)

Figure 7. 


\section{Chapter 6. General Conclusions}

ICP-MS is the leading trace element analysis technique. One of its weaknesses are polyatomic ions. This dissertation has added to the fundamental understanding of some of these polyatomic ions, their origins and behavior. Although mainly continuing the work of others, certain novel approaches have been introduced here. Chapter 2 includes the first reported efforts to include high temperature corrections to the partition functions of the polyatomic ions in ICP-MS. This and other objections to preceeding papers in this area were addressed. Errors in the measured $\mathrm{T}_{\text {gas }}$ values were found for given errors in the experimental and spectroscopic values. The ionization energy of the neutral polyatomic ion was included in calculations to prove the validity of ignoring more complicated equilibria. Work was begun on the question of agreement between kinetics of the plasma and interface and the increase and depletion seen in certain polyatomic ions. This dissertation was also the first to report day to day ranges for $\mathrm{T}_{\text {gas }}$ values and to use a statistical test to compare different operating conditions. This will help guide comparisons of previous and future work.

Chapter 4 was the first attempt to include the excited electronic state ${ }^{2} \Pi$ in the partition function of $\mathrm{ArO}^{+}$as well as the first to address the different dissociation products of the ground and first electronic levels of $\mathrm{ArO}^{+}$. Chapter 5 reports an interesting source of memory in ICP-MS that could affect mathematical corrections for polyatomic ions.

For future work on these topics I suggest the following experiments and investigations. Clearly not an extensive list, they are instead the first topics curiosity brings to mind! 
1. Measurement of $\mathrm{T}_{\text {gas }}$ values when using the flow injection technique of Appendix B. It was believed that there was a fundamental difference in the plasma when the autosampler was used versus a continuous injection. Is this reflected in $\mathrm{T}_{\text {gas }}$ values?

2. The work of Chapter 3 can be expanded and supplemented with more trials, new cone materials (i.e. copper, stainless steel) and more cone geometries. Some of this equipment is already present in the laboratory, others could be purchased or made.

3. $\mathrm{T}_{\text {gas }}$ values from Chapter 3 could be correlated with instrument pressures during the experiment. Pressures after the skimmer cone were recorded for many days but have yet to be collated with the measured $\mathrm{T}_{\text {gas }}$ values.

4. The work in Chapter 5 could be expanded to include more metals. Does the curious correlation between measured $\mathrm{T}_{\mathrm{gas}}$ and element boiling point persist?

5. Investigate non-linear correlations to $\mathrm{T}_{\text {gas }}$ values of the $\mathrm{MO}^{+}$memory in Chapter 5 . Temperatures along the skimmer walls are not a linear gradient. Ring deposits have been observed on the cone and photographs of the interface show light intensities shaping a sort of tailing peak along the outside skimmer wall. Is there a physical property of the metals or metal oxides that would give this peak with the $\mathrm{T}_{\text {gas }}$ values?

6. Chemical state speciation of the metal deposits on the skimmers of Chapter 5. There may be a more logical correlation between $\mathrm{T}_{\text {gas }}$ and a physical property of the depositing chemical if all the metals do not deposit in the same form.

7. A collaboration with our computational collegues would be most welcome. Newer calculations for $\mathrm{ArO}^{+}$and $\mathrm{RuO}^{+}$would be very helpful. 
APPENDIX A.

\title{
POLYATOMIC IONS IN INDUCTIVELY COUPLED PLASMA - MASS \\ SPECTROMETRY. PART II: ORIGINS OF $\mathrm{N}_{2} \mathrm{H}^{+}$AND $\mathrm{H}_{\mathrm{X}} \mathrm{CO}^{+}$IONS USING EXPERIMENTAL MEASUREMENTS COMBINED WITH CALCULATED ENERGIES AND STRUCTURES
}

\author{
Jill Wisnewski Ferguson, Timothy J. Dudley, Kyle C. Sears, Sally M. McIntyre, \\ Mark S. Gordon, and R. S. Houk \\ Ames Laboratory U. S. Department of Energy \\ Department of Chemistry \\ Iowa State University, Ames Iowa 50011, USA
}

A paper published in Spectrochimica Acta Part B, 2009, 64, 690-696. 


\begin{abstract}
Several polyatomic ions in ICP-MS are studied experimentally and by computational methods. Novel calculations based on spin-restricted open shell second order perturbation theory (ZAPT2) and coupled cluster $(\mathrm{CCSD}(\mathrm{T}))$ theory are performed to determine the energies, structures and partition functions of the ions. These values are combined with experimental data to evaluate a dissociation constant and gas kinetic temperature $\left(\mathrm{T}_{\text {gas }}\right)$ value. In our opinion, the resulting $\mathrm{T}_{\text {gas }}$ value can sometimes be interpreted to deduce the location where the polyatomic ion of interest is generated. The dissociation of $\mathrm{N}_{2} \mathrm{H}^{+}$to $\mathrm{N}_{2}^{+}$leads to a calculated $\mathrm{T}_{\mathrm{gas}}$ of 4550 to $4900 \mathrm{~K}$, depending on the computational data used. The $\mathrm{COH}^{+}$to $\mathrm{CO}^{+}$system yields a similar temperature, which is not surprising considering the similar energies and structures of $\mathrm{COH}^{+}$and $\mathrm{N}_{2} \mathrm{H}^{+}$. The dissociation of $\mathrm{H}_{2} \mathrm{CO}^{+}$to $\mathrm{HCO}^{+}$leads to a much lower $\mathrm{T}_{\text {gas }}(<1000$ to $2000 \mathrm{~K})$. Finally, the dissociation of $\mathrm{H}_{2} \mathrm{COH}^{+}$to $\mathrm{HCOH}^{+}$generates a $\mathrm{T}_{\text {gas }}$ value between those from the other $\mathrm{H}_{\mathrm{x}} \mathrm{CO}^{+}$ions studied here. All of these measured $\mathrm{T}_{\text {gas }}$ values correspond to formation of extra polyatomic ion in the interface or extraction region. The computations reveal the existence of isomers such as $\mathrm{HCO}^{+}$and $\mathrm{COH}^{+}$, and $\mathrm{H}_{2} \mathrm{CO}^{+}$and $\mathrm{HCOH}^{+}$, which have virtually the same $m / z$ values and need to be considered in the interpretation of results.
\end{abstract}

Keywords: polyatomic ions, dissociation reaction, inductively coupled plasma - mass spectrometry, ICP-MS, spectral interferences, $\mathrm{N}_{2} \mathrm{H}^{+}, \mathrm{HCO}^{+}, \mathrm{COH}^{+}, \mathrm{H}_{2} \mathrm{CO}^{+}, \mathrm{HCOH}^{+}, \mathrm{H}_{2} \mathrm{COH}^{+}$. 


\begin{abstract}
Abbreviations
ICP-MS: Inductively Coupled Plasma-Mass Spectrometry

ZAPT2: Second order Z-averaged Perturbation Theory

CCSD(T): Coupled Cluster Singles and Doubles with Perturbative Triples

$\mathrm{T}_{\text {gas }}$ : Gas kinetic temperature

IPA: Isopropanol
\end{abstract}

\title{
Introduction
}

Inductively coupled plasma-mass spectrometry (ICP-MS) is a highly sensitive technique for the identification and quantification of elements in various samples. One strength of this method is the ability of the ICP to atomize and ionize the sample; the resulting atomic analyte ions are desired for multielement analysis. However, the ICP does not completely atomize everything. Polyatomic ions survive and are observed in the spectra. These ions cause interferences and require correction or attenuation by methods such as high resolution, solvent removal, cool plasma, and collision cells, particularly when analysis is done at the lowest possible analyte concentrations.

A number of papers describe various fundamental aspects of polyatomic ion production in ICP-MS [1-15]. Our group has described ways to evaluate the likely origin of a particular ion from measured ion signal ratios and information about the electronic, vibrational, and rotational energy states of the ions. Perhaps steps could then be taken to reduce the abundance of the polyatomic ion, thus improving the figures of merit of all ICP-MS devices. 
Previous work used literature values from experimental measurements of these fundamental properties and was thus restricted to species abundant enough to be studied in detail by other methods, e.g., photoionization MS. The present work reports such results using our own energy level parameters obtained by electronic structure calculations. This greatly extends the range of polyatomic ions that can be evaluated, which is valuable because many species can be seen at low abundance from the ICP. The computations also divulge the presence of isomeric structures that would be difficult to find experimentally [16]. The high sensitivity and resolution of a magnetic sector MS and the ability to assign elemental formulas from accurate $\mathrm{m} / \mathrm{z}$ measurements are particularly valuable for these measurements. Some of these polyatomic ions may be of interest in their own right in other scientific areas such as interstellar chemistry [17] or the low pressure plasmas used in semiconductor production.

\section{Theory}

Previous papers describe the process of studying a polyatomic ion in detail [1-3]. Briefly, the ions $\mathrm{AB}^{+}$and $\mathrm{A}^{+}$are measured and identified with a MS, in this case a magnetic sector instrument capable of high resolution. A dissociation reaction is written:

$$
\mathrm{AB}^{+} \rightleftharpoons \mathrm{A}^{+}+\mathrm{B} \quad \mathrm{D}_{0}\left(\mathrm{~A}^{+}-\mathrm{B}\right)=\text { dissociation energy }
$$

As stated by Houk and Praphairaksit [1,2], this reaction can be written as convenient for analytical measurement, as it does not need to take competing reactions into account. For this generic dissociation reaction, the dissociation constant $\mathrm{K}_{\mathrm{d}}$ (Eqn. 2) is evaluated experimentally using the measured signal ratio $\mathrm{A}^{+} / \mathrm{AB}^{+}$, including correction for mass bias, and an es- 
timate of $n_{B}$, the number density of the neutral product $\mathrm{B}$ (usually Ar atoms or $\mathrm{H}$ or $\mathrm{O}$ atoms from solvent):

$$
\begin{aligned}
& K_{d}=\left(\frac{\mathrm{n}_{\mathrm{A}^{+}}}{\mathrm{n}_{\mathrm{AB}^{+}}}\right) \mathrm{n}_{\mathrm{B}}=\mathrm{f}\left(\mathrm{T}_{\mathrm{gas}}, \mathrm{D}_{0}\right) \\
& \log \mathrm{K}_{\mathrm{d}}=\frac{3}{2} \log \mathrm{T}_{\mathrm{gas}}-\frac{5040 \mathrm{D}_{0}}{\mathrm{~T}_{\mathrm{gas}}}+\frac{3}{2} \log \frac{\mathrm{M}_{\mathrm{A}^{+}} \mathrm{M}_{\mathrm{B}}}{\mathrm{M}_{\mathrm{AB}^{+}}}+\log \frac{\mathrm{Z}_{\mathrm{A}^{+}}^{\prime} \mathrm{Z}_{\mathrm{B}}^{\prime}}{\mathrm{Z}_{\mathrm{AB}^{+}}^{\prime}}+20.274
\end{aligned}
$$

where $\mathrm{n}$ is the number density of the indicated species (particles $/ \mathrm{cm}^{3}$ ), $\mathrm{D}_{0}$ is the dissociation energy of the ion $\mathrm{AB}^{+}(\mathrm{eV}), \mathrm{M}$ is the atomic or molecular weight of the indicated species $(\mathrm{g} / \mathrm{mol}), \mathrm{Z}^{\prime}$ is the product of the electronic, vibrational, and rotational partition function terms, $\mathrm{T}_{\text {gas }}$ is the gas kinetic temperature $(\mathrm{K})$, and the logarithms are in base 10 . Note that the neutral species density and partition functions are themselves dependent on $\mathrm{T}_{\text {gas }}$, and are calculated separately for each $\mathrm{T}_{\text {gas }}$. For a single atom species such as $\mathrm{H}$ or $\mathrm{O}$, the $\mathrm{Z}$ ' term is comprised only of the electronic partition function [1].

The experimentally-measured $\mathrm{K}_{\mathrm{d}}$ value (Eqn. 2) is used in Eqn. 3 with a Microsoft Excel spreadsheet to determine the $\mathrm{T}_{\text {gas }}$ value where the two sides are most nearly equal [1]. In the likely range of temperatures seen in these experiments, only one such $\mathrm{T}_{\text {gas }}$ value results.

We contend that this measured $\mathrm{T}_{\text {gas }}$ value can be interpreted to identify the likely origin of the $\mathrm{AB}^{+}$ion. There are three common scenarios. The first is when the calculated $\mathrm{T}_{\text {gas }}$ is approximately 5500 to $6500 \mathrm{~K}$, close to the usual value at the sampling position for an ICP operated in "hot" mode. Two other ICP-MS results that support this generic value of $\mathrm{T}_{\text {gas }}$ 5000 to $6000 \mathrm{~K}$ for the usual sampling position are the pressure reduction method $[18,19]$ and the slope of a plot of ion energy vs m/z ratio [20]. Recent work by Farnsworth et al. determined $\mathrm{T}_{\text {gas }}$ from gas flow velocity from fluorescence measurements behind the sampler 
[21]. The results are hard to compare exactly to those in the present work for a variety of reasons. For example, the sampling positions differ (12 $\mathrm{mm}$ vs $10 \mathrm{~mm}$ ); the load coil in the present work is shielded, and the shield probably absorbs some of the forward power. For similar power values (1000 to $1200 \mathrm{~W}$ ) and aerosol gas flow rates (1.0 to $1.15 \mathrm{~L} / \mathrm{min})$, Farnsworth et al. found $\mathrm{T}_{\text {gas }}$ values of 5500 to $6400 \mathrm{~K}$ (see Fig. 3 of ref. 21), again in a similar range as the $\mathrm{T}_{\text {gas }}$ values cited above as "typical" for common ICP-MS operating conditions. A number of measurement methods for $\mathrm{T}_{\text {gas }}$ in the conventional ICP (i.e., one that has no sampler cone present) also yield values in this general range: $\mathrm{OH}$ rotational temperatures [22,23] Rayleigh scattering [24], and widths and shapes of emission lines [25-27].

In general, these findings suggest that polyatomic ions whose abundance corresponds to $\mathrm{T}_{\text {gas }}$ values $\sim 6000 \mathrm{~K}$ are present in the ICP itself. This diagnosis is common for strongly bound $\mathrm{MO}^{+}$ions such as $\mathrm{CeO}^{+}$.

The second outcome occurs when the determined $\mathrm{T}_{\text {gas }}$ is less than $5500 \mathrm{~K}$. There is more $\mathrm{AB}^{+}$in the spectrum than that expected from the ICP itself, which suggests that extra $\mathrm{AB}^{+}$is being generated after the ICP. Alternatively, perhaps the ICP does not atomize everything as expected. For example, droplet clouds in the ICP are obviously not in equilibrium with the rest of the plasma [28] and likely account for effects like the abundant $\mathrm{C}_{\mathrm{x}} \mathrm{H}_{\mathrm{y}} \mathrm{O}_{\mathrm{z}}{ }^{+}$ions seen from aqueous carbohydrate samples by Longerich et al. [29]. We minimize such effects by using low-flow nebulizers, which minimize solvent load and provide dry or nearly dry particles to the ICP.

The "extra" $\mathrm{AB}^{+}$could also be generated via reactions in the supersonic jet or in the extraction process. Such reactions are used in other systems to deliberately make cluster species like $\mathrm{Ar}_{2}$ and $\mathrm{Ar}_{2}{ }^{+}$[30]. Although the high starting temperature of the ICP is expected 
to suppress these species [31], some could still be made this way. A number of ions, including $\mathrm{OH}^{+}$and $\mathrm{H}_{2} \mathrm{O}^{+}$, are consistently observed at abundances that yield a $\mathrm{T}_{\text {gas }}$ value of $\sim 4000$ $\mathrm{K}$, which is close to the $\mathrm{T}_{\text {gas }}$ value expected at the axial position where $\operatorname{Mach}$ number $(\mathrm{M})=1$. This is about $0.5 \mathrm{~mm}$ behind the upstream tip of the sampling orifice [5,31]. We believe this common $\mathrm{T}_{\text {gas }}$ value indicates that these ions have a similar origin and are formed in moderate excess by collisions in the early phases of the supersonic expansion [3]. Cooling of the extracted gas due to thermal conduction to the sampler cone may also contribute to $\mathrm{T}_{\text {gas }}$ values in this range of $\sim 4000 \mathrm{~K}[32]$.

Finally, in some cases the measured $\mathrm{T}_{\text {gas }}$ value is greater than $6000 \mathrm{~K}$; the polyatomic ion $\mathrm{AB}^{+}$is less abundant that that expected from the ICP. Some process removes $\mathrm{AB}^{+}$relative to $\mathrm{A}^{+}$, perhaps via collision induced dissociation in the extraction process or supersonic jet. The dissociation of $\mathrm{NO}^{+}$to $\mathrm{N}^{+}$exhibits these high $\mathrm{T}_{\text {gas }}$ values [1-3].

The vibrational, rotational, and electronic partition functions are necessary for the ions in question. Through our collaborative efforts, we attain energies calculated via the $\operatorname{CCSD}(\mathrm{T})$ and ZAPT2 methods with a high degree of certainty. Articles by Gordon and coworkers explain the general methods used [33]. Specific dissociation energies and structures for the ions in question in this study have been published [16]. The vibrational frequencies and rotational constants derived from these structures and used in the partition function calculations and $\mathrm{T}_{\text {gas }}$ determinations are reported in various tables below. Agreement between results from different computational methods helps validate the results.

In general, the structures of these ions (e.g., $\mathrm{N}_{2} \mathrm{H}^{+}$) have been studied previously by either experiment or computation. Our calculated values are consistent with previously published values [17,34-36]. 


\section{Experimental Section}

Groups of ions of similar mass to charge ratio $(\mathrm{m} / \mathrm{z})$ are measured using a magnetic sector ICP-MS device, capable of resolution of approximately 300, 4000, or 11,000. A single magnet mass setting is used for a particular group of ions to aid in their identification, as the offset between actual $\mathrm{m} / \mathrm{z}$ and measured $\mathrm{m} / \mathrm{z}$ varies with magnetic field setting [3]. In this work, the ions studied generally differ by one $\mathrm{H}$ atom, so they can be measured by electrostatic scanning using a single magnet mass setting.

Once spectra are collected in the $m / z$ range of interest, the offsets determined between the $m / z$ values measured for $\mathbf{M}^{+}$ions from elemental standards and their actual $\mathrm{m} / \mathrm{z}$ values are used to determine an accurate $\mathrm{m} / \mathrm{z}$ value for the unknown ions. A line correction equation is derived from the $m / z$ values for atomic ions from standard solutions to assist in actual mass estimation. The approximate actual $\mathrm{m} / \mathrm{z}$ of unknown ions from the spectra are then compared to that of various combinations of atoms to help assign an identity. Suggested elemental compositions are guided by the fact that species with many atoms are not likely from the ICP, compared to the plethora of molecules considered in organic mass spectrometry. The elemental formulas are confirmed by the examination of isotope peaks, addition of organic solvent, and/or nebulization of $\mathrm{D}_{2} \mathrm{O}[3]$.

Mass bias corrections are determined from the $\mathrm{M}^{+}$signals from multielement standard solutions, as described previously [3]. In the present work, the ions in the ratio $n_{A}+/ n_{A B}+$ in Eqn. 2 differ by only one $\mathrm{H}$ atom, so mass bias is much less extensive than when ion ratios 
involving loss of $\mathrm{O}$ or Ar atoms are used. The number density of $\mathrm{H}$ atoms is estimated from the solvent load as described [3].

Operating conditions (Table 1) are chosen to provide maximum $\mathrm{M}^{+}$signal from multielement standards. These conditions also provide reproducible levels of $\mathrm{MO}^{+}$and $\mathrm{M}^{2+}$ ions ( signal ratios for $\mathrm{CeO}^{+} / \mathrm{Ce}^{+} \sim 1 \% ; \mathrm{Ce}^{2+} / \mathrm{Ce}^{+} \sim 2 \%$ ). We refer to this condition as "hot" plasma mode, to distinguish it from "cool" mode. The forward power and sampling position are normally kept constant and the aerosol gas flow rate is adjusted to achieve this condition. The optimum value of aerosol gas flow rate differs slightly from day to day, which is common, so a range of values are shown in Table 1. Also, this method of selecting operating conditions is much like that used in common analytical practice. It provides very consistent $\mathrm{T}_{\text {gas }}$ values from day to day for most species and between three different ICP-MS instruments $[1,3]$

The sample was $1 \%$ aqueous $\mathrm{HNO}_{3}$ for the smaller ions. For the larger $\mathrm{H}_{\mathrm{x}} \mathrm{CO}^{+}$ions, $10 \%$ isopropanol (IPA) was added to enhance their abundances. This nonvolatile alcohol did not change the optimum aerosol gas flow rate, solvent load, or $\mathrm{T}_{\text {gas }}$ outcome significantly .

\section{Results}

\section{1. $\mathrm{N}_{2} \mathrm{H}^{+}$and $\mathrm{N}_{2}^{+}$}

$\mathrm{N}_{2}{ }^{+}$is a common polyatomic ion seen in ICP-MS. The presence of $\mathrm{N}_{2}{ }^{+}$in the mass spectrum is expected since the plasma flows into the air, nitric acid is a common solvent, $\mathrm{N}_{2}$ is a likely impurity in the argon tanks, and the sample could also contain some dissolved $\mathrm{N}_{2}$ gas. However, the authors were initially surprised to note that $\mathrm{N}_{2} \mathrm{H}^{+}$was more abundant than 
$\mathrm{N}_{2}^{+}$(Figs. 1 and 2). Polyatomic ions with more atoms are generally expected to be less abundant at the high temperatures present in the ICP. This anomaly is significant analytically. ${ }^{29} \mathrm{Si}^{+}$is often chosen to determine $\mathrm{Si}$ because of the ${ }^{14} \mathrm{~N}_{2}{ }^{+}$interference commonly considered to be more severe on the major ${ }^{28} \mathrm{Si}^{+}$isotope.

Once the true identity of the ions was clear via accurate $\mathrm{m} / \mathrm{z}$ measurements, isotope ratio measurements, and solvent manipulation, we used the following reaction.

$$
\mathrm{N}_{2} \mathrm{H}^{+} \rightleftharpoons \mathrm{N}_{2}^{+}+\mathrm{H} \quad \mathrm{K}_{\mathrm{d} 4}=\mathrm{K}_{\mathrm{d}}\left(\mathrm{N}_{2}^{+}-\mathrm{H}\right)
$$

Energy level values for $\mathrm{N}_{2} \mathrm{H}^{+}$are reported in Table 2.

For a $1 \%$ aqueous $\mathrm{HNO}_{3}$ sample, the experimental $\mathrm{N}_{2}{ }^{+} / \mathrm{N}_{2} \mathrm{H}^{+}$signal ratio of 1.7 yields a $\mathrm{T}_{\text {gas }}$ value of $4550 \mathrm{~K}$ using energies provided by the ZAPT2 calculation; $\mathrm{CCSD}(\mathrm{T})$ data produces a $\mathrm{T}_{\text {gas }}$ value around $4900 \mathrm{~K}$. The difference in temperature is primarily attributed to the variation in calculated dissociation energy between the two methods. The $\operatorname{CCSD}(\mathrm{T})$ method is the higher level calculation and thus is thought to be superior. In this case, the two computation methods yield $\mathrm{T}_{\text {gas }}$ values that differ by only $350 \mathrm{~K}$ based on high dissociation energies (6.891 vs $7.449 \mathrm{eV})$ that differ by a large amount $(\sim 0.5 \mathrm{eV})$. Thus, even a large uncertainty in a large dissociation energy does not affect the basic diagnosis of the likely origin of the ions. Errors in other terms like the partition functions make even less difference [37]. $\mathrm{T}_{\text {gas }}$ values in this range $(4550$ or $4900 \mathrm{~K})$ are lower than those seen from ions which are believed to originate in the plasma, such as $\mathrm{CeO}^{+}[1,9,18,31]$. This observation suggests that additional $\mathrm{N}_{2} \mathrm{H}^{+}$is being produced in the interface or extraction process. The high dissociation energy and larger vibrational and rotational partition functions for $\mathrm{N}_{2} \mathrm{H}^{+}$also help ac- 
count for its larger abundance compared to $\mathrm{N}_{2}{ }^{+}$. In retrospect, a stable Lewis structure can be drawn for $\mathrm{N}_{2} \mathrm{H}^{+}$as $: \mathrm{N} \equiv \mathrm{N}-\mathrm{H}^{\rceil+}$

Interestingly, computational modeling of dissociation of $\mathrm{N}_{2} \mathrm{H}^{+}$provides information about the likely mechanism of the reaction [16]. The lowest energy pathway for dissociation is loss of $\mathrm{H}^{+}$, instead of the $\mathrm{H}$ atom as shown in $\mathrm{Rxn}$. 4. Upon dissociation, the more easily ionized product would be expected to carry the positive charge, as expected from the following cycle:

$$
\begin{array}{lll}
\mathrm{N}_{2} \mathrm{H}^{+} \rightleftharpoons \mathrm{N}_{2}+\mathrm{H}^{+} & \mathrm{D}_{0}\left(\mathrm{~N}_{2}-\mathrm{H}^{+}\right) & \mathrm{K}_{\mathrm{d} 5} \\
\mathrm{H}^{+}+\mathrm{e} \rightleftharpoons \mathrm{H} & \Delta \mathrm{H}=-\mathrm{IE}(\mathrm{H})=-13.598 \mathrm{eV} & 1 / \mathrm{K}_{6} \\
\underline{\mathrm{N}_{2}} \rightleftharpoons \mathrm{N}_{2}^{+}+\mathrm{e} & \underline{\mathrm{H}=\mathrm{IE}\left(\mathrm{N}_{2}\right)=14.65 \mathrm{eV}} & \mathrm{K}_{7} \\
\mathrm{~N}_{2} \mathrm{H}^{+} \rightleftharpoons \mathrm{N}_{2}^{+}+\mathrm{H} & \mathrm{D}_{0}\left(\mathrm{~N}_{2}^{+}-\mathrm{H}\right)=\mathrm{D}_{0}\left(\mathrm{~N}_{2}-\mathrm{H}^{+}\right)+1.05 \mathrm{eV}
\end{array}
$$

However, whether the calculations are done in one overall step (Eqn. 4) or three steps (Eqns. 5, 6, and 7), the final $\mathrm{K}_{\mathrm{d}}$ values should be equivalent:

$$
\mathrm{K}_{\mathrm{d} 4}=\mathrm{K}_{\mathrm{d} 5} \mathrm{~K}_{7} / \mathrm{K}_{6}
$$

where $\mathrm{K}_{\mathrm{d} 5}, \mathrm{~K}_{6}$ and $\mathrm{K}_{7}$ are the "equilibrium" constants defined above for Reactions 5, 6, and 7. The same result for $\mathrm{T}_{\text {gas }}$ and probable ion origin should result, if the position of Reactions 5, 6, and 7 are described by the same numerical value of temperature. Experimentally, this is fortunate. Direct use of Reaction 5 would require measurement of $\mathrm{H}^{+}$, which is possible but difficult. Correction for mass bias at $m / z, 1$ is harder still.

\section{2. $\mathrm{HCO}^{+}, \mathrm{COH}^{+}$, and $\mathrm{CO}^{+}$}

The computational results (Table 3) agree closely. $\mathrm{HCO}^{+}$is a strongly bound ion. The isomer $\mathrm{COH}^{+}$is much more easily dissociated than $\mathrm{HCO}^{+}$. 
The computations indicate the probable presence of both $\mathrm{HCO}^{+}$and $\mathrm{COH}^{+}$isomers at $m / z$ 29.0027:

$$
\mathrm{HCO}^{+} \rightleftharpoons \mathrm{COH}^{+} \rightleftharpoons \mathrm{CO}^{+}+\mathrm{H}
$$

The mass spectrometer cannot discriminate between these two species; the signal observed is that for the sum of $\mathrm{HCO}^{+}$and $\mathrm{COH}^{+}$. The question of whether the presence of $\mathrm{COH}^{+}$affects the diagnosis of the origin of $\mathrm{HCO}^{+}$and $\mathrm{COH}^{+}$is addressed as follows. The formalism is much like that used to calculate the abundances of various forms of a polyprotic weak acid in solution.

$$
\begin{array}{rlrl}
\mathrm{HCO}^{+} & \rightleftharpoons \mathrm{COH}^{+} & \begin{array}{l}
\mathrm{E}_{\mathrm{r}}=\text { rearrangement energy } \\
\mathrm{K}_{\mathrm{r}}=\mathrm{n}_{\mathrm{COH}}+\mathrm{n}_{\mathrm{HCO}}+
\end{array} \\
\mathrm{HCO}^{+} \rightleftharpoons \mathrm{CO}^{+}+\mathrm{H} & \mathrm{K}_{\mathrm{d}} \\
\mathrm{K}_{\mathrm{d}}=\left(\frac{\mathrm{n}_{\mathrm{CO}^{+}}}{\mathrm{n}_{\mathrm{HCO}^{+}}}\right) \mathrm{n}_{\mathrm{H}}=\left(\frac{\mathrm{n}_{\mathrm{CO}^{+}}}{\mathrm{N}_{29.0027}}\right)\left(\mathrm{K}_{\mathrm{r}}+1\right) \mathrm{n}_{\mathrm{H}}
\end{array}
$$

where $\mathrm{N}_{29.0027}$ is the total signal at $\mathrm{m} / \mathrm{z} 29.0027$, i.e., the $\mathrm{m} / \mathrm{z}$ value for both $\mathrm{HCO}^{+}$and $\mathrm{COH}^{+}$.

The measured signal ratio $\mathrm{CO}^{+} /\left(\mathrm{HCO}^{+}+\mathrm{COH}^{+}\right)$from $1 \%$ aqueous $\mathrm{HNO}_{3}$ is about 2.5. The $\mathrm{T}_{\text {gas }}$ values that result from use of various dissociation reactions for these ions are given in Table 4. Some observations from the table are as follows. Use of either CCSD(T) or ZAPT2 results does not affect the measured $\mathrm{T}_{\text {gas }}$. Inclusion of the $\mathrm{COH}^{+}$isomer also has little effect. The dissociation energy of $\mathrm{COH}^{+}$is almost $5 \mathrm{eV}$ lower than that of $\mathrm{HCO}^{+}$, so $\mathrm{COH}^{+}$does not appear to be very important in this system. However, incorrect assignment of the lowest energy isomer to $\mathrm{COH}^{+}$would lead to a much lower $\mathrm{T}_{\text {gas }}$ value and thus cause a large difference in the diagnosis of the origin of these ions.

For the $\mathrm{HCO}^{+}, \mathrm{COH}^{+} / \mathrm{CO}^{+}$system, the measured $\mathrm{T}_{\text {gas }}$ value is similar to that found for $\mathrm{N}_{2} \mathrm{H}^{+} / \mathrm{N}_{2}{ }^{+}$. On one hand, this similarity of $\mathrm{T}_{\text {gas }}$ values is expected based on the similar disso- 
ciation energies and partition functions for these groups of ions. On the other hand, the measured signal ratio for $\mathrm{N}_{2} \mathrm{H}^{+} / \mathrm{N}_{2}^{+}$is 1.7 , substantially higher than that for $\left(\mathrm{HCO}^{+}+\right.$ $\left.\mathrm{COH}^{+}\right) / \mathrm{CO}^{+}(0.4$, Figs. 1 and 2$)$.

\section{3. $\mathrm{H}_{2} \mathrm{CO}^{+}$and $\mathrm{HCOH}^{+}$}

The $\mathrm{H}_{2} \mathrm{CO}^{+}$system presents an additional challenge. For most species, ZAPT2 and $\mathrm{CCSD}(\mathrm{T})$ produce structural results that are very similar. However, for the $\mathrm{H}_{2} \mathrm{CO}^{+}$system, the two calculation methods identify different isomers to have the lowest energy: $\mathrm{HCOH}^{+}$by ZAPT2 , and $\mathrm{H}_{2} \mathrm{CO}^{+}$by CCSD(T) (Table 5). Furthermore, the product ion also has two isomers: $\mathrm{HCO}^{+}$and $\mathrm{COH}^{+}$. Both computational methods yield very low dissociation energies, so neither $\mathrm{HCOH}^{+}$nor $\mathrm{H}_{2} \mathrm{CO}^{+}$are expected to be very abundant. Indeed, the measured signal ratio for $\left(\mathrm{H}_{2} \mathrm{CO}^{+}+\mathrm{HCOH}^{+}\right) /\left(\mathrm{HCO}^{+}+\mathrm{COH}^{+}\right)$is only $\sim 5 \times 10^{-4}$, a small value.

$\mathrm{T}_{\text {gas }}$ is evaluated in the following way.

$$
\begin{array}{ll}
\mathrm{H}_{2} \mathrm{CO}^{+} \rightleftharpoons \mathrm{HCOH}^{+} & \mathrm{E}_{\mathrm{r}}\left(\mathrm{H}_{2} \mathrm{CO}^{+}\right) \\
\mathrm{H}_{2} \mathrm{CO}^{+} \rightleftharpoons \mathrm{HCO}^{+}+\mathrm{H} & \mathrm{K}_{\mathrm{r}}\left(\mathrm{H}_{2} \mathrm{CO}^{+}\right) \\
\mathrm{HCO}^{+} \rightleftharpoons \mathrm{COH}^{+} & \mathrm{D}_{0}\left(\mathrm{H}_{2} \mathrm{CO}^{+}\right) \\
& \mathrm{E}_{\mathrm{r}}\left(\mathrm{HCO}^{+}\right) \\
& \mathrm{K}_{\mathrm{r}}\left(\mathrm{HCO}^{+}\right)
\end{array}
$$

If only the isomers of $\mathrm{H}_{2} \mathrm{CO}^{+}$are considered, the equation for $\mathrm{K}_{\mathrm{d}}$ is:

$$
\mathrm{K}_{\mathrm{d}}=\left(\frac{\mathrm{n}_{\mathrm{HCO}^{+}}}{\mathrm{N}_{30.0106}}\right)\left[\mathrm{K}_{\mathrm{r}}\left(\mathrm{H}_{2} \mathrm{CO}^{+}\right)+1\right] \mathrm{n}_{\mathrm{H}}
$$

where $\mathrm{N}_{30.0106}$ is the total signal at the $\mathrm{m} / \mathrm{z}$ value for both $\mathrm{H}_{2} \mathrm{CO}^{+}$and $\mathrm{HCOH}^{+}$. Including the isomers of $\mathrm{HCO}^{+}$in the numerator gives: 


$$
\mathrm{K}_{\mathrm{d}}=\left(\frac{\mathrm{N}_{29.0027}}{\mathrm{~N}_{30.0106}}\right)\left[\frac{\mathrm{K}_{\mathrm{r}}\left(\mathrm{H}_{2} \mathrm{CO}^{+}\right)+1}{\mathrm{~K}_{\mathrm{r}}\left(\mathrm{HCO}^{+}\right)+1}\right] \mathrm{n}_{\mathrm{H}}
$$

Table 6 lists $T_{\text {gas }}$ values from the same measured signals derived from these various possibilities. Here the sample is $1 \%$ aqueous $\mathrm{HNO}_{3}+10 \%$ IPA; the latter additive enhances the abundance of the larger $\mathrm{H}_{\mathrm{x}} \mathrm{CO}^{+}$ions. The entries are grouped according to the various isomers used. Basically, all the measured $\mathrm{T}_{\text {gas }}$ values derived from ZAPT2 data are $\sim 1500 \mathrm{~K}$. All the values from $\operatorname{CCSD}(\mathrm{T})$ data are $~ 2200$ to $2300 \mathrm{~K}$.

The modest difference between $\mathrm{T}_{\text {gas }}$ values derived from ZAPT2 data vs. CCSD(T) data is not considered important. What does matter is that all these temperatures are lower than those found above for $\mathrm{N}_{2} \mathrm{H}^{+} / \mathrm{N}_{2}{ }^{+},\left(\mathrm{HCO}^{+}+\mathrm{COH}^{+}\right) / \mathrm{CO}^{+}$, and a number of other polyatomic ions [3]. One explanation for this discrepancy is that excess $\mathrm{HCOH}^{+}$and/or $\mathrm{H}_{2} \mathrm{CO}^{+}$ ions continues to be made further aft in the supersonic expansion, where the $T_{\text {gas }}$ is expected to be cooler, than is the case for the other species. Perhaps there is a shock wave there $[5,38,39]$. Another possibility is that there is a kinetically favorable route to make $\mathrm{H}_{2} \mathrm{CO}^{+}$ during ion extraction, more so than $\mathrm{HCO}^{+}$or $\mathrm{COH}^{+}$. The measured $\mathrm{T}_{\text {gas }}$ values are still well above those of $\sim 150 \mathrm{~K}$ estimated for a clean supersonic expansion at the skimmer orifice [31].

\section{4. $\mathrm{H}_{2} \mathrm{COH}^{+}$}

The two computational methods yield almost the same energies and a single structure for $\mathrm{H}_{2} \mathrm{COH}^{+}$(Table 7). However, the lowest energy dissociation product is either $\mathrm{HCOH}^{+}$ (according to ZAPT2) or $\mathrm{H}_{2} \mathrm{CO}^{+}$(from $\mathrm{CCSD}(\mathrm{T})$ ). 


$$
\begin{aligned}
& \mathrm{H}_{2} \mathrm{COH}^{+} \rightleftharpoons \mathrm{HCOH}^{+}+\mathrm{H} \\
& \mathrm{H}_{2} \mathrm{COH}^{+} \rightleftharpoons \mathrm{H}_{2} \mathrm{CO}^{+}+\mathrm{H}
\end{aligned}
$$

Although the dissociation energies of $\mathrm{H}_{2} \mathrm{COH}^{+}$are fairly high, it is the least abundant ion from the $\mathrm{H}_{\mathrm{x}} \mathrm{CO}^{+}$family in the mass spectrum.

To observe $\mathrm{H}_{2} \mathrm{COH}^{+}$, a $10 \%$ IPA: $1 \% \mathrm{HNO}_{3}$ in water solution was nebulized. Using the values in Table 7, measured $\mathrm{T}_{\text {gas }}$ values are $3650 \mathrm{~K}$ (ZAPT2) and $3610 \mathrm{~K}(\mathrm{CCSD}(\mathrm{T}))$. These two values are similar to those measured for $\mathrm{N}_{2} \mathrm{H}^{+}$and the $\mathrm{HCO}^{+} / \mathrm{COH}^{+}$systems. The ICP was not obviously different with this dose of isopropanol. The IPA would be expected to cool the plasma, if it had much effect.

The different product ions predicted by the two computational methods make little difference in the diagnosis of the origin of $\mathrm{H}_{2} \mathrm{COH}^{+}$. Inclusion of isomers in the product $\mathrm{H}_{2} \mathrm{CO}^{+} / \mathrm{HCOH}^{+}$also makes only a $100 \mathrm{~K}$ difference in the resulting $\mathrm{T}_{\text {gas }}$ (data not shown).

\subsection{Effect of $\mathrm{T}_{\text {gas }}$ regime on importance of isomers}

Inclusion of isomers does not make much difference in the interpretation of the experimental $\mathrm{T}_{\text {gas }}$ measurements in the above examples. This is largely because the ions studied are observed at abundances well above those expected from the ICP alone, i.e., the $\mathrm{T}_{\text {gas }}$ values that result from the measurements are lower than that expected from the ICP. More energetic isomers are less populated at low temperatures. However, such isomers would be more important if the ions came from a region where $\mathrm{T}_{\text {gas }}$ was larger. To illustrate this effect, the fundamental data (ZAPT2 or CCSD(T)) are used to generate hypothetical ion signal ratios characteristic of two hotter regimes: $\mathrm{T}_{\text {gas }}=4500 \mathrm{~K}$ (often seen for $\mathrm{H}_{\mathrm{x}} \mathrm{O}^{+}$ions from water) and $5800 \mathrm{~K}$ (characteristic of $\mathrm{MO}^{+}$ions) [1,3]. These hypothetical signal ratios are then 
used in different spreadsheets that include the isomers. The resulting change in $\mathrm{T}_{\text {gas }}$ indicates whether the isomers matter.

First, the simple reaction

$$
\mathrm{HCOH}^{+} \rightleftharpoons \mathrm{HCO}^{+}+\mathrm{H} \quad \mathrm{T}_{\mathrm{gas}}=4500 \mathrm{~K} \text { or } 5800 \mathrm{~K} \text { assumed }
$$

was examined using ZAPT2 fundamental data. This system is chosen because the isomers have similar energies. The apparent temperature changed, first from $4500 \mathrm{~K}$ to $5300 \mathrm{~K}$, then from $5800 \mathrm{~K}$ to $7330 \mathrm{~K}$, when the same signal ratios were used with all the likely isomers included:

$$
\begin{aligned}
& \mathrm{HCOH}^{+} \rightleftharpoons \mathrm{H}_{2} \mathrm{CO}^{+} \rightleftharpoons \mathrm{HCO}^{+} \rightleftharpoons \mathrm{COH}^{+} \\
& +\mathrm{H}
\end{aligned}
$$

The related reaction was also studied using $\operatorname{CCSD}(\mathrm{T})$ data:

$$
\mathrm{H}_{2} \mathrm{CO}^{+} \rightleftharpoons \mathrm{HCO}^{+}+\mathrm{H} \quad \mathrm{T}_{\mathrm{gas}}=4500 \mathrm{~K} \text { or } 5800 \mathrm{~K} \text { assumed }
$$

Again, the apparent temperatures changed; 4500 became $5260 \mathrm{~K}$, and $5800 \mathrm{~K}$ became 7250 $\mathrm{K}$, when the more complicated reaction was used:

$$
\begin{aligned}
& \mathrm{H}_{2} \mathrm{CO}^{+} \rightleftharpoons \mathrm{HCOH}^{+} \rightleftharpoons \mathrm{HCO}^{+} \rightleftharpoons \mathrm{COH}^{+} \\
& +\mathrm{H}
\end{aligned}
$$

$\mathrm{T}_{\text {gas }}$ values $\sim 5800 \mathrm{~K}$ vs. $\sim 7300 \mathrm{~K}$ would lead to quite different diagnoses as to the origin of the ions. So the presence of isomers can make a difference in temperature regimes close to those of the ICP, although this is not an issue for the polyatomic ions studied here.

\section{Acknowledgements}

This research was supported by the National Science Foundation (Award No. CHE0309381) through the Institute for Physical Research and Technology at ISU. JWF was also 
supported by the Velmer A. and Mary K. Fassel Fellowship, and SMM is supported by the Conoco Phillips Fellowship. The nebulizers used were provided by Elemental Scientific Inc. The ICP-MS device was obtained with funds provided by the U. S. Department of Energy, Office of Nuclear Nonproliferation (NA-22) and the Office of Basic Energy Sciences. Ames Laboratory is operated for the U.S. Department of Energy by Iowa State University under Contract No. W-7405-Eng-82. 


\section{References}

1. R. S. Houk, N. Praphairaksit, Dissociation of polyatomic ions in the inductively coupled plasma, Spectrochim. Acta Part B 56 (2001) 1069-1096.

2. R. S. Houk, Erratum to "Dissociation of polyatomic ions in inductively coupled plasma mass spectrometry,” Spectrochim. Acta Part B 61 (2006) 235-236

3. J. W. Ferguson, R. S. Houk, High resolution studies of the origins of polyatomic ions in inductively coupled plasma - mass spectrometry part I: identification methods and effects of neutral density assumptions, extraction voltage, and cone material, Spectrochim. Acta Part B, 61 (2006) 905-915.

4. H. Niu, R. S. Houk, Fundamental aspects of ion extraction in inductively coupled plasma mass spectrometry, Spectrochim. Acta Part B 51 (1996) 779-815.

5. A. L Gray, Visual observation of shock waves in an ICP-MS expansion stage, J. Anal. At. Spectrom. 4 (1989) 371-373.

6. N. Nonose, M. Kubota, Non-spectral and spectral interferences in inductively coupled plasma high resolution mass spectrometry Part I: optical characteristics, J. Anal. At. Spectrom. 16 (2001) 551-559.

7. N. Nonose, M. Kubota, Non-spectral and spectral interferences in inductively coupled plasma high resolution mass spectrometry Part II:comparison of interferences in quadrupole and high resolution, J. Anal. At. Spectrom. 16 (2001) 560-566.

8. N. Nonose, Formation of interfering polyatomic ion species in ICP-MS, J. Mass Spectrom. Soc. Jpn. 45 (1997) 77-89. 
9. S.D. Tanner, Plasma temperature from ion kinetic energies and implications for the source of diatomic oxide ions in inductively coupled plasma-mass spectrometry, J. Anal. At. Spectrom. 8 (1993) 891-897.

10. J.S. Becker, H.-J. Dietze, Investigations on cluster and molecular ion formation by plasma mass spectrometry, Fresenius' J. Anal. Chem. 359 (1997) 338-345.

11. E. H. Evans, L. Ebdon, L. Rowley, Comparative study of the determination of equilibrium dissociation temperature in inductively coupled plasma-mass spectrometry, Spectrochim. Acta Part B 57 (2002) 741-754.

12. M.M. Fraser, D. Beauchemin, Effect of concomitant elements on the distribution of ions in inductively coupled plasma-mass spectrometry—Part 2: polyatomic ions, Spectrochim. Acta Part B 57 (2001) 2479-2495.

13. A.E. Holliday, D. Beauchemin, Spatial profiling of ion distributions in a nitrogen-argon plasma in inductively coupled plasma-mass spectrometry, J. Anal. At. Spectrom. 18 (2003) 289-295.

14. N.F. Zahran, A.I. Helal, M.A. Amr, A. Abdel-Hafiez, H.T. Mohsen, Formation of polyatomic ions from the skimmer cone in ICP-MS, Int. J. Mass Spectrom. 226 (2003) 271-278. 15. S. Liu, D. Beauchemin, The effect of pre-evaporation on ion distribution in inductively coupled plasma mass spectrometry, Spectrochim. Acta Part B 61 (2006) 157-163.

16. K. C. Sears, J. W. Ferguson, T. J. Dudley, R. S. Houk, M. S. Gordon, Theoretical investigation of small polyatomic ions observed in inductively coupled plasma mass spectrometry: $\mathrm{H}_{\mathrm{x}} \mathrm{CO}^{+}$and $\mathrm{H}_{\mathrm{x}} \mathrm{N}_{2}^{+}(x=1,2,3)$, J. Phys. Chem. A 112 (2008) 2610-2617. 
17. J. Crovisier, Constants for molecules of astrophysical interest in the gas phase: photodissociation, microwave and infrared spectra. Version 4.2 (May 2002), http://wwwusr.obspm.fr/ crovisie/basemole/.

18. S. D. Tanner, Plasma temperature from ion kinetic energies and implications for the source of diatomic oxide ions in ICP-MS, J. Anal. At. Spectrom. 8 (1993) 891-897.

19. D. J. Douglas, Some current perspectives on ICP-MS, Canad. J. Spectrosc. 34 (1989) 3849.

20. J. E. Fulford and D. J. Douglas, Ion kinetic energies in ICP-MS, Appl. Spectrosc. 1986 (40) 971-974.

21. J. B. Olsen, J. H. Macedone and P. B. Farnsworth, Source gas kinetic temperatures in an ICP-MS determined by measurements of the gas velocities in the first vacuum stage, J. Anal. Atomic Spectrom. 21 (2006) 856-860.

22. T. Hasegawa, M. Umemoto, H. Haraguchi, C. Hsieh and A. Montaser, Fundamental properties of ICPs, in A. Montaser and D. W. Golightly, Eds., ICPs in analytical atomic spectrometry, $2^{\text {nd }}$ ed., VCH, New York, Sect. 8.2.3, p. 386 (1992).

23. I. Ishii and A. Montaser, A tutorial discussion on measurement of rotational temperatures in an ICP, Spectrochim. Acta Part B 46 (1991) 1197-1206.

24. S. A. Lehn, K. A. Warner, M. Huang and G. M. Hieftje, Effect of an ICP-MS sampling interface on electron temperature, electron number density, gas-kinetic temperature and analyte emission intensity upstream in the plasma, Spectrochim. Acta Part B 57 (2002) 17391751.

25. H. G. C. Human and R. H. Scott, The shapes of spectral lines emitted by an ICP, Spectrochim. Acta part B 31 (1976) 459-473. 
26. P. W. J. M Boumans and J. J. A. M. Vrakking, The widths and shapes of about 350 prominent lines of 65 elements emitted by an ICP, Spectrochim. Acta Part B 41 (1986) 12351275.

27. L. M. Faires, B. A. Palmer and J. W. Brault, Line widths and line shape analysis in the ICP by high resolution Fourier transform spectrometry, Spectrochim. Acta Part B 40 (1985) $135-143$.

28. J. W. Olesik, Investigating the fate of individual sample droplets in ICPs, Appl. Spectrosc. 51 (1997) 158A-175A.

29. V.F. Taylor, R.E. March, H.P. Longerich, C.J. Stadey, A mass spectrometric study of glucose, sucrose, and fructose using an inductively coupled plasma and electrospray ionization, Int. J. Mass Spectrom. 243 (2005) 71-84.

30. H. C. Beijerinck, R. J. F. van Gerwen, E. R. T. Kerstel, J. F. M. Martens, E. J. W. Van Vliembergen, M. R. Th. Smits and G. H Kaashoek, Campargue-type supersonic beam sources: absolute intensities, skimmer transmission and scaling laws for mono-atomic gases He, Ne and Ar, Chem. Phys. 96 (1985) 153-173.

31. D. J. Douglas, J. B. French, Gas dynamics of the inductively coupled plasma mass spectrometry interface, J. Anal. Atom. Spectrom. 3 (1988) 743-747.

32. R. L. Spencer, J. Krogel, J. Palmer, A. Payne, A. Sampson and C. N. Woods, Modeling the gas flow upstream and in the sampling nozzle of the inductively coupled plasma mass spectrometer via the direct simulation Monte Carlo algorithm, Spectrochim. Acta Part B 2009 in press.

33. M. W. Schmidt, K. K. Baldridge, J. A. Boatz, S. T. Elbert, M. S. Gordon, J. H. Jensen, S. Koseki, N. Matsunaga, K. A. Nguyen, S. Su, T. L. Windus, M. Dupuis, J. A. Montgomery, 
Jr., General atomic and molecular electronic structure system, J. Comp. Chem. 14 (1993) 1347-1363; M.S. Gordon, M.W. Schmidt, “Advances in Electronic Structure Theory: GAMESS a Decade Later", Theory and Applications of Computational Chemistry, Ch.. 41, C. E. Dykstra, G. Frenking, K.S. Kim, G.E. Scuseria, Eds., Elsevier, 2005.

34. NIST Chemistry Webbook, Vibrational and/or electronic energy levels. http://webbook.nist.gov

35. J. Liu, B. Uselman, B. Van Devener, S. L. Anderson, Vibrational mode effects as a probe of inter-channel coupling in the reactions of formaldehyde cation with ammonia and water, J. Phys. Chem. A 108 (2004) 9945-9956.

36. P. Blowers, R. I. Masel, Calculated vibrational spectra for $\mathrm{CH}_{\mathrm{n}} \mathrm{OH}_{\mathrm{m}}$ species, J. Phys. Chem A 104 (2000) 34-44.

37. S. M. McIntyre, Ph.D. dissertation, Iowa State University, 2010.

38. H. Niu and R. S. Houk, Langmuir probe measurements of the ion extraction process in ICP-MS. I. Spatially resolved measurements of electron density and electron temperature, Spectrochim. Acta Part B 49 (1994) 1283-1303.

39. T. N. Olney, W. Chen and D. J. Douglas, Gas dynamics of the ICP-MS interface: impact pressure probe measurements of gas flow profiles, J. Anal. At. Spectrom. 14 (1999) 9-17. 


\section{Tables}

Table 1. Experimental conditions

$\begin{array}{ll}\text { Resolution } & \text { Medium }(\mathrm{m} / \Delta \mathrm{m} \approx 4000), \text { except where otherwise stated } \\ \text { Nebulizer } & \text { Elemental Scientific Inc. PFA } 100 \mu \mathrm{L} / \mathrm{min} \\ & \text { or } 20 \mu \mathrm{L} / \mathrm{min} \text { as needed } \\ \text { Spray Chamber } & \text { Teflon Scott type double pass } \\ \text { Cones } & \text { Nickel sampler (1.0 mm hole diam.) } \\ & \text { and skimmer ("H” geometry, } 0.8 \mathrm{~mm} \text { diam.) } \\ & \text { Sampler skimmer spacing } 9.2 \mathrm{~mm} \\ \text { Power } & 1200 \mathrm{~W}\end{array}$

Gas flow rates (L/min):

Outer gas 15

Auxiliary gas $\quad 1.0$

Aerosol gas $\quad 1.0$ to 1.1

Optimized daily to maximize $\mathrm{M}^{+}$signal

Solutions Standards in $1 \%$ nitric acid. Other solutions used as indicated.

Torch Fassel type, $20 \mathrm{~mm}$ OD

Shielded with shield grounded

Sampling $\quad 12 \mathrm{~mm}$ downstream from load coil

Position On center 
Table 2. Calculated properties of $\mathrm{N}_{2} \mathrm{H}^{+}$by ZAPT2 and CCSD(T) theory.

ZAPT2

Dissociation Energy (eV)

to $\mathrm{N}_{2}^{+}+\mathrm{H}$

Vibrational

Frequencies $\left(\mathrm{cm}^{-1}\right)$

Rotational Constant $\left(\mathrm{cm}^{-1}\right)$
6.891

731.87

731.87

2151.1

3418.2

1.536
$\operatorname{CCSD}(\mathrm{T})$

7.449

732.58

732.58

2283.9

3434.9

1.557 
Table 3. Calculated properties of $\mathrm{HCO}^{+}, \mathrm{COH}^{+}$, and $\mathrm{CO}^{+}$.

ZAPT2

Dissociation Energy to $\mathrm{CO}^{+}(\mathrm{eV}) \quad \frac{\underline{\mathrm{HCO}^{+}}}{6.929} \quad \frac{\underline{\mathrm{COH}^{+}}}{2.03} \quad \underline{\mathrm{CO}^{+}}$

Vibrational

859.76

321.80

2115.1

Frequencies $\left(\mathrm{cm}^{-1}\right)$

859.76

321.80

2150.4

1761.9

3251.4

3349.4

Rotational Constant $\left(\mathrm{cm}^{-1}\right)$

1.536

1.487

1.960

$\operatorname{CCSD}(\mathrm{T})$

Dissociation Energy to $\mathrm{CO}^{+}(\mathrm{eV}) \quad \frac{\underline{\mathrm{HCO}^{+}}}{6.925} \quad \frac{\underline{\mathrm{COH}^{+}}}{1.75} \quad \underline{\mathrm{CO}^{+}}$

Vibrational

861.84

149.43

2203.1

Frequencies $\left(\mathrm{cm}^{-1}\right)$

861.84

149.43

2212.3

1942.6

3327.1

3482.8

Rotational Constant $\left(\mathrm{cm}^{-1}\right)$ 
Table 4. $\mathrm{T}_{\text {gas }}$ results for $\mathrm{HCO}^{+} \mathrm{COH}^{+} \mathrm{CO}^{+}$system, $1 \%$ aqueous $\mathrm{HNO}_{3}+10 \%$ IPA.

Comp.

$\underline{\text { Reaction }}$

$\mathrm{HCO}^{+} \rightleftharpoons \mathrm{CO}^{+}+\mathrm{H}$

$\mathrm{HCO}^{+} \rightleftharpoons \mathrm{CO}^{+}+\mathrm{H}$

$\mathrm{HCO}^{+} \rightleftharpoons \mathrm{COH}^{+} \rightleftharpoons \mathrm{CO}^{+}+\mathrm{H}$

$\mathrm{COH}^{+} \rightleftharpoons \mathrm{CO}^{+}+\mathrm{H}$

$\mathrm{COH}^{+} \rightleftharpoons \mathrm{CO}^{+}+\mathrm{H}$
Method $\quad \underline{\mathrm{T}}_{\text {gas }}(\mathrm{K})$

ZAPT2 4710

$\operatorname{CCSD}(\mathrm{T}) \quad 4710$

ZAPT2 4710

$\operatorname{CCSD}(\mathrm{T}) \quad 4710$

ZAPT2 1590

$\operatorname{CCSD}(\mathrm{T}) \quad 1510$ 
Table 5. Calculated properties of $\mathrm{HCOH}^{+}$and $\mathrm{H}_{2} \mathrm{CO}^{+}$.

\begin{tabular}{|c|c|c|}
\hline ZAPT2 & $\underline{\mathrm{HCOH}}^{+}$ & $\underline{\mathrm{H}}_{2} \underline{\mathrm{CO}}^{+}$ \\
\hline Dissociation Energy to $\mathrm{HCO}^{+}(\mathrm{eV})$ & 0.845 & 0.13 \\
\hline Vibrational & 971.65 & 856.28 \\
\hline Frequencies $\left(\mathrm{cm}^{-1}\right)$ & 1001.5 & 1114.1 \\
\hline & 1248.9 & 1321.9 \\
\hline & 1727.8 & 1633.3 \\
\hline & 3122.0 & 2898.2 \\
\hline & 3497.4 & 3045.6 \\
\hline Rotational Constant $\mathrm{x}\left(\mathrm{cm}^{-1}\right)$ & 13.74 & 8.861 \\
\hline Rotational Constant y $\left(\mathrm{cm}^{-1}\right)$ & 1.271 & 1.348 \\
\hline Rotational Constant $\mathrm{z}\left(\mathrm{cm}^{-1}\right)$ & 1.167 & 1.174 \\
\hline $\operatorname{CCSD}(\mathrm{T})$ & $\underline{\mathrm{H}}_{2} \underline{\mathrm{CO}}^{+}$ & $\underline{\mathrm{HCOH}^{+}}$ \\
\hline Dissociation Energy to $\mathrm{HCO}^{+}(\mathrm{eV})$ & 1.378 & 0.23 \\
\hline Vibrational & 855.58 & 969.57 \\
\hline Frequencies $\left(\mathrm{cm}^{-1}\right)$ & 1071.0 & 1000.8 \\
\hline & 1272.6 & 1254.5 \\
\hline & 1663.2 & 1691.7 \\
\hline & 2811.4 & 3076.9 \\
\hline & 2920.5 & 3515.4 \\
\hline Rotational Constant $\mathrm{x}\left(\mathrm{cm}^{-1}\right)$ & 8.917 & 13.68 \\
\hline Rotational Constant y $\left(\mathrm{cm}^{-1}\right)$ & 1.327 & 1.264 \\
\hline Rotational Constant $\mathrm{z}\left(\mathrm{cm}^{-1}\right)$ & 1.160 & 1.160 \\
\hline
\end{tabular}


Table 6. Measured $\mathrm{T}_{\text {gas }}$ values for $\mathrm{HCOH}^{+} \mathrm{H}_{2} \mathrm{CO}^{+} \mathrm{HCO}^{+}$system, $1 \% \mathrm{HNO}_{3}+10 \%$ IPA Comp.

\begin{tabular}{|c|c|c|}
\hline Reaction & Method & $\underline{\mathrm{T}}_{\mathrm{gas}}(\mathrm{K})$ \\
\hline $\mathrm{HCOH}^{+} \rightleftharpoons \mathrm{HCO}^{+}+\mathrm{H}$ & ZAPT2 & 1500 \\
\hline $\mathrm{H}_{2} \mathrm{CO}^{+} \rightleftharpoons \mathrm{HCO}^{+}+\mathrm{H}$ & $\operatorname{CCSD}(\mathrm{T})$ & 2180 \\
\hline $\mathrm{HCOH}^{+} \rightleftharpoons \mathrm{HCO}^{+}+\mathrm{H}$ & ZAPT2 & 1500 \\
\hline \multicolumn{3}{|l|}{$\mathrm{HCO}^{+} \rightleftharpoons \mathrm{COH}^{+}$} \\
\hline $\mathrm{HCOH}^{+} \rightleftharpoons \mathrm{HCO}^{+}+\mathrm{H}$ & ZAPT2 & 1540 \\
\hline \multicolumn{3}{|l|}{$\mathrm{HCOH}^{+} \rightleftharpoons \mathrm{H}_{2} \mathrm{CO}^{+}$} \\
\hline \multicolumn{3}{|l|}{$\mathrm{HCO}^{+} \rightleftharpoons \mathrm{COH}^{+}$} \\
\hline $\mathrm{HCOH}^{+} \rightleftharpoons \mathrm{HCO}^{+}+\mathrm{H}$ & ZAPT2 & 1540 \\
\hline \multicolumn{3}{|l|}{$\mathrm{HCOH}^{+} \rightleftharpoons \mathrm{H}_{2} \mathrm{CO}^{+}$} \\
\hline $\mathrm{H}_{2} \mathrm{CO}^{+} \rightleftharpoons \mathrm{HCO}^{+}+\mathrm{H}$ & $\operatorname{CCSD}(\mathrm{T})$ & 2280 \\
\hline \multicolumn{3}{|l|}{$\mathrm{H}_{2} \mathrm{CO}^{+} \rightleftharpoons \mathrm{HCOH}^{+}$} \\
\hline \multicolumn{3}{|l|}{$\mathrm{HCO}^{+} \rightleftharpoons \mathrm{COH}^{+}$} \\
\hline $\mathrm{H}_{2} \mathrm{CO}^{+} \rightleftharpoons \mathrm{HCO}^{+}+\mathrm{H}$ & $\operatorname{CCSD}(\mathrm{T})$ & 2280 \\
\hline
\end{tabular}


Table 6 continued

Comp.

$\underline{\text { Reaction }}$

$\underline{\text { Method }} \underline{\mathrm{T}}_{\text {gas }}(\mathrm{K})$

$\mathrm{H}_{2} \mathrm{CO}^{+} \rightleftharpoons \mathrm{HCO}^{+}+\mathrm{H}$

CCSD(T) 2180

$\mathrm{HCO}^{+} \rightleftharpoons \mathrm{COH}^{+}$ 
Table 7. Calculated properties of $\mathrm{H}_{2} \mathrm{COH}^{+}$by ZAPT2 and CCSD(T) methods

$\begin{array}{lll}\text { Dissociation Energy }(\mathrm{eV}) & 5.341 & 5.17 \\ \left(\text { to } \mathrm{HCOH}^{+}\right) & \left(\text {to } \mathrm{H}_{2} \mathrm{CO}^{+}\right) \\ \text {Vibrational frequencies }\left(\mathrm{cm}^{-1}\right) & 1054.3 & 1038.3 \\ & 1123.8 & 1121.0 \\ & 1266.3 & 1246.8 \\ & 1396.3 & 1400.4 \\ & 1510.3 & 1488.7 \\ & 1688.9 & 1663.2 \\ \text { Rotational Constant } \mathrm{x}\left(\mathrm{cm}^{-1}\right) & 3150.5 & 3109.5 \\ \text { Rotational Constant } \mathrm{y}\left(\mathrm{cm}^{-1}\right) & 3301.4 & 3255.5 \\ \text { Rotational Constant } \mathrm{z}\left(\mathrm{cm}^{-1}\right) & 3610.0 & 3620.4 \\ & & \\ & 6.658 & 6.637 \\ & 1.153 & 1.146 \\ & 0.9869 & 0.9800\end{array}$




\section{Figures}

\section{Captions}

Figure 1: Medium resolution spectrum of $\mathrm{CO}^{+}$(left or low mass peak) and $\mathrm{N}_{2}^{+}$(right or high mass peak) from $1 \%$ nitric acid.

Figure 2: Medium resolution spectrum of $\mathrm{HCO}^{+}$(left or low mass peak) and $\mathrm{N}_{2} \mathrm{H}^{+}$(right or high mass peak) from $1 \%$ nitric acid.

Figure 1

\section{$1 \%$ Nitric Acid in Medium Resolution}

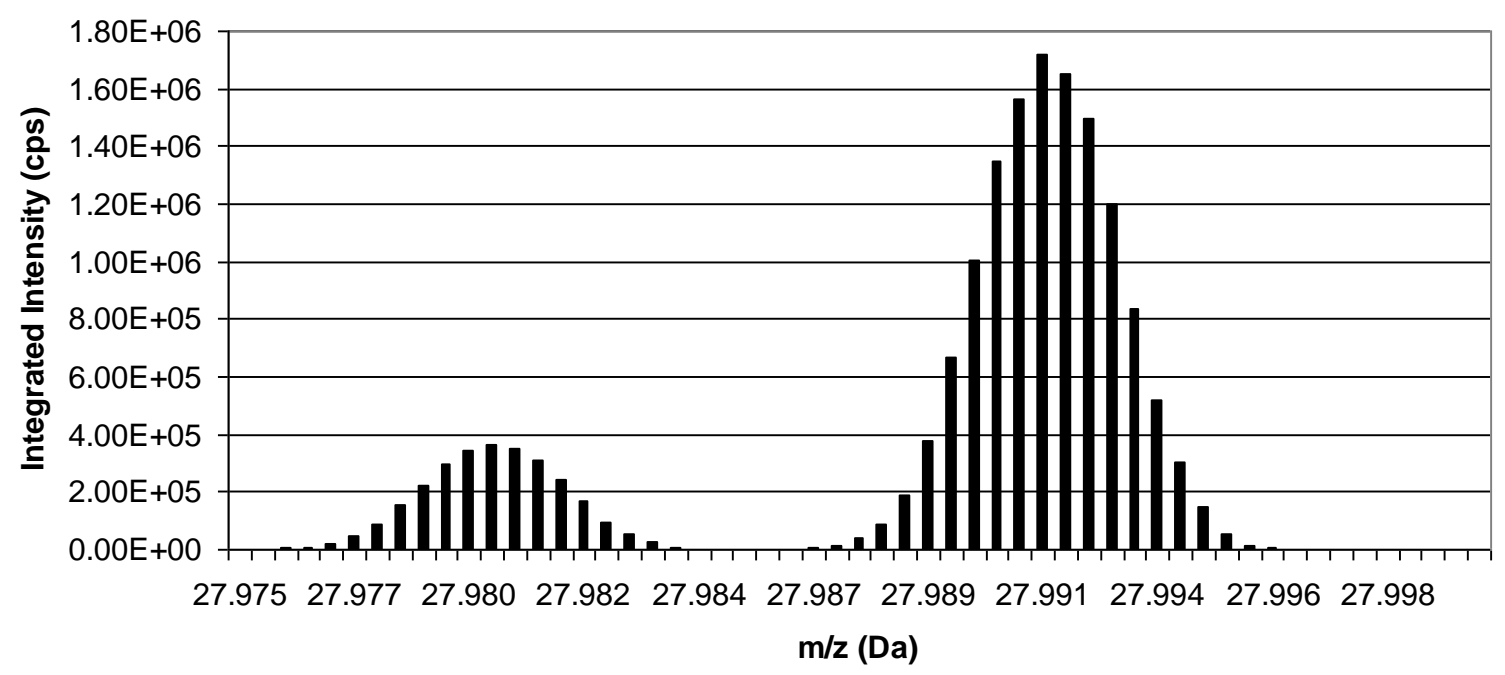

Figure 1: Medium resolution spectrum of $\mathrm{CO}^{+}$(left or low mass peak) and $\mathrm{N}_{2}{ }^{+}$(right or high mass peak) from $1 \%$ nitric acid. 
Figure 2

\section{1\% Nitric Acid in Medium Resolution}

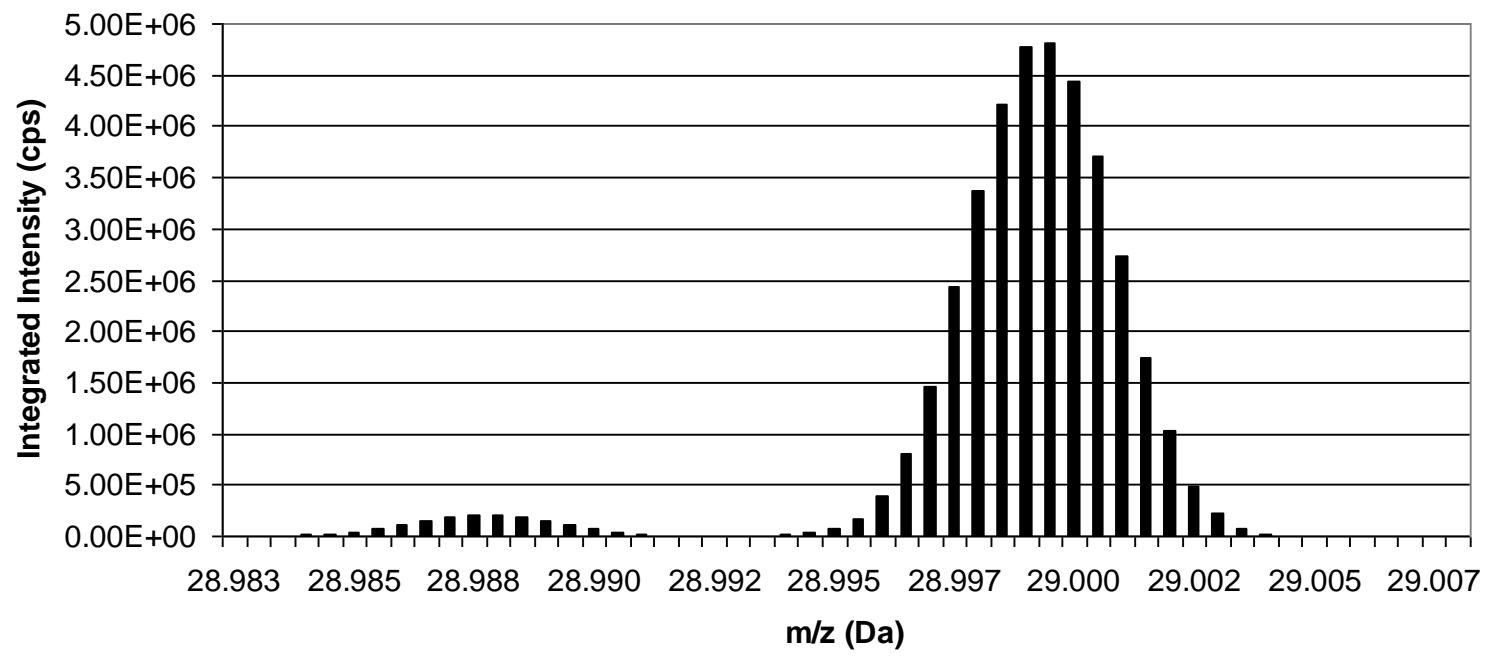

Figure 2: Medium resolution spectrum of $\mathrm{HCO}^{+}$(left or low mass peak) and $\mathrm{N}_{2} \mathrm{H}^{+}$(right or high mass peak) from $1 \%$ nitric acid. 


\title{
Appendix B.
}

\section{Reduction of Matrix Effects in Inductively Coupled Plasma Mass Spectrometry \\ by Flow Injection with an Unshielded Torch}

Cory T. Gross, Sally M. McIntyre and R.S. Houk

\author{
Ames Laboratory U. S. Department of Energy \\ Department of Chemistry
}

Iowa State University, Ames, Iowa 50011 USA

A paper published in Analytical Chemistry, 2009, 81, 4898-4905. 


\begin{abstract}
Solution samples with matrix concentrations above $\sim 0.1 \%$ generally present difficulties for analysis by inductively coupled plasma mass spectrometry (ICP-MS) due to cone clogging and matrix effects. Flow injection (FI) is coupled to ICP-MS to reduce deposition from samples such as $1 \%$ sodium salts (as $\mathrm{NaCl})$ and seawater ( 3\% dissolved salts). Surprisingly, matrix effects are also less severe during flow injection, at least for some matrix elements on the particular instrument used. Sodium chloride at $1 \% \mathrm{Na}$ and undiluted seawater cause only 2 to $29 \%$ losses of signal for typical analyte elements. A heavy matrix element (Bi) at $0.1 \%$ also induces only $\sim 14 \%$ loss of analyte signal. However, barium causes a much worse matrix effect, i. e., $~ 90 \%$ signal loss at 5000 ppm Na. Also, matrix effects during FI are much more severe when a grounded metal shield is inserted between the load coil and torch, which is the most common mode of operation for the particular ICP-MS device used.
\end{abstract}

\title{
Introduction
}

ICP-MS is a sensitive and accurate means to determine the trace element content of solutions. Unfortunately, the analyte signal depends not only on analyte concentration but also on the concentration and identity of matrix elements. Many previous studies show that matrix elements usually suppress analyte sensitivity. ${ }^{1-10}$ Such signal losses are usually blamed mainly on space charge effects as the ions leave the skimmer. ${ }^{111-13 .}$ However, signal enhancements caused by matrix elements are occasionally seen. ${ }^{14}$ Solid materials from the 
sample matrix also coat onto the sampler and/or skimmer cone, which is one cause of signal drift.

Internal standardization is commonly used to correct for these problems. In general, the quality of the internal standardization correction is best if the extent of change of analyte signal with matrix concentration is less severe. Since the magnitude of the matrix effect varies with the atomic weight of the analyte ion, ${ }^{4,15}$ several different internal standard elements that span the $\mathrm{m} / \mathrm{z}$ range are usually added to correct for matrix effects in multielement analysis.

For these reasons, the total solute content of the sample is usually restricted to no more than $0.1 \%$ in ICP-MS. Chemical separations for matrix removal and/or analyte preconcentration are one option for analyzing samples with higher matrix levels. ${ }^{16-21}$ Analyzing the sample directly is preferable because it is simpler, faster and better suited to the determination of more elements. Alternative procedures that attenuate matrix effects and cone clogging could allow more routine measurements at lower dilution factors, which would have various scientific benefits.

Introduction of only a discrete plug of sample solution by FI attenuates cone clogging. ${ }^{22,23}$ Indeed, the matrix effect experiments in the first ICP-MS paper required FI because the pinhole sampler (60 $\mu \mathrm{m}$ diam.) clogged easily. ${ }^{24}$ Memory effects are also reduced by FI, and sample rinse-out times are shortened. Field et al. ${ }^{25}$ have recently demonstrated the use of a new, commercial FI system with a magnetic sector instrument for fast analysis of seawater, a difficult matrix. They dilute the sample tenfold to attenuate matrix effects and salt deposition on the cones; addition of glucose also helps reduce deposition. The sector instrument still provides sufficient sensitivity for the intended application, the quantification of 
diagnostic elements to trace exhaust of ballast by ocean-going ships. The present work describes recent experiments that indicate that the matrix effect can also be attenuated by FI, at least for one type of instrument and certain sample matrices.

\section{Experimental Section}

ICP-MS Instrumentation. These experiments were performed on a quadrupole ICP-MS (HP 4500, now Agilent, Santa Clara, CA). The operating parameters (Table 1) were selected in the following fashion. First, lens voltages, power, sample gas flow rate, sampling position, and other parameters were selected to maximize signal for ${ }^{7} \mathrm{Li}^{+},{ }^{89} \mathrm{Y}^{+}$and ${ }^{205} \mathrm{Tl}^{+}$. The sample gas flow rate was then adjusted slightly to give tolerable levels of $\mathrm{CeO}^{+}(\sim 2 \%)$ and $\mathrm{Ce}^{2+}\left(\sim 1 \%\right.$, relative to $\left.\mathrm{Ce}^{+}\right)$from clean, multielement standards. Under these conditions, this instrument typically gives about the same count rates for ${ }^{89} \mathrm{Y}^{+}$and ${ }^{205} \mathrm{Tl}^{+}$from the $10 \mathrm{ppb}$ tuning solution. Sensitivity for $\mathrm{Ce}^{+}$is often about $50 \%$ higher than that for $\mathrm{Y}^{+}$and $\mathrm{Tl}^{+}$, for reasons that are unclear. The optimum lens voltages found in this fashion were almost the same from day to day throughout the course of these experiments and were typical of those that provide maximum signal for other users of this type of instrument.

The standard, reversed load coil ${ }^{26}$ supplied with the instrument was used. The torch was not shielded (i.e., the shield was not present) in all except the last result reported below.

FI and Sample Introduction. The Babington nebulizer originally supplied with the instrument was replaced with a microconcentric nebulizer (PFA-100, Elemental Scientific Inc., Omaha, NE, nominal uptake rate $\sim 100 \mu \mathrm{L} / \mathrm{min}$ ). The glass spray chamber was the standard double pass type, ${ }^{27}$ internal volume $\sim 70 \mathrm{~mL}$, cooled to $2^{\circ} \mathrm{C}$. 
FI was performed with an autosampler equipped with a programmable sample valve and loops (Model FAST SC-2, Elemental Scientific Inc., Omaha, NE). ${ }^{25}$ This device featured an onboard vacuum pump to fill the $100 \mu \mathrm{L}$ sample loop. Small segments of the loop were then injected for 1,5 or 10 seconds via a computer controlled injection valve. Thus, the volumes injected were $1.7,8.3$ or $17 \mu \mathrm{L}$; these volumes are smaller than those common with this FI system. The sample plug emerging from the loop is unsegmented and is driven by the carrier $\left(1 \%\right.$ aqueous $\left.\mathrm{HNO}_{3}\right)$ behind it. To minimize dispersion, the loop and valve were mounted as close to the nebulizer as possible; the dead volume in the liquid between loop and nebulizer was only $\sim 20 \mu \mathrm{L}$.

Sample Preparation and Standard Solutions. One set of samples was prepared by dissolving weighed amounts of solid $\mathrm{NaCl}$ (certified A.C.S. grade, Fisher Scientific, Fair Lawn, NJ) into a multielement standard solution (Spex Certiprep, Metuchen NJ) containing $10 \mathrm{ppb}$ of various analytes, including $\mathrm{Li}, \mathrm{Sc}, \mathrm{Y}, \mathrm{Ce}$, and $\mathrm{Tl}$. These elements were chosen to span most of the elemental mass range. Final matrix concentrations were 1000, 2000, 5000, and 10,000 ppm Na.

The second group of solutions was prepared using a coastal seawater reference material (CASS-1, $\sim 3.2 \%$ total salts, acidified to $\mathrm{pH} 1.6$ with nitric acid by the supplier, Marine Analytical Chemistry Standards Program, Division of Chemistry, National Research Council of Canada (NRCC), Ottawa, ON, Canada). The expected concentrations of the major cations were approximately 10,000 ppm Na, 1000 ppm Mg, 500 ppm Ca and 340 ppm K. ${ }^{28}$ This sample was diluted to varying degrees: 10x, 5x, or 2x. One portion of seawater was left undiluted. Each of these solutions were also spiked with $10 \mathrm{ppb}$ of the same multielement standard described in the previous paragraph. The seawater sample was spiked to minimize 
possible contributions from polyatomic ions in subsequent measurements of matrix effects. Again, signals from the seawater samples were compared to those from the $10 \mathrm{ppb}$ clean multielement standard. These seawater samples all contained $1 \%$ aqueous $\mathrm{HNO}_{3}$.

The $\mathrm{Ba}$ matrix samples were prepared by dissolving weighed amounts of solid $\mathrm{BaCl}_{2}$ (certified A.C.S grade, Fisher Scientific, Fair Lawn, NJ) into the same multielement standard described in the $\mathrm{NaCl}$ preparation. Final Ba matrix concentrations were $1000 \mathrm{ppm}, 5000$ ppm, and 10,000 ppm. Bismuth matrix samples were prepared using a 1000 ppm Bi elemental standard solution (PlasmaChem, Bradley Beach, NJ). The 1000 ppm Bi and a 500 ppm dilution were spiked with $5 \mathrm{ppb}$ of $\mathrm{Li}, \mathrm{Sc}, \mathrm{Y}, \mathrm{Ce}$, and $\mathrm{Tl}$.

Matrix blanks containing only $\mathrm{NaCl}, \mathrm{BaCl}_{2}$, or the $\mathrm{Bi}$ matrix were also prepared and analyzed; none of these matrix blanks contained appreciable analyte compared to the $10 \mathrm{ppb}$ spikes. The unspiked seawater sample was analyzed and found to contain negligible amounts of the analyte elements except $\mathrm{Li}$, which is typically present at $\sim 0.15 \mathrm{ppm}$ in seawater. $^{29}$ Thus, the effect of dilution factor on Li sensitivity was not measured in seawater. All dilutions were performed with distilled deionized water (18 M $\Omega$, Nanopure-II, Barnstead Co., Newton, MA). All solutions were acidified to $1 \% \mathrm{HNO}_{3}$ (A.C.S. reagent grade plus, Fisher, Fair Lawn, NJ).

Data Acquisition. Samples were loaded into the sample rack of the autosampler, which was programmed to fill the sample loop and open the injection valve for the appropriate length of time. When the sample was not being injected a $100 \mu \mathrm{l} / \mathrm{min}$ carrier flow of $1 \%$ $\mathrm{HNO}_{3}$ was continuously nebulized to keep solvent load on the nebulizer and plasma constant.

Data were collected during each injection for the five analyte elements ( $\mathrm{Li}, \mathrm{Sc}, \mathrm{Y}, \mathrm{Ce}$, and $\mathrm{Tl}$ at $\mathrm{m} / \mathrm{z}=7,45,89,140$, and 205 respectively) and presented in time resolved mode. 
The integration period for each $\mathrm{m} / \mathrm{z}$ value was $10 \mathrm{~ms}$, which was fast enough to cover the FI peak for the shortest (1 s) injections tested. After the injection of a sample the sample probe was double rinsed in $1 \% \mathrm{HNO}_{3}$, and the process was repeated. The matrix effect is measured by comparing the steady state signal for each element with matrix present to that from clean standard solutions. Peak areas were used for the $1 \mathrm{~s}$ injections because the signals did not reach the steady state level. Similar experiments were done while measuring only one analyte element at a time to verify that the number of elements measured did not affect the matrix interference results.

\section{Results and Discussion}

Matrix Effects from NaCl. For reference, results obtained during continuous sample introduction are shown first (Figure 1a), using $\mathrm{Tl}$ as the analyte element. Here the FI system was removed and the sample was aspirated by natural uptake at $\sim 100 \mu \mathrm{l} / \mathrm{min}$, the same flow rate used subsequently. Signal is observed between $\sim 35$ and $60 \mathrm{~s}$ after the sample is changed. The solutions were analyzed in order of increasing matrix concentration; the cones were not cleaned between measurements. At $2000 \mathrm{ppm} \mathrm{Na}, \mathrm{Tl}^{+}$signal is suppressed by $\sim 32 \%$. At 10,000 ppm Na, the suppression is worse, and either cone clogging or poor nebulizer performance causes the signal to fall soon after injection. Signals from other, lighter elements are suppressed even more extensively (Table 2).

The general magnitude of signal losses due to the $\mathrm{NaCl}$ matrices for continuous injection (Figure 1a and Table 2) are more or less the norm in ICP-MS. The extent of the signal suppression is a bit less dependent on the atomic weight of the analyte than that seen by many workers. ${ }^{4,15}$ 
Analogous results from FI experiments are described next (Figure 1b). The sample gets to the nebulizer and plasma faster in FI mode because of the shorter connecting tubing from the valve to the nebulizer. For the $1 \mathrm{~s}$ injections (Figure 1b), Na at $5000 \mathrm{ppm}$ causes only $~ 15 \%$ loss of $\mathrm{Tl}^{+}$signal. Similar suppression curves were obtained for 1000 and 2000 ppm Na; the data are not plotted for clarity. The 10,000 ppm Na solution suppresses $\mathrm{Tl}^{+}$signal more extensively, but still only by $\sim 30 \%$.

Injections for 5 and $10 \mathrm{~s}$ (Figures $2 \mathrm{a}$ and $2 \mathrm{~b}$ ) are long enough for the $\mathrm{Tl}^{+}$signal to reach the steady state briefly. The suppressions observed for a given matrix concentration at these longer injections are similar to each other. The rinse-in profiles (i.e., the curve between the initial signal rise and the plateau or steady-state) for these longer injections are almost the same as for continuous nebulization and are characteristic of the time required to replace the blank droplets in the spray chamber with those from the newly-injected sample. ${ }^{27,31}$

In some cases the actual signal levels for a given element differ among the various plots, here and below. These experiments were done over a period of several months to verify their reproducibility. Factors like detector gain, cone condition, and small variations in selection of operating conditions affect the signal seen on a given day. Figures $1 \mathrm{~b}$ and 2 were obtained in the same experiment, so their signals can be compared. The maximum count rates for the clean $\mathrm{Tl}^{+}$standard for the $1 \mathrm{~s}$ injection (Figure 1b) are about half of those for the 5 or $10 \mathrm{~s}$ injections (Figure 2). Thus, the dispersion coefficient ${ }^{30}$ for the $1 \mathrm{~s}$ injections is $\sim 0.5$.

Note also that analyte signals from the matrix blanks are negligible in Figures 1 and 2, so the apparent tolerance to matrix effects is not merely caused by impurities in the matrix compounds. 
Matrix effects from $\mathrm{NaCl}$ for continuous introduction and $\mathrm{FI}$ (5 s injections) are summarized for the five analyte elements in Table 2. Here signal recovery is expressed as the following ratio: (analyte signal from matrix solution/analyte signal from clean solution) $\mathrm{x} 100 \%$. In Table 2, the general magnitude of the matrix effect is about as expected for the control experiments done with continuous flow; the variation of matrix effect with analyte atomic weight will be discussed separately below. When the sample is introduced by FI, the matrix effects for each analyte are still present, but they are much less pronounced.

If the matrix effect is less extensive, perhaps the quality of corrections derived from internal standardization is also improved. Table 3 illustrates this to be the case; a single internal standard element $\left(\mathrm{Y}^{+}\right)$does a much better job of correction for the FI results, especially at higher $\mathrm{Na}$ concentrations. In some cases, the quality of the internal standard corrections approaches the inherent limit of the measurement precision, typically no better than $\sim 2 \%$. Thus, there is less need for multiple internal standard elements with FI.

Matrix Effects in Seawater Samples. Seawater is generally diluted extensively before analysis by ICP-MS; some analyte elements then require chemical matrix removal and/or preconcentration. Compared to the results presented above for a synthetic $\mathrm{NaCl}$ matrix (Figures 1 and 2; Tables 2 and 3), similar improvements in signal recovery are seen with seawater samples during FI. Representative results are shown for $\mathrm{Tl}^{+}$and $\mathrm{Sc}^{+}$in Figure 3. Even for undiluted seawater ( $\sim 3 \%$ total solutes), the $\mathrm{Ce}^{+}$signal is suppressed by only $\sim 26 \%$. The signal recoveries for all analyte elements in seawater are summarized in Table 4 .

Results for $\mathrm{Li}$ in seawater are not shown because the sample had substantial Li originally. Also, the nebulizer performed poorly if straight seawater was nebulized continuously, so matrix effects during continuous nebulization were not evaluated for seawater. Undiluted 
seawater could be injected repeatedly by FI for $10 \mathrm{~s}$ intervals without appreciable signal loss due to cone clogging (data not shown), in general agreement with other observations that FI greatly reduces deposition on the cones. ${ }^{22-24}$

Variation of Matrix Effects with Atomic Weight of Analyte. For a given matrix, many workers find that recoveries for heavier analyte elements (e.g., $\mathrm{Tl}^{+}$) are closer to unity than recoveries for lighter analytes (e.g., $\left.\mathrm{Li}^{+}\right){ }^{4,15}$ This is why the analyte elements were chosen to span most of the $\mathrm{m} / \mathrm{z}$ range. However, this common trend is not prominent in Tables 2 and 4. For example, consider the continuous flow results in Table 2. Only at the highest matrix concentrations is the Li recovery greatly lower than that for $\mathrm{Sc}, \mathrm{Y}$ and $\mathrm{Ce}$. All the analyte elements, including $\mathrm{Li}$, have recoveries of 60 to $70 \%$ at $1000 \mathrm{ppm} \mathrm{Na}$;i and $\mathrm{Tl}$ are suppressed about the same, and more than the other analytes, at 10,000 ppm Na. The recoveries for Sc are consistently as good as, or even better than, those for $\mathrm{Tl}$, for either $\mathrm{NaCl}$ (Table 2) or seawater matrices (Table 4). The expectation is that recovery for Sc would be lower than that for $\mathrm{Tl}^{4,15}$

Effects of Other Matrix Elements. The matrix effect is usually more extensive the greater the atomic weight of the matrix element. ${ }^{4,15}$ Traditionally, this variation is considered to be an attribute of space charge effects. ${ }^{12,13,15}$ Scandium signals from Bi solutions up to 1000 ppm are shown in Figure 4a. The $\mathrm{Sc}^{+}$signal recovery in $1000 \mathrm{ppm} \mathrm{Bi}$ is $\sim 80 \%$, worse than with the Na matrix, but still reasonable.

A similar experiment with Ba matrix (Figure 4b) shows quite a different result. Originally, we thought Ba would simply act as a matrix element with an intermediate atomic weight between that of $\mathrm{Na}$ and $\mathrm{Bi}$. Thus, only small matrix effects were expected during FI. However, Figure $4 \mathrm{~b}$ shows that the matrix effect from $\mathrm{Ba}$ is substantial, more like those nor- 
mally observed. Barium caused similar large matrix effects on the other analyte elements (data not shown).

Why should Ba be different from the other matrix elements studied? It forms substantial numbers of doubly charged ions, and the main ionization form $\left(\mathrm{Ba}^{+}\right)$has accessible electronic states with excitation energies in the visible. The most abundant matrix element (i.e., the $\mathrm{Na}$ in $\mathrm{NaCl}$ or seawater) in the other samples studied lacks these characteristics. For that matter, matrix effects in ICP emission spectrometry caused by alkali metal matrices (e.g., Na and K) differ from those induced by alkaline earth matrices (e.g., Ca). ${ }^{32}$

Matrix Effects with a Shielded Torch. Modern versions of this particular ICP-MS instrument usually use a grounded metal shield inserted between the load coil and torch. This shield reduces capacitive coupling between the load coil and plasma, thus the plasma potential is lower with the shield. ${ }^{1,26,33}$ A lower plasma potential yields ions with a narrower spread of kinetic energy, which can improve sensitivity and is particularly valuable when a collision cell is used to reduce polyatomic ion interferences by kinetic energy discrimination. $^{34}$

To look for possible reasons for the low matrix effects reported above, a few experiments were done with a shielded torch. The effect of $\mathrm{NaCl}$ matrix on $\mathrm{Sc}^{+}$signal with a grounded shield present during FI is shown in Figure 5. Here the same forward power and sampling position are used as in the previous results, but the sample gas flow rate is reduced by $\sim 0.15 \mathrm{~L} / \mathrm{min}$ to re-maximize $\mathrm{Ce}^{+}$, and keep the $\mathrm{CeO}^{+} / \mathrm{Ce}^{+}$and $\mathrm{Ce}^{2+} / \mathrm{Ce}^{+}$signal ratios about the same as before, $\sim 2 \%$ and $\sim 1 \%$, respectively. The need for lower sample gas flow is consistent with the expectation that the actual power reaching the plasma is slightly lower with the shield, as the power that gets to the plasma by capacitive coupling is now dissipated into 
the shield. In our experience, this method of adjusting ICP operating parameters to yield certain values of $\mathrm{MO}^{+} / \mathrm{M}^{+}$and $\mathrm{M}^{2+} / \mathrm{M}^{+}$is an effective way to sample a comparable region of the plasma when some external parameter is altered. Using this optimization criterion, the tip of the sampler cone is typically just 1 or $2 \mathrm{~mm}$ downstream from the end of the initial radiation zone seen when a high concentration of an oxide-forming element like yttrium is introduced, even when large changes to the plasma are made, such as use of the shield.

First, comparison of Figures $4 \mathrm{~b}$ and 5 shows that the shield improves the $\mathrm{Sc}^{+}$signal for the clean standard by $\sim 3 \mathrm{X}$, in agreement with other observations with this make of instrument. ${ }^{33}$ Note also that the matrix effect in Figure 5 is more like that seen in conventional ICP-MS experiments, i.e., 40\% signal loss at 1000 ppm Na, 90\% signal loss at 10,000 ppm Na. Thus, whether the torch is shielded plays a key role in the extent of matrix interferences, which is not expected. One report by Appelblad et al. ${ }^{35}$ does indicate an analogous result concerning the effect of a torch shield on matrix effects with a magnetic sector instrument; in Appelblad's work, the $\mathrm{M}^{+}$sensitivity is much higher with the shield present.

\section{Conclusion}

These observations indicate that some samples can be analyzed with less extensive dilution, fewer internal standard elements, and/or better internal standard corrections using FI, at least on one particular instrument. The compromise is a three fold loss of sensitivity with an unshielded torch.

These experiments also raise questions about the basic mechanism(s) responsible for matrix effects. Indeed, it is hard to see why the duration of the sample injection pulse should 
have any influence on the matrix effect if the latter occurs mainly by space charge effects inside the vacuum system. The ions pass through the sampler, skimmer and ion lens in only a few $\mu \mathrm{s},{ }^{1,36,37}$ much faster than even the shortest FI injections $(\sim 4 \mathrm{~s})$.

The observations that a) the matrix effect from $\mathrm{Ba}$ is much worse than that from the other elements tested in FI mode, and b) the shield makes matrix effects worse, argue that matrix effects in ICP-MS can be more significant outside the sampler, in the ICP itself, than usually thought, at least on some instruments. Some indications along these lines have surfaced occasionally over the years. ${ }^{35,38,39}$ Most previous studies of matrix effects were done with continuous sample introduction and steady-state signals. Perhaps a) conditions in the ICP take a certain time to reach steady state after the matrix element is first added, and b) properties of the matrix element other than ionization efficiency and atomic weight matter more than previously thought. Conditions in the axial channel upstream inside the load coil could be influenced by the nature and concentration of the matrix and the presence or absence of the shield. This region of the ICP has not been studied extensively; indeed, it is hard to observe it optically due to the bright emission from the surrounding induction region. For example, Blades and Hieftje $\mathrm{e}^{40}$ propose that radiative processes transfer energy from the induction region into the upstream reaches of the axial channel, and such processes are known to be influenced by matrix elements in some DC plasmas. ${ }^{41}$ Other effects of the matrix like a) spatial changes in the positions of atomization and ionization, ${ }^{42}$ and b) deposition and conditioning of the cones due to deposited material, could also play a role. The general subject of the basic reason(s) for the moderate matrix effects reported in this paper merits further study. 


\section{Acknowledgements}

The authors thank Agilent for donating the ICP-MS instrument as well as ESI for donating the autosampling unit used in this research. Funding was provided by the Chemical and Biological Sciences Program, Office of Basic Energy Sciences, Ames Laboratory U. S. Department of Energy under Contract No. DE-AC02-07CH11358.

\section{References}

1. Niu; H.; Houk, R.S. Spectrochim. Acta, Part B, 1996, 51, 779- 815.

2. Olivares, J.A.; Houk, R.S. Anal. Chem., 1988, 58, 20-25

3. Crain, J.S.; Houk, R.S.; Smith, F.G. Spectrochim. Acta, Part B, 1989, 44, 1355-1364.

4. Tan, S.; Horlick, G. J. Anal. Atomic Spectrom., 1987, 2, 745-763.

5. $\quad$ Evans, E.H.; Giglio, J.J. J. Anal. Atomic Spectrom., 1993, 8, 1-18.

6. Gregoire, D.C. Spectrochim. Acta Part B 1987, 42B, 895-907.

7. Vanhoe, H.; Dams, R.; Vandecasteele, C.; Versieck, J. Anal. Chim. Acta, 1993, 281, 401-411.

8. Kawaguchi, H.; Tanaka, T.; Nakamura, T.; Morishita, M.; Mizuike, A. Anal. Sci., 1987, 3, 305-308.

9. Hobbs, S.E.; Olesik, J. Appl. Spectrosc., 1991, 45, 1395-1407.

10. Lazar, A.C.; Farnsworth, P.B. Appl. Spectrosc., 1999, 53, 465-470

11. Gillson, G.R.; Douglas, D.J.; Fulford, J.E.; Halligan, K.W.; Tanner, S.D. Anal. Chem., 1988, 60, 1472-1474.

12. Tanner, S.D. Spectrochim. Acta, Part B, 1992, 47, 809-823. 
13. Praphairaksit, N; Houk, R. S. Anal. Chem. 2000, 72, 2351-2356; 2356-2361; 4354440.

14. Liu, S.; Beauchemin, D. Spectrochim. Acta, Part B, 2006, 61, 319-325.

15. Montaser, A., Inductively Coupled Plasma Mass Spectrometry, Wiley-VCH, NY, 1998, Chap. 7.

16. Keil, O.; Dahmen, J.; Volmer, D. Fresenius J. Anal. Chem., 1999, 364, 694-699.

17. Alves, L.C.; Allen, L.A.; Houk, R.S. Anal. Chem., 1993, 65, 2468-2471.

18. Plantz, M.R.; Fritz, J.S.; Smith, F.G.; Houk, R.S. Anal. Chem., 1989, 61, 149-153.

19. Beauchemin, D.; McLaren, J.W.; Mykytiuk, A.P.; Berman S.S. J. Anal. Atomic Spectrom., 1988, 3, 305-308.

20. Beauchemin, D.; Berman, S.S Anal. Chem., 1989, 61, 1857-1862.

21. Huang, Z.Y.; Chen, F.R.; Zhuang, X.R.; Lee, F.S.C. Anal. Chim. Acta., 2004, 508, 239-245.

22. Thompson, J.J.; Houk, R.S. American Mineralogist, 1982, 67, 238-243.

23. McClenathan, D.M.; Ray, S.J.; Hieftje, G.M. J. Anal. Aomic. Spectrom., 2001, 16, 987-990.

24. Houk, R. S., Fassel, V. A.; Flesch, G. D.; Svec, H. J.; Gray, A. L.; Taylor, C. E. Anal. Chem. 1980, 52, 2283-2289.

25. Field, M. P.; La Vigne, M.; Murphy, K. R.; Ruiz, G. M.; Sherrell, R. M. J. Anal Atomic Spectrom., 2007, 22, 1145-1151.

26. Gray, A. L. J. Anal. Atomic Spectrom., 1986, 1, 247-249.

27. Scott, R. H.; Fassel, V. A.; Kniseley, R. N.; Nixon, D. E. Anal. Chem. 1974, 46, 7580. 
28. Willie, S. N. The Preparation of National Research Council Certified Reference Materials, in Reference Materials for Environmental Analysis, Clement, R. E.; Keith, L. E.; Siu, K. W. M.; Eds.; CRC, Boca Raton FL, 1996.

29. Okamoto, H.; Okamoto, Y.; Hirokawa, T.; Timerbaev, A. R. Analyst 2003, 128, $1439-1442$.

30. Skoog, D. A.; Holler, F. J.; Nieman, T. A. Principles of Instrumental Analysis, 5th ed., Brooks/Cole/Thomson Learning, p. 836.

31. Sharp, B. L. J. Anal. Atomic Spectrom. 1988, 3, 939-963.

32. Chan, G. C.-Y.; Hieftje, G. M. Spectrochim. Acta Part B 2008, 63B, 355-366.

33. Sakata, K.; Kawabata, K. Spectrochim. Acta Part B 1994, 49, 1027-1038; Sakata, K. personal communication, 1994.

34. Yamada, N.; Takahashi, J.; Sakata, K. J. Anal. Atomic Spectrom., 2002, 17, 12131222.

35. Appelblad, P.K.; Rodushkin, I.; Baxter, D.C. J. Anal. Atomic Spectrom., 2000, 15, 359-364.

36. Douglas, D.; French, J. B. J. Anal. Atomic Spectrom., 1988, 3, 743-747.

37. Spencer, R. L.; Krogel, J.; Palmer, J.; Payne, A.; Sampson, A.; Woods, C. N. Spectrochim. Acta Part B 2009, submitted.

38. Olesik, J.; Thaxton, K.; Olesik, S. J. Anal. Atomic Spectrom., 1997, 12, 507-515.

39. Duersch, B. S.; Farnsworth, P. B. Spectrochim. Acta Part B 1999, 54, 545-555, esp. Fig. 9.

40. Blades, M. W.; Hieftje, G. M. Spectrochim. Acta Part B 1982, 37B, 191-197. 
41. Miller, M. H.; Eastwood, D.; Hendrick, M. S. Spectrochim. Acta Part B 1984, 39B, 13-56.

42. Fraser, M. M.; Beauchemin, D. Spectrochim. Acta Part B 2000, 55B, 1705-1731. 


\section{Tables}

\section{Table 1. ICP-MS Operating Conditions}

$\begin{array}{ll}\text { Forward power } & 1200 \mathrm{~W} \\ \text { Argon gas flow rates (L/min): } & 14 \\ \text { Outer } & 1.5 \\ \text { Auxiliary } & 0.95 \\ \text { Sample } & 8 \mathrm{~mm} \text { from load coil } \\ \text { Sampling position } & \text { On center } \\ & \text { Nickel, } 1.1 \mathrm{~mm} \text { diam. } \\ \text { Sampler cone } & \text { Nickel, } 0.4 \mathrm{~mm} \text { diam. } \\ \text { Skimmer cone } & \\ \text { Ion lens voltages } & \\ \text { Extract 1 } & -227 \mathrm{~V} \\ \text { Extract 2 } & -65 \mathrm{~V} \\ \text { Einzel 1, 3 } & -123 \mathrm{~V} \\ \text { Einzel 2 } & \end{array}$


Table 2. Signal Recoveries (\%) for 10 ppb Analyte Solutions with NaCl Matrix.

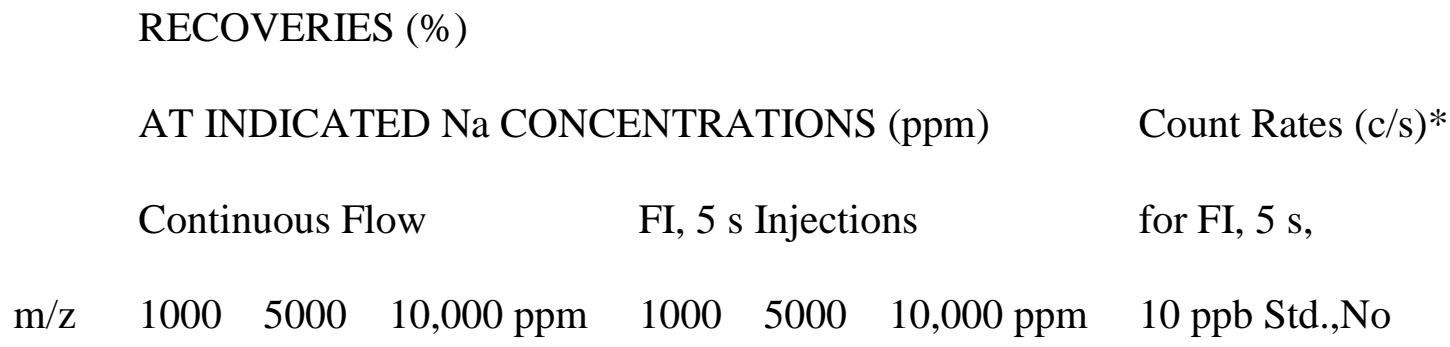

Matrix

$\begin{array}{lllllllll}\mathrm{Li} & 7 & 63 & 55 & 36 & 97 & 80 & 71 & 5,000 \\ \mathrm{Sc} & 45 & 67 & 61 & 45 & 94 & 89 & 82 & 10,000 \\ \mathrm{Y} & 89 & 69 & 65 & 57 & 97 & 91 & 84 & 8,000 \\ \mathrm{Ce} & 140 & 60 & 50 & 45 & 87 & 85 & 80 & 15,000 \\ \mathrm{Tl} & 205 & 68 & 56 & 38 & 96 & 91 & 81 & 8,500\end{array}$

*Original count rates for matrix-free analyte solution are given here. 
Table 3. Signal Recovery Ratios (\%) Using $\mathrm{Y}^{+}$as Internal Standard for $\mathrm{NaCl}$ Matrix at Indicated $\mathrm{Na}$ Concentrations (ppm)

\author{
RECOVERY RATIOS $\left(\mathrm{M}^{+} / \mathrm{Y}^{+}\right)(\%)$ \\ AT INDICATED Na CONCENTRATIONS (ppm)
}

Continuous Flow FI, 5 s Injections

$\begin{array}{llllllll}\text { Analyte } & \mathrm{m} / \mathrm{z} & 1000 & 5000 & 10,000 \mathrm{ppm} & 1000 & 5000 & 10,000 \mathrm{ppm} \mathrm{Na} \\ \mathrm{Li} & 7 & 91 & 85 & 63 & 100 & 88 & 84 \\ \mathrm{Sc} & 45 & 97 & 94 & 79 & 97 & 98 & 98 \\ \mathrm{Ce} & 140 & 87 & 77 & 79 & 90 & 93 & 95 \\ \mathrm{Tl} & 205 & 98 & 86 & 67 & 99 & 100 & 96\end{array}$


Table 4. Signal Recoveries (\%) for Analyte Elements Spiked at 10 ppb into CASS-1 Seawater Matrix at Various Dilution Factors

RECOVERIES (\%)
AT INDICATED DILUTION FACTORS

Matrix

$\begin{array}{ccccccc}\text { Sc } & 45 & 92 & 86 & 80 & 76 & 6,000 \\ \mathrm{Y} & 89 & 97 & 95 & 91 & 86 & 4,500 \\ \mathrm{Ce} & 140 & 90 & 89 & 85 & 74 & 9,000 \\ \mathrm{Tl} & 205 & 92 & 86 & 81 & 76 & 5,000\end{array}$

*Original count rates for matrix-free analyte solution are given here. 


\section{Figures}

\section{CAPTIONS}

Figure 1. Matrix effects on $\mathrm{Tl}^{+}$signal from $\mathrm{NaCl}$ at indicated $\mathrm{Na}$ concentrations: a) continuous introduction, b) FI with $1 \mathrm{~s}$ injections. In b) the curves for $1000 \mathrm{ppm}$ and $2000 \mathrm{ppm} \mathrm{Na}$ fall between those for $\mathrm{Tl}$ alone and $5000 \mathrm{ppm} \mathrm{Na}$; these curves at intermediate $\mathrm{Na}$ concentrations are not plotted for clarity.

Figure 2. Matrix effects on $\mathrm{Tl}^{+}$signal from $\mathrm{NaCl}$ at indicated $\mathrm{Na}$ concentrations: a) FI with 5 s injection, b) FI with $10 \mathrm{~s}$ injections. Again, the curves for $1000 \mathrm{ppm}$ and $2000 \mathrm{ppm} \mathrm{Na}$ fall between those for $\mathrm{Tl}$ alone and $5000 \mathrm{ppm} \mathrm{Na}$. Note the different time scales in the two plots. Figure 3. Matrix effects on $\mathrm{Tl}$ and $\mathrm{Sc}$ at $5 \mathrm{ppb}$ in clean $1 \% \mathrm{HNO}_{3}$ standard vs. 5 ppb spiked into CASS-1 seawater at various dilutions during FI, $10 \mathrm{~s}$ injections.

Figure 4. Matrix effects on Sc, 5 s injections: a) effect of Bi matrix on 5 ppb Sc; b) effect of Ba matrix on $10 \mathrm{ppb}$ Sc. Barium causes a much more severe matrix effect than the other elements studied.

Figure 5. Matrix effects on $\mathrm{Sc}$ at $10 \mathrm{ppb}, 5 \mathrm{~s}$ injections, for $\mathrm{NaCl}$ matrix at indicated $\mathrm{Na}$ concentrations, with grounded shield in torch. With the unshielded torch and $5 \mathrm{~s}$ injections, recoveries for Sc were $94 \%, 89 \%$ and $82 \%$ at 1000, 5000 and 10,000 ppm Na, respectively (Table 2). 

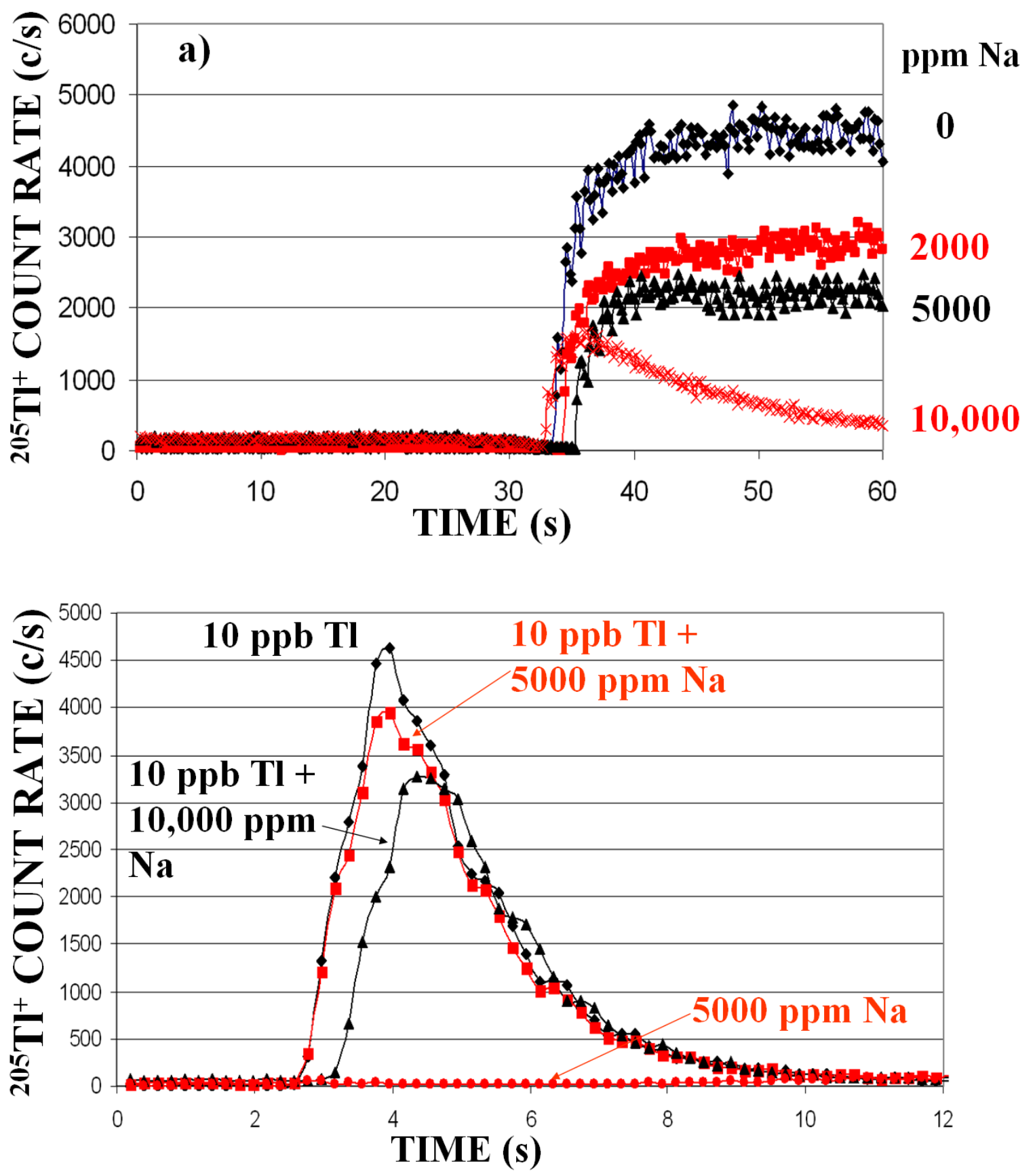

Figure 1. Matrix effects on $\mathrm{Tl}^{+}$signal from $\mathrm{NaCl}$ at indicated $\mathrm{Na}$ concentrations: a) continuous introduction, b) FI with $1 \mathrm{~s}$ injections. In b) the curves for $1000 \mathrm{ppm}$ and $2000 \mathrm{ppm} \mathrm{Na}$ fall between those for $\mathrm{Tl}$ alone and $5000 \mathrm{ppm} \mathrm{Na}$; these curves at intermediate $\mathrm{Na}$ concentrations are not plotted for clarity. 

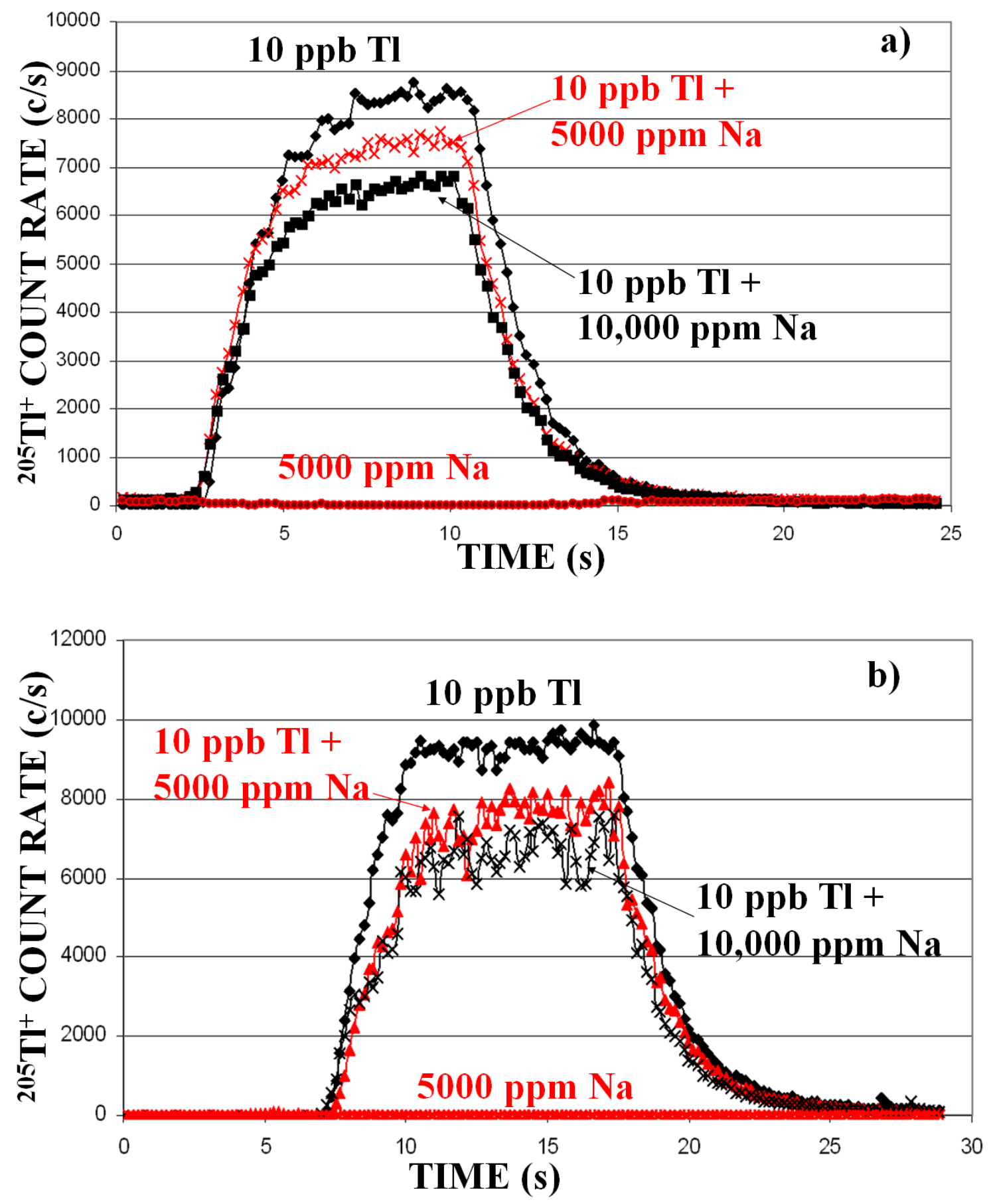

Figure 2. Matrix effects on $\mathrm{Tl}^{+}$signal from $\mathrm{NaCl}$ at indicated $\mathrm{Na}$ concentrations: a) FI with 5 $\mathrm{s}$ injection, b) FI with $10 \mathrm{~s}$ injections. Again, the curves for $1000 \mathrm{ppm}$ and $2000 \mathrm{ppm} \mathrm{Na}$ fall between those for $\mathrm{Tl}$ alone and $5000 \mathrm{ppm} \mathrm{Na}$. Note the different time scales in the two plots. 

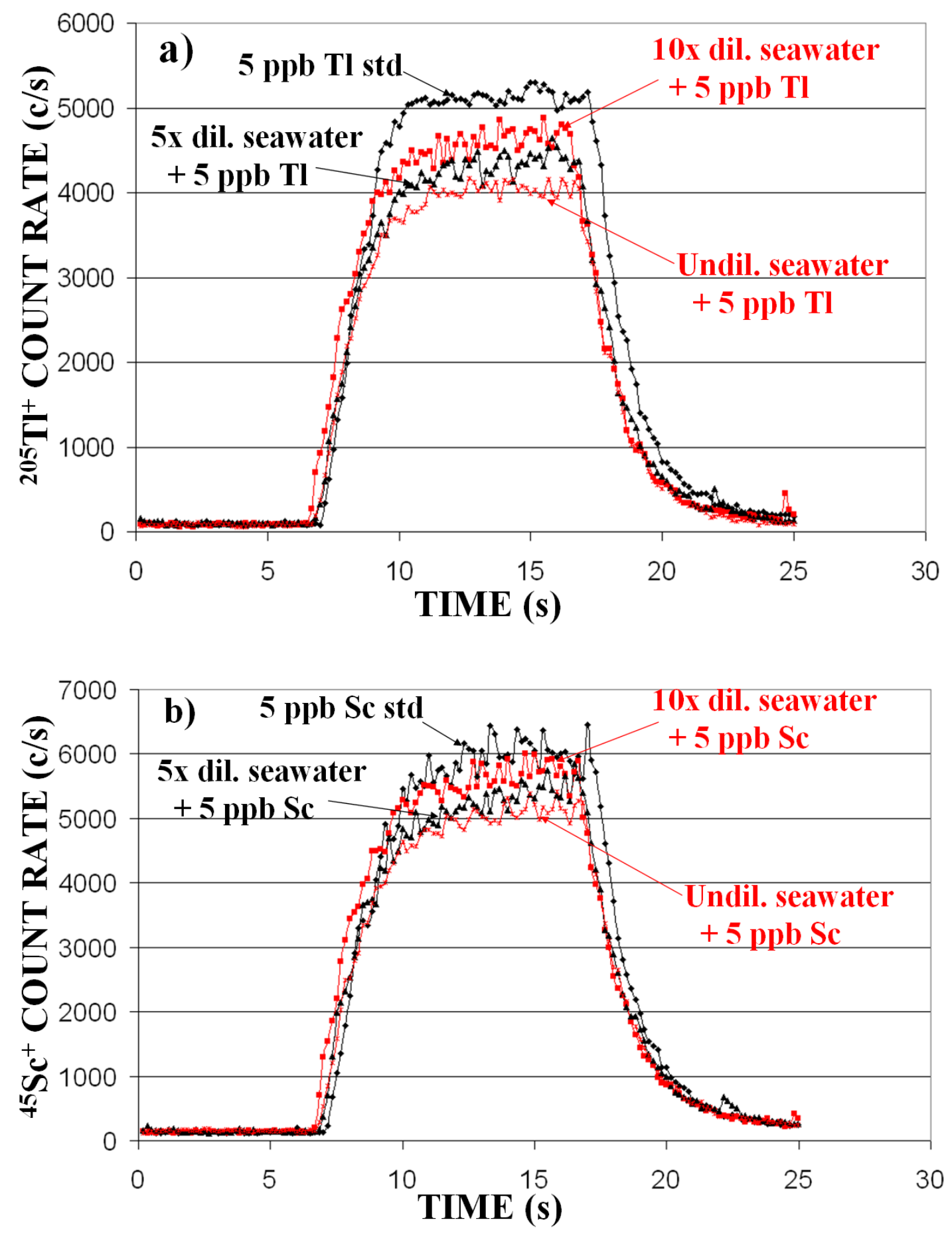

Figure 3. Matrix effects on $\mathrm{Tl}$ and $\mathrm{Sc}$ at $5 \mathrm{ppb}$ in clean $1 \% \mathrm{HNO}_{3}$ standard vs. 5 ppb spiked into CASS-1 seawater at various dilutions during FI, 10 s injections. 


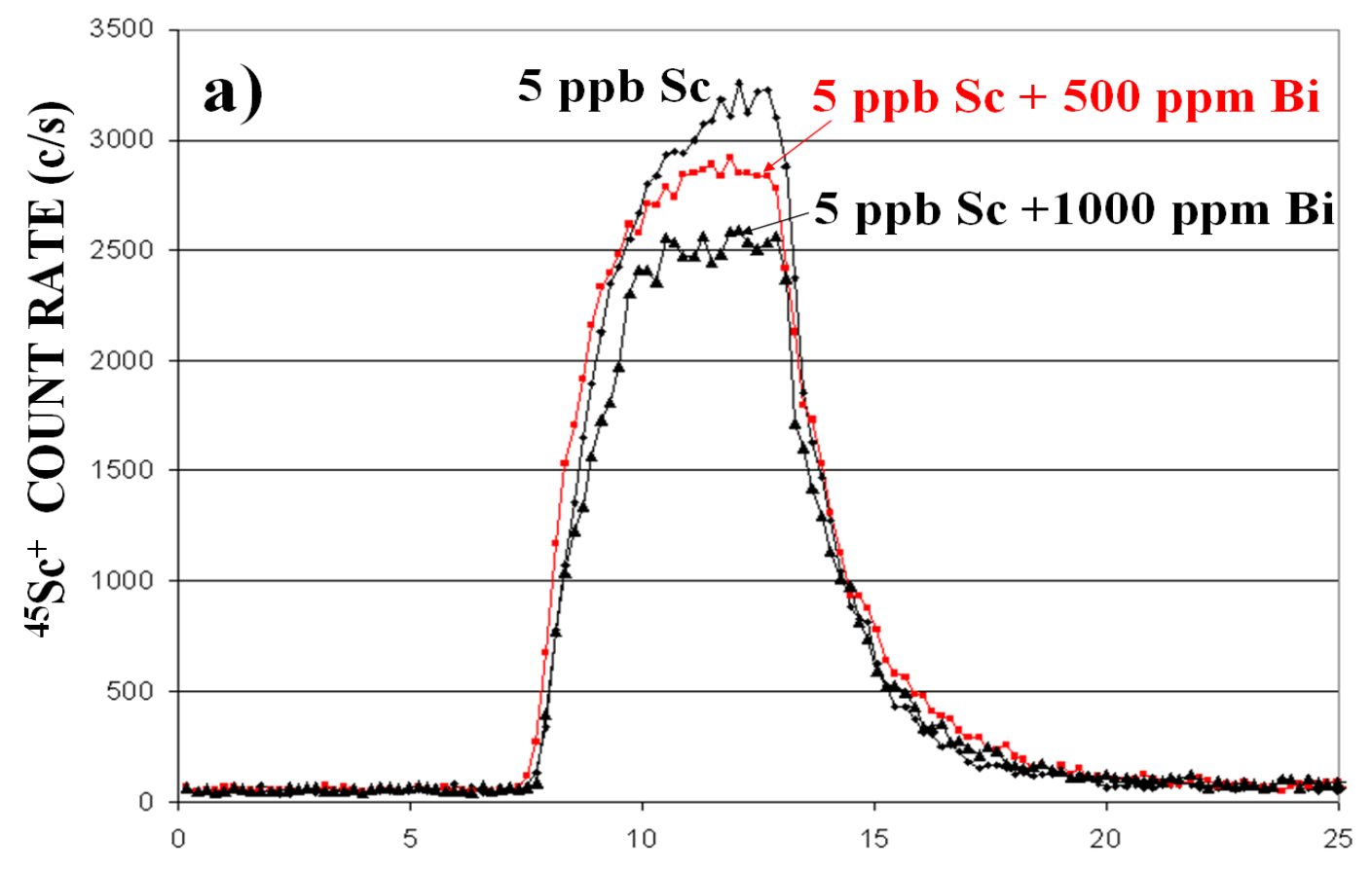

TIME (s)

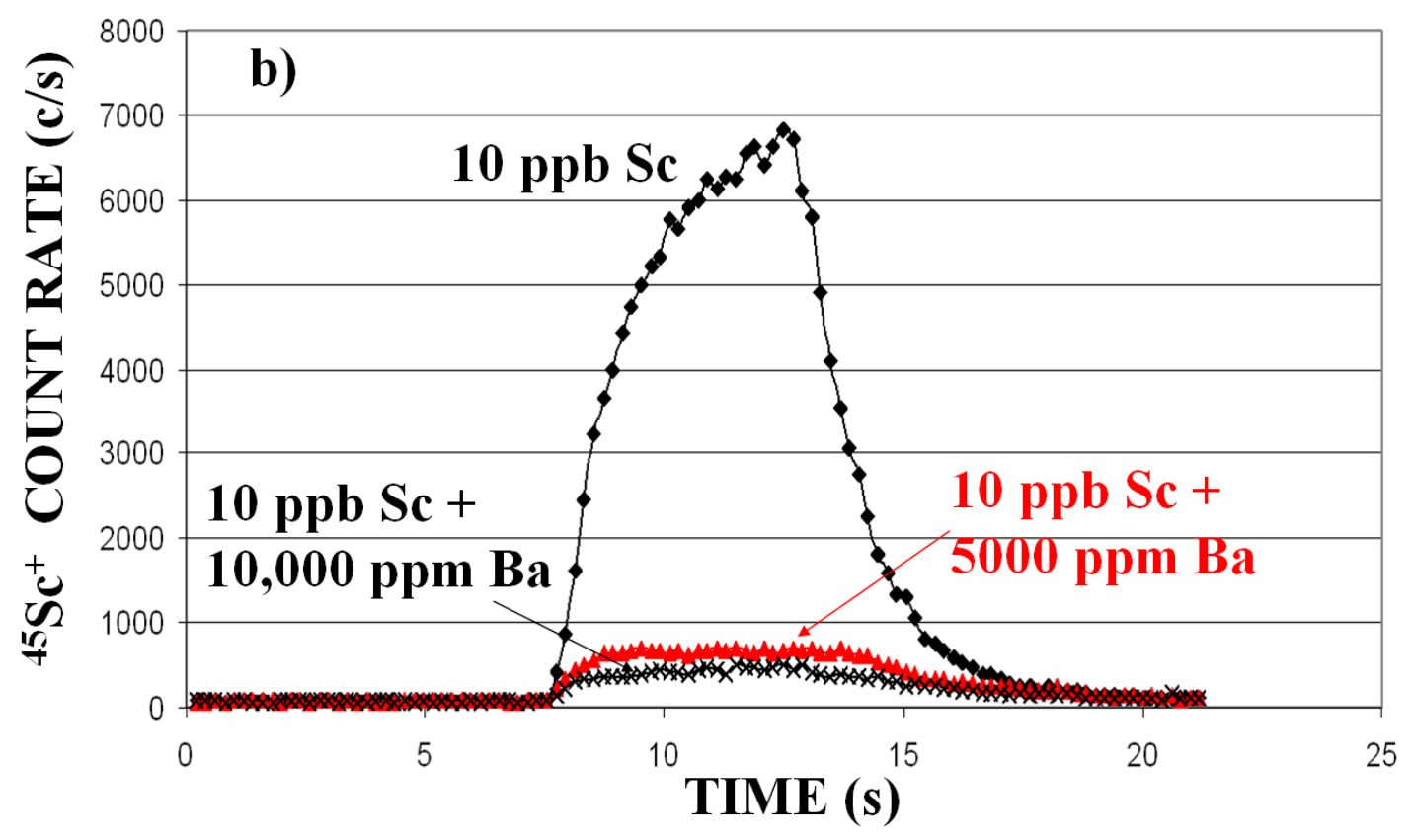

Figure 4. Matrix effects on Sc, 5 s injections: a) effect of Bi matrix on $5 \mathrm{ppb} \mathrm{Sc}$; b) effect of Ba matrix on $10 \mathrm{ppb} \mathrm{Sc}$. Barium causes a much more severe matrix effect than the other elements studied. 


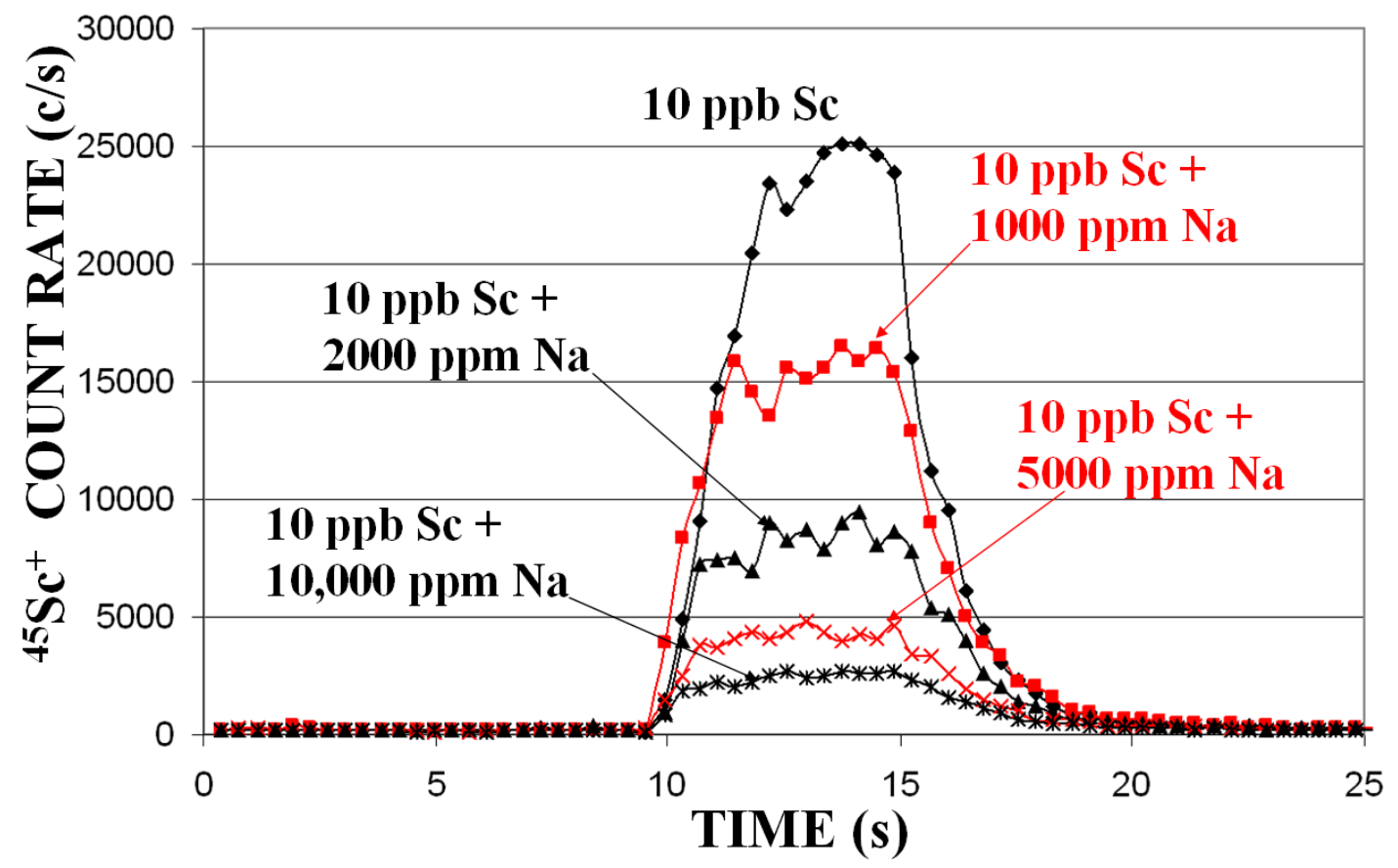

Figure 5. Matrix effects on $\mathrm{Sc}$ at $10 \mathrm{ppb}, 5 \mathrm{~s}$ injections, for $\mathrm{NaCl}$ matrix at indicated $\mathrm{Na}$ concentrations, with grounded shield in torch. With the unshielded torch and $5 \mathrm{~s}$ injections, recoveries for Sc were 94\%, 89\% and 82\% at 1000, 5000 and 10,000 ppm Na, respectively (Table 2). 